\title{
Social networks in relation to infectious diseases and type 2 diabetes
}

Citation for published version (APA):

Brinkhues, S. (2018). Social networks in relation to infectious diseases and type 2 diabetes. [Doctoral Thesis, Maastricht University]. Maastricht University. https://doi.org/10.26481/dis.20181031sb

Document status and date:

Published: 01/01/2018

DOI:

10.26481/dis.20181031sb

Document Version:

Publisher's PDF, also known as Version of record

\section{Please check the document version of this publication:}

- A submitted manuscript is the version of the article upon submission and before peer-review. There can be important differences between the submitted version and the official published version of record.

People interested in the research are advised to contact the author for the final version of the publication, or visit the DOI to the publisher's website.

- The final author version and the galley proof are versions of the publication after peer review.

- The final published version features the final layout of the paper including the volume, issue and page numbers.

Link to publication

\footnotetext{
General rights rights.

- You may freely distribute the URL identifying the publication in the public portal. please follow below link for the End User Agreement:

www.umlib.nl/taverne-license

Take down policy

If you believe that this document breaches copyright please contact us at:

repository@maastrichtuniversity.nl

providing details and we will investigate your claim.
}

Copyright and moral rights for the publications made accessible in the public portal are retained by the authors and/or other copyright owners and it is a condition of accessing publications that users recognise and abide by the legal requirements associated with these

- Users may download and print one copy of any publication from the public portal for the purpose of private study or research.

- You may not further distribute the material or use it for any profit-making activity or commercial gain

If the publication is distributed under the terms of Article $25 \mathrm{fa}$ of the Dutch Copyright Act, indicated by the "Taverne" license above, 


\section{SOCIAL NETWORKS IN RELATION TO INFECTIOUS DISEASES AND TYPE 2 DIABETES}

Stephanie Brinkhues 
(c) Copyright: Stephanie Brinkhues, Maastricht 2018

Cover Design: Margret Reijnders | Creatieve Communicatie

Lay-out: Boekenplan

Printed by: Boekenplan

ISBN: 978-90-8666-456-6

No part of this thesis may be reproduced, stored, or transmitted in any form or by any means, electronic or mechanical, including photocopy, recording or any information storage or retrieval system, without prior permission of the copyright owner.

This thesis was prepared at The Maastricht Study, the Care and Public Health Research Institute (CAPHRI) and the CARIM School for Cardiovascular Diseases at Maastricht University, in collaboration with the Department of Medical Microbiology of the Maastricht University Medical Center (MUMC+) and the Department of Sexual Health, Infectious Diseases and Environmental Health at the Public Health Service South Limburg (GGD Zuid-Limburg). The research presented in chapter 3 of this thesis was financially supported by The Netherlands Organisation for Health Research and Development (ZonMw, 522002002)

\section{OD.}

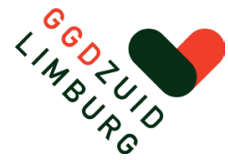

( CAPHRI 


\section{SOCIAL NETWORKS IN RELATION TO INFECTIOUS DISEASES AND TYPE 2 DIABETES}

PROEFSCHRIFT

ter verkrijging van de graad van doctor aan de Universiteit Maastricht, op gezag van de Rector Magificus, Prof. dr. Rianne M. Letschert

volgens het besluit van het College van Decanen,

in het openbare te verdedigen

op woensdag 31 oktober 2018 om 12.00 uur

door

Stephanie Brinkhues

Geboren op 20 september 1989 te Aken. 


\section{Promotores}

Prof. dr. Christian J.P.A. Hoebe

Prof. dr. Paul H.M. Savelkoul

\section{Copromotores}

Dr. Nicole H.T.M. Dukers-Muijrers

Dr. Miranda T. Schram

\section{Beoordelingscommisie}

Prof. dr. G.J. Dinant (voorzitter)

Prof. dr. K. Horstman

Dr. F. Rutters (VU medisch centrum, Amsterdam)

Prof. dr. J. van der Velden (Radboud Universiteit, Nijmegen) 


\section{Contents}

Chapter $1 \quad 1.1$ General Introduction

1.2 Study population and measurement of social networks 16

Part I Social networks in relation to infectious diseases

Chapter 2 Social networks in relation to self-reported symptomatic infections in individuals aged 40-75 - The Maastricht Study BMC Infectious Diseases, 2018, 18.1:300

Chapter 3 Development of prediction models for upper- and lower 57

Respiratory and gastrointestinal tract infections using social network parameters in middle-aged and older persons - The Maastricht Study -

Epidemiology \& Infection, 2018, 146.5:533-543

59

\section{Part II Social networks in relation to type 2 diabetes}

Chapter 4 Socially isolated individuals are more prone to have newly diagnosed and prevalent type 2 diabetes mellitus

- The Maastricht Study -

BMC Public Health, 2017, 17.1:955

Chapter 5 Social network characteristics are associated with 115 type 2 diabetes complications - The Maastricht Study Diabetes Care 2018; 41:1-9

Chapter 6 General Discussion

$\begin{array}{lll}\text { Chapter } 7 & \text { Summary } & 151\end{array}$

Samenvatting 155

Valorisation of the thesis $\quad 159$

Dankwoord 163

$\begin{array}{ll}\text { Curriculum Vitae } & 167\end{array}$

$\begin{array}{ll}\text { Portfolio } & 169\end{array}$

List of publications 173 


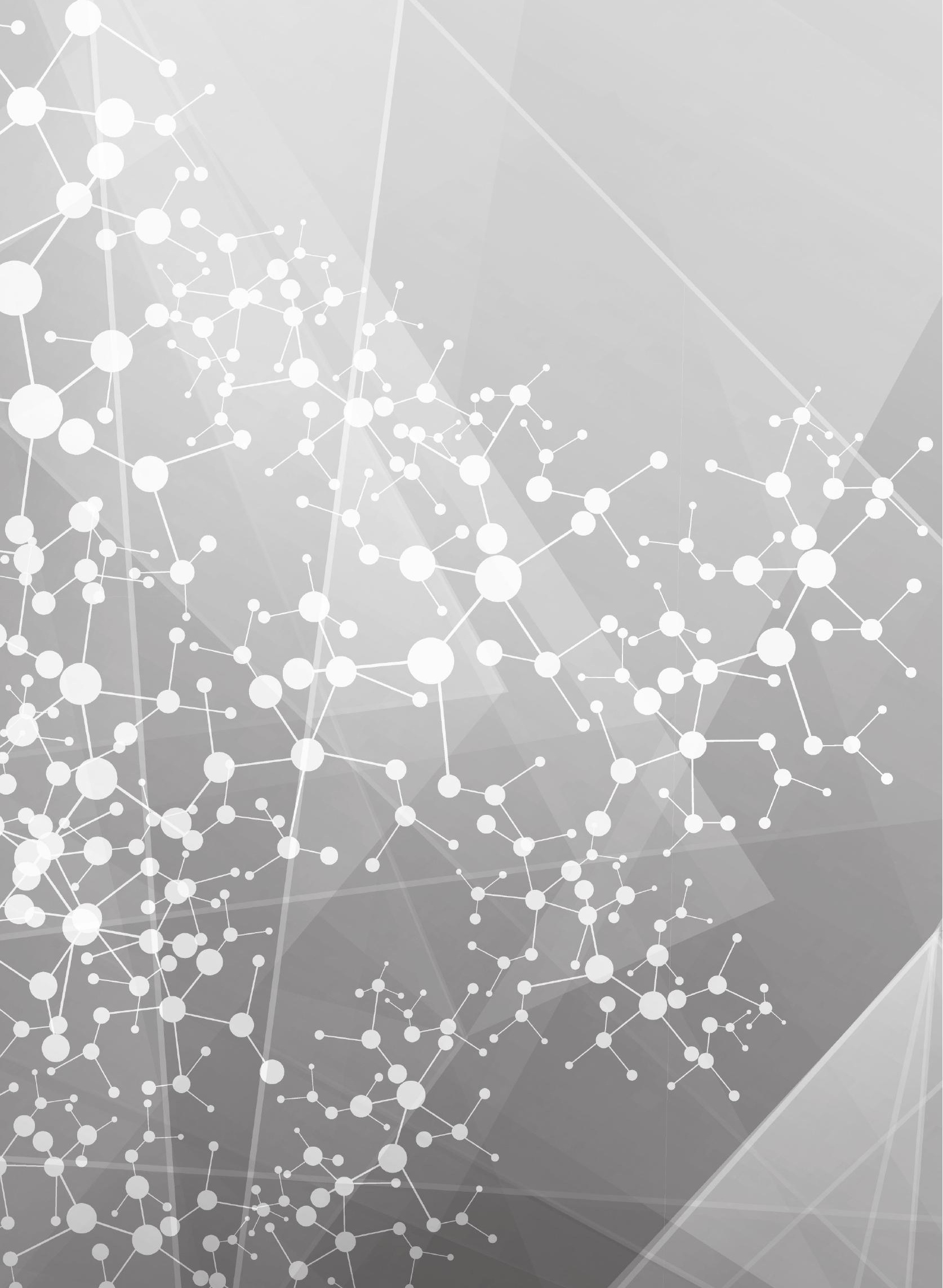




\section{Chapter 1}

1.1 General introduction 
Over the last decades, population ageing has become a global issue [1]. World-wide, the proportion of people aged 60 and over is growing rapidly, and it is expected to rise to one quarter of the population in Europe in 2020 [1, 2]. Therefore, there is a need to increase knowledge about how to promote good health among older persons and how to prevent costly and negative impacts on the population as a whole [3]. Many diseases in later life are preventable, and effective prevention strategies can even ensure that older persons can remain healthy, active and independent. Current EU policy expects the promotion of active ageing, including participation in society and support for informal caregivers [4]. Overall, there is a societal responsibility for ageing in good health, and for protection of those who are more vulnerable in the population.

In this thesis, we focus on the associations between social networks and health, illustrated by studies on infectious diseases and type 2 diabetes mellitus (T2DM).

\section{Infectious diseases}

Infectious diseases are a major cause of mortality in older persons [5]. Older persons generally have greater susceptibility to infections than younger adults, caused by an age-related compromised immune system [6]. It is well known that ageing is associated with decreased cell-mediated immunity and decreased antibody production to new antigens $[5,7]$.

Respiratory infections (RI) are a major challenge in health care of older persons [5]. The common cold, influenza, pneumonia, bronchitis and a number of other infections were defined as RI. Most RI infections are caused by viruses, especially influenza virus $A$ and $B$, rhinovirus, respiratory syncytial virus, and coronavirus [8]. Rls can be divided into upper and lower RIs. Upper respiratory tract infections (URI) include symptoms such as a running nose, sneezing and headache, while the main symptoms of lower respiratory tract infections (LRI) are cough, shortness of breath, and fever. Pneumonia is the main pathological feature of LRI [9]. URI and LRI can be separated by clinical symptoms, but it is the differing immune response of the individual to the virus that determines the clinical severity and management. A mild infection from the upper respiratory tract in one person may develop to a life-threatening pneumonia in another person. The main transmission route of Rls is by coughing or sneezing out a large number of micro-organisms in a fine aerosol of droplets, which are then either breathed in by other persons, enter via the conjunctiva or are swallowed from fingers or utensils [9].

Next to RIs, gastrointestinal tract infections (GI) are impending infections for health of the older persons. Gastrointestinal infections are viral, bacterial or parasitic infections that cause gastroenteritis, an inflammation of the gastrointestinal tract involving both the stomach and the small intestine. Symptoms include diarrhoea, vomiting, and abdominal pain [9]. The major route of transmission is person to person via faecal-oral route or by ingestion of contaminated food or water. Dehydration is the main danger of gastrointestinal infections in older persons [10]. 


\section{Type 2 diabetes}

To date, type 2 diabetes mellitus (T2DM) is one of the most prevalent diseases worldwide. With increased ageing of the population, the prevalence of T2DM is raising, with an estimated 366 million individuals having T2DM in 2030 [11]. Therefore, T2DM in adults is a growing public health burden [11].

T2DM is a chronic, metabolic disease that is characterized by elevated blood glucose levels (hyperglycemia), which result from defects in insulin metabolism and/or production [12]. Patients with T2DM will lose 16 to 18 quality-adjusted life-years due to diabetes [13], and will die, on average, six years earlier than their counterparts without diabetes [14].

The impact of diabetes on patients' quality of life is high as treatment of T2DM involves intensive daily self-management of glucose monitoring, dietary behaviors, physical activity, and when needed, diabetes medication [15]. Treatment prevents some of its devastating complications but does not usually restore normoglycemia or eliminate all adverse consequences [16].

Patients with T2DM have an increased risk for the development of macro- (e.g. myocardial infarction, stroke, peripheral arterial disease) and microvascular complications (e.g. neuropathy, retinopathy, and nephropathy) $[17,18]$. These macrovascular and microvascular complications impose a substantial burden on patients, their surroundings, and health care systems. Additionally, the treatment of diabetes and it's complications is costly. Overall, $50 \%$ of the costs are attributed to diabetes treatment itself, and $50 \%$ to the treatment of complications [19]. Since current methods of treating T2DM and related complications remain inadequate, prevention is preferable [16].

\section{Social networks and health}

Several epidemiological studies have pointed out the importance of social relationships for morbidity and mortality. Already in 1979, Berkman and Syme found that individuals with social and community ties have lower mortality rates than individuals without [20], as well as a number of following studies, demonstrating a protective association between social relationships and mortality [21-24]. Uchino et al. linked the effect of social relationships to physiological processes [25]. In their review, they concluded that there is relative strong evidence that social networks are associated with several aspects of the cardiovascular, endocrine and immune system [25].

On the one hand, transmission and acquisition of infectious diseases are for a large part determined by social networks [26-29], as social relationships may act as a vehicle for the transmission of infections. Diverse and large social networks are associated with close contact with a broad range of people and hence an increased risk of exposure to a range of infectious agents [26]. This increases the risk of acquiring disease, particularly among more vulnerable individuals, whose resistance is compromised (e.g. older persons or individuals with comorbidities) [26]. 
On the other hand, it has been shown that social networks can act as a buffer for infections by increasing immune function $[27,28]$. Nonetheless, it is not yet fully understood which social network characteristics are related to the risk of infections, and whether these characteristics have detrimental (transmission) or beneficial (buffer) effects or both. Most previous research on the transmission of infectious disease through social contacts was done using mathematical disease transmission models [30-35]. Moreover, evidence on whether associations differ by type of infection is scarce, lacking direct comparative data for different types of infections. Most studies on networks and infections so far addressed URIs alone $[29,36,37]$. Therefore, new epidemiological insights into social network related risk factors for different types of infections would be highly relevant to inform infectious disease control strategies, and therefore contribute to successful prevention strategies for middle-aged and older persons.

Next to immune function, buffering effects have been found for cardiovascular and endocrine function; higher levels of social support have been associated with lower blood pressure and lower LDL cholesterol [38], better glycemic control [39], and improved lifestyle behaviours [39, 40]. Recently, there is raising interest for the role of social network characteristics in the development of T2DM [41-43]. However, previous studies on social network characteristics have typically focused on single indicators of social networks, such as emotional support or living alone [41-43], and studies accounting for pre-diabetes and newly diagnosed T2DM are rare.

Although the literature on social networks has contributed to the understanding of the potential role of social networks in T2DM, many aspects remain unclear. Therefore, a more detailed and conjoint investigation of a broad range of social network characteristics and its association with T2DM is essential.

\section{Theoretical foundations of social network approaches in public health}

Individuals live within webs of social relationships, often referred to as social networks. Social networks provide a frame in which individuals can interact with each other. Individuals in a social network influence each other, exchange resources, cooperate, compete, conflict, support and seduce one another [44]. Several mechanisms through which social networks may affect health have been proposed, including the provision of social support (both perceived and actual), social influence (e.g., norms, social control, health behaviors and lifestyle), social engagement (e.g. participation in social activities or religious groups), person- to- person contacts (e.g., pathogen exposure, secondhand cigarette smoke), and access to resources (e.g., money, jobs, information) [45, 46].

One of the criticism most often mentioned in the discussion of social network research is that the field lacks a (native) theoretical understanding-it is "merely descriptive" or "just methodology" [47]. In this thesis, I endeavour to go beyond this criticism by combining disciplines of epidemiological public health research and social network analysis. 
All networks comprise two essential elements, a set of nodes (individuals) and a set of ties (relationships). Moreover, they may also include node attributes (attributes of the individuals, e.g. sex, age). In general, we distinguish two levels of social networks: First (1) egocentric (or personal) networks, defined as a network centered on a specific individual (called the "ego"). Each person who has a relationship with the ego can be defined as a network member (called alter) $[48,49]$. An example of an egocentric network is depicted in figure 1.

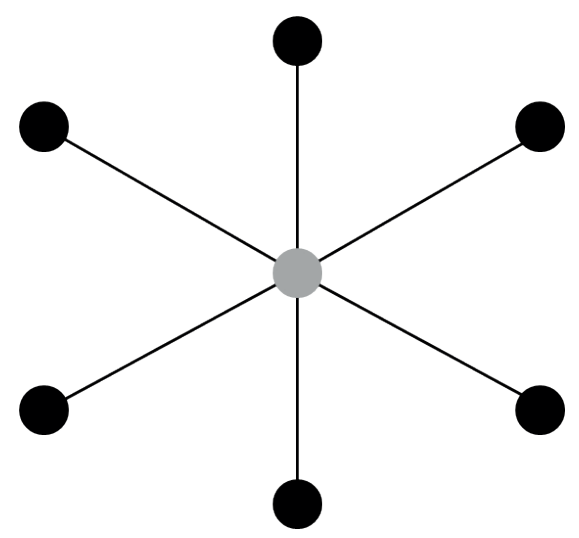

Figure 1- Egocentric network with 6 alters

Second (2) sociocentric (or complete, whole) networks, in which all or nearly all members of a community or group and their relationships to each other are represented. An example of a sociocentric network is depicted in figure 2 .
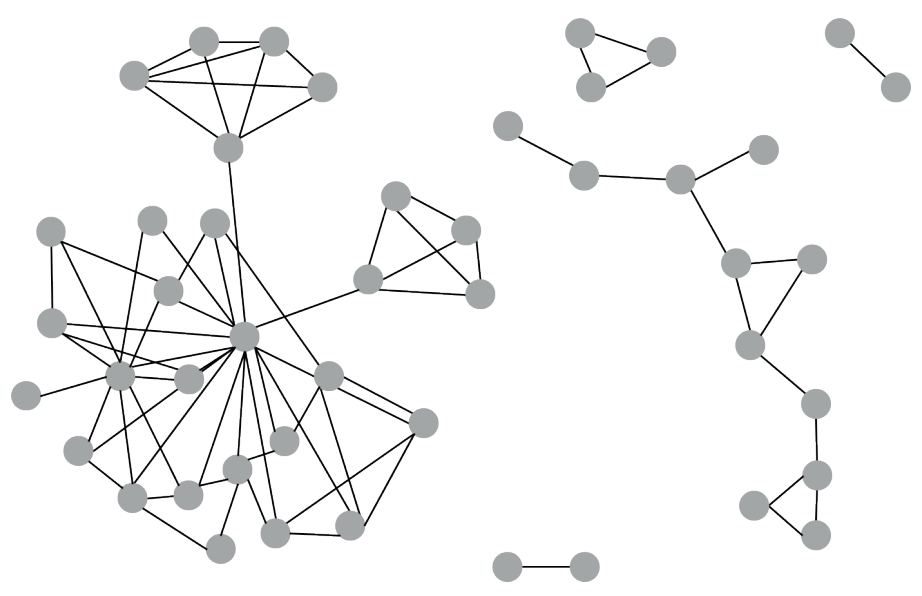

Figure 2 - Sociocentric network 
The crucial difference between the two is that egocentric networks include data from individuals (ego) about members in their network (alters), whereas sociocentric networks include the network information from each individual, and also information from the network members themselves [50, 51]. Each individual in a sociocentric network has an own egocentric network. It is possible to extract egocentric networks from sociocentric networks, and subsequently to recombine egocentric networks into whole networks, allowing to move between the levels of the egocentric and sociocentric network. Research on sociocentric networks usually focuses on "closed" networks implying that the boundaries of the network are defined a priori. In many cases, this approach remains the gold standard because of its ability to gather data for the entire network [52]. However, it is not always possible and not always desirable to study whole networks [44]. The investigation of sociocentric networks is only feasible in small populations, whereas the investigation of egocentric networks is possible in larger study populations [44], such as the population-based study used in this thesis. Moreover, sociocentric network data contradict the assumptions of standard statistical approaches in public health research, and therefore, can only be analysed by means of a range of specifically adapted methods. In contrast, egocentric network data is compatible with most of the techniques of statistical analysis and modelling in epidemiological research [44, 52]. In light of these considerations, this thesis focusses on an egocentric social network approach.

\section{Measurement of egocentric networks}

In general, data on social networks have been obtained via surveys and questionnaires, observation, diaries, electronic traces, and experiments [48]. Social networks are, by definition, hard to measure [53]. Surveys and questionnaires are the most common used method to gather egocentric social network data. Techniques for collecting egocentric network data typically determine membership in an individual's (ego) network via one or more name generators; questions asking to identify network members (alters) [54]. Each person who has a relationship with an ego can be defined as a network member [55]. The list of network members that is produced by name generator items forms the basis to obtain additional information about the network members via name interpreter items. Name interpreters collect information on the attributes of network members (alters) enumerated (e.g. sex and age), and on the properties of the relationship (tie) between ego and alter (e.g. frequency of contact or type of relationship) [54].

Therefore, name generators/interpreters are used to map the egocentric social network and to collect information about the alters of an ego, resulting in a detailed description of a participant's social network. 


\section{Structure vs. function of egocentric networks}

The web of an individual's social relationships may be described in structural terms (more "objective" measures) or functional terms (more "subjective" measures) [56, 57]. Structural characteristics of the social network include terms such as size (number of network members), frequency of contact (number of contacts with the network members), composition (the types of relationships in the network), geographic dispersion (geographic distance between network members), density (the extent to which network members are connected to each other), or homogeneity/ heterogeneity (the extent to which network members are similar/ different to each other) [56]. Functional characteristics of the social network describe the provision or exchange of social support between members of a social network [56,57]. The exchange of social support is an important function of social relationships. Several types of social support can be distinguished, such as informational support, instrumental/ practical support and emotional support [57]. Social support can be provided by many types of network members, both in an individual's informal network (e.g. family, friends, acquaintances) and in more formal networks (e.g. health care professionals).

Although many investigations on the associations of social networks on health have narrowly focused on functional characteristics, the provision of social support, a broader approach including both structural and functional characteristics of the social network is favourable [57]. Therefore, we included both structural and functional characteristics of the social network in the studies presented in this thesis.

\section{Aim and outline of this thesis}

Overall, the aim of this thesis was to examine the associations of a broad range of structural and functional social network characteristics with infectious disease and type 2 diabetes, using a novel approach of combined epidemiological and social network research, to gain more insight in the social context of infectious diseases and T2DM.

This thesis includes studies on the social context of infectious diseases (chapter 2 and 3), type 2 diabetes (chapter 4) and diabetes complications (chapter 5).

In chapter 1.2, the study population and measurement of social networks used in this thesis were described as background information.

The first part of this thesis focuses on the association of a broad range of structural and functional social network characteristics with infectious diseases. Chapter 2 examines the detrimental as well as the beneficial associations between a broad range of network characteristics and upper respiratory (URI), lower respiratory (LRI), gastrointestinal (GI) and urinary tract infections (UTI). Chapter 3 describes the development and internal validation of prediction models for URI, LRI, and $\mathrm{GI}$ based on a range of variables including social network parameters. 
The second part of this thesis focuses on the association of structural and functional characteristics of the social network with type 2 diabetes and its complications. Chapter 4 evaluates the associations of social network characteristics with prediabetes, newly diagnosed T2DM, and previously diagnosed T2DM. The associations of functional and structural network characteristics with macroand microvascular complications in T2DM were assessed in chapter 5.

Finally, the main findings of the studies on infectious diseases and type 2 diabetes and its complications, methodological considerations and challenges, the potential of social networks for prevention strategies, and future directions were discussed in chapter 6. 



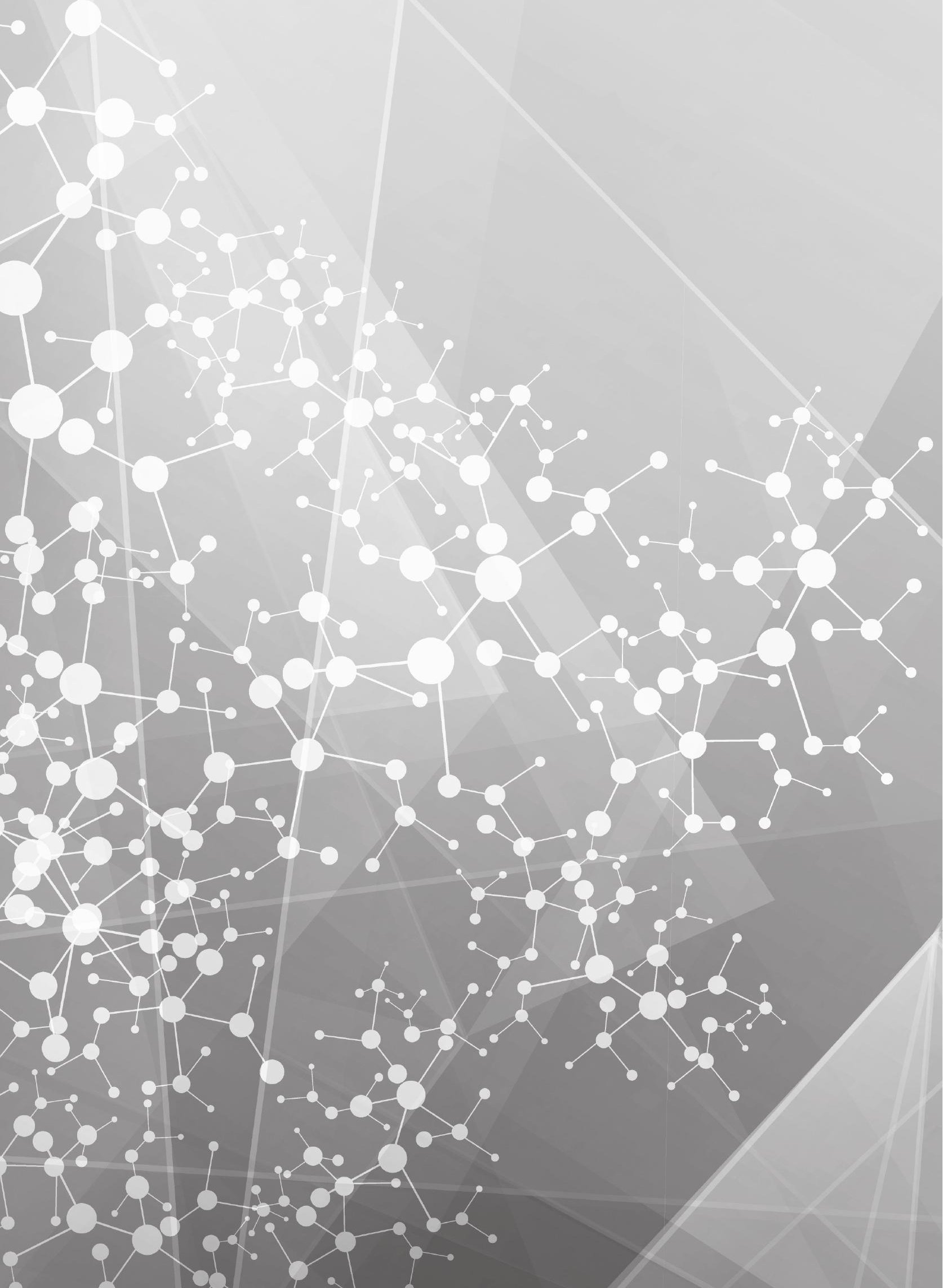




\section{Chapter 1}

1.2 Study population and measurement of social networks 


\section{The Maastricht Study}

In this thesis, we used data from The Maastricht Study, an observational prospective populationbased cohort study [58]. In brief, the study focuses on the etiology, pathophysiology, complications and comorbidities of type 2 diabetes mellitus (T2DM) and is characterized by an extensive phenotyping approach. Eligible for participation were all individuals aged between 40 and 75 years and living in the southern part of the Netherlands. Participants were recruited through mass media campaigns and from the municipal registries and the regional Diabetes Patient Registry via mailings. Recruitment was stratified according to known T2DM status, with an oversampling of individuals with T2DM, for reasons of efficiency. This thesis includes cross-sectional data from the first 3451 participants, who completed the baseline survey between November 2010 and September 2013.

\section{Social network data collection}

Data on individual social networks were collected through an online questionnaire using name generator/ interpreter items [54]. The assessment of the social network covered contacts (interactions between persons) within a period of six months. To simplify terminology in the following description, "participant" refers to the ego, and "network member" refers to an alter. The participants received a questionnaire with seven questions on different types of contacts and were asked to name a maximum of five persons (network members) per question. Questions concerned persons

1) who advised them on problems,

2) who could offer them practical help if they were sick,

3) who provided emotional support when they were feeling unwell,

4) who helped them with small and larger jobs around the house,

5) they visited for social purposes or that they could go out with sometimes, and

6) with whom they could discuss important matters and, finally,

7) participants were asked to name a maximum number of ten additional persons who were also important for them because of mutual activities.

In total, participants could name a maximum number of 40 network members. After every question and for each network member named, they were asked to indicate their frequency of contact with this person over the last six months (daily or weekly, monthly, quarterly, and half-yearly). Moreover, the participants were asked to identify their relationship to this person (e.g., partner, sister, friend, neighbor, etc. (28 options)), how far away this person lived (walking distance, less than half an hour away by car, more than half an hour away by car, more distant), and to indicate this person's sex and actual or estimated age. 
Further, participants were asked to rate two statements on a five-point Likert scale ranging from strongly agree to strongly disagree: "most of my friends know each other" and "my best friends know my family". The participants were also asked whether they were a member of a club (yes/no, e.g. sports club, religious group, volunteer organization, discussion group, self-support group, Internet club, or another organization).

\section{Social network characteristics used in this thesis}

First, in the literature we identified a broad range of structural and functional social network characteristics that had previously been examined in relation to infectious diseases and chronic diseases. Next, the social network parameters listed below were computed and used in the studies presented in this thesis.

\section{Structural characteristics of the social network}

\section{Degree}

Network size

The total number of unique network members mentioned in the questionnaire

\section{Contact frequency}

Total contacts per half year

Total friend contacts per half year

Total family contacts per half year

Total household contacts per half year

Total neighbor contacts per half year

Total acquaintance contacts per half year

Total work relation contacts per half year

Total child contacts per half year
A contact was defined as an interaction between persons. Total contacts (interactions between persons) per half year were computed as follows.

We used the highest contact frequency (e.g., daily contact) for every network member as an indicator of the actual contact frequency. Second, we recoded the answer categories of the questionnaire to an estimated number of contacts per half year. For example, "half-yearly" was assumed to comprise one contact, "quarterly" two contacts, "monthly" 6 contacts and "daily or weekly" 48 contacts. Third we computed the sum of all contacts per half year as the total contact frequency.

Fourth, we computed the sum of all contacts per type of relationship, for example the sum of all friend contacts.

Proportion of network members with dailyWe computed the percentages of network members that the participant had daily/ weekly, monthly, quarterly and

Proportion of network members with monthly contact half-yearly contact with, for example as the number of daily/ weekly contacts divided by network size.

Proportion of network members with quarterly contact

Proportion of network members with half-yearly contact 


\section{Proximity}

Proportion of network members who are household members

Proportion of network members living within walking distance

Proportion of network members living less than 1/2h away by car

Proportion of network members living more than 1/2h away by car

Proportion of network members living further away

Living alone
We calculated geographical proximity as the proportion of all network members that were household members, lived within walking distance, lived less than half an hour away by car, lived more than half an hour away by car, and lived further away (e.g. in another country). For example, we calculated the proportion of household members as the number of network members living in the same household divided by network size.

\section{Mixing}

Proportion of same-sex network members

Living alone was defined as a person who lived alone in his/ her household (single household size).

To indicate sex mixing, we calculated the percentage of same-sex network members. For example, for a female participant the number of her female network members was divided by her network size to obtain the percentage of same-sex network members.

Proportion of same-age network members ( \pm 5 years)

Proportion of younger network members

(>15 years younger)

Proportion of younger network members

(5-15 years younger)

Proportion of older network members

(>15 years older)

Proportion of older network members

(5-15 years older)

\section{Heterogeneity}

Sex heterogeneity (IQV, range 0-1)
To identify the proportion of network members who are of the same age as the participant, we calculated the difference between the participants' age and the network members' age for every network member named. Next, we computed the proportion of younger (>15 years and 5 to 15 years younger), same age ( \pm 5 years) and older ( $>15$ years and 5 to 15 years older) network members for each participant. 


\section{Type of relationship}

Proportion of network members who are family members

Proportion of network members who are friends

Proportion of network members who are acquaintances (colleague, neighbour, club mate, other)

\begin{tabular}{l} 
Network density \\
Density friends \\
(friends know each other) \\
\hline Density friends and family (friends know family)
\end{tabular}

\section{Social participation}

Participation in social activities

Total number of club memberships

Functional characteristics of the social network

Informational support

Emotional support (discomfort)

Emotional support (important decisions)

Practical support (jobs)

Practical support (sickness)
We computed the proportion of network members that were family members, friends, and acquaintances. For example, we calculated the proportion of family members within the network as the number of family members divided by network size.

Density was defined as the extent to which network members in the network know each other. Density between friends was computed from the statement "most of my friends know each other" (five-point Likert scale ranging from strongly agree to strongly disagree) and density between friends and family was computed from the statement "my best friends know my family".

Participation in social activities was defined as membership in, for instance, a sports club, religious group, volunteer organization, discussion group, self-support group, internet club, or other organization.

We computed the total number of club memberships (and the number of clubs the participant frequented on a daily or weekly, monthly or occasional basis)

Informational support was defined as the number of network members that give advice on problems

Emotional support related to discomfort was defined as the number of network members that provide emotional support when participants were feeling unwell

Emotional support related to important decisions was defined as the number of network members that provide the opportunity to discuss important matters

Practical support related to jobs was defined as the number of network members that help with small and larger jobs around the house

Practical support related to sickness was defined as the number of network members that provide practical help when participants were sick 


\section{Visualized examples of structural social network characteristics}

In the following section, two examples of structural social network characteristics used in this thesis were visualized, network size and the type of relationship.

Network size

Network size was computed as the total number of unique network members. Figure 1a illustrates a social network that is composed of 12 network members, figure $1 \mathrm{~b}$ illustrates a network that is composed of 6 network members.
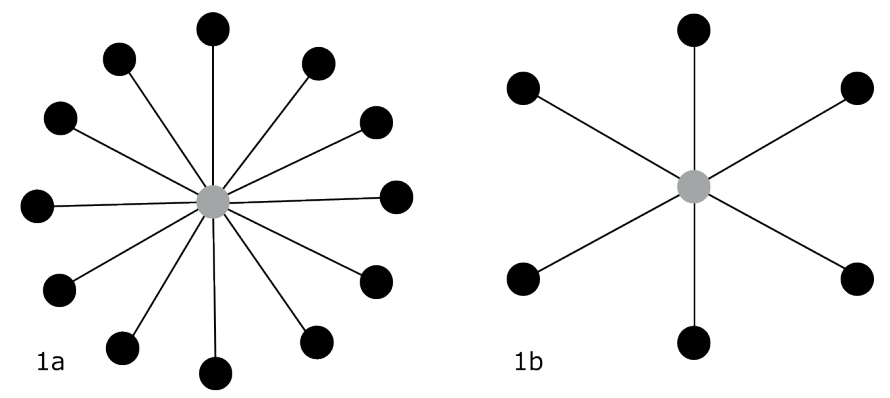

Figure 1- Network size

\section{Type of relationship}

The proportion of network members that were family members, friends, and acquaintances was calculated as the number of family members, friends and acquaintances divided by network size. Figure 2a illustrates a network composed of $66.7 \%$ family members, $16.7 \%$ friends and $16.7 \%$ acquaintances. Figure $2 \mathrm{~b}$ illustrates a network composed of $33.3 \%$ family members, $50 \%$ friends and $16.7 \%$ acquaintances.

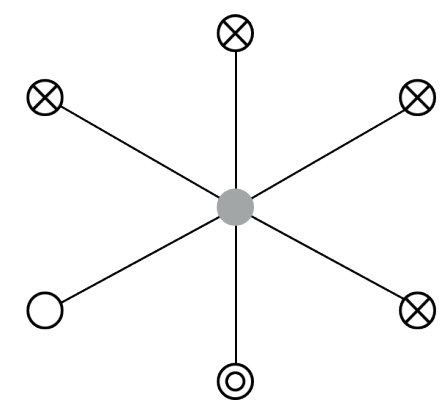

$2 a$

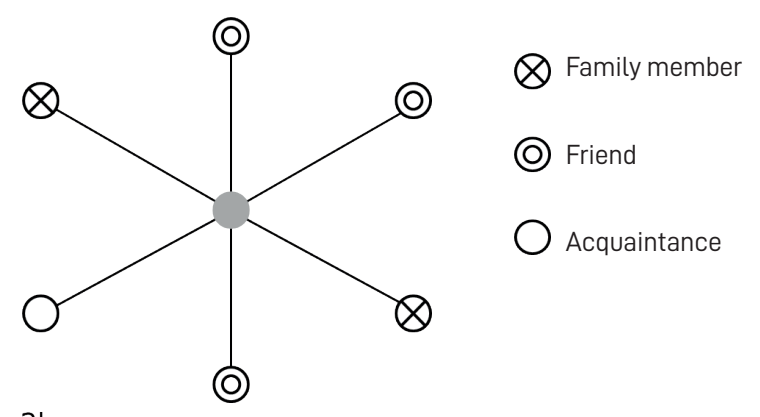

$2 b$

Figure 2 - Type of relationship 


\section{References}

1. World Health Organization, Active Ageing: A Policy Framework. 2002, World Health Organization: Geneva.

2. Rechel, B., et al., Ageing in the European Union. The Lancet, 2013. 381(9874): p. 1312-1322.

3. Agren, G. and K. Berensson, Healthy ageing: a challenge for Europe. Swedish National Institute of Public Health, 2006. 2006: p. 29.

4. Walker, A. and T. Maltby, Active ageing: A strategic policy solution to demographic ageing in the European Union. International Journal of Social Welfare, 2012. 21(s1).

5. Yoshikawa, T.T., Epidemiology and unique aspects of aging and infectious diseases. Clinical Infectious Diseases, 2000. 30(6): p. 931-3.

6. Derhovanessian, E., A. Larbi, and G. Pawelec, Biomarkers of human immunosenescence: impact of Cytomegalovirus infection. Current opinion in immunology, 2009. 21(4): p. 440-445.

7. Strausbaugh, L.J., Emerging health care-associated infections in the geriatric population. Emerging Infectious Diseases, 2001. 7(2): p. 268-71.

8. Nicholson, K.G., et al., Acute viral infections of upper respiratory tract in elderly people living in the community: comparative, prospective, population based study of disease burden. Behavioral Medicine, 1997. 315: p. 1060-1064.

9. Webber, R., Communicable Diseases: A Global Perspective. 2012: CABI.

10. Guerrant, R.L., et al., Practice Guidelines for the Management of Infectious Diarrhea. Clinical Infectious Diseases, 2001. 32(3): p. 331-351.

11. Wild, S., et al., Global prevalence of diabetes estimates for the year 2000 and projections for 2030. Diabetes care, 2004. 27(5): p. 1047-1053.

12. World Health Organization, Definition and diagnosis of diabetes mellitus and intermediate hyperglycaemia. 2006: Geneva, Switserland.

13. Narayan, K.M., et al., Lifetime risk for diabetes mellitus in the United States. Jama, 2003. 290(14): p. 1884-90.
14. Rao Kondapally Seshasai, S., et al., Diabetes Mellitus, Fasting Glucose, and Risk of Cause-Specific Death. The New England journal of medicine, 2011. 364(9): p. 829-841.

15. Inzucchi, S.E., et al., Management of hyperglycaemia in type 2 diabetes: a patient-centered approach. Position statement of the American Diabetes Association (ADA) and the European Association for the Study of Diabetes (EASD). Diabetologia, 2012. 55(6): p. 1577-1596.

16. Group, D.P.P.R., Reduction in the incidence of type 2 diabetes with lifestyle intervention or metformin. New England journal of medicine, 2002. 346(6): p. 393-403.

17. Williams, R., L. Van Gaal, and C. Lucioni, Assessing the impact of complications on the costs of Type II diabetes. Diabetologia, 2002. 45(7): p. S13-S17.

18. Beulens, J.W., D.E. Grobbee, and B. Nealb, The global burden of diabetes and its complications: an emerging pandemic. European Journal of Cardiovascular Prevention \& Rehabilitation, 2010. $17(1$ suppl): p. s3-s8.

19. Economic costs of diabetes in the U.S. In 2007. Diabetes Care, 2008. 31(3): p. 596-615.

20. Berkmann, L.F. and S.L. Syme, Social networks, host resistance, and mortality: A nine-year follow-up study of Almeda country residents. American Journal of Epidemiology, 1979. 109(2): p. 186-204.

21. Eng, P.M., et al., Social Ties and Change in Social Ties in Relation to Subsequent Total and Cause-specific Mortality and Coronary Heart Disease Incidence in Men. American Journal of Epidemiology, 2002. 155(8): p. 700-709.

22. Orth-Gomer, K., A. Rosengreen, and L. Wilhelmsen, Lack of Social Support and Incidence of Coronary Heart Disease in Middle-Aged Swedish Men. Psychosomatic Medicine, 1993. 55: $\mathrm{p}$. 37-43.

23. Kawachi, I., et al., A prospective study of social networks in relation to total mortality and cardiovascular disease in men in the USA. Journal of Epidemiology and Community Health, 1996. 50: p. 245-251. 
24. Kroenke, C.H., et al., Social Networks, Social Support, and Survival After Breast Cancer Diagnosis. Journal of Clinical Oncology, 2006. 24(7): p. 1105-1111.

25. Uchino, B.N., J.T. Cacioppo, and J.K. Kiecolt-Glaser, The Relationship Between Social Support and Physiological Processes: A Review With Emphasis on Underlying Mechanisms and Implications for Health. Psychological Bulletin, 1996. 119(3): p. 488-531.

26. Hamrick, N., S. Cohen, and M.S. Rodriguez, Being popular can be healthy or unhealthy: stress, social network diversity, and incidence of upper respiratory infection. Health Psychology, 2002. 21(3): p. 294.

27. Cohen, S., et al., Social Ties and susceptibility to the Common Cold. JAMA, 1997. 277(24): p. 19401944.

28. Pressman, S.D., et al., Loneliness, social network size, and immune response to influenza vaccination in college freshmen. Health Psychology, 2005. 24(3): p. 297.

29. Mossong, J.l., et al., Social contacts and mixing patterns relevant to the spread of infectious diseases. PLoS medicine, 2008. 5(3): p. e74.

30. Read, J.M., K.T. Eames, and W.J. Edmunds, Dynamic social networks and the implications for the spread of infectious disease. Journal of The Royal Society Interface, 2008. 5(26): p. 10011007.

31. Del Valle, S.Y., J.M. Hyman, and N. Chitnis, Mathematical models of contact patterns between age groups for predicting the spread of infectious diseases. Mathematical biosciences and engineering: MBE, 2013. 10: p. 1475.

32. Fu, Y.-C., D.-W. Wang, and J.-H. Chuang, Representative contact diaries for modeling the spread of infectious diseases in Taiwan. Plos one, 2012. 7(10): p. e45113.

33. Melegaro, A., et al., What types of contacts are important for the spread of infections? Using contact survey data to explore European mixing patterns. Epidemics, 2011. 3(3): p. 143-151.

34. Stehle, J., et al., Simulation of an SEIR infectious disease model on the dynamic contact network of conference attendees. BMC Med, 2011. 9: p. 87.
35. Machens, A., et al., An infectious disease model on empirical networks of human contact: bridging the gap between dynamic network data and contact matrices. BMC Infect Dis, 2013. 13: p. 185.

36. Potter, G.E., et al., Estimating within-household contact networks from egocentric data. The annals of applied statistics, 2011. 5(3): p. 1816.

37. Glass, L.M. and R.J. Glass, Social contact networks for the spread of pandemic influenza in children and teenagers. BMC public health, 2008. 8(1): p. 61.

38. Rees, C.A., A.J. Karter, and B.A. Young, Race/ ethnicity, social support, and associations with diabetes self-care and clinical outcomes in NHANES. The Diabetes Educator, 2010. 36(3): p. 435-445.

39. Strom, J.L. and L.E. Egede, The impact of social support on outcomes in adult patients with type 2 diabetes: a systematic review. Current diabetes reports, 2012. 12(6): p. 769-781.

40. van Dam, H.A., et al., Social support in diabetes: a systematic review of controlled intervention studies. Patient education and counseling, 2005. 59(1): p. 1-12.

41. Norberg, M., et al., Work stress and low emotional support is associated with increased risk of future type 2 diabetes in women. Diabetes Research and Clinical Practice, 2007. 76(3): p. 368-377.

42. Lidfeldt, J., et al., Women living alone have an increased risk to develop diabetes, which is explained mainly by lifestyle factors. Diabetes Care, 2005. 28(10): p. 2531-2536.

43. Meisinger, C., U. Kandler, and K.-H. Ladwig, Living alone is associated with an increased risk of type 2 diabetes mellitus in men but not women from the general population: the MONICA/KORA Augsburg Cohort Study. Psychosomatic medicine, 2009. 71(7): p. 784-788.

44. Crossley, N., et al., Social network analysis for ego-nets: Social network analysis for actor-centred networks. 2015: Sage.

45. Berkman, L.F. and T. Glass, Social integration, social networks, social support, and health. Social epidemiology, 2000. 1: p. 137-173. 
46. Umberson, D. and J.K. Montez, Social Relationships and Health: A Flashpoint for Health Policy. J Health Soc Behav, 2010. 51(Suppl): p. S5466.

47. Borgatti, S.P., et al., Network analysis in the social sciences. science, 2009. 323(5916): p. 892895.

48. Marsden, P.V., Network data and measurement. Annual review of sociology, 1990. 16(1): p. 435463.

49. McCallister L, F.C., A procedure for surveying personal networks. Sociological Methods and Research, 1978: p. 131-148.

50. Scott, J., Social network analysis. Third ed. 2012: Sage.

51. Smith, K.P. and N.A. Christakis, Social networks and health. Annu. Rev. Sociol, 2008. 34: p. 405429.

52. Chung, K., L. Hossain, and J. Davis, Exploring Sociocentric and Egocentric Approaches for Social Network Analysis. 2005.

53. Salathé, M., et al., A high-resolution human contact network for infectious disease transmission. Proceedings of the National Academy of Sciences, 2010. 107(51): p. 22020-22025.

54. McCallister, L. and C. Fischer, A procedure for surveying personal networks. Sociological Methods and Research 1978. 7: p. 131-148.

55. Christakis, N.A. and J.H. Fowler, The spread of obesity in a large social network over 32 years. New England journal of medicine, 2007. 357(4): p. 370-379.

56. Antonucci, T.C. and H. Akiyama, Social networks in adult life and a preliminary examination of the convoy model. Journal of Gerontology, 1987. 42(5): p. 519-527.

57. Heaney, C.A. and B.A. Israel, Social networks and social support, in Health Behavior and Health Education, K. Glanz, B.K. Rimer, and K. Viswanath, Editors. 2008, Jossey Bass: San Francisco. p. 189-210.

58. Schram, M.T., et al., The Maastricht Study: an extensive phenotyping study on determinants of type 2 diabetes, its complications and its comorbidities. European journal of epidemiology, 2014. 29(6): p. 439-451.
59. Hardy, M.A. and A. Bryman, Handbook of Data Analysis. 2009: SAGE Publications. 



\section{Part I}

Social networks in relation to infectious diseases 


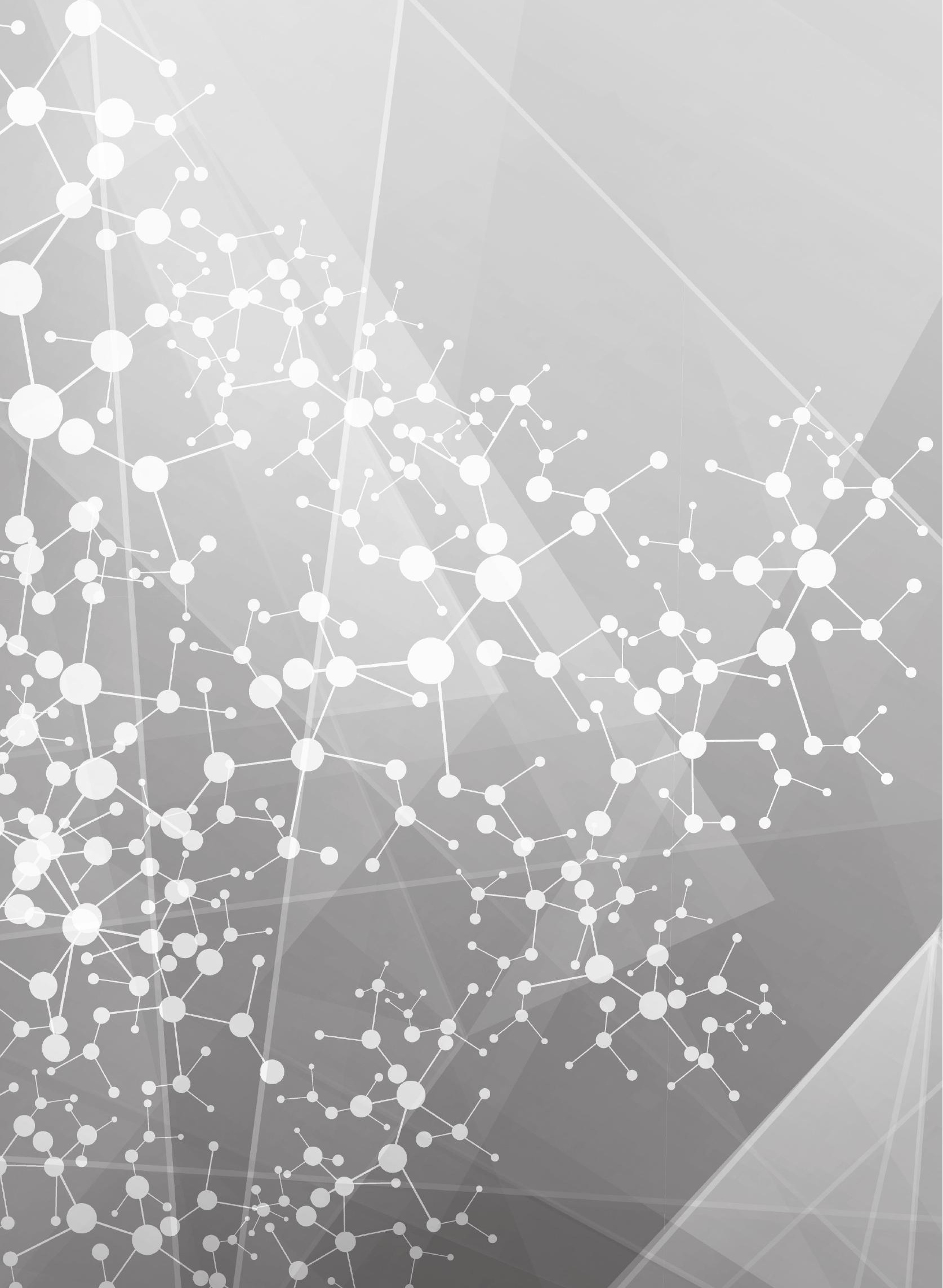




\section{Chapter 2}

Social networks in relation to self-reported symptomatic infections in individuals aged 40-75

\section{- The Maastricht Study -}

Stephanie Brinkhues, Miranda T. Schram, Christian J.P.A. Hoebe, Mirjam E.E. Kretzschmar, Annemarie Koster, Pieter C. Dagnelie, Simone J.S. Sep, Sander M.J. van Kuijk, Paul H.M. Savelkoul,

Nicole H.T.M. Dukers-Muijrers 


\section{Abstract}

Background: Most infections are spread through social networks (detrimental effect). However, social networks may also lower infection acquisition (beneficial effect). This study aimed to examine associations between social network parameters and prevalence of self-reported upper and lower respiratory, gastrointestinal and urinary tract infections in a population aged 40-75.

Methods: In this population-based cross-sectional cohort study ( $\mathrm{N}=3004$, mean age $60.0 \pm 8.2$ years, $49 \%$ women), infections within the past two months were assessed by self-administered questionnaires. Social network parameters were assessed using a name generator questionnaire. To examine the associated beneficial and detrimental network parameters, univariable and multivariable logistic regression was used.

Results: Participants reported an average of 10 people (alters) with whom they had 231 contacts per half year. Prevalences were $31.1 \%$ for upper respiratory, $11.5 \%$ for lower respiratory, $12.5 \%$ for gastrointestinal, and $5.7 \%$ for urinary tract infections. Larger network size, and a higher percentage of alters that were friends or acquaintances were associated with higher odds of upper respiratory, lower respiratory and/or gastrointestinal infections (detrimental). A higher total number of contacts, higher percentages of alters of the same age, and higher percentages of family members/ acquaintances were associated with lower odds of upper respiratory, lower respiratory and/or gastrointestinal infections (beneficial).

Conclusion: We identified both detrimental and beneficial associations of social network parameters with the prevalence of infections. Our findings can be used to complement mathematical models on infection spread, as well as to optimize current infectious disease control. 


\section{Background}

Social networks are assumed to have a powerful influence on health [1-8]. The social network of an individual can be defined as the web of social relationships that surround that individual (ego), referring to contacts with other individuals (alters) [2]. Social relationships may enhance the ability to resist infection but may also act as a vehicle for the transmission of infections. Cohen et al. (1997) demonstrated that individuals with a larger and/or more diverse social network are less susceptible to upper respiratory tract infections (URIs) [9]. Another study showed that smaller social networks were associated with poorer immune response to influenza vaccination in young and healthy adults [10]. In addition, better immune function has been found to be associated with social support [4]: higher levels of social support showed an association with increased natural killer cell activity and decreased interleukin-4 concentration [11, 12]. However, having large and diverse social networks may not always be protective. Hamrick et al. (2002) found that larger social networks were associated with increased numbers of URIs when host resistance to infectious agents was compromised (e.g. among individuals with high levels of stress) [13]. Large social networks were associated with close proximity interactions with a broad range of alters and hence an increased risk of exposure to a broad range of infectious agents. Infectious agents from an infected person can reach a susceptible alter in close proximity, which is typically within a distance of 3 meters or less [14, 15]. Previous studies have shown that close-proximity interactions were highly relevant for infectious disease transmission [14, 16, 17], and that close contacts are a better proxy for several infection transmissions than total contacts $[14,18]$.

To date, it is not yet fully understood which social network characteristics are related to the risk of infections, whether these characteristics have detrimental or beneficial effects or both, and whether relations differ by type of infection. Most previous research on the transmission of infectious disease through social contacts was done using mathematical disease transmission models [19-27]. Previous studies included measures on degree (which is the total number of alters), mixing patterns (percentages of alters younger than, same age or older than ego/ percentages same sex as ego), contact patterns (frequency and duration of contact), relationships (e.g. household member/ friend/ colleague) and social distance [19-26, 28-34].

Furthermore, most studies on networks and infections so far addressed URIs alone $[23,27,28,30$, $33,34]$. Also, there is a lack of direct comparative data for different types of infections. Different infectious diseases require different modes of contact for transmission [17, 35]. URIs and lower respiratory tract infections (LRIs) are mainly transmitted via droplets (sneezing, coughing), whereas gastrointestinal infections (GIs) require surface contamination and are related to food, personal hygiene and/or close contact, and urinary tract infections (UTIs) are more likely to arise from self-transmission or compromised immunity [35]. 
Infectious diseases are a major challenge in health care of the older persons [36], aging is associated to increased susceptibility to infections caused by an age-related comprised immune system $[37,38]$. Therefore, insights into risk factors for infections would be highly relevant to inform infectious disease control strategies in middle-aged and older persons.

The current study examines the detrimental as well as the beneficial associations between a broad range of network parameters and URI, LRI, GI, and UTI. Comparison across multiple infections will increase robustness of the findings and provide insight into the social network related determinants of infections in the specific group of people aged 40-75.

The current study adds insights into empirical egocentric social network data with infection prevalences on four different infectious diseases in an epidemiological study. This may contribute to enhancement of current infectious disease control, especially by non-pharmaceutical infection prevention strategies $[39,40]$. Moreover, by estimating population social structures directly from egocentric contact data, this article provides new information for the estimation of transmission parameters, and thus a basis for more realistic projections of epidemiological data and the effects of interventions by mathematical disease modelling.

\section{Methods}

\section{Study population}

In the present study, we used data from an observational prospective population-based cohort study. The rationale and methodology of The Maastricht Study have been described by Schram et al. (2014) [41]. All individuals living in the southern part of the Netherlands and aged between 40 and 75 years were eligible for participation. Recruitment strategies have been described previously [41]. We included cross-sectional data from the first 3451 participants (baseline survey between November 2010 and September 2013) [41]. Participants adhere to a protocol that covers 4 half day visits to The Maastricht Study research center [41]. The present study includes data from assessments and questionnaires that are given within the first study site visit. Of the 3,451 participants, 3,004 individuals provided data on social network and infections. The participants without social network and infection data $(n=447,12.9 \%)$ did not differ from those with these data with respect to sex, educational level, smoking status, alcohol use, diabetes status or body mass index (BMI). However, participants who did not provide social network and infection data were slightly younger than those who did (mean age 59 versus 60 years, $(p<0.001)$ ). 


\section{Measurements}

\section{Social network}

Multiple previous studies applied various methods and techniques to collect empirical data on social networks and contact patterns, such as reviewed by Read et al. [17].

In the present study, social networks were identified by a name generator, one of the best known and most widely used instruments for examining ego-centered network data [42]. The name generator/interpreter is used to map the ego-centered social network and to collect information about the alters of an ego-centered social network, resulting in a detailed description of a participant's social network. An ego-centered network is defined as a network centered on a specific individual, called the ego [43]. Each person who has a relationship with an ego was defined as an "alter" [44]. The social network measured within this study mainly focused on close-proximity interactions [14].

A detailed description of the name generator questionnaire can be found elsewhere [45]. In brief, the name generator first requires a respondent to identify actual persons (alters) in response to seven questions on different types of contacts (e.g. persons who advised them on problems or persons they visited for social purposes or that they could go out with sometimes). For all seven types of contacts, they were asked to indicate their frequency of contact with this person over the last six months (daily or weekly, monthly, quarterly, and half-yearly). In total, participants could name a maximum number of 40 alters. Next, several additional questions about all alters named were asked (sex, age, type of relationship, geographical proximity). Moreover, participants were asked to rate the statements "most of my friends know each other" and "my best friends know my family" on a five-point Likert scale ranging from strongly agree to strongly disagree. Finally, participants had to indicate whether they were a member of a club (yes/no), and, if so, to identify the club(s) concerned (sports club, volunteer organization, religious group, self-support group, discussion group, Internet club, or another organization) and how often they frequented this club (daily/weekly, monthly, occasionally).

\section{Self-reported infections}

In a structured questionnaire, participants were asked whether they had suffered from sudden symptoms such as a cough, runny nose, sore throat, fever, vomitus with fever, or pain when urinating, in the previous two months. They were also asked whether they had suffered from sudden onset of influenza, pneumonia, urinary tract infection, middle ear infection, diarrhea, or skin infection in the previous two months. All of these questions were yes/no questions.

\section{General measurements}

Self-administered questionnaires were used to assess educational level (low (no education, primary education, and lower vocational education)/ medium (intermediate vocational education, higher secondary education, and vocational education)/ high (higher professional education, university)), employment status (employed/ retired or not employed/ not known), smoking status (never/ former/ current) 
and alcohol consumption (non-consumers/ low consumers ( $\leq 7$ glasses per week for women, $\leq 14$ glasses per week for men)/ high consumers ( $>7$ glasses per week for women, $>14$ glasses per week for men)). To determine type 2 diabetes, all participants (except those who used insulin) underwent a standardized 7-point $75 \mathrm{gr}$. OGTT after an overnight fast. Height, weight and BMI were assessed as described previously [41], and defined according to the WHO classification (normal $(B M \mid<25)$, overweight (BMI 25-<30), and obese (BMI $\geq 30)$ ).

\section{Exposure variables: social network parameters}

First, in the literature we identified several social network parameters that had previously been examined in relation to infections. Next, the social network parameters listed below were computed and used in the current study. The majority of social network parameters used in the current study focused on close-proximity interactions as previous studies had shown their importance in infectious disease transmission $[14,18]$.

\section{Network size (degree)}

Previous studies identified social network size as determinant for several health outcomes and it is also widely used in mathematical disease transmission models $[9,10,13,16,19,25,28,33,42,46]$. Therefore, the degree of the social network was defined as the total number of alters mentioned in the questionnaire and was computed as the size of the ego network (network size).

\section{Contact frequency}

In line with several studies on mathematical modelling of the spread of infectious disease, we also investigated contact frequency $[19,21,22,25,33]$. First, we used highest contact frequency (e.g. daily contact) for every alter as an indicator of the actual contact frequency. For example, if participants reported alter 1 as a person they visited for social purposes, with a frequency of "daily or weekly" and also named the same alter as a person who provided practical help if they were sick, with a frequency of "quarterly", we considered "daily or weekly" as the actual frequency of contact between the ego and the alter. Second, we recoded the answer categories of the questionnaire in an estimated number of contacts per half year. For example, "half-yearly" was assumed to comprise one contact, "quarterly" two contacts, "monthly" 6 contacts and "daily or weekly" 48 contacts [21]. Third, we computed the sum of all contacts per half year as the total contact frequency. In addition, we computed the percentages of alters that the ego had daily/ weekly, monthly, quarterly and half-yearly contact with, for example as the number of daily/weekly contacts divided by network size. 


\section{Geographical proximity}

Previous studies included measures on home contacts and distance from home $[21,22,28,33]$. In the current study, we calculated geographical proximity as the percentage of all alters that were household members, lived within walking distance, lived less than half an hour away by car, lived more than half an hour away by car, and lived further away (e.g. in another country). For example, we calculated the percentage of household members as the number of alters living in the same household divided by network size.

\section{Network heterogeneity}

In accordance with another study among social networks in the Netherlands, we also computed heterogeneity of age and sex [42]. To assess sex heterogeneity within the ego's network, we computed the Index of Qualitative Variation (IQV) by Mueller and Schuessler (1961) [47]. This index indicates the probability that two randomly chosen network alters belong to the same category. The statistical formula for the derivation of the IQV can be found in the supplemental file 1. In brief, the IQV is defined as the ratio of observed differences divided by maximum possible differences, where "0" represents a fully homogeneous and "1" a fully heterogeneous network [47]. Observed differences were calculated through multiplication of the total number of men in the ego's network by the total number of women in the ego's network. We calculated maximum differences as (network size/ 2) ${ }^{2}$ [47]. The IQV was computed as observed differences/ maximum possible differences. We defined age heterogeneity of network alters as the standard deviation of the mean age of all alters of the ego [42].

\section{Mixing}

According to studies on mathematical infectious disease modelling, we calculated mixing parameters for age mixing patterns (whether the ego had contact with younger, same age or older alters) and sex mixing patterns (whether the ego had contact with alters of the same sex or the opposite sex) [22, 28, 33]. To identify age mixing, we calculated the difference between the ego's age and the alter's age for every alter named. Next, we computed the percentages of younger ( $>15$ years and 5 to 15 years younger), same age ( \pm 5 years) and older ( $>15$ years and 5 to 15 years older) alters for each participant. To indicate sex mixing, we calculated the percentage of same-sex alters. For example, for a female participant the number of her female alters was divided by her network size to obtain the percentage of same-sex alters.

\section{Type of relationship}

The questionnaire also assessed the type of relationship between the ego and the alter. To the best of our knowledge, this is the first study that examines network composition in terms of the type of relationship. To that end, we computed the percentage of alters that were family members, friends, colleagues and acquaintances. For example, we calculated the percentage of family members within the network as the number of family members divided by network size. Whether the ego had a partner was 
derived from the social network questionnaire and computed as having/ not having a partner. A partner was defined as an intimate relationship with another person.

\section{Density}

We assessed network density in two questions $[42,48]$, categorizing density scores separately for density of the ego's friends and density of the ego's friends and family. Density was defined as the extent to which alters in the network know each other. Density between friends was computed from the statement "most of my friends know each other" (five-point Likert scale ranging from strongly agree to strongly disagree) and density between friends and family was computed from the statement "my best friends know my family". We used tertiles to compute three equal groups of low density, medium density and high density.

\section{Superficial contacts}

We included a proxy for more superficial contacts than close-proximity interactions as transmission of infections may also occur via contact with contaminated surfaces or exposure that does not involve conversation or touch [49]. We therefore constructed a variable representing the total number of club memberships (and the number of clubs the ego frequented on a daily or weekly, monthly or occasional basis) as a proxy for superficial contacts.

\section{Close proximity interactions}

While all of the types of interactions in the name generator suggest close and direct contact, the questions do not explicitly include information on whether an interaction is physical (e.g. kiss or handshake), face-to-face or by phone/internet. Some interactions such as help with jobs around the house or persons they visited for social purposes require close proximity interactions, whereas other interactions such as advice on problems or provision of emotional support may have occurred by telephone/ internet.

To assess the proportion of close proximity interactions, we additionally computed the network size and total contact frequency from those type of interactions with alters that are by definition in close proximity; persons who could offer them practical help if they were sick, persons who helped them with small and larger jobs around the house, persons who were also important for them because of mutual activities, and/or household contacts. The additionally computed social network size of close proximity interactions represented $86 \%$ of the total social network size ( 8,5 alters in a network of 10 alters), and the total contact frequency of close proximity interactions represented $87 \%$ of the total contact frequency (202 contacts per half year in a total number of 231 contacts per half year).

In all analyses, the total network size and total contact frequency per half year were used. 


\section{Outcome variables: self-reported symptomatic infections over the past two months}

The symptoms "runny nose" and "sore throat" were pooled as indicators of URI. Influenza, pneumonia and fever were pooled as indicators of LRI. Pain when urinating and urinary tract infection were pooled as UTI. Vomitus with fever and diarrhea were pooled as GI. We excluded cough from the analysis because it is strongly related to smoking and asthma [50], and not exclusively a specific indicator for infection.

The observed prevalences for each month of the year (Figure 1) display the expected seasonality of the diseases.

\section{Statistical analyses}

We performed descriptive analyses to examine the characteristics of the participants in terms of baseline characteristics, prevalence of self-reported infections, and network parameters.

First, we conducted bivariate correlation analyses to rule out multicollinearity between the network variables. With all correlation cut-off values below 0.7 , none of the variables were considered collinear.

Second, we conducted univariable logistic regression analyses to assess the association between the exposure variables, i.e. network parameters, and the outcomes of URI, LRI, GI, and UTI. All network parameters were continuous variables, except for density. For every network parameter, odds ratios (ORs) and $95 \%$ confidence intervals $(95 \% \mathrm{Cl})$ were calculated.

Network size as (unadjusted) determinant for the four infections was visually presented using polynomials (cubic function).

Third, we built two multivariable models to determine the most important detrimental and beneficial network parameters. We forced network size and total contact frequency into the models as these variables are considered essential for the assessment of detrimental and beneficial social network effects, and have been shown to be related to the transmission of infections as well as to decrease susceptibility to infections $[9,10,13,19,21,22,28,29,33,42]$. In the detrimental exposure model, we further included all variables that were positively associated with URI (odds ratio $>1$ ), regardless of their statistical significance. In the beneficial exposure model, we further included all variables that were negatively related with URI (odds ratio $<1$ ), again regardless of their statistical significance. Next to the social network size and total contact frequency, we used several social network parameters in percentages, to be able to assess the effect of the composition of the social network independent of the social network size and total contact frequency. For those social network parameters that were computed as percentages within the network, the associations were presented in steps of $10 \%$. Based on an average network size of 10 network members, a change in one network member corresponds to 
$10 \%$. For the detrimental and beneficial models, we used the stepwise backward method $(p<0.1)$ to obtain the final model, including possible confounders, network size, and total contact frequency. These analyses were repeated for LRI, GI and UTI. We used the variance inflation factor (VIF) to measure collinearity in all regression models. Values for VIF and tolerance did not indicate multicollinearity problems with cut-off values of VIF $<10$ and tolerance (1/VIF) $>0.1$.

We adjusted all associations for possible confounders, i.e. diabetes status (type 2 diabetes oversampled by design), age, sex, BMI, smoking status, alcohol consumption, educational level, and employment status. We also adjusted all associations for the season in which the measurement took place to account for the likelihood of encountering an infected source. In the multivariable models, associations with $p<0.05$ were considered statistically significant.

In addition, we tested statistical interaction (effect modification) of the network parameters with sex and age to check whether the associations between network parameters and outcome differed by sex and age. However, none of the interactions of the network parameters with sex and age were statistically significant $(p>0.1)$.

We performed sensitivity analyses to verify the model building process; we replicated multivariable logistic regression analyses by using the complete model instead of backward elimination, and used degrees instead of percentages. The findings were in line with the results presented.

All analyses were conducted using IBM SPSS Statistics version 21.0 (IBM Corp. Armonk, NY, USA).

\section{Results}

The overall study population consisted of 3004 participants with a mean age of 60.0 years. Participants were mainly Caucasian (98.6\%), slightly less than half were women (49\%), nearly one third had type 2 diabetes (by design), two thirds were overweight (or obese), and one in seven were current smokers (Table 1).

URI, LRI, UTI and GI in the past two months were reported by $31.1 \%, 11.5 \%, 5.7 \%$ and $12.5 \%$ of the participants, respectively (Table 1). The prevalences of URI, LRI, GI and UTI for every month of the year were presented in Figure 1. 


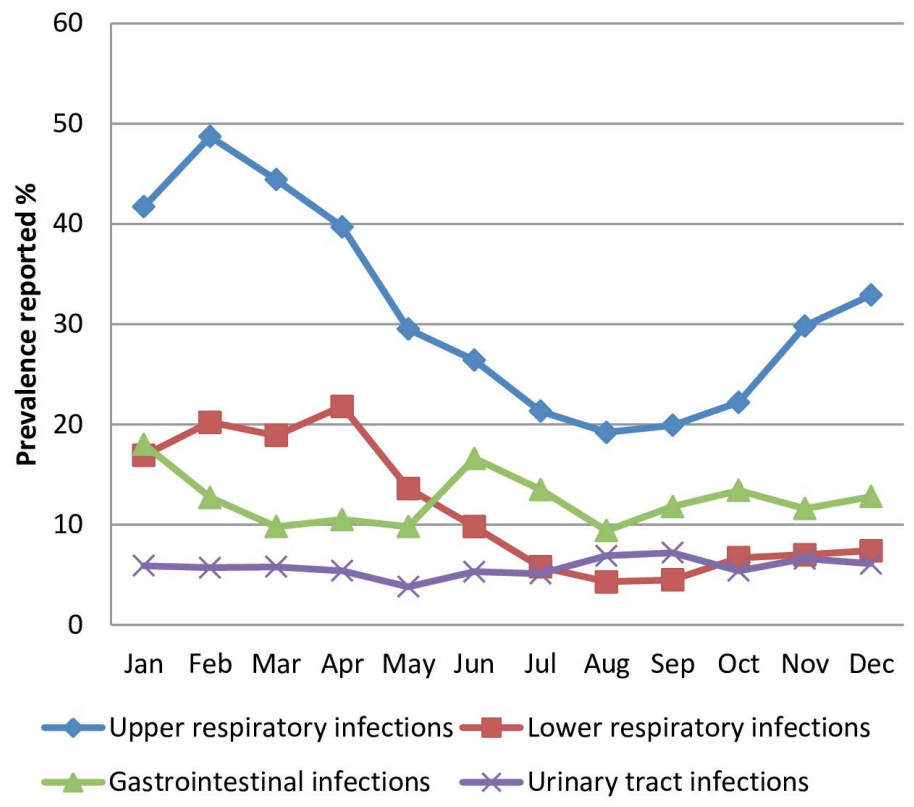

Figure 1 - The observed prevalences of URI, LRI, GI and UTI for each month of the year.

\section{Table 1-Characteristics of the participants and prevalences of infections}

\begin{tabular}{|c|c|c|c|}
\hline \multirow[t]{3}{*}{ Individual characteristics } & $\%(n=3004)$ & \multicolumn{2}{|l|}{ Alcohol consumption } \\
\hline & or & - Non-consumers (no alcohol use) & $18.3(n=537)$ \\
\hline & Mean (SD) & - Low consumers ( $\leq 7$ glasses per & $56.0(n=1645)$ \\
\hline \multicolumn{2}{|l|}{ Sex } & week for women; $\leq 14$ glasses per & \multirow{5}{*}{$25.7(n=755)$} \\
\hline - Men & $51.2(n=1537)$ & week for men) & \\
\hline - Women & $48.8(n=1467)$ & \multirow{3}{*}{$\begin{array}{l}\text { High consumers (> } 7 \text { glasses per } \\
\text { week for women; >14 glasses per } \\
\text { week for men) }\end{array}$} & \\
\hline Age & $60.0(8.2)$ & & \\
\hline \multicolumn{2}{|l|}{ Educational level } & & \\
\hline - Low & $33.4(n=980)$ & \multicolumn{2}{|l|}{ Smoking status } \\
\hline - Medium & $28.1(n=823)$ & \multirow{3}{*}{$\begin{array}{l}\text { - Never } \\
\text { - Former } \\
\text { - Current }\end{array}$} & $34.6(n=1020)$ \\
\hline - High & $38.5(n=1129)$ & & $52.0(n=1529)$ \\
\hline \multicolumn{2}{|l|}{ Employment status } & & $13.4(n=394)$ \\
\hline - Employed & $39.0(n=1172)$ & \multicolumn{2}{|l|}{ Infections (self-reported, past 2 months) } \\
\hline - Unemployed/ retired & $51.0(n=1531)$ & \multirow{4}{*}{$\begin{array}{l}\text { - Upper respiratory infection (URI) } \\
\text { - Lower respiratory infection (LRI) } \\
\text { - Urinary tract infection (UTI) } \\
\text { - Gastrointestinal tract infection (GI) }\end{array}$} & $31.1(n=921)$ \\
\hline - Not known & $10.0(n=301)$ & & $11.5(n=339)$ \\
\hline \multicolumn{2}{|l|}{ Diabetes status } & & $5.7(n=170)$ \\
\hline \multirow{2}{*}{$\begin{array}{l}\text { - No type } 2 \text { diabetes } \\
\text { - Type } 2 \text { diabetes }\end{array}$} & $71.3(n=2141)$ & & $12.5(n=370)$ \\
\hline & $28.7(n=863)$ & \multicolumn{2}{|l|}{ Month of assessment } \\
\hline \multicolumn{2}{|l|}{ Body Mass Index } & \multirow{4}{*}{$\begin{array}{l}\text { - May-October } \\
\text { - November-April } \\
\end{array}$} & $52.7(n=1584)$ \\
\hline - Normal $(<25$ kg/m²) & $35.6(n=1067)$ & & $47.3(n=1420)$ \\
\hline - Overweight $\left(25-30 \mathrm{~kg} / \mathrm{m}^{2}\right)$ & $42.3(n=1268)$ & & \\
\hline - Obese $\left(\geq 30 \mathrm{~kg} / \mathrm{m}^{2}\right)$ & $22.2(n=666)$ & & \\
\hline
\end{tabular}


On average, participants reported a network size of 10 alters, and 231 contacts per half year (Table 2). Only $15(0.5 \%)$ participants reported a network size of 25 or more alters, and only $10(0.3 \%)$ participants reported more than 750 contacts per half year. Participants reported to have daily or weekly contact with nearly half the number of their alters, $15 \%$ of the alters were household members, and sex heterogeneity in the network was high. About half of the alters were not of the same sex and age $( \pm 5$ years) as the participant. The majority of participants reported to have a partner. More than half of the alters were family members, one third were friends and the remaining alters were acquaintances such as neighbors, club mates and colleagues (Table 2). Figure 2 visualizes the average social network of the participants, indicating the average network size, with frequency of contacts, the type of relationship, and the proximity of alters. Further, the unadjusted prevalences for URI. LRI, GI and UTI for network size were presented in Figure 3. Nearly half of participants reported high density between friends ("my friends know each other"), whereas one third reported a high density between friends and family ("best friends know my family"). On average, participants were a member of one club (table 2). The associations of demographic characteristics (sex, age, type 2 diabetes, body mass index, season, educational level, smoking status, alcohol consumption, and employment status) with URI, LRI, GI and UTI were shown in a supplemental table (see Supplemental file 2).

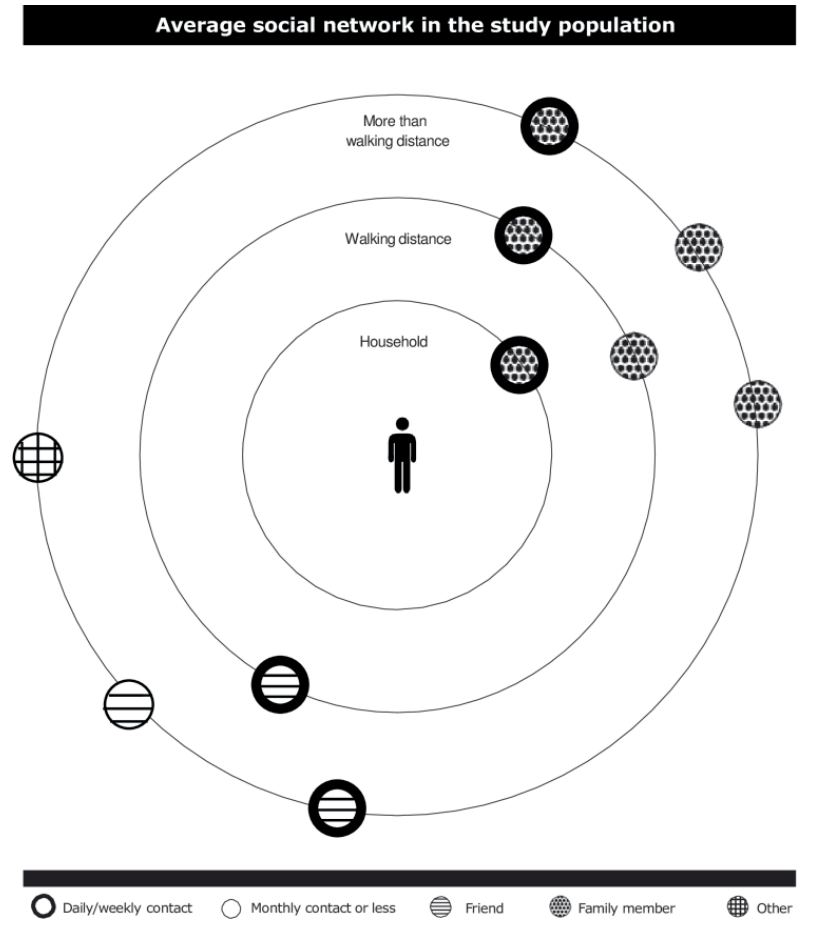

Figure 2 - Visualization of the average social network of the study population with regard to composition of contact frequency, proximity, and type of relationship. 


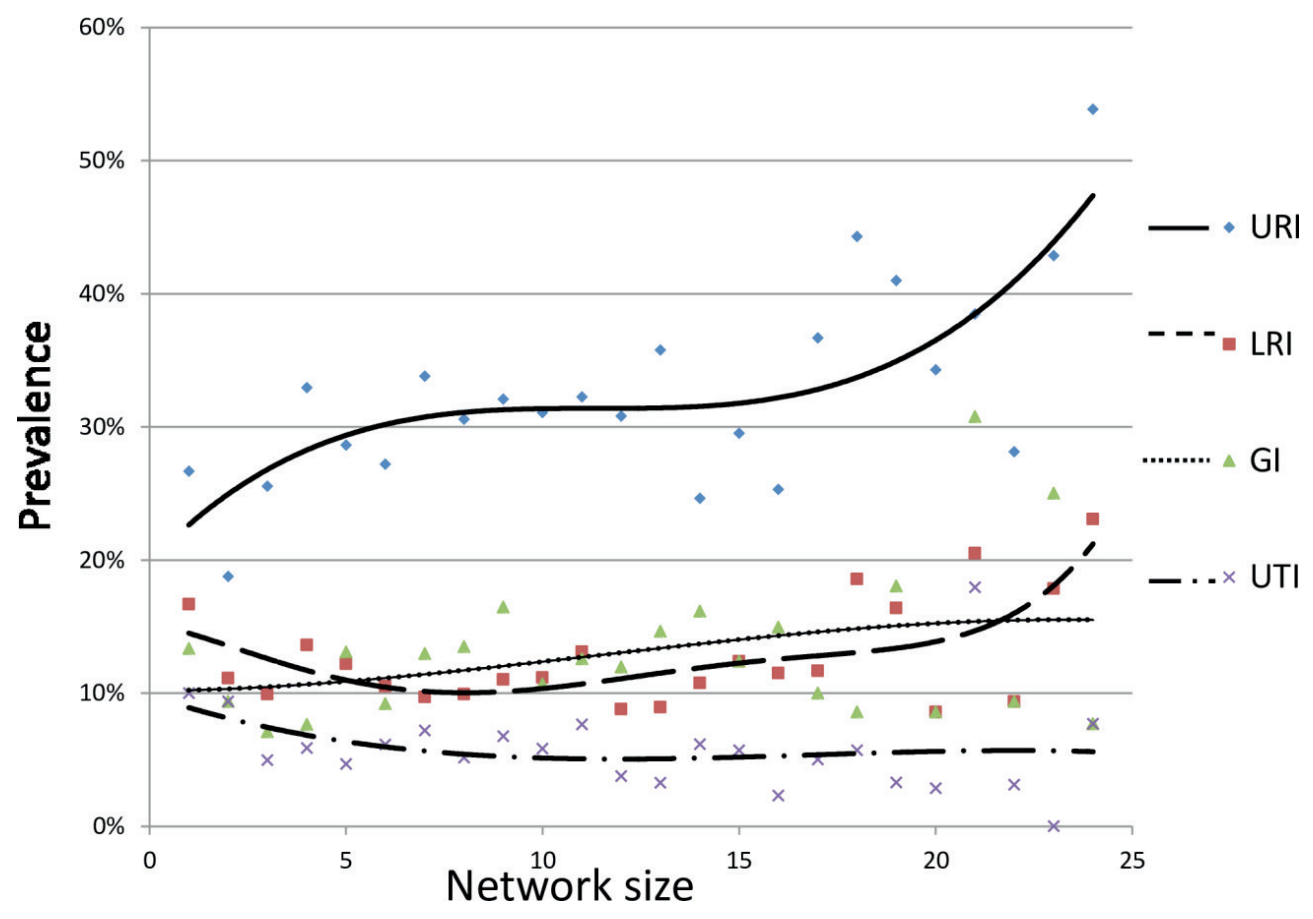

Figure 3 - Unadjusted prevalences of URI, LRI, GI, and UTI for network size presented using polynomials (cubic function). 
Table 2 - Means and prevalences of social network parameters

Mean (SD) or $\%(n)$

Network size (number of alters) (mean, SD)

$9.83(5.17)$

Contact frequency

Total contacts per half year (mean, SD)

$231.18(141.16)$

Percentage of alters with daily-weekly ego/alter contact (mean, SD)

$48.96(25.88)$

Percentage of alters with monthly ego/alter contact (mean, SD)

23.34 (19.49)

Percentage of alters with quarterly ego/alter contact (mean, SD)

$12.50(15.15)$

Percentage of alters with half-yearly ego/alter contact (mean, SD)

$15.17(19.47)$

\section{Proximity}

Percentage of alters who are household members (mean, SD)

$15.43(15.08)$

Percentage of alters living within walking distance (mean, SD)

$28.80(22.58)$

Percentage of alters living less than $1 / 2 \mathrm{~h}$ away by car (mean, SD)

$38.35(24.06)$

Percentage of alters living more than $1 / 2 \mathrm{~h}$ away by car (mean, SD)

$13.93(17.80)$

Percentage of alters living further away (mean, SD)

\section{Mixing}

Percentage of same-sex alters (mean, SD)

$58.15(17.72)$

Percentage of same-age alters ( \pm 5 years) (mean, SD)

$44.28(21.20)$

Percentage of younger alters ( $>15$ years younger) (mean, SD)

$6.50(10.82)$

Percentage of younger alters ( 5 to 15 years younger) (mean, SD)

$11.39(14.29)$

Percentage of older alters ( $>15$ years older) (mean, SD)

$26.73(20.46)$

Percentage of older alters ( 5 to 15 years older) (mean, SD)

$12.83(15.56)$

\section{Heterogeneity}

Sex heterogeneity (IQV, range 0-1) (mean, SD)

$0.85(0.21)$

Age heterogeneity (SD) (mean, SD)

$14.44(5.17)$

\section{Type of relationship}

Participants who have a partner (\%)

$81.1(n=2436)$

Percentage of alters who are family members (mean, SD)

$58.86(24.03)$

Percentage of alters who are friends (mean, SD)

Percentage of alters who are acquaintances (colleague, neighbor, club mate, other) (mean, SD)

$13.98(16.91)$

\section{Proxy for superficial contacts}

Number of club memberships (mean, SD)

Number of clubs with daily/weekly participation (mean, SD)

Number of clubs with monthly participation (mean, SD)

Number of clubs with less frequent participation (mean, SD)

\section{Network density}

Density friends

- Low density (1-3) (\%)

- medium density (4) (\%)

- high density (5) (\%)

Density friends and family

- Low density (1-3) (\%)

- medium density (4) (\%)

- high density (5) (\%) 


\section{Social network related to URI}

Table 3 presents the results of the adjusted univariable analyses, all associations were adjusted for potential confounders. Each additional alter reported was associated with a $2 \%$ higher odds of reporting URI. Every additional 10\% of the network contacted infrequently (once per half year) or living at larger distance was associated with a $6 \%$ and $5 \%$ higher odds of reporting URI, respectively. Every additional $10 \%$ of the network contacted frequently (daily or weekly), household members, and alters of the same age were associated with a $4 \%, 7 \%$, and $5 \%$ lower odds of URI, respectively.

Table 4 presents the results of the multivariable analyses, all associations were adjusted for potential confounders. In the multivariable detrimental exposure model, network size remained independently associated with URI; with each additional alter reported, the odds of reporting an URI was $4 \%$ higher. In the multivariable beneficial exposure model, it was further shown that every additional 10 contacts within half a year and every additional $10 \%$ of the network of the same age were associated with $1 \%$ and $6 \%$ lower odds of reporting URI, respectively.

\section{Social network related to LRI}

In the adjusted univariable analyses, every additional $10 \%$ of the network living more distant, who were 5 to 15 years younger and friends were associated with a $7 \%, 9 \%$ and $8 \%$ higher odds of reporting LRI, respectively. Every additional $10 \%$ of the network of the same age or family members were associated with a $8 \%$ lower odds of reporting LRI (Table 3 ).

In the multivariable detrimental exposure model, every additional SD in age heterogeneity and every additional $10 \%$ of the network that were friends and who were 5 to 15 years older and 5 to 15 years younger were associated with a $3 \%, 12 \%, 12 \%$ and $11 \%$ lower odds of reporting LRI, respectively. In the multivariable beneficial exposure model, every additional 10 contacts were associated with a $1 \%$ lower odds of reporting LRI. Moreover, with every additional $10 \%$ of the network that were alters of the same age or family members the odds of reporting LRI was $11 \%$ and $9 \%$ lower, respectively (Table 4).

\section{Social network related to $\mathrm{GI}$}

In the adjusted univariable analyses, every additional alter reported was associated with a $3 \%$ higher odds of reporting $\mathrm{GI}$. With every additional $10 \%$ of the network that were alters with a moderate contact frequency (quarterly), who lived further away, who were 5 o 15 years younger, or friends, the odds of reporting GI was 10\%,7\%, $9 \%$ and $12 \%$ higher, respectively. With every $10 \%$ increment of the network that were alters contacted on a daily or weekly basis, household members, and family members the odds of reporting GI was $5 \%, 13 \%$, and $9 \%$ lower, respectively. Having a partner was associated with a $26 \%$ lower odds of reporting GI (Table 3 ).

In the multivariable detrimental exposure model, the part of the network that were friends remained independently associated with $\mathrm{Gl}$. In the multivariable beneficial exposure model, every additional $10 \%$ of the network of alters of the same age, family members, and acquaintances was associated with a $7 \%, 11 \%$, and $9 \%$ lower odds of reporting Gl, respectively (Table 4). 


\section{Social network related to UTI}

In the adjusted univariable analyses, no statistically significant associations were found between network parameters and UTI (Table 3). In the multivariable detrimental exposure model, every additional 10 contacts were associated with a $2 \%$ higher odds of reporting UTI. The multivariable beneficial exposure model revealed no statistically significant associations (Table 4).

Table 3 - Associations between network parameters and infections, derived from logistic regression analysis, adjusted for characteristics of the participant

\begin{tabular}{|c|c|c|c|c|c|c|c|c|}
\hline & \multicolumn{2}{|c|}{$\begin{array}{c}\text { Upper } \\
\text { respiratory tract } \\
\text { infection }\end{array}$} & \multicolumn{2}{|c|}{$\begin{array}{l}\text { Lower } \\
\text { respiratory tract } \\
\text { infection }\end{array}$} & \multicolumn{2}{|c|}{$\begin{array}{l}\text { Gastrointestinal } \\
\text { infection }\end{array}$} & \multicolumn{2}{|c|}{$\begin{array}{l}\text { Urinary tract } \\
\text { infection }\end{array}$} \\
\hline & OR & $95 \% \mathrm{Cl}$ & OR & $95 \% \mathrm{Cl}$ & OR & $95 \% \mathrm{Cl}$ & OR & $95 \% \mathrm{Cl}$ \\
\hline $\begin{array}{l}\text { Network size (for every additional } \\
\text { alter) }\end{array}$ & $1.02^{*}$ & $1.00-1.04$ & 1.01 & $0.99-1.04$ & $1.03^{*}$ & $1.01-1.05$ & 0.99 & $0.96-1.0$ \\
\hline
\end{tabular}

\section{Contact frequency}

Total contacts per half year (for every 10 additional contacts) 1.00

Percentage of alters with dailyweekly ego/alter contact (for every additional $10 \%$ )

$\begin{array}{llllllll}0.96 * & 0.93-0.99 & 0.97 & 0.92-1.01 & 0.95^{*} & 0.90-0.99 & 1.05 & 0.99-1.12\end{array}$

Percentage of alters with monthly ego/alter contact (for every additional $10 \%$ )

1.00

Percentage of alters with quarterly ego/alter contact (for every additional $10 \%$ )

Percentage of alters with half-yearly ego/alter contact (for every additional 10\%)

\section{Proximity}

Percentage of alters who are household members (for every additional 10\%)

Percentage of alters living within walking distance (for every additional 10\%)

Percentage of alters living less than $1 / 2 \mathrm{~h}$ away by car (for every additional $10 \%)$

Percentage of alters living more than $1 / 2 \mathrm{~h}$ away by car (for every additional $10 \%)$

Percentage of alters living further away (for every additional $10 \%$ ) $\begin{array}{llllllll}0.93^{*} & 0.88-0.99 & 0.98 & 0.90-1.07 & 0.87^{* *} & 0.80-0.95 & 1.01 & 0.91-1.13\end{array}$

$\begin{array}{llllllll}0.99 & 0.96-1.03 & 1.01 & 0.96-1.07 & 0.99 & 0.94-1.04 & 0.99 & 0.92-1.06\end{array}$

$$
1.0
$$

$\begin{array}{llllllll}1.06 * * & 1.01-1.10 & 1.02 & 0.96-1.08 & 0.99 & 0.93-1.05 & 0.92 & 0.84-1.01\end{array}$

$\begin{array}{llllllll}1.00 & 0.97-1.04 & 0.97 & 0.92-1.02 & 1.02 & 0.97-1.07 & 1.01 & 0.94-1.08\end{array}$

$\begin{array}{llllllll}1.05^{*} & 1.00-1.10 & 1.07^{*} & 1.00-1.14 & 1.07^{*} & 1.01-1.14 & 0.96 & 0.87-1.06\end{array}$

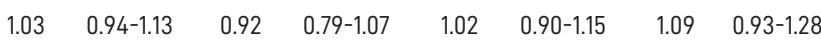




\begin{tabular}{|c|c|c|c|c|c|c|c|c|}
\hline \multicolumn{9}{|l|}{ Mixing } \\
\hline $\begin{array}{l}\text { Percentage of same-sex alters } \\
\text { (for every additional } 10 \% \text { ) }\end{array}$ & 1.00 & $0.96-1.05$ & 1.01 & $0.94-1.08$ & $1.06 \#$ & $0.99-1.14$ & 0.93 & $0.85-1.02$ \\
\hline $\begin{array}{l}\text { Percentage of same-age alters ( } \pm 5 \\
\text { years) (for every additional } 10 \% \text { ) }\end{array}$ & $0.95^{*}$ & $0.91-0.99$ & $0.92^{* *}$ & $0.86-0.97$ & 0.96 & $0.91-1.01$ & 0.99 & $0.92-1.07$ \\
\hline $\begin{array}{l}\text { Percentage of younger alters } \\
\text { (>15years younger) (for every }\end{array}$ & & & & & & & & \\
\hline $\begin{array}{l}\text { additional } 10 \% \text { ) } \\
\text { Percentage of younger alters } \\
\text { (5-15years younger) (for every }\end{array}$ & 1.00 & $0.91-1.09$ & 0.97 & $0.85-1.10$ & 0.97 & $0.86-1.10$ & 1.03 & $0.86-1.22$ \\
\hline additional $10 \%)$ & 1.03 & $0.97-1.09$ & $1.09^{*}$ & $1.01-1.18$ & $1.09^{*}$ & $1.01-1.17$ & 0.94 & $0.84-1.06$ \\
\hline $\begin{array}{l}\text { Percentage of older alters (>15 years } \\
\text { older) (for every additional } 10 \% \text { ) }\end{array}$ & $1.04 \#$ & $1.00-1.09$ & 1.03 & $0.97-1.10$ & 0.99 & $0.93-1.05$ & 1.03 & $0.95-1.12$ \\
\hline $\begin{array}{l}\text { Percentage of older alters ( } 5-15 \text { years } \\
\text { older) (for every additional } 10 \% \text { ) }\end{array}$ & 1.02 & $0.97-1.08$ & $1.07 \#$ & $0.99-1.15$ & 1.05 & $0.97-1.12$ & 1.02 & $0.92-1.14$ \\
\hline \multicolumn{9}{|l|}{ Heterogeneity } \\
\hline Sex heterogeneity (IQV, range 0-1) & 1.38 & $0.91-2.10$ & 1.20 & $0.65-2.22$ & 0.92 & $0.53-1.58$ & 1.20 & $0.54-2.68$ \\
\hline Age heterogeneity (per SD increase) & 1.01 & $1.00-1.03$ & 1.01 & $0.99-1.04$ & 1.00 & $0.98-1.02$ & 1.00 & $0.96-1.03$ \\
\hline \multicolumn{9}{|l|}{ Type of relationship } \\
\hline Participants who have a partner (\%) & 0.99 & $0.80-1.23$ & $0.75 \#$ & $0.56-1.00$ & $0.74^{*}$ & $0.56-0.97$ & 1.35 & $0.87-2.08$ \\
\hline $\begin{array}{l}\text { Percentage of alters who are family } \\
\text { members (for every additional } 10 \% \text { ) }\end{array}$ & $0.97 \#$ & $0.94-1.00$ & $0.92^{* *}$ & $0.88-0.97$ & $0.91^{* * *}$ & $0.87-0.96$ & 1.04 & $0.97-1.12$ \\
\hline $\begin{array}{l}\text { Percentage of alters who are friends } \\
\text { (for every additional } 10 \% \text { ) }\end{array}$ & 1.01 & $0.97-1.05$ & $1.08^{*}$ & $1.02-1.14$ & $1.12^{* * *}$ & $1.06-1.18$ & 0.99 & $0.92-1.08$ \\
\hline $\begin{array}{l}\text { Percentage of alters who are } \\
\text { acquaintances (for every additional }\end{array}$ & & & & & & & & \\
\hline $10 \%)$ & $1.04 \#$ & $1.00-1.10$ & 1.04 & $0.97-1.12$ & 1.00 & $0.93-1.07$ & 0.93 & $0.83-1.03$ \\
\hline \multicolumn{9}{|l|}{ Proxy for superficial contacts } \\
\hline Number of club memberships & 1.02 & $0.93-1.11$ & 1.03 & $0.91-1.16$ & 1.04 & $0.93-1.17$ & 0.99 & $0.84-1.16$ \\
\hline $\begin{array}{l}\text { Number of clubs with daily/weekly } \\
\text { participation }\end{array}$ & 0.99 & $0.89-1.10$ & 1.00 & $0.86-1.16$ & 1.02 & $0.89-1.18$ & 0.97 & $0.79-1.20$ \\
\hline $\begin{array}{l}\text { Number of clubs with monthly } \\
\text { participation }\end{array}$ & 1.10 & $0.92-1.32$ & 1.18 & $0.92-1.51$ & 1.06 & $0.83-1.35$ & 1.06 & $0.74-1.52$ \\
\hline $\begin{array}{l}\text { Number of clubs with less frequent } \\
\text { participation }\end{array}$ & 1.01 & $0.80-1.28$ & 0.97 & $0.68-1.38$ & 1.15 & $0.85-1.55$ & 0.95 & $0.58-1.55$ \\
\hline \multicolumn{9}{|l|}{ Network density } \\
\hline \multicolumn{9}{|l|}{ Density between friends } \\
\hline - Low density (1-3) & 1.00 & & 1.00 & & 1.00 & & 1.00 & \\
\hline - medium density (4) & 1.13 & $0.92-1.38$ & 0.87 & $0.65-1.16$ & 0.94 & $0.72-1.24$ & 0.90 & $0.60-1.35$ \\
\hline - high density (5) & 1.08 & $0.86-1.35$ & 0.92 & $0.67-1.25$ & 0.89 & $0.66-1.20$ & 1.09 & $0.71-1.67$ \\
\hline \multicolumn{9}{|l|}{ Density between friends and family } \\
\hline - low density (1-3) & 1.00 & & 1.00 & & 1.00 & & 1.00 & \\
\hline - medium density (4) & 1.16 & $0.92-1.47$ & 0.93 & $0.67-1.29$ & 1.01 & $0.74-1.39$ & 1.13 & $0.70-1.81$ \\
\hline - high density (5) & $1.27^{*}$ & $1.00-1.61$ & 0.87 & $0.65-1.26$ & 1.04 & $0.75-1.43$ & 1.24 & $0.77-2.00$ \\
\hline
\end{tabular}

All analyses were adjusted for: sex, age, smoking status, diabetes status, BMI, alcohol consumption, educational level, employment status, and season. OR Odds Ratio, $95 \% \mathrm{Cl} ; 95 \%$ Confidence Interval, $\# p<0.1^{*} p<0.05^{* *} p<0.01^{* * *} p<0.001$ 
Table 4 - Detrimental exposure model and beneficial exposure model derived from Bstep logistic regression analyses, adjusted for characteristics of the participant

\begin{tabular}{|c|c|c|c|c|c|c|c|c|}
\hline & \multicolumn{2}{|c|}{$\begin{array}{l}\text { Upper respiratory } \\
\text { tract infection }\end{array}$} & \multicolumn{2}{|c|}{$\begin{array}{l}\text { Lower respiratory } \\
\text { tract infection }\end{array}$} & \multicolumn{2}{|c|}{$\begin{array}{l}\text { Gastrointestinal } \\
\text { infection }\end{array}$} & \multicolumn{2}{|c|}{$\begin{array}{l}\text { Urinary tract } \\
\text { infection }\end{array}$} \\
\hline & OR & $95 \% \mathrm{Cl}$ & OR & $95 \% \mathrm{Cl}$ & OR & $95 \% \mathrm{Cl}$ & OR & $95 \% \mathrm{Cl}$ \\
\hline \multicolumn{9}{|l|}{ Detrimental exposure model } \\
\hline $\begin{array}{l}\text { Network size (for every additional } \\
\text { alter) }\end{array}$ & $1.04^{* *}$ & $1.01-1.06$ & 1.02 & $0.99-1.06$ & $1.03 \#$ & $1.00-1.06$ & 0.96 & $0.92-1.01$ \\
\hline $\begin{array}{l}\text { Total contacts per half year } \\
\text { (for every additional } 10 \text { contacts) }\end{array}$ & $0.99^{*}$ & $0.98-1.00$ & $0.99^{*}$ & $0.98-1.00$ & 1.00 & $0.99-1.01$ & $1.02^{*}$ & $1.00-1.03$ \\
\hline $\begin{array}{l}\text { Percentage of alters living more } \\
\text { than } 1 / 2 \mathrm{~h} \text { away by car (for every } \\
\text { additional } 10 \% \text { ) }\end{array}$ & $\mathrm{N} / \mathrm{A}$ & & $\mathrm{N} / \mathrm{A}$ & & $1.06 \#$ & $1.00-1.13$ & $\mathrm{~N} / \mathrm{A}$ & \\
\hline $\begin{array}{l}\text { Percentage of older alters } \\
\text { (>15 years older) } \\
\text { (for every additional } 10 \% \text { ) }\end{array}$ & $1.05 \#$ & $0.98-1.09$ & $1.08 \#$ & $0.99-1.17$ & N/A & & $\mathrm{N} / \mathrm{A}$ & \\
\hline $\begin{array}{l}\text { Percentage of older alters (5-15 } \\
\text { years older) } \\
\text { (for every additional } 10 \% \text { ) }\end{array}$ & $\mathrm{N} / \mathrm{A}$ & & $1.12^{*}$ & $1.02-1.22$ & $\mathrm{~N} / \mathrm{A}$ & & $\mathrm{N} / \mathrm{A}$ & \\
\hline $\begin{array}{l}\text { Percentage of younger alters } \\
\text { ( } 5 \text { - } 15 \text { years younger) (for every } \\
\text { additional } 10 \%)\end{array}$ & N/A & & $1.11^{*}$ & $2.01-1.21$ & $1.08 \#$ & $0.99-1.16$ & $\mathrm{~N} / \mathrm{A}$ & \\
\hline Age heterogeneity (SD) & $\mathrm{N} / \mathrm{A}$ & & $1.03^{* *}$ & $1.00-1.06$ & $\mathrm{~N} / \mathrm{A}$ & & $\mathrm{N} / \mathrm{A}$ & \\
\hline $\begin{array}{l}\text { Percentage of alters who are } \\
\text { friends } \\
\text { (for every additional } 10 \% \text { ) }\end{array}$ & N/A & & $1.12^{* * *}$ & $1.04-1.20$ & $1.11^{* * *}$ & $1.05-1.16$ & $\mathrm{~N} / \mathrm{A}$ & \\
\hline $\begin{array}{l}\text { Percentage of alters who are } \\
\text { acquaintances } \\
\text { (for every additional 10\%) }\end{array}$ & N/A & & $1.08 \#$ & $0.99-1.17$ & N/A & & $\mathrm{N} / \mathrm{A}$ & \\
\hline \multicolumn{9}{|l|}{ Beneficial exposure model } \\
\hline $\begin{array}{l}\text { Network size (for every additional } \\
\text { alter) }\end{array}$ & $1.03^{* *}$ & $1.01-1.06$ & 1.02 & $0.99-1.06$ & $1.03^{*}$ & $1.00-1.06$ & 0.96 & $0.92-1.01$ \\
\hline $\begin{array}{l}\text { Total contacts per half year } \\
\text { (for every additional } 10 \text { contacts) }\end{array}$ & $0.99^{*}$ & $0.98-1.00$ & $0.99^{*}$ & $0.98-1.00$ & 0.99 & $0.98-1.00$ & $1.02^{*}$ & $1.00-1.03$ \\
\hline $\begin{array}{l}\text { Percentage of same-age alters }( \pm \\
5 \text { years) (for every additional } 10 \%)\end{array}$ & $0.94^{* *}$ & $0.90-0.98$ & $0.89^{* * *}$ & $0.84-0.95$ & $0.93^{*}$ & $0.88-0.98$ & $\mathrm{~N} / \mathrm{A}$ & \\
\hline $\begin{array}{l}\text { Percentage of alters who are } \\
\text { family members (for every } \\
\text { additional } 10 \% \text { ) }\end{array}$ & $0.97 \#$ & $0.93-1.01$ & $0.91^{* * *}$ & $0.87-0.96$ & $0.89^{* * *}$ & $0.84-0.94$ & $\mathrm{~N} / \mathrm{A}$ & \\
\hline $\begin{array}{l}\text { Percentage of alters who are } \\
\text { acquaintances (for every } \\
\text { additional } 10 \% \text { ) }\end{array}$ & N/A & & $\mathrm{N} / \mathrm{A}$ & & $0.91^{*}$ & $0.84-0.98$ & $\mathrm{~N} / \mathrm{A}$ & \\
\hline
\end{tabular}

All analyses were adjusted for: sex, age, smoking status, diabetes status, BMI, alcohol consumption, educational level, employment status and season. OR Odds Ratio, $95 \% \mathrm{Cl} ; 95 \%$ Confidence Interval, $\# p<0.1^{*} p<0.05^{* *} p<0.01^{* * *} p<0.001$ 


\section{Discussion}

The current study is unique, as we were able to combine sophisticated, real-time social network data with infection prevalences in an epidemiological study on four different infectious diseases: URI, LRI, $\mathrm{GI}$ and UTI. We identified both detrimental and beneficial associations of social network parameters with the prevalence of infections. We observed that larger network size was associated with a higher prevalence of URI and GI, while a high total number of contacts was associated with less URI and LRI. In addition, participants with networks mainly composed of friends presented a higher prevalence of LRI and GI, as opposed to those with a higher family percentage, who presented lower LRI and GI prevalences. Finally, a higher percentage of network members of the same age was associated with lower URI, LRI and GI prevalences. We found no clear associations with UTI, although a high total number of contacts was associated with higher UTI prevalence.

In the present study, social network size was associated with a higher prevalence of URI and GI. A likely explanation for our findings is that a larger network indicates exposure to a greater range of infectious agents, and therefore leads to a greater incidence of symptomatic infections. In addition, the likelihood of meeting an infected person is higher in a large network. We observed no association between network size and UTI. This is in line with infection spread theory, i.e. that infections that are transmitted through the air or direct contact (URI, LRI and GI) are spread through social networks, whereas UTIs, mainly caused by commensal bacteria, are not. UTI however was positively associated with the total number of contacts. The underlying mechanism that explains how more contacts, independent of social network size, is related to an increased risk of UTI remains unclear in the present study, and may be a subject of interest in future research.

A higher total number of contacts was associated with lower URI and LRI prevalences. This association was independent of network size. This is in line with a previous study, which showed that susceptibility to URI was lower among participants with more types of social ties [9, 13]. Our results indicate that network size and total number of contacts have an independent association in opposite direction with infection prevalences. Hence infection prevalence is reflected by both of these measures, and not merely as a function of increased infection spread in relation to the network, and therefore both should be considered in studies on their association with infections.

Independent of the number of alters and contacts, participants with networks composed of a relatively large percentage of friends presented a higher prevalence of LRI and GI. Contacts with friends are assumed to be intimate, including touching or kissing, and play an important role in the transmission of LRI and GI. This is in line with previous research, which suggests that friends are a group with a high potential for transmission [30], and in line with a study that proposes monitoring the friends of randomly selected individuals as a novel strategy for early detection of influenza [51]. Note that when a person's network contained a relatively high percentage of acquaintances, the prevalence of GI was lower. A possible explanation for the latter is that $\mathrm{GI}$ transmission requires surface contamination or physically direct contact, and contacts with acquaintances (neighbors or colleagues) tend to be less 
close than contacts with friends. A large percentage of family members within the network was associated with fewer reported LRIs and Gls. Previous research has shown that the family is an important source of social support [52], and higher levels of social support have been shown to enhance several aspects of immune function [11, 12]. The ego's family may act as a buffer for LRI and GI through high levels of social support, indicating a positive impact on lower susceptibility to these infections.

Notably, while some mathematical models consider the number of household contacts to be highly relevant for disease transmission [21, 22, 28, 30,31,33], we did not find such association. On the contrary, the present results show that a relatively large percentage of household members is associated with lower URI and GI prevalences.

A high percentage of alters in the same age range ( \pm 5 years) was associated with lower URI, LRI and GI, but not with lower UTI. Mathematical models usually incorporate age-mixing patterns, which range from fully assortative (individuals infect only those in the same age group) to disassortative (those of one age group only infect individuals in another age group) [16, 22, 28, 33]. Our current study confirms that individuals tend to mix assortatively ( $44 \%$ of participants had contacts with others within the same age group) $[22,28,33]$. However, while mathematical models usually assume that individuals infect those in the same age group, we found the opposite effect: when the network contains a relatively high percentage of alters of the participant's age, lower URI, LRI and GI prevalence was observed. A high variability in ages of alters (age heterogeneity), as well as a high percentage in alters that were younger or older (5 to 15 years) was associated with higher LRI prevalence, which may indicate exposure to a wider range of infectious agents from people in broader age ranges, and as transmission rates were higher among children and the elderly [53], higher variability in age and dissasortative mixing patterns may indicate more contacts with high-transmission risk individuals. To the best of our knowledge, this is the first study that assessed the associations between mixing or heterogeneity within the composition of a network and the prevalence of symptomatic infections, revealing new insights into the transmission potential of assortative and disassortative age mixing patterns.

One strength of the present study is that it provides new empirical data on the social network at the participant level. This has given us the opportunity to examine a set of questions that, to the best of our knowledge, have not been addressed before. Recent research on infection dynamics using mathematical models shows the importance of contact patterns for transmission dynamics and the use of parameters estimated directly from contact data. Our study improves the understanding of the epidemiology of infectious disease, and can be used to complement mathematical models of infection spread on the importance of network composition for the estimation of transmission parameters, as well as in further epidemiological research on the association of specific network parameters and the prevalence of several infections.

Nevertheless, this study also has limitations. First, as the data was cross-sectional, causal relationships could not be examined. Second, self-reporting may be subject to bias. Although the self-reporting of infections has been used successfully in the past in relation to network assessment [23, 28], symptoms may be under or over-reported. Third, as contact networks are, by definition, hard to mea- 
sure [14] our assessment and computed network parameters also have strengths and limitations. Social networks can be measured by different methods, such as reviewed by Read et al. [17], one of which is the egocentric approach used in the present study. Egocentric networks are useful for measuring likely proxies of the true underlying network of potentially infectious contacts, yielding valid data and insight in ego-network composition in relation to infections $[13,22,33,54]$. Fourth, the assumptions made to calculate the total number of contacts may under- or overestimate the actual total number of contacts. For every alter named, the highest contact frequency (e.g. monthly contact) was used as an indicator of actual contact frequency, and as participants report to meet one alter every month on several questions, this alter is assumed to be met on a monthly basis. It is possible however that the participant met this alter once a month for one activity, but also once a month for another activity. Moreover, the "daily or weekly" answer category was assumed to refer to two contacts per week. This assumption, too, may result in an underestimation of the actual contact frequency.

Moreover, the questionnaire consisted of seven questions on different types of interactions, some of these types require direct close proximity interactions (such as visits for social purposes or offering practical help), and other types of interactions may also have occurred by telephone/internet conversations (such as provision of emotional support or advise on problems). Therefore, estimations of the total network size and total contact frequency may over represent the actual number of close proximity interactions, as a maximum of $13-14 \%$ of the interactions may potentially not have occurred in close proximity.

Another limitation of the questionnaire was missing information on the duration of contacts between the ego and the alters, which has been shown to be highly relevant for disease modelling $[25,26]$. Additionally, use of public transport has not been measured, which may have impact on the number of contacts participants made in the study period. However, previous research has shown that the transmission rate in public transport is low [55].

Finally, The Maastricht Study has a population based design and is enriched with type 2 diabetes participants for reasons of efficiency; i.e. to increase the statistical power to identify any potential contrasts between individuals with and without type 2 diabetes. Subsequently, participants were slightly more overweight/ obese than the general population [56]. To control for this design-related oversampling, we adjusted all analyses for diabetes status and BMI. Although higher prevalences of type 2 diabetes and overweight may have slightly increased the prevalences of infections within the study population, odds ratios are likely unbiased. Another limitation of the design is that the study population consisted of adult participants only and it is unknown whether results are representative for people younger than 40 years of age. Further, the age range of the participants probably leads to an underrepresentation of children in the ego's network, while it has been shown that children and teenagers may have an important role in the spread of close-contact infections [33].

Moreover, the extensive phenotyping forces participants to cover 4 half-day visits at the research center, which may be difficult for people who work and travel a lot and have many contacts. To enable participation for those more "busy" people, visits were also offered in the evening hours and on Satur- 
day. The design of the present study may have some limitations, but it is also unique in the examination of the association between social network parameters and infections, and may therefore lead to new insights in the understanding of the epidemiology of infectious diseases.

\section{Conclusions}

To conclude, social network size and total number of contacts were important determinants for the prevalence of URI, LRI and GI. Moreover, the composition of the social network in terms of types of alters (friends, family, age) appears to be related to the risk of infection. While further studies are needed to examine underlying mechanisms and causality, our findings could have important implications for the estimation of transmission parameters to optimize current infectious disease control, and can be used for the development of non-pharmaceutical infection prevention strategies. 


\section{References}

1. Orth-Gomer $\mathrm{K}$, Rosengreen $\mathrm{A}$, Wilhelmsen L: Lack of Social Support and Incidence of Coronary Heart Disease in Middle-Aged Swedish Men. Psychosomatic Medicine 1993, 55:37-43.

2. Heaney CA, Israel BA: Social networks and social support. In: Health Behavior and Health Education. Fourth edn. Edited by Glanz K, Rimer BK, Viswanath K. San Francisco: Jossey Bass; 2008: 189-210.

3. Berkmann LF, Glass T, Brissette I, Seeman TE: From social integration to health: Durkheim in the new millennium. Social Science \& Medicine 2000, 51:843-857.

4. Uchino BN, Cacioppo JT, Kiecolt-Glaser JK: The Relationship Between Social Support and Physiological Processes: A Review With Emphasis on Underlying Mechanisms and Implications for Health. Psychological Bulletin 1996, 119(3):488-531.

5. Eng PM, Rimm EB, Fitzmaurice G, Kawachi I: Social Ties and Change in Social Ties in Relation to Subsequent Total and Cause-specific Mortality and Coronary Heart Disease Incidence in Men. American Journal of Epidemiology 2002, 155(8):700-709.

6. Kawachi I, Colditz GA, Ascherio A, Rimm EB, Giovannucci E, Stampfer MJ, Willett WC: A prospective study of social networks in relation to total mortality and cardiovascular disease in men in the USA. Journal of Epidemiology and Community Health 1996, 50:245-251.

7. Kroenke CH, Kubzansky LD, Schernhammer ES, Holmes MD, Kawachi I: Social Networks, Social Support, and Survival After Breast Cancer Diagnosis. Journal of Clinical Oncology 2006, 24(7):1105-1111.

8. Berkmann LF, Syme SL: Social networks, host resistance, and mortality: A nine-year follow-up study of Almeda country residents. American Journal of Epidemiology 1979, 109(2):186-204.

9. Cohen S, Doyle W, Skoner DP, Rabin BS, Gwaltney JMJ: Social Ties and susceptibility to the Common Cold. JAMA 1997, 277(24):1940-1944.

10. Pressman SD, Cohen S, Miller GE, Barkin A, Rabin BS, Treanor JJ: Loneliness, social network size, and immune response to influenza vaccination in college freshmen. Health Psychology 2005, 24(3):297.

11. Miyazaki $T$, Ishikawa $T$, Nakata $A$, Sakurai $T$, Miki A, Fujita O, Kobayashi F, Haratani T, limori $\mathrm{H}$, Sakami S: Association between perceived social support and Th1 dominance. Biological psychology 2005, 70(1):30-37.

12. Lutgendorf SK, Sood AK, Anderson B, McGinn S, Maiseri H, Dao M, Sorosky JI, De Geest K, Ritchie J, Lubaroff DM: Social support, psychological distress, and natural killer cell activity in ovarian cancer. Journal of Clinical Oncology 2005, 23(28):7105-7113.

13. Hamrick N, Cohen S, Rodriguez MS: Being popular can be healthy or unhealthy: stress, social network diversity, and incidence of upper respiratory infection. Health Psychology 2002, 21(3):294.

14. Salathé M, Kazandjieva M, Lee JW, Levis P, Feldman $\mathrm{MW}$, Jones $\mathrm{JH}$ : A high-resolution human contact network for infectious disease transmission. Proceedings of the National Academy of Sciences 2010, 107(51):22020-22025.

15. Xie X, Li Y, Chwang AT, Ho PL, Seto WH: How far droplets can move in indoor environments--revisiting the Wells evaporation-falling curve. Indoor air 2007, 17(3):211-225.

16. Wallinga J, Teunis $P$, Kretzschmar M: Using data on social contacts to estimate age-specific transmission parameters for respiratory-spread infectious agents. American Journal of Epidemiology 2006, 164(10):936-944.

17. Read JM, Edmunds WJ, Riley S, Lessler J, Cummings DAT: Close encounters of the infectious kind: methods to measure social mixing behaviour. Epidemiology \& Infection 2012, 140(12):2117-2130.

18. Kucharski AJ, Kwok KO, Wei VW, Cowling BJ, Read JM, Lessler J, Cummings DA, Riley S: The contribution of social behaviour to the transmission of influenza $A$ in a human population. PLoS pathogens 2014, 10(6):e1004206.

19. Read JM, Eames KT, Edmunds WJ: Dynamic social networks and the implications for the 
spread of infectious disease. Journal of The Royal Society Interface 2008, 5(26):1001-1007.

20. Del Valle SY, Hyman JM, Chitnis N: Mathematical models of contact patterns between age groups for predicting the spread of infectious diseases. Mathematical biosciences and engineering: MBE 2013, 10:1475.

21. Fu Y-C, Wang D-W, Chuang J-H: Representative contact diaries for modeling the spread of infectious diseases in Taiwan. PloS one 2012, 7(10):e45113.

22. Melegaro A, Jit M, Gay N, Zagheni E, Edmunds WJ: What types of contacts are important for the spread of infections? Using contact survey data to explore European mixing patterns. Epidemics 2011, 3(3):143-151.

23. Stein $M L$, van Steenbergen $J E$, Chanyasanha $C$, Tipayamongkholgul $M$, Buskens $V$, van der Heijden PG, Sabaiwan W, Bengtsson L, Lu $X$ Thorson AE: Online respondent-driven sampling for studying contact patterns relevant for the spread of close-contact pathogens: a pilot study in Thailand. PloS one 2014, 9(1):e85256.

24. Dodd PJ, Looker C, Plumb ID, Bond V, Schaap $A$, Shanaube K, Muyoyeta M, Vynnycky E, Godfrey-Faussett $P$, Corbett EL: Age-and sex-specific social contact patterns and incidence of Mycobacterium tuberculosis infection. American journal of epidemiology 2016, 183(2):156166.

25. Stehle J, Voirin N, Barrat A, Cattuto C, Colizza V Isella L, Regis $\mathrm{C}$, Pinton JF, Khanafer $\mathrm{N}$, Van den Broeck W et al: Simulation of an SEIR infectious disease model on the dynamic contact network of conference attendees. BMC medicine 2011, 9:87.

26. Machens A, Gesualdo F, Rizzo C, Tozzi AE, Barrat $A$, Cattuto $C$ : An infectious disease model on empirical networks of human contact: bridging the gap between dynamic network data and contact matrices. BMC infectious diseases 2013, 13:185.

27. Ciavarella C, Fumanelli L, Merler S, Cattuto C, Ajelli M: School closure policies at municipality level for mitigating influenza spread: a model-based evaluation. BMC infectious diseases 2016, 16(1):576.
28. Stein $M L$, Van Steenbergen JE, Buskens V, Van Der Heijden PG, Chanyasanha C, Tipayamongkholgul $M$, Thorson AE, Bengtsson L, Lu $X$, Kretzschmar ME: Comparison of Contact Patterns Relevant for Transmission of Respiratory Pathogens in Thailand and the Netherlands Using Respondent-Driven Sampling. PloS one 2014, 9(11):e113711.

29. Danon $L$, Ford $A P$, House $T$, Jewell $C P$, Keeling MJ, Roberts GO, Ross JV, Vernon MC: Networks and the epidemiology of infectious disease. Interdisciplinary perspectives on infectious diseases 2011, 2011.

30. Glass LM, Glass RJ: Social contact networks for the spread of pandemic influenza in children and teenagers. BMC public health 2008, 8(1):61.

31. Johnstone-Robertson SP, Mark D, Morrow C, Middelkoop K, Chiswell M, Aquino LD, Bekker $L-G$, Wood R: Social mixing patterns within a South African township community: implications for respiratory disease transmission and control. American journal of epidemiology 2011:kwr251.

32. Stehle J, Voirin N, Barrat A, Cattuto C, Isella L, Pinton JF, Quaggiotto M, Van den Broeck W, Regis $C$, Lina B et al: High-resolution measurements of face-to-face contact patterns in a primary school. PLoS One 2011, 6(8):e23176.

33. Mossong Jl, Hens $N$, Jit $M$, Beutels $P$, Auranen K, Mikolajczyk R, Massari M, Salmaso S, Tomba GS, Wallinga J: Social contacts and mixing patterns relevant to the spread of infectious diseases. PLoS medicine 2008, 5(3):e74.

34. Potter GE, Handcock MS, Longini Jr IM, Halloran $M E$ : Estimating within-household contact networks from egocentric data. The annals of applied statistics 2011, 5(3):1816.

35. Smieszek T, Fiebig L, Scholz RW: Models of epidemics: when contact repetition and clustering should be included. Theoretical Biology and Medical Modelling 2009, 6(1):11.

36. Yoshikawa TT: Epidemiology and unique aspects of aging and infectious diseases. Clinical Infectious Diseases 2000, 30(6):931-933.

37. Derhovanessian E, Larbi A, Pawelec G: Biomarkers of human immunosenescence: impact of Cytomegalovirus infection. Current 
opinion in immunology 2009, 21(4):440-445.

38. Pawelec G, Derhovanessian E, Larbi A, Strindhall J, Wikby A: Cytomegalovirus and human immunosenescence. Reviews in medical virology 2009, 19(1):47-56.

39. Almirall J, Bolíbar I, Balanzó X, González CA: Risk factors for community-acquired pneumonia in adults: a population-based case-control study. European Respiratory Journal 1999, 13:349-355.

40. Sintonen S, Pehkonen A: Effect of social networks and well-being on acute care needs. Health and social care in the community 2014, 22(1):87-95.

41. Schram M, Sep SJ, Kallen van der CJ, Dagnelie PC, Koster A, Schaper N, Henry RM, CD S: The Maastricht Study: An Extensive Phenotyping Study on Determinants of Type 2 Diabetes, its Complications and its Comorbidities. European Journal of Epidemiology 2014.

42. van der Gaag M: Measurement of individual social capital. In. Groningen: ICS dissertation; 2005.

43. Scott J: Social network analysis, Third edn: Sage; 2012.

44. Christakis NA, Fowler JH: The spread of obesity in a large social network over 32 years. New England journal of medicine 2007, 357(4):370379.

45. Brinkhues S, Van Kuijk S, Hoebe C, Savelkoul P, Kretzschmar M, Jansen M, De Vries N, Sep S, Dagnelie $\mathrm{P}, \mathrm{NC}$ S. Development of prediction models for upper and lower respiratory and gastrointestinal tract infections using social network parameters in middle-aged and older persons-The Maastricht Study. Epidemiology \& Infection. 2017:1-14.

46. Rafnsson SB, Shankar A, Steptoe A: Longitudinal Influences of Social Network Characteristics on Subjective Well-Being of Older Adults
Findings From the ELSA Study. Journal of Aging and Health 2015:0898264315572111.

47. Hardy MA, Bryman A: Handbook of Data Analysis: SAGE Publications; 2009.

48. Campbell KE, Lee BA: Name generators in surveys of personal networks. Social Networks 1991, 13(3):203-221.

49. Brankston G, Gitterman L, Hirji Z, Lemieux C, Gardam M: Transmission of influenza A in human beings. The Lancet Infectious Diseases 2007, 7(4):257-265.

50. Janson C, Chinn S, Jarvis D, Burney P: Determinants of cough in young adults participating in the European Community Respiratory Health Survey. European Respiratory Journal 2001, 18(4):647-654.

51. Christakis NA, Fowler JH: Social network sensors for early detection of contagious outbreaks. PloS one 2010, 5(9):e12948.

52. Shanas E: The family as a social support system in old age. The Gerontologist 1979, 19(2):169-174.

53. Longini IM, Halloran ME: Strategy for distribution of influenza vaccine to high-risk groups and children. American Journal of Epidemiology 2005, 161(4):303-306.

54. Van Kerckhove K, Hens N, Edmunds WJ, Eames $\mathrm{KT}$ : The impact of illness on social networks: Implications for transmission and control of influenza. American Journal of Epidemiology 2013, 178(11):1655-1662.

55. Piso RJ, Albrecht $Y$, Handschin P, Bassetti S: Low transmission rate of 2009 H1N1 Influenza during a long-distance bus trip. Infection 2011, 39(2):149-153.

56. Statistics Netherland: Gezondheidsmonitor; regio, bevolking van 19 jaar of ouder. In: 2012. 2017. 

Supplemental material to chapter 2 


\section{Statistical formula for the derivation of the Index of Qualitative Variation}

To assess sex heterogeneity within the ego's network, we computed the Index of Qualitative Variation (IQV) by Mueller and Schuessler (1961) [46]. The IQV is defined as the ratio of observed differences divided by maximum possible differences, where " 0 " represents a fully homogeneous and "1" a fully heterogeneous network [46].

Observed differences were calculated as

$$
\text { Observed differences }=\sum f_{i} f_{j} i \neq j
$$

Where $\mathrm{f}$ refers to the frequencies of category i,j.

To calculate the maximum number of possible differences (MPD), we used the formula

$$
\mathrm{MPD}=\frac{c(c-1)}{2}\left(\frac{n}{c}\right)^{2}
$$

Where $\mathrm{c}$ is the number of categories, and $\mathrm{n}$ is the number of observations.

The IQV was computed as

$$
I Q V=\frac{\text { observed differences }}{\text { maximum possible differences }}
$$

Below we show the derivation of the IQV for an ego network with 7 men and 4 women.

The observed differences were

$$
\text { Observed differences }=7 * 4=28
$$

In a network of 11 network members, the maximum possible differences were

$$
\text { MPD }=\frac{2(2-1)}{2}\left(\frac{11}{2}\right)^{2}=\left(\frac{11}{2}\right)^{2}=30.25
$$

In a network of 11 members, of which 7 men and 4 women, the IQV is

$$
I Q V=\frac{28}{30.25}=0.926
$$


Supplemental Table 1 - Associations between characteristics of the participants and self reported upper- and lower respiratory, gastrointestinal, and urinary tract infections in The Maastricht Study $(n=3004)$

\begin{tabular}{|c|c|c|c|c|c|c|c|c|}
\hline & \multicolumn{2}{|c|}{$\begin{array}{l}\text { Upper respiratory } \\
\text { tract infection }\end{array}$} & \multicolumn{2}{|c|}{$\begin{array}{l}\text { Lower respiratory } \\
\text { tract infection }\end{array}$} & \multicolumn{2}{|c|}{$\begin{array}{l}\text { Gastrointestinal } \\
\text { tract infection }\end{array}$} & \multicolumn{2}{|c|}{$\begin{array}{l}\text { Urinary tract } \\
\text { infection }\end{array}$} \\
\hline & OR & $95 \% \mathrm{Cl}$ & OR & $95 \% \mathrm{Cl}$ & OR & $95 \% \mathrm{Cl}$ & OR & $95 \% \mathrm{Cl}$ \\
\hline Sex (male) & 0.94 & $0.79-1.11$ & 0.94 & $0.74-1.21$ & 0.86 & $0.68-1.09$ & $0.43^{* * *}$ & $0.29-0.61$ \\
\hline Age (years) & 0.99 & $0.98-1.00$ & $0.98^{\#}$ & $0.97-1.00$ & $0.98^{\#}$ & $0.97-1.00$ & 1.00 & $0.98-1.03$ \\
\hline Type 2 diabetes (yes) & 1.01 & $0.82-1.24$ & 0.97 & $0.72-1.31$ & $1.60^{* *}$ & $1.22-2.09$ & $2.05^{* * *}$ & $1.38-3.05$ \\
\hline Body Mass Index $\left(\mathrm{kg} / \mathrm{m}^{2}\right)$ & 1.01 & $0.99-1.03$ & $1.05^{* * *}$ & $1.02-1.08$ & 1.02 & $1.00-1.05$ & 0.99 & $0.96-1.03$ \\
\hline Season (winter) & $2.29^{* * *}$ & $1.95-2.70$ & $2.43^{* * *}$ & $1.91-3.10$ & 1.07 & $0.86-1.34$ & 1.17 & $0.85-1.62$ \\
\hline \multicolumn{9}{|l|}{ Educational level } \\
\hline - low & 1.00 & & 1.00 & & 1.00 & & 1.00 & \\
\hline - medium & 1.07 & $0.86-1.33$ & 1.28 & $0.94-1.74$ & 1.20 & $0.89-1.62$ & 0.86 & $0.56-1.31$ \\
\hline - high & $1.28^{*}$ & $1.04-1.57$ & 1.11 & $0.82-1.51$ & $1.37^{*}$ & $1.03-1.83$ & 0.99 & $0.66-1.48$ \\
\hline \multicolumn{9}{|l|}{ Smoking status } \\
\hline - never & 1.00 & & 1.00 & & 1.00 & & 1.00 & \\
\hline - former & 1.08 & $0.90-1.29$ & 1.03 & $0.79-1.34$ & 1.07 & $0.83-1.37$ & 0.90 & $0.62-1.31$ \\
\hline - current & $1.44^{* *}$ & $1.11-1.86$ & $1.36^{\#}$ & $0.95-1.94$ & 1.20 & $0.85-1.71$ & $1.78^{*}$ & $1.12-2.81$ \\
\hline \multicolumn{9}{|l|}{ Alcohol consumption } \\
\hline - Non-consumers & 1.00 & & & & 1.00 & & 1.00 & \\
\hline - Low consumers & 0.89 & $0.71-1.11$ & 0.92 & $0.67-1.26$ & 1.13 & $0.82-1.55$ & 0.95 & $0.62-1.45$ \\
\hline - High consumers & $0.76^{*}$ & $0.59-0.99$ & 0.81 & $0.55-1.18$ & 1.30 & $0.91-1.86$ & 1.11 & $0.68-1.80$ \\
\hline \multicolumn{9}{|l|}{ Employment status } \\
\hline - Employed & 1.00 & & 1.00 & & 1.00 & & 1.00 & \\
\hline - Unemployed/ retired & 1.20 & $0.91-1.59$ & $1.40^{\#}$ & $0.95-2.06$ & 0.97 & $0.65-1.44$ & 1.06 & $0.63-1.80$ \\
\hline - Not known & 0.92 & $0.74-1.29$ & 1.13 & $0.84-1.53$ & 0.91 & $0.68-1.21$ & 0.75 & $0.49-1.15$ \\
\hline
\end{tabular}

OR Odds Ratio, 95\% $\mathrm{Cl} ; 95 \%$ Confidence Interval, $\# p<0.1,{ }^{*} p<0.05,{ }^{* *} p<0.01,{ }^{* * *} p<0.001$.

All analyses were adjusted for: sex, age, smoking status, diabetes status, alcohol consumption, educational level, employment status and season. 


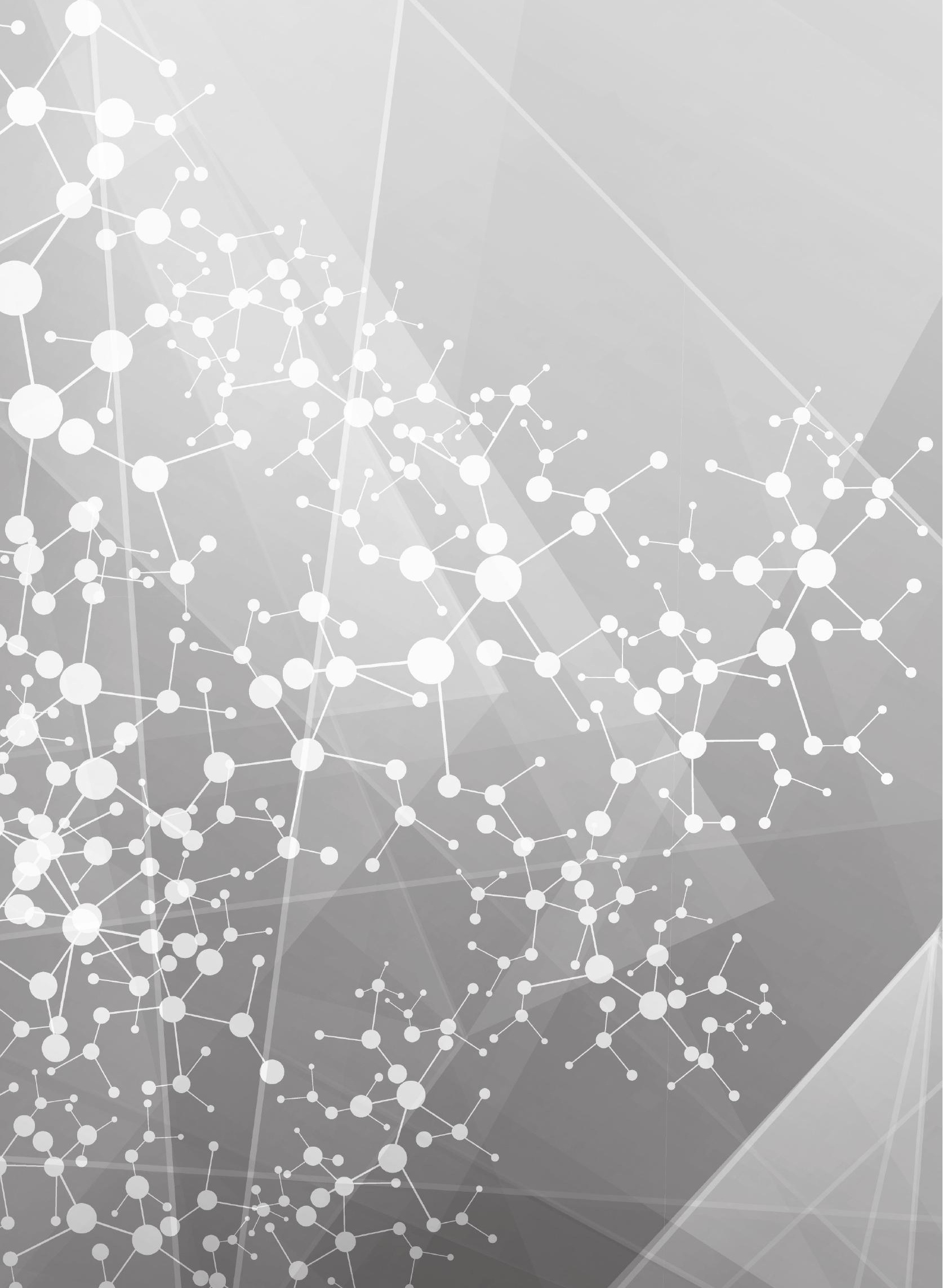




\section{Chapter 3}

Development of prediction models for upper-and lower respiratory and gastrointestinal tract infections using social network parameters in middle-aged and older persons

- The Maastricht Study -

Stephanie Brinkhues, Sander M.J. van Kuijk, Christian J.P.A. Hoebe, Paul H.M. Savelkoul, Mirjam E.E. Kretzschmar, Maria W.J. Jansen, Nanne de Vries, Simone J.S. Sep, Pieter C. Dagnelie, Nicolaas C.Schaper, Frans R.J. Verhey, Hans Bosma, Jo Maes, Miranda T. Schram, Nicole H.T.M. Dukers-Muijrers 


\section{Abstract}

The ability to predict upper respiratory infections (URI), lower-respiratory infections (LRI), and gastrointestinal tract infections (GI) in independently living older persons would greatly benefit population and individual health. Social network parameters have so far not been included in prediction models. Data were obtained from The Maastricht Study, a population-based cohort study ( $N=3074$, mean age ( \pm SD) $59.8 \pm 8.3,48.8 \%$ women). We used multivariable logistic regression analysis to develop prediction models for self-reported symptomatic URI, LRI, and GI (past 2 months). We determined performance of the models by quantifying measures of discriminative ability and calibration. Overall, 953 individuals (31.0\%) reported URI, 349 (11.4\%) LRI, and 380 (12.4\%) GI. The area under the curve (AUC) was 64.7\% (95\% confidence interval [CI]: 62.6\%-66.8\%), for URI, 71.1\% (95\% Cl: 68.4-73.8) for LRI, and 64.2\% (95\% Cl: 61.3-67.1\%) for GI. All models had good calibration (based on visual inspection of calibration plot, and Hosmer-Lemeshow goodness of fit test). Social network parameters were strong predictors for URI, LRI, and GI. Using social network parameters in prediction models for URI, LRI, and GI seems highly promising. Such parameters may be used as potential determinants that can be addressed in a practical intervention in older persons, or in a predictive tool to compute an individual's probability of infections. 


\section{Background}

Over the last decade, population ageing has become a global issue [1]. World-wide, the proportion of people aged 60 and over is growing rapidly, and it is expected to rise to one quarter of the populations in Europe and North America in 2020 [1, 2].

Infectious diseases are a major challenge in health care of the older persons [3], due to increased susceptibility to infections caused by an age-related compromised immune system [4]. Older persons have decreased cell-mediated immunity and decreased antibody production to new antigens $[3,5]$. Pneumonia and influenza are among the ten major causes of death in the older persons [3]. The incidence and severity of community-acquired upper respiratory infections (URI), lower-respiratory infections (LRI), and gastrointestinal tract infections (GI) are often higher than in other age groups.

To date, we lack evidence on non-pharmaceutical interventions to prevent infections in older persons living at home. Current EU policy expects promotion of active ageing and solidarity between generations, guiding principles include participation in society and support for informal caregivers. Hence older persons are expected to take care of themselves as much as possible with help of their social network including informal carers [6]. A new prevention strategy may fit this policy. Therefore, we focus on the possible contributions of personal social contact networks for improving prevention strategies. Transmission and acquisition of an infectious disease are for a large part determined by social networks [7-11], as social relationships may act as a vehicle for the transmission of infections. Diverse and large social networks are associated with close contact with a broad range of people and hence an increased risk of exposure to a range of infectious agents [7]. This increases risk of acquiring disease, particularly among more vulnerable people, whose resistance is compromised (e.g. older persons or people with comorbidities) [7]. Social networks on the other hand are shown to have a strong influence on a person's health, well-being, and self-management, and are thought to be a promising target for effective infection prevention interventions [12]. It has been shown that social networks can act as a buffer for infections by increasing immune function [8, 9]. Especially for older persons and persons with chronic disease, social networks can provide the necessary support to enable them to live independently. As such, higher levels of social support are found to have a positive association with better self-management behaviours of chronically ill [13]. Foremost, social networks and their characteristics are highly useful in novel interventions as networks can be managed by an individual older person and by their formal and informal caregivers who are all part of the same network. Most social network interventions use social networks to accelerate behaviour change or improve organizational performance, knowing different strategies and multiple tactical alternatives [14, 15]. For example, peer-based interventions were shown to have positive effects on physical activity, smoking cessation, and condom use [15]. However, by our knowledge, neither prediction models with individual risk assessment, nor the specific social network parameters of personal social contact networks as determinants have been used in social network interventions so far. 
Yet, to date, it is not fully understood which social network parameters are related to the risk of infections, whether these relations differ by type of infection, and whether these parameters can be used to predict an individual's probability of an infection. More insight into these issues is needed for the development of effective infection prevention programmes. Prediction models are useful for providing such insight, and they make individual risk assessment possible. However, previous attempts to develop prediction models for individual incidences of respiratory tract infections (RI) or GI, based on demographic, environmental, and lifestyle information showed only poor to moderate predicting power [16]. To the best of our knowledge, the role of social networks in predicting infectious diseases in middle-aged and older persons has not yet been studied using prediction models. Therefore, the aim of the current study was to develop and internally validate prediction models for URI, LRI, and GI in a large group of independently living middle-aged and older persons based on a range of variables including social network parameters. We hypothesize that the application of such prediction models can help in deciding about concrete infection prevention strategies for patient self-management, personalized health care, and home care. A better choice of prevention strategies might contribute to lowering the infectious burden and its associated risks in the growing group of older persons.

\section{Methods}

\section{Study population}

We used data from The Maastricht Study, an observational prospective population-based cohort study. The rationale and methodology have been described previously [17]. In brief, the study focuses on the aetiology, pathophysiology, complications, and comorbidities of type 2 diabetes mellitus (T2DM) and is characterized by an extensive phenotyping approach. Eligible for participation were all individuals aged between 40 and 75 years and living in the southern part of the Netherlands. Participants were recruited through mass media campaigns and from the municipal registries and the regional Diabetes Patient Registry via mailings. Recruitment was stratified according to known T2DM status, with an oversampling of individuals with T2DM, for reasons of efficiency. The present report includes crosssectional data from the first 3451 participants, who completed the baseline survey between November 2010 and September 2013. The study has been approved by the institutional medical ethical committee (NL31329.068.10) and the Minister of Health, Welfare and Sports of the Netherlands (Permit 131088105234-PG). All participants gave written informed consent. In the present analysis, all participants that received the social network questionnaire $(\mathrm{N}=3074)$ were included. 


\section{Measurements}

\section{Social network questionnaire}

Data on individual social networks were collected through an online questionnaire using a name generator method $[18,19]$. The assessment of the social network covered contacts (interactions between persons) within a period of six months. The participants received a questionnaire with seven questions on different types of contacts and were asked to name a maximum of five persons (network members) per question. Questions concerned 1) persons who advised them on problems, 2) persons who could offer them practical help if they were sick, 3) persons who provided emotional support when they were feeling unwell, 4) persons who helped them with small and larger jobs around the house, 5) persons they visited for social purposes or that they could go out with sometimes, and 6) persons with whom they could discuss important matters and, finally, 7) participants were asked to name a maximum number of ten additional persons who were also important for them because of mutual activities. In total, participants could name a maximum number of 40 network members. After every question and for each network member named, they were asked to indicate their frequency of contact with this person over the last six months (daily or weekly, monthly, quarterly, and half-yearly). Moreover, the participants were asked to identify their relationship to this person (e.g., partner, sister, friend, neighbor, etc. (28 options)), how far away this person lived (walking distance, less than half an hour away by car, more than half an hour away by car, more distant), and to indicate this person's sex and actual or estimated age.

Further, participants were asked to rate two statements on a five-point Likert scale ranging from strongly agree to strongly disagree: "most of my friends know each other" and "my best friends know my family". The participants were also asked whether they were a member of a club (yes/no, e.g. sports club, religious group, volunteer organization, discussion group, self-support group, Internet club, or another organization).

\section{Parameters of the social network}

The network parameters were computed from the questionnaire. A detailed definition of the network parameters is presented in Table 1. In brief, network size was defined as the total number of unique network members mentioned in the questionnaire. Total contacts per half year was defined as the sum of all contacts per half year. The percentage of network members that were of the same-age, that were household members, that lived within walking distance, less than $1 / 2$ hour away by car, more than $1 / 2$ hour away by car, and the percentage of network members that were family members, friends, or acquaintances was computed. Club membership was defined as membership in, for instance, a sports club, religious group, or other organization. Density was defined as the extent to which network members know each other. Moreover, participants were asked to indicate the number of members (maximum of 5) who provided informational support, emotional support, and practical support. 


\section{General measurements}

All participants were also asked information on: age, sex, educational level, income, smoking behavior, alcohol consumption, mobility (problems with walking, daily activities (EuroQol) [20]), employment status, partner status, ethnicity, healthcare (paramedic/ nurse, mental health professional, inpatient care) consumption in past half year, history of cardiovascular disease (CVD), BMI ( $\left.\mathrm{kg} / \mathrm{m}^{2}\right)$, depressive symptoms (Patient Health Questionnaire-9 (PHQ-9) [21]. Presence of type 2 diabetes (by standardized $75 \mathrm{~g}$ oral glucose tolerance test (OGTT) after an overnight fast [17]), Mini International Neuropsychiatric Interview (M.I.N.I.) [22]), and general cognitive function (by Mini-Mental State Examination (MMSE) [23]) were assessed as described elsewhere [17]. All general measurements can be found in table 2 .

\section{Outcome variables}

We used self-administered questionnaires to measure the occurrence of community-acquired URI, $\mathrm{LRI}$, or GI over the two-month period before completing the questionnaire. Moreover, we recorded the season in which the reported symptomatic infections occurred. The symptoms "runny nose" and "sore throat" were pooled as indicators of URI. Influenza, pneumonia, and fever were pooled as indicators of LRI. Vomiting with fever and diarrhoea were pooled as GI.

Table 1 - Description of the social network parameters that were used as candidate predictors

\begin{tabular}{|c|c|}
\hline Social network parameter & Description \\
\hline \multicolumn{2}{|l|}{ Degree } \\
\hline Network size & $\begin{array}{l}\text { The total number of unique network members mentioned in the } \\
\text { questionnaire }\end{array}$ \\
\hline \multicolumn{2}{|l|}{ Contact frequency } \\
\hline Total contacts per half year & \multirow{8}{*}{$\begin{array}{l}\text { A contact was defined as an interaction between persons. Total } \\
\text { contacts (interactions between persons) per half year were } \\
\text { - computed as follows. } \\
\text { - We used the highest contact frequency (e.g., daily contact) for every } \\
\text { - Second, we recoded the answer categories of the questionnaire to } \\
\text { - "hn estimated number of contacts per half year. For example, } \\
\text { contacts, "monthly" } 6 \text { contacts and "daily or weekly" } 48 \text { contacts. } \\
\text { Third, we computed the sum of all contacts per half year as the total } \\
\text { contact frequency. }\end{array}$} \\
\hline Total friend contacts per half year & \\
\hline Total family contacts per half year & \\
\hline Total household contacts per half year & \\
\hline Total neighbour contacts per half year & \\
\hline Total acquaintance contacts per half year & \\
\hline Total work relation contacts per half year & \\
\hline Total child contacts per half year & \\
\hline
\end{tabular}

\begin{tabular}{l} 
Proximity \\
Proportion of network members who are \\
household members \\
\hline Proportion of network members living \\
within walking distance \\
\hline Proportion of network members living \\
less than $1 / 2 \mathrm{~h}$ away by car \\
\hline Proportion of network members living \\
more than $1 / 2 \mathrm{~h}$ away by car
\end{tabular}

We calculated geographical proximity as the proportion of all network members that were household members, lived within walking distance, lived less than half an hour away by car, lived more than half an hour away by car, and lived further away (e.g. in another country). For example, we calculated the proportion of household members as the number of network members living in the same household divided by network size.

Proportion of network members living further away 


\section{Mixing}

Proportion of same-age network

To identify the proportion of network members who are of the same members ( \pm 5 years) age as the participant, we calculated the difference between the participants' age and the network members' age for every network member named. Next, we computed the proportion of same age $( \pm 5$ years) network members for each participant.

\section{Heterogeneity}

Sex heterogeneity (IQV, range 0-1)
To assess sex heterogeneity within the participants' network, we computed the Index of Qualitative Variation (IQV) by Mueller and Schuessler (1961) [40]. This index indicates the probability that two randomly chosen network members belong to the same category. The IQV is defined as the ratio of observed differences divided by maximum differences, where " 0 " represents a fully homogeneous and "1" a fully heterogeneous network [40]. Observed differences were calculated through multiplication of the total number of men by the total number of women. We calculated maximum differences as (network size/ 2) ${ }^{2}$ [40]

\section{Type of relationship}

Proportion of network members who are family members

Proportion of network members who are friends

Proportion of network members who are acquaintances (colleague, neighbour, club mate, other)

\section{Proxy for superficial contacts}

Club membership (yes)
We computed the proportion of network members that were family members, friends, colleagues and acquaintances. For example, we calculated the proportion of family members within the network as the number of family members divided by network size.

\begin{tabular}{l} 
Network density \\
Density friends (friends know each other) \\
\hline Density friends and family (friends know \\
family)
\end{tabular}

Club membership was defined as membership in, for instance, a sports club, religious group, volunteer organization, discussion group, self-support group, internet club, or other organization.

Density was defined as the extent to which network members in the network know each other. Density between friends was computed from the statement "most of my friends know each other" (five-point Likert scale ranging from strongly agree to strongly disagree) and density between friends and family was computed from the statement "my best friends know my family".

\begin{tabular}{|c|c|}
\hline \multicolumn{2}{|c|}{ Functional characteristics of the social network } \\
\hline Emotional support (discomfort) & $\begin{array}{l}\text { Emotional support related to discomfort was defined as providing } \\
\text { emotional support when participants were feeling unwell }\end{array}$ \\
\hline Emotional support (important decisions) & $\begin{array}{l}\text { Emotional support related to important decisions was defined as } \\
\text { providing the opportunity to discuss important matters }\end{array}$ \\
\hline Practical support & $\begin{array}{l}\text { Practical support was defined as help with small and larger jobs } \\
\text { around the house. }\end{array}$ \\
\hline Informational support & Informational support was defined as advice on problems. \\
\hline
\end{tabular}




\section{Statistical analyses}

\section{Candidate predictors}

In the literature we identified several general variables and social network parameters that had previously been examined in relation to infections $[3,5,7-12,16,24,25]$. Based on this extensive literature search we included 52 variables as potential predictors, of which 26 network variables and 26 general variables. All candidate predictors are described in Tables 1-3.

\section{Model development}

Missing information on potential general predictor variables $(0-26 \%)$ was imputed using stochastic regression imputation, since complete case analysis may bias results and can cause a decrease in sample size [26]. The imputations were drawn using predictive mean matching, which ensures only realistic values are imputed that are observed elsewhere in the data [27]. Information on missing valves of potential general predictor variables can be found in Table 2 .

Per infection, we added all potential predictor variables to a logistic regression model. We used stepwise backward elimination based on the Akaike Information Criterion (AIC) for variable selection, which is a goodness-of-fit measure that penalizes the model fit for model complexity [28]. As a result, predictors included in the model do not necessarily have a p-value of 0.05 or lower. We used restricted cubic splines to test whether continuous variables were non-linearly associated to the log-odds of experiencing an infection, and tested for statistical interactions of the social network parameters with sex, age, and type 2 diabetes.

We determined the performance of each of the prediction models by quantifying measures of discriminative ability and calibration. A model's discriminative ability refers to its ability to discriminate between those who developed an infection over the course of 2 months and those who did not develop an infection, and is expressed as the AUC, which is the area under the receiver operating characteristic (ROC) curve. The AUCs will be tested against the null-hypothesis that the AUC is $50 \%$, which is no more than flipping a coin. Calibration refers to the agreement between predicted probabilities and observed probabilities. To assess calibration, we visually inspected a calibration plot and applied the Hosmer-Lemeshow (HL) goodness of fit test. An HL-test that yields a p-value of 0.05 or lower is considered to indicate poor calibration. As we were especially interested in the prediction of infections in older persons, we computed the AUC for all models applied to persons of 60 years and older, and for persons who were younger than 60 years old.

As a sensitivity analysis for the imputation procedure we computed the three models for the data set of complete cases only, to judge whether the AUCs differed to any clinically relevant extent.

\section{Model validation}

It is a well-known phenomenon that prediction model performance degrades when applied to new persons who were not used to develop the model [29]. Often, predictions derived from a model are too 
extreme (i.e. persons at low risk are predicted too low, and vice versa). To estimate the performance of the prediction models in data involving new persons, and to counteract the too extreme predictions in the future, we performed an internal validation step. For each prediction model, we drew 1000 bootstrap samples. On each sample, model development was repeated and the performance (measured by AUC) of those bootstrap models was calculated on both the bootstrap sample as well as in the original sample. The average difference in performance between the bootstrap sample and the original sample is the estimate of the optimism in model performance. This optimism can subsequently be subtracted from the initial performance measures. In addition, the bootstrap routine yields a shrinkage factor that can be used to multiply the original regression coefficients by. As the shrinkage factor has a value between 0 and 1 , the regression coefficients are shrunk towards zero, and future predictions are less extreme [30].

\section{Results}

A total of 3074 patients with a mean age of $59.8( \pm 8.3)$ years were included in this cohort. Of them, 953 $(31.0 \%)$ reported experiencing recent URI, $349(11.4 \%)$ LRI, and $380(12.4 \%) \mathrm{GI}$. There was some overlap between the infections, $65(2.1 \%)$ reported URI, LRI, and GI, $176(5.7 \%)$ reported URI and LRI, 20 (0.7\%) reported $\mathrm{LRI}$ and $\mathrm{GI}$ and 134 (4.4\%) reported URI and $\mathrm{GI}$. The general and social network characteristics of the study population were presented in Tables 2 and 3. The general and social network characteristics broken down for infection status were presented in supplementary tables S1 and S2.

The restricted cubic spline regression did not reveal non-linear associations between continuous variables and the log-odds of experiencing any of the three types of infections, nor did we find any statistically significant interactions between sex, age, or type 2 diabetes and network parameters.

Table 4 shows the coefficients and odds ratios (ORs) of the prediction model for URI. The AUC of this model was $64.7 \%$ ( $95 \%$ confidence interval [Cl]: $62.6 \%-66.8 \%$ ). The model was based on 16 predictors, of which nine network parameters and seven general predictors. Smoking, BMI, problems with daily activities, and emotional support were positively related to URI, while age, season, total friend contacts per half year, the proportion of network members who are household members, who are living within walking distance, who are living less than $1 / 2$ hour away by car, proportion of same-age network members, proportion of network members who are family members, density between friends and family, and practical support showed an inverse relationship with URI. Table 5 shows the coefficients and ORs of the prediction model for LRI. For this model, the AUC was $71.1 \%$ (95\% Cl: 68.4- 73.8). The model was based on 14 predictors, of which five network parameters and nine general predictors. BMI, problems with daily activities, depression, the proportion of network members living more than $1 / 2$ away by car, the proportion of network members who are friends, and the proportion of network members who are acquaintances were positively associated with LRI, while age, high or low educational level, season, the proportion of same-age network members, and informational support were negatively associ- 
ated with LRI. The AUC of the prediction model for GI was $64.2 \%$ ( $95 \% \mathrm{Cl}: 61.3-67.1 \%$ ) (table 6). The model was based on 12 predictors, of which six network parameters and six general predictors. Problems with daily activities, depression, MMSE score, type 2 diabetes, mental healthcare consumption, network size, and the proportion of network members living more than $1 / 2$ hour away showed positive associations with $\mathrm{Gl}$, while paramedical healthcare consumption, proportion of same-age network members, proportion of network members who are family members and acquaintances, and practical support showed an inverse association with Gl. See table 7 for a summary of the associated social network parameters.

The sensitivity analysis on only complete cases yielded AUCs that did not differ more than $1.4 \%$ (data not shown).

When the models were applied to persons of 60 years and older, and subsequently to persons younger than 60 years, the AUCs were comparable to the whole group. For upper respiratory tract infection this was $64.0(95 \% \mathrm{Cl}: 61.1-66.8)$ for $>60$ years and $65.3(95 \% \mathrm{Cl}: 62.2-68.3)$ for $<60$ years, for lower respiratory infection this was $71.0(95 \% \mathrm{Cl}: 67.0-74.6)$ for $>60$ years and $71.1(95 \% \mathrm{Cl}: 67.2-74.9)$ for $<60$ years, and for gastrointestinal infection this was $63.1(95 \% \mathrm{Cl}: 59.1-67.2)$ for $>60$ years and 65.0 (95\% Cl: $60.8-69.2)$ for $<60$ years.

Supplementary figure $\mathrm{S} 1$ shows the calibration plots for the three prediction models. All plots show good agreement between predicted probabilities of an infection, and the actual, or observed frequency of infections. Furthermore, the Hosmer and Lemeshow goodness-of-fit test yielded a p-value of 0.30 , 0.12 , and 0.25 for the models URI, LRI, and GI, respectively, verifying that the models are well calibrated.

The formula to compute an individual's probability of an infection in a period of 2 months can be found in the Supplementary Material.

\section{Internal validation}

The internal validation step yielded a shrinkage factor for each prediction model. This shrinkage factor was used as a correction factor for the regression coefficients. Tables 3-5 show the shrunken regression coefficients and the re-estimated intercept. Using these coefficients for calculating the probability of an infection for future patients will less likely result in too extreme predictions compared to the coefficients of the initial models.

In addition to a prediction model specific shrinkage factor, the internal validation yielded a measure of optimism in the estimation of the AUC of each model. The optimism in the AUC was $1 \%$ for upper and lower respiratory tract infection, and $2 \%$ for gastrointestinal infection. Hence, we expect that the discriminative ability of these models when applied to new patients will be $63.7 \%, 70.1 \%$, and $62.2 \%$, respectively. 
Table 2 - Baseline characteristics that were potential general predictors

\begin{tabular}{|c|c|c|}
\hline & $\begin{array}{l}\text { Total group } \\
(\mathrm{N}=3074)^{\mathrm{a}}\end{array}$ & $\begin{array}{c}\text { Missing values } \\
\mathrm{n}(\%)\end{array}$ \\
\hline Age (year) & $59.8(8.3)$ & $0(0 \%)$ \\
\hline Male sex & $1575(51.2 \%)$ & $0(0 \%)$ \\
\hline Income ( $€$, equivalent household size) & $2028.7(821.9)$ & $786(25.6 \%)$ \\
\hline Educational level ${ }^{\mathrm{b}}$ & & $77(2.2 \%)$ \\
\hline - Low & $1002(32.6 \%)$ & \\
\hline - Intermediate & $839(27.3 \%)$ & \\
\hline - High & $1161(37.8 \%)$ & \\
\hline Employed (yes) & $1775(57.7 \%)$ & $96(3.1 \%)$ \\
\hline Partner (yes) & $2542(82.7 \%)$ & $56(1.8 \%)$ \\
\hline Ethnicity (Caucasian) & $3028(98.5 \%)$ & $3(0.1 \%)$ \\
\hline Body Mass Index $\left(\mathrm{kg} / \mathrm{m}^{2}\right)$ & $27.1(4.6)$ & $3(0.1 \%)$ \\
\hline Smoking status & & $61(2.0 \%)$ \\
\hline - Never & $1049(34.8 \%)$ & \\
\hline - Former & $1565(51.9 \%)$ & \\
\hline - Current & $399(13.2 \%)$ & \\
\hline Alcohol consumption (yes) & $2448(81.4 \%)$ & $67(2.2 \%)$ \\
\hline Type 2 diabetes (yes) & $870(28.6 \%)$ & $37(1.2 \%)$ \\
\hline Prior CVD (yes) & $485(16.3 \%)$ & $96(3.1 \%)$ \\
\hline Depression (PHQ9, yes) & $148(4.8 \%)$ & $252(8.2 \%)$ \\
\hline Depression (MINI current depressive episode, yes) & $110(3.7 \%)$ & $128(4.2 \%)$ \\
\hline Mental health status (MMSE total score) & $28.1(1.3)$ & $107(3.5 \%)$ \\
\hline \multicolumn{3}{|l|}{ Mobility } \\
\hline - Problems with daily activities (yes) & $300(10.0 \%)$ & $82(2.7 \%)$ \\
\hline - Problems with walking (yes) & $497(16.2 \%)$ & $78(2.5 \%)$ \\
\hline \multicolumn{3}{|l|}{ - Healthcare consumption } \\
\hline - Medical specialist (yes) & $1083(38.7 \%)$ & $277(9.0 \%)$ \\
\hline - Paramedic/ nurse (yes) & $773(27.7 \%)$ & $284(9.2 \%)$ \\
\hline - Mental health professional (yes) & $165(5.9 \%)$ & $297(9.7 \%)$ \\
\hline - Inpatient care (yes) & $34(1.1 \%)$ & $279(9.1 \%)$ \\
\hline Season of assessment & & $0(0.0 \%)$ \\
\hline - Winter (December-March) & $663(21.6 \%)$ & \\
\hline - Spring (March-June) & $833(27.1 \%)$ & \\
\hline - Summer (June-September) & $862(28.0 \%)$ & \\
\hline - Autumn (September-December) & $716(23.3 \%)$ & \\
\hline
\end{tabular}

${ }^{a}$ Data are presented as mean and standard deviation or absolute value $(\mathrm{n})$ and percentage

${ }^{b}$ low education (no education, primary education, and lower vocational education), intermediate education (intermediate vocational education, higher secondary education, and vocational education) and high education (higher professional education, university) 
Table 3 - Network parameters that were used as potential predictors

\begin{tabular}{|c|c|c|}
\hline & Total group ${ }^{\mathrm{a}}(\mathrm{N}=3074)$ & Missing values $\mathrm{n}(\%)$ \\
\hline Network size & $9.81(5.2)$ & $0(0.0 \%)$ \\
\hline \multicolumn{3}{|l|}{ Contact frequency } \\
\hline Total contacts per half year & $228(142)$ & $1(0.0 \%)$ \\
\hline Total friend contacts per half year ${ }^{b}$ & $19(2-74)$ & $0(0.0 \%)$ \\
\hline Total family contacts per half year ${ }^{b}$ & $70(17-144)$ & $0(0.0 \%)$ \\
\hline Total household contacts per half year ${ }^{b}$ & $48(48-48)$ & $0(0.0 \%)$ \\
\hline Total neighbour contacts per half year ${ }^{b}$ & $0(0-2)$ & $0(0.0 \%)$ \\
\hline Total acquaintance contacts per half year ${ }^{b}$ & $0(0-1)$ & $0(0.0 \%)$ \\
\hline Total work relation contacts per half year ${ }^{b}$ & $0(0-0)$ & $0(0.0 \%)$ \\
\hline Total child contacts per half year ${ }^{b}$ & $0(0-0)$ & $0(0.0 \%)$ \\
\hline \multicolumn{3}{|l|}{ Proximity } \\
\hline Percentage of network members who are household members ${ }^{b}$ & $13(7-20)$ & $0(0.0 \%)$ \\
\hline Percentage of network members living within walking distance ${ }^{b}$ & $26(11-44)$ & $0(0.0 \%)$ \\
\hline Percentage of network members living less than $1 / 2 \mathrm{~h}$ away by car ${ }^{\mathrm{b}}$ & $36(20-55)$ & $0(0.0 \%)$ \\
\hline Percentage of network members living more than $1 / 2 \mathrm{~h}$ away by car $^{\mathrm{b}}$ & $7(0-22)$ & $0(0.0 \%)$ \\
\hline Percentage of network members living further away ${ }^{b}$ & $0(0-0)$ & $0(0.0 \%)$ \\
\hline \multicolumn{3}{|l|}{ Mixing } \\
\hline Percentage of same-age network members ( \pm 5 years) & $44.2(21.2)$ & $0(0.0 \%)$ \\
\hline \multicolumn{3}{|l|}{ Heterogeneity } \\
\hline Sex heterogeneity (IQV, range $0-1)$ & $0.85(0.21)$ & $0(0.0 \%)$ \\
\hline \multicolumn{3}{|l|}{ Type of relationship } \\
\hline Percentage of family members ${ }^{b}$ & $58(41-75)$ & $0(0.0 \%)$ \\
\hline Percentage of friends ${ }^{b}$ & $25(10-43)$ & $0(0.0 \%)$ \\
\hline Percentage of acquaintances (colleague, neighbour, club mate, other) ${ }^{b}$ & $10(0-22)$ & $0(0.0 \%)$ \\
\hline \multicolumn{3}{|l|}{ Proxy for superficial contacts } \\
\hline Club membership (yes) & $2020(65.8 \%)$ & $0(0.0 \%)$ \\
\hline \multicolumn{3}{|l|}{ Network density } \\
\hline Density friends (friends know each other) & & $21(0.7 \%)$ \\
\hline - Totally agree (1) & $937(30.7 \%)$ & \\
\hline - Agree (2) & $1343(44.0 \%)$ & \\
\hline - Neutral (3) & $469(15.4 \%)$ & \\
\hline - Disagree (4) & $273(8.9 \%)$ & \\
\hline - Totally disagree (5) & $31(1.0 \%)$ & \\
\hline Density friends and family (friends know family) & & $23(0.7 \%)$ \\
\hline - Totally agree (1) & $1208(39.6 \%)$ & \\
\hline - Agree (2) & $1312(43.0 \%)$ & \\
\hline - Neutral (3) & $357(11.7 \%)$ & \\
\hline - Disagree (4) & $146(4.8 \%)$ & \\
\hline - Totally disagree (5) & $28(0.9 \%)$ & \\
\hline \multicolumn{3}{|l|}{ Functional characteristics of the social network } \\
\hline Emotional support (discomfort) & $2.67(1.60)$ & $0(0.0 \%)$ \\
\hline Emotional support (important decisions) & $3.02(1.60)$ & $0(0.0 \%)$ \\
\hline Practical support & $2.78(1.53)$ & $0(0.0 \%)$ \\
\hline Informational support & $3.21(1.67)$ & $0(0.0 \%)$ \\
\hline
\end{tabular}

${ }^{a}$ Data are presented as mean and standard deviation or absolute value $(n)$ and percentage, unless stated otherwise

${ }^{\mathrm{b}}$ Due to skewed distribution, data are presented as median and IQR. 
Table 4 - Coefficients of the prediction model for upper respiratory tract infection

\begin{tabular}{|c|c|c|c|c|}
\hline Variable & Coefficient & Odds ratio $(95 \% \mathrm{Cl})$ & P-value & Shrunken coefficient ${ }^{\mathrm{a}}$ \\
\hline Intercept & 1.216 & & & 1.058 \\
\hline Age (years) & -0.010 & $0.99(0.98,1.00)$ & 0.050 & -0.009 \\
\hline Smoking (yes) & 0.287 & $1.33(1.06,1.67)$ & 0.014 & 0.264 \\
\hline Body Mass Index $\left(\mathrm{kg} / \mathrm{m}^{2}\right)$ & 0.014 & $1.01(1.00,1.03)$ & 0.130 & 0.013 \\
\hline Problems with daily activities & 0.330 & $1.39(1.09,1.78)$ & 0.009 & 0.303 \\
\hline \multicolumn{5}{|l|}{ Season } \\
\hline - Spring ${ }^{b}$ & -0.579 & $0.56(0.46,0.69)$ & $<0.001$ & -0.533 \\
\hline - Summer ${ }^{\mathrm{b}}$ & -1.195 & $0.30(0.24,0.38)$ & $<0.001$ & -1.100 \\
\hline - Autumn ${ }^{b}$ & -0.750 & $0.47(0.38,0.59)$ & $<0.001$ & -0.690 \\
\hline Total friend contacts per half year & -0.002 & $1.00(1.00,1.00)$ & 0.013 & -0.002 \\
\hline $\begin{array}{l}\text { Proportion of network members who are } \\
\text { household members }\end{array}$ & -0.944 & $0.39(0.20,0.74)$ & 0.004 & -0.869 \\
\hline $\begin{array}{l}\text { Proportion of network members living } \\
\text { within walking distance }\end{array}$ & -0.495 & $0.61(0.38,0.98)$ & 0.041 & -0.455 \\
\hline $\begin{array}{l}\text { Proportion of network members living } \\
\text { less than } 1 / 2 \text { hour away by car }\end{array}$ & -0.417 & $0.66(0.42,1.03)$ & 0.067 & -0.384 \\
\hline $\begin{array}{l}\text { Proportion of same-age network } \\
\text { members }\end{array}$ & -0.487 & $0.61(0.42,0.91)$ & 0.014 & -0.448 \\
\hline $\begin{array}{l}\text { Proportion of network members who are } \\
\text { family members }\end{array}$ & -0.489 & $0.61(0.41,0.91)$ & 0.015 & -0.449 \\
\hline Density between friends and family & -0.144 & $0.87(0.79,0.95)$ & 0.002 & -0.132 \\
\hline Emotional support (important decisions) & 0.070 & $1.07(1.01,1.14)$ & 0.032 & 0.065 \\
\hline Practical support & -0.066 & $0.94(0.88,1.00)$ & 0.042 & -0.061 \\
\hline
\end{tabular}

${ }^{a}$ Coefficients shrunken after internal validation yielded a shrinkage factor of 0.92 . The intercept was subsequently re-estimated.

${ }^{\mathrm{b}}$ Reference category winter 
Table 5 - Coefficients of the prediction model for lower respiratory tract infection

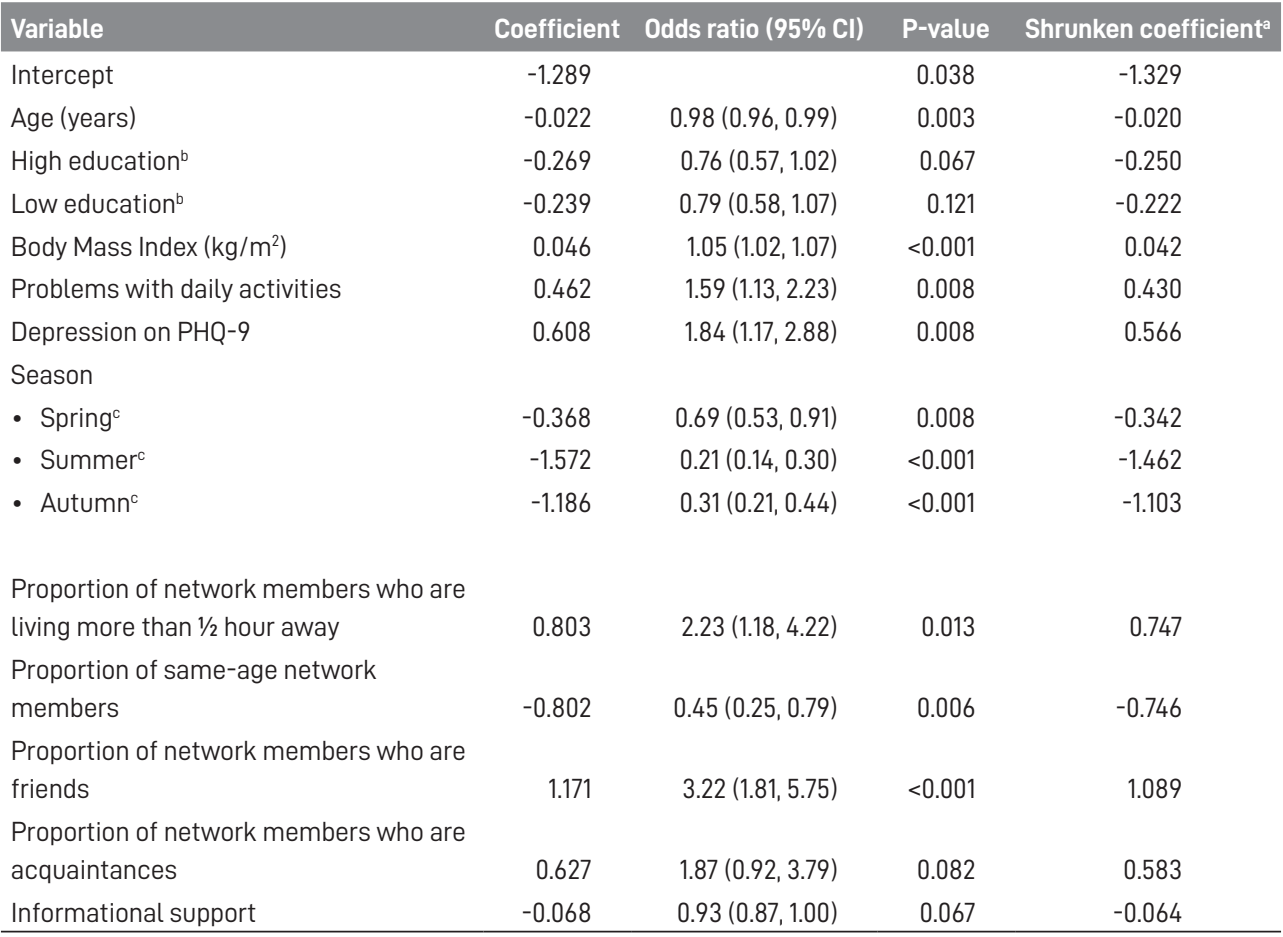

${ }^{\text {a }}$ Coefficients shrunken after internal validation yielded a shrinkage factor of 0.93 . The intercept was subsequently re-estimated.

${ }^{\mathrm{b}}$ Reference category intermediate education

${ }^{\mathrm{c}}$ Reference category winter 
Table 6 - Coefficients of the prediction model for gastrointestinal infection

\begin{tabular}{|c|c|c|c|c|}
\hline Variable & Coefficient & Odds ratio $(95 \% \mathrm{CI})$ & P-value & Shrunken coefficient ${ }^{a}$ \\
\hline Intercept & -3.966 & & 0.003 & -3.737 \\
\hline Problems with daily activities & 0.390 & $1.48(1.06,2.06)$ & 0.021 & 0.347 \\
\hline Depression on PHQ-9 & 0.799 & $2.22(1.44,3.44)$ & $<0.001$ & 0.711 \\
\hline MMSE score & 0.091 & $1.09(1.00,1.20)$ & 0.054 & 0.081 \\
\hline Type 2 diabetes (yes) & 0.468 & $1.60(1.25,2.05)$ & $<0.001$ & 0.416 \\
\hline $\begin{array}{l}\text { Paramedical healthcare consumption in } \\
\text { the past } 6 \text { months (yes) }\end{array}$ & -0.224 & $0.80(0.62,1.03)$ & 0.081 & -0.200 \\
\hline $\begin{array}{l}\text { Mental healthcare consumption in the } \\
\text { past } 6 \text { months (yes) }\end{array}$ & 0.348 & $1.42(0.94,2.13)$ & 0.094 & 0.310 \\
\hline Network size & 0.036 & $1.04(1.01,1.07)$ & 0.010 & 0.032 \\
\hline $\begin{array}{l}\text { Proportion of network members living } \\
\text { more than } 1 / 2 \text { hour away by car }\end{array}$ & 0.587 & $1.80(0.99,3.28)$ & 0.055 & 0.523 \\
\hline $\begin{array}{l}\text { Proportion of same-age network } \\
\text { members }\end{array}$ & -0.438 & $0.65(0.38,1.11)$ & 0.114 & -0.390 \\
\hline $\begin{array}{l}\text { Proportion of network members who are } \\
\text { family members }\end{array}$ & -1.185 & $0.31(0.18,0.53)$ & $<0.001$ & -1.055 \\
\hline $\begin{array}{l}\text { Proportion of network members who are } \\
\text { acquaintances }\end{array}$ & -1.090 & $0.34(0.16,0.71)$ & 0.004 & -0.970 \\
\hline Practical support & -0.068 & $0.93(0.86,1.02)$ & 0.135 & -0.060 \\
\hline
\end{tabular}

${ }^{a}$ Coefficients shrunken after internal validation yielded a shrinkage factor of 0.89 . The intercept was subsequently re-estimated. 


\section{Discussion}

To the best of our knowledge, this study is the first attempt to develop prediction models for URI, LRI, and GI including social network parameters as potential predictors. This study describes the development and internal validation of three prediction models for symptomatic infections in a period of two months: URI, LRI, and GI. The models were able to discriminate between those who experienced an infection and those who did not, and had good calibration. The main finding was that the social network parameters are strong independent predictors for infections in middle-aged and older persons. Moreover, most social network parameters had a beneficial association with the three infections. As such, social network parameters are likely to be highly promising concepts in future infection prevention strategies in older persons living at home. This study showed that the preventive potential of the social network parameters is twofold. Combined with other factors such as season and problems with daily activities, the beneficial social network parameters may be used as potential determinants that can be reinforced by preventive interventions, and all social network parameters may be used in a predictive tool to compute an individual's probability of an infection. Prior to the development of such strategies or a tool, prospective external validation could be encouraged [31]. We do expect that external validation of the models would provide similar results as the shrinkage factors and optimism estimates in our models were very small.

In the development of the prediction models, we focussed on social network parameters as it has been shown that social networks can act as a buffer for infections by increasing immune function but can also act as a vehicle for the spread of infections [7-9]; also, previous attempts to develop a prediction model based on demographic, environmental, and lifestyle characteristics alone explained only a relatively small proportion of the occurrence of respiratory infections or GI [16].

The results of the present study showed detrimental as well as beneficial associations of the social network, and in all models, social network parameters were strong independent predictors for infections. Simplified, results indicate that infection risk is higher with a higher number of social network members (greater social network size), and with higher levels of emotional support. The latter seems surprising, however, it may indicate that host resistance of persons with a higher need of emotional support is compromised, as it has been shown that infection risk was higher among those with more stressful life events [7]. A likely explanation for our findings is that a larger network indicates exposure to a greater range of infectious agents, and therefore leads to a greater incidence of symptomatic infections. In addition, the likelihood of meeting an infected person is higher in a large network. Yet, most social network parameters assessed are negatively associated with an individual's probability of infections; preventive factors include close geographic proximity (persons living nearby), more network members of the same age, higher proportion of family members, more contact moments with friends, receiving more informational and practical support, and friends and family knowing each other. Previous research has shown that the family is an important source of social support [32], and higher levels of social support have been shown to enhance several aspects of immune function [33, 34]. A possible 
explanation for our findings is that the participant's close social network may act as a buffer for infections, indicating a positive impact on lower susceptibility to these infections.

There was some overlap between the models, as well as between infections reported. Therefore, we checked whether we could combine URI and LRI, and URI, LRI, and GI in combined prediction models. Yet, AUCs were substantially lower when combining the infections.

The use of social network assessment in the prevention of infectious diseases may be a promising target in personalized care for the middle-aged and older persons population. Social network parameters can be used twofold, namely directly to predict the probability of infections in a predictive tool, and indirectly in preventive intervention programmes by addressing the beneficial parameters of the social network or their counterparts. Yet, most network interventions were aiming to accelerate behaviour change, many of them using peer-based interventions $[14,15]$. The present study adds new insights in possibilities to make use of the social network in prevention strategies. A summary of the associated social network parameters and an indication of their potential use in preventive intervention programs is depicted in table 7.

We currently face a gap in the management of infections in older persons: a growing population [1], living longer [2], and being more susceptible to infections [3,5], demanding increasing health care due to infectious burden. If we would be able to slightly lower the mean level of exposure, we might have more health impact at population level ('the population strategy') compared to individual treatment of patients (a much smaller group) [35]. Our results may inform feasible and effective infection control, and better self-management in older persons contributing to "healthy ageing" of the population. Our results agree with the current EU policy that expects older persons to take care of themselves as much as possible with help of their social network [6]. A new prevention strategy may fit this policy by reinforcing the beneficial characteristics of the social network in older persons.

One strength of our study is that it includes a broad range of social network parameters in the development of a prediction model for URI, LRI, and GI, which has not been done before. Another strength is the internal validation procedure. Using shrinkage factor coefficients for calculating the probability of an infection for future patients will less likely results in too extreme predictions. Furthermore, we only had few missing values on most general predictors and the records that were incomplete were imputed. Although we observed $25.6 \%$ missing values on income, we assumed the data were missing at random, which means that the probability of missing is related to observed covariates. We used a large amount of variables from the cohort for the imputation model. Our sensitivity analysis showed no clinically relevant differences in AUC when the models where estimated on complete cases only. We did not use complete case analysis for the main analysis since the assumptions are more strict and thus is more likely to yield biased results and can cause a decrease in statistical power compared to using imputation methods [26]. Moreover, we did not dichotomize continuous predictors, as this may result in loss of information and reduction in statistical power [36].

Nevertheless, this study also has limitations. First, our data was of cross-sectional nature. External validation is desirable and planned in prospective data to rule out reversed causality. Nonetheless, as 
our network assessment covered the past 6 months and infections in the past 2 months it is highly unlikely that reverse causation would play a role and would have strongly biased our results. Second, self-reporting may be subject to bias. Although the self-reporting of infections has been used successfully in the past in relation to network assessment [10,37], symptoms may be under or over-reported. However, we focused on symptomatic infections, which may be favourable compared to laboratory assessment, as we only include infections that were experienced as 'illness', and therefore contribute to the perceived infectious burden in middle-aged and older persons. Third, we had seven events per predictor in LRI and GI, while 10 events (infections reported) per predictor variable is recommended [38]. However, we performed internal validation of the models to prevent overfitting that may be induced by less than 10 events per variable in LRI and GI. Another limitation of this study was missing information on degree of urbanization, as this variable has also been shown to associate with respiratory infections [39]. However, the study area is defined by postal codes, approximately $60 \%$ of the population lives in an urban setting, and $~ 40 \%$ lives in a suburban/ rural setting [17].

\section{Conclusions}

To conclude, the use of social network parameters in prediction models for URI, LRI, and GI seems highly promising. In the present study, we used candidate predictors that were easily measurable in practice, and may potentially be used in a practical intervention. Based on the models' discriminatory capacity and accuracy, results could be used directly to estimate a risk for infection given a defined set of parameters, and indirectly in intervention programmes by addressing the beneficial parameters of the social network. Thereby, the use of social network-based prediction models in the prevention of infections in middle-aged and older persons may result in high benefits on a population level. 
Table 7 - Summary of associated social network parameters and indication of their potential use in preventive infection intervention programs

$\begin{array}{cccc}\begin{array}{c}\text { Upper respiratory } \\ \text { tract infection }\end{array} & \begin{array}{l}\text { Lower respiratory } \\ \text { tract infection }\end{array} & \begin{array}{l}\text { Gastrointestinal } \\ \text { tract infection }\end{array} & \begin{array}{l}\text { Potential use in } \\ \text { intervention }\end{array} \\ \text { Social network parameters that were considered useful to be reinforced in intervention programs }\end{array}$

\begin{tabular}{|c|c|c|c|c|}
\hline Close proximity & $\begin{array}{l}\text { Beneficial } \\
\text { association }\end{array}$ & $\begin{array}{l}\text { Beneficial } \\
\text { association }^{b}\end{array}$ & $\begin{array}{l}\text { Beneficial } \\
\text { association }^{b}\end{array}$ & $\begin{array}{l}\text { Reinforce relation to } \\
\text { close proximity } \\
\text { network members }\end{array}$ \\
\hline $\begin{array}{l}\text { Proportion of } \\
\text { same-age network } \\
\text { members }\end{array}$ & $\begin{array}{l}\text { Beneficial } \\
\text { association }\end{array}$ & $\begin{array}{l}\text { Beneficial } \\
\text { association }\end{array}$ & $\begin{array}{l}\text { Beneficial } \\
\text { association }\end{array}$ & $\begin{array}{l}\text { Reinforce relation to } \\
\text { same-age network } \\
\text { members }\end{array}$ \\
\hline $\begin{array}{l}\text { Practical support/ } \\
\text { Informational } \\
\text { support }\end{array}$ & $\begin{array}{l}\text { Beneficial } \\
\text { association }\end{array}$ & $\begin{array}{l}\text { Beneficial } \\
\text { association }\end{array}$ & $\begin{array}{l}\text { Beneficial } \\
\text { association }\end{array}$ & $\begin{array}{l}\text { Reinforce practical } \\
\text { and informational } \\
\text { support from } \\
\text { network members }\end{array}$ \\
\hline $\begin{array}{l}\text { Total friend contacts } \\
\text { per half year }\end{array}$ & $\begin{array}{l}\text { Beneficial } \\
\text { association }\end{array}$ & & & $\begin{array}{l}\text { Reinforce friend } \\
\text { contacts }\end{array}$ \\
\hline $\begin{array}{l}\text { Density between } \\
\text { friends and family }\end{array}$ & $\begin{array}{l}\text { Beneficial } \\
\text { association }\end{array}$ & & & $\begin{array}{l}\text { Reinforce network } \\
\text { density }\end{array}$ \\
\hline \multicolumn{5}{|c|}{ Social network parameters that were not considered useful for intervention programs } \\
\hline Social network size & & & $\begin{array}{l}\text { Detrimental } \\
\text { association }\end{array}$ & $\begin{array}{l}\text { Not considered } \\
\text { useful to decrease } \\
\text { social network size }\end{array}$ \\
\hline Emotional support & $\begin{array}{l}\text { Detrimental } \\
\text { association }\end{array}$ & & & $\begin{array}{l}\text { Not considered } \\
\text { useful to reinforce } \\
\text { less emotional } \\
\text { support }\end{array}$ \\
\hline $\begin{array}{l}\text { Proportion of } \\
\text { network members } \\
\text { who are family } \\
\text { members }\end{array}$ & $\begin{array}{l}\text { Beneficial } \\
\text { association }\end{array}$ & $\begin{array}{l}\text { Beneficial } \\
\text { association }^{b}\end{array}$ & $\begin{array}{l}\text { Beneficial } \\
\text { association }\end{array}$ & $\begin{array}{l}\text { Not considered } \\
\text { possible to increase } \\
\text { proportion of family } \\
\text { members in social } \\
\text { network }\end{array}$ \\
\hline
\end{tabular}

a Combined Proportions of network members who are household members, Proportion of network members living within walking distance, Proportion of network members living less than $1 / 2$ hour away by car

${ }^{\mathrm{b}}$ In this model, the reference category showed a positive relationship 


\section{References}

1. World Health Organization (2002) Active Ageing: A Policy Framework. Geneva: World Health Organization.

2. Rechel $B$, et al. (2013) Ageing in the European Union. The Lancet 381 (9874), 1312-1322.

3. Yoshikawa TT (2000) Epidemiology and unique aspects of aging and infectious diseases. Clinical Infectious Diseases 30(6), 931-933.

4. Derhovanessian $E_{1}$ Larbi $A$ and Pawelec $G$ (2009) Biomarkers of human immunosenescence: impact of cytomegalovirus infection. Current Opinion in Immunology 21(4), 440-445.

5. Strausbaugh LJ (2001) Emerging health care-associated infections in the geriatric population. Emerging Infectious Diseases 7(2), 268-271.

6. Anon (2014) Report from the Commission to the European Parliament, the Council, the European Economic and Social Committee and the Committee of the Regions on the Implementation, Results and Overall Assessment of the 2012 European Year for Active Ageing and Solidarity Between Generations. Brussels: Council of the European Union.

7. Hamrick N, Cohen S and Rodriguez MS (2002) Being popular can be healthy or unhealthy: stress, social network diversity, and incidence of upper respiratory infection. Health Psychology 21(3), 294.

8. Cohen S, et al. (1997) Social ties and susceptibility to the common cold. JAMA 277(24), 19401944.

9. Pressman SD, et al. (2005) Loneliness, social network size, and immune response to influenza vaccination in college freshmen. Health Psychology 24(3), 297.

10. Stein ML, et al. (2014) Comparison of contact patterns relevant for transmission of respiratory pathogens in Thailand and the Netherlands using respondent-driven sampling. PLoS ONE 9(11), e113711.

11. Mossong JL, et al. (2008) Social contacts and mixing patterns relevant to the spread of infectious diseases. PLoS Medicine 5(3), e74.
12. Uchino BN, Cacioppo JT and Kiecolt-Glaser JK (1996) The relationship between social support and physiological processes: a review with emphasis on underlying mechanisms and implications for health. Psychological Bulletin 119(3), 488-531.

13. Gallant MP (2003) The influence of social support on chronic illness selfmanagement: a review and directions for research. Health Education \& Behavior 30(2), 170-195.

14. Valente TW (2012) Network interventions. Science 337(6090), 49-53.

15. Webel AR, et al. (2010) A systematic review of the effectiveness of peerbased interventions on health-related behaviors in adults. American Journal of Public Health 100(2), 247-253.

16. Hovi $T$, et al. (2016) Development of a prognostic model based on demographic, environmental and lifestyle information for predicting incidences of symptomatic respiratory or gastrointestinal infection in adult office workers. Trials 17(1), 545.

17. Schram M, et al. (2014) The Maastricht study: an extensive phenotyping study on determinants of type 2 diabetes, its complications and its comorbidities. European Journal of Epidemiology 29(6), 439-451.

18. McCallister LFC (1978) A procedure for surveying personal networks. Sociological Methods and Research 7(2), 131-148.

19. van der Gaag M (2005) Measurement of Individval Social Capital. ICS dissertation, Groningen.

20. Brooks R (1996) Euroqol: the current state of play. Health Policy (Amsterdam, Netherlands) 37(1), 53-72.

21. Kroenke K, Spitzer RL and Williams JB (2001) The PHQ-9: validity of a brief depression severity measure. Journal of General Internal Medicine 16 (9), 606-613.

22. Sheehan DV, et al. (1998) The Mini-International Neuropsychiatric Interview (M.I.N.I.): the development and validation of a structured diagnostic psychiatric interview for DSM-IV and ICD-10. The Journal of Clinical Psychiatry 59(Suppl 20), 22-33; quiz 34-57. 
23. Folstein MF, Folstein SE and McHugh PR (1975) 'Mini-mental state'. A practical method for grading the cognitive state of patients for the clinician. Journal of Psychiatric Research 12(3), 189-198.

24. Loeb M, et al. (1999) Risk factors for pneumonia and other lower respiratory tract infections in elderly residents of long-term care facilities. Archives of Internal Medicine 159(17), 20582064.

25. Kiecolt-Glaser JK and Glaser R (2002) Depression and immune function: central pathways to morbidity and mortality. Journal of Psychosomatic Research 53(4), 873-876.

26. van Kuijk SM, et al. (2016) Bias in regression coefficient estimates when assumptions for handling missing data are violated: a simulation study. Epidemiology, Biostatistics and Public Health 13(1), 1-8.

27. Van Buuren S (2012) Flexible Imputation of Missing Data. CRC Press.

28. Akaike H (1973) Information theory and an extension of the maximum likelihood principle. In Petrov BN and Csaki F (eds). 2nd International Symposium on Information Theory. Budapest: Akademia Kiado, pp. 267-281.

29. Altman DG and Royston P (2000) What do we mean by validating a prognostic model? Statistics in Medicine 19(4), 453-473.

30. Steyerberg E (2008) Clinical Prediction Models: A Practical Approach to Development, Validation, and Updating. New York: Springer Science \& Business Media.

31. Bleeker $S$, et al. (2003) External validation is necessary in prediction research: a clinical example. Journal of Clinical Epidemiology 56(9), 826-832.

32. Shanas $E$ (1979) The family as a social support system in old age. The Gerontologist 19(2), 169-174.

33. Miyazaki T, et al. (2005) Association between perceived social support and Th1 dominance. Biological Psychology 70(1), 30-37.

34. Lutgendorf SK, et al. (2005) Social support, psychological distress, and natural killer cell activity in ovarian cancer. Journal of Clinical Oncology 23(28), 7105-7113.
35. Rose G (2001) Sick individuals and sick populations. International Journal of Epidemiology 30(3), 427-432.

36. Royston P, Altman DG and Sauerbrei W (2006) Dichotomizing continuous predictors in multiple regression: a bad idea. Statistics in Medicine 25 (1), 127-141.

37. Stein $M L$, et al. (2014) Online respondent-driven sampling for studying contact patterns relevant for the spread of close-contact pathogens: a pilot study in Thailand. PLoS ONE 9(1), e85256.

38. Harrell F (2015) Regression Modeling Strategies: With Applications to Linear Models, Logistic and Ordinal Regression, And Survival Analysis. New York: Springer.

39. van Gageldonk-Lafeber $A B$, et al. (2005) A case-control study of acute respiratory tract infection in general practice patients in The Netherlands. Clinical Infectious Diseases 41(4), 490-497.

40. Hardy MA and Bryman A (2009) Handbook of Data Analysis. London: SAGE Publications. 

Supplemental material to chapter 3 

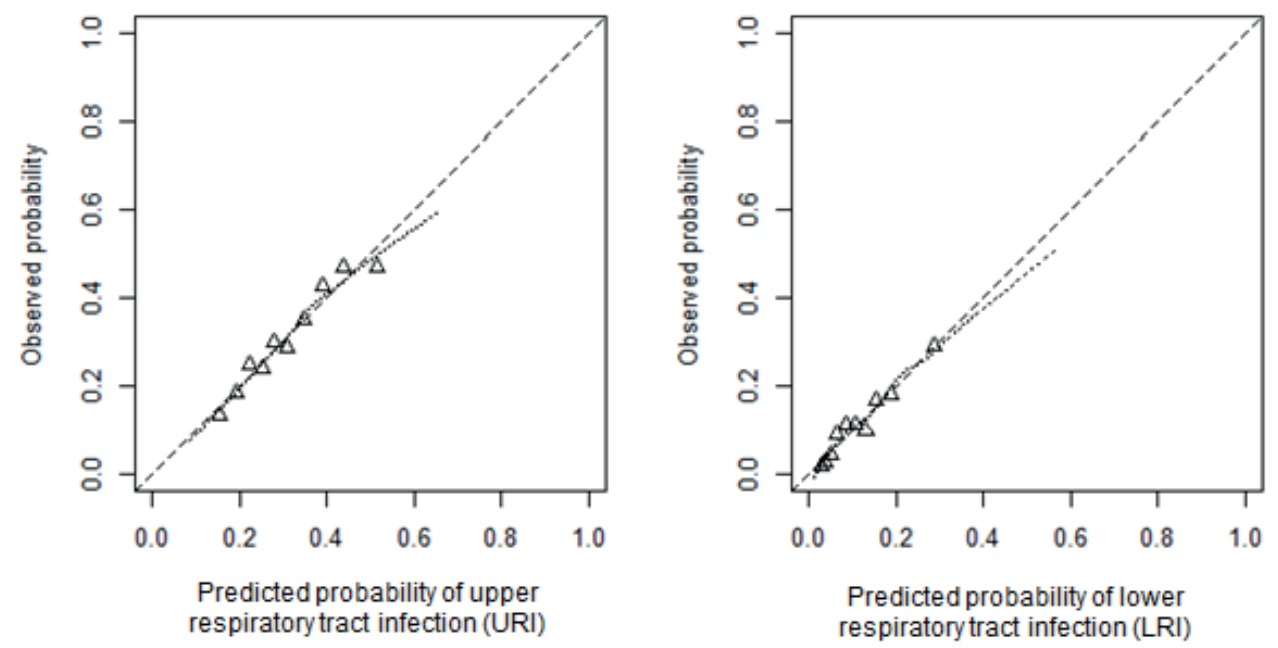

respiratory tract infection (URI)

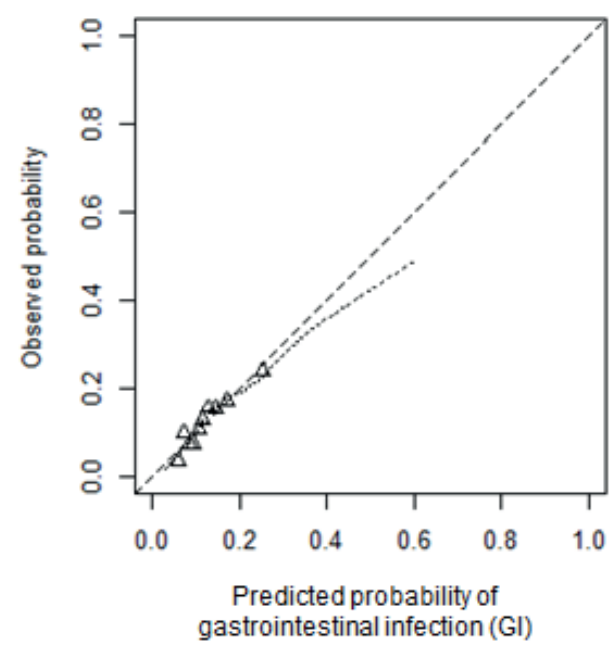

$\begin{array}{ll}--- & \text { Ideal } \\ \text {..... } & \text { Nonparametric }\end{array}$

$\Delta$ Grouped observations

Figure S1 - Calibration plots of the prediction models for different infections 


\section{The formula to compute an individual's probability of an upper respiratory tract infection in a period of 2 months}

The probability of an infection is $=1 /(1+e-L P)$, in which LP is de linear predictor or the combination of all coefficients multiplied by their respective predictor values.

For example: the probability of an upper respiratory tract infection can be calculated as $1 /$ ( $1+\mathrm{e}-\mathrm{LP})$, $\mathrm{LP}=1.058-0.009^{*}$ age (years) $+0.264^{*}$ smoking behavior (yes $\left.=1\right)+0.013^{*} \mathrm{BMI}(\mathrm{kg} / \mathrm{m} 2)+0.303^{*}$ problems with daily activities (yes $=1$ ) $-0.533^{*}$ spring (yes $=1$ ) $-1.100^{*}$ summer (yes $=1$ ) $-0.690^{*}$ autumn (yes $=1$ ) $0.002^{*}$ total friend contacts per half year $-0.869^{*}$ proportion of network members who are household members $-0.455^{*}$ proportion of network members living within walking distance $-0.384^{*}$ proportion of network members who are living less than $1 / 2$ hour away by car $-0.448^{*}$ proportion of same-age network members $-0.449^{*}$ proportion of network members who are family members $-0.132^{*}$ density between friends and family (score) $+0.065^{*}$ emotional support (score) $-0.061^{*}$ practical support (score). 


\section{Supplemental Table 1-Baseline characteristics that were potential general predictors separated for infection status}

\begin{tabular}{|c|c|c|c|c|c|c|}
\hline & $\begin{array}{r}\text { No URI } \\
(n=2103)\end{array}$ & $\begin{array}{r}\text { URI } \\
(n=945)\end{array}$ & $\begin{array}{r}\text { No LRI } \\
(n=2703)\end{array}$ & $\begin{array}{r}\text { LRI } \\
(n=345)\end{array}$ & $\begin{array}{r}\text { No GI } \\
(n=2671)\end{array}$ & $\begin{array}{r}G I \\
(n=378)\end{array}$ \\
\hline Age (year) & $60.1(8.2)$ & $59.3(8.4)$ & $60.0(8.2)$ & $58.4(8.3)$ & $59.9(8.2)$ & $59.2(8.3)$ \\
\hline Male sex & $1087(51.7 \%)$ & $589(50.7 \%)$ & $1388(51.4 \%)$ & $177(51.3 \%)$ & $1371(51.3 \%)$ & $194(51.3 \%)$ \\
\hline Income ( $€$, equivalent household size) & $2032.9(815.0)$ & $2029.0(840.5)$ & $2036.7(814.7)$ & $1984.5(889.1)$ & $2032.5(820.3)$ & $2024.8(843.0)$ \\
\hline \multicolumn{7}{|l|}{ Educational level ${ }^{1}$} \\
\hline - Low & $697(34.0 \%)$ & $291(31.4 \%)$ & $888(33.6 \%)$ & $100(29.6 \%)$ & $880(33.8 \%)$ & $110(29.5 \%)$ \\
\hline - Intermediate & $571(27.8 \%)$ & $262(28.3 \%)$ & $719(27.2 \%)$ & $114(33.7 \%)$ & $726(27.9 \%)$ & $106(28.4 \%)$ \\
\hline - High & $783(38.2 \%)$ & $374(40.3 \%)$ & $1033(39.1 \%)$ & $124(36.7 \%)$ & $1000(38.4 \%)$ & $157(42.1 \%)$ \\
\hline Employed (yes) & $821(43.0 \%)$ & $380(45.4 \%)$ & $1048(42.8 \%)$ & $153(51.0 \%)$ & $1048(43.5 \%)$ & $153(45.1 \%)$ \\
\hline Partner (yes) & $1736(84.4 \%)$ & $789(84.3 \%)$ & $2241(84.5 \%)$ & $284(83.0 \%)$ & $2229(85.1 \%)$ & $298(79.7 \%)$ \\
\hline Ethnicity (Caucasian) & $929(98.5 \%)$ & $2073(98.6 \%)$ & $2662(98.6 \%)$ & $340(98.8 \%)$ & $2630(98.6 \%)$ & $373(98.7 \%)$ \\
\hline Body Mass Index (kg/m²) & $27.0(4.5)$ & $27.1(4.5)$ & $26.9(4.5)$ & $27.8(4.8)$ & $27.0(4.4)$ & $27.5(4.9)$ \\
\hline \multicolumn{7}{|l|}{ Smoking status } \\
\hline - Never & $728(35.5 \%)$ & $313(33.4 \%)$ & $928(35.1 \%)$ & $113(33.1 \%)$ & $921(35.2 \%)$ & $121(32.4 \%)$ \\
\hline - Former & $1076(52.4 \%)$ & $477(51.0 \%)$ & $1382(52.2 \%)$ & $171(50.1 \%)$ & $1357(51.9 \%)$ & $195(52.1 \%)$ \\
\hline - Current & $249(12.1 \%)$ & $146(15.6 \%)$ & $337(12.7 \%)$ & $57(16.7 \%)$ & $337(12.9 \%)$ & $58(15.5 \%)$ \\
\hline Alcohol consumption (yes) & $1681(82.0 \%)$ & $749(80.3 \%)$ & $2158(81.7 \%)$ & $271(79.5 \%)$ & $2125(81.4 \%)$ & $303(81.2 \%)$ \\
\hline Type 2 diabetes (yes) & $598(28.7 \%)$ & $262(28.2 \%)$ & $759(28.4 \%)$ & $101(30.0 \%)$ & $731(27.7 \%)$ & $131(35.4 \%)$ \\
\hline Prior CVD (yes) & $330(16.3 \%)$ & $149(16.1 \%)$ & $417(15.9 \%)$ & $62(18.4 \%)$ & $420(16.2 \%)$ & $61(16.6 \%)$ \\
\hline Depression (PHQ9, yes) & $79(4.1 \%)$ & $40(4.7 \%)$ & $94(3.8 \%)$ & $25(8.2 \%)$ & $88(3.6 \%)$ & $31(9.0 \%)$ \\
\hline \multicolumn{7}{|l|}{ Depression (MINI current depressive } \\
\hline episode, yes) & $67(3.3 \%)$ & $40(4.4 \%)$ & $88(3.3 \%)$ & $20(6.0 \%)$ & $88(3.4 \%)$ & $20(5.4 \%)$ \\
\hline Mental health status (MMSE total score) & $28.1(1.3)$ & $28.1(1.3)$ & $28.1(1.3)$ & $28.0(1.6)$ & $28.1(1.3)$ & $28.2(1.2)$ \\
\hline \multicolumn{7}{|l|}{ Mobility } \\
\hline - Problems with daily activities (yes) & $172(8.4 \%)$ & $108(11.6 \%)$ & $228(8.7 \%)$ & $53(15.6 \%)$ & $232(8.9 \%)$ & $50(13.6 \%)$ \\
\hline - Problems with walking (yes) & $316(15.5 \%)$ & $170(18.3 \%)$ & $414(15.7 \%)$ & $72(21.2 \%)$ & $415(15.9 \%)$ & $72(19.6 \%)$ \\
\hline \multicolumn{7}{|l|}{ Healthcare consumption } \\
\hline - Medical specialist (yes) & $747(38.6 \%)$ & $335(39.6 \%)$ & $952(38.4 \%)$ & $130(43.2 \%)$ & $935(38.3 \%)$ & $147(43 \%)$ \\
\hline - Paramedic/ nurse (yes) & $524(27.2 \%)$ & $246(29.0 \%)$ & $670(27.1 \%)$ & $100(33.3 \%)$ & $678(27.9 \%)$ & $93(27.1 \%)$ \\
\hline - Mental health professional (yes) & $116(6.1 \%)$ & $48(5.7 \%)$ & $140(5.7 \%)$ & $24(8.1 \%)$ & $133(5.5 \%)$ & $31(9.1 \%)$ \\
\hline - Inpatient care (yes) & $24(1.2 \%)$ & $10(1.2 \%)$ & $31(1.3 \%)$ & $3(1.0 \%)$ & $28(1.1 \%)$ & $6(1.8 \%)$ \\
\hline \multicolumn{7}{|l|}{ Season of assessment } \\
\hline - Winter (December-March) & $433(20.6 \%)$ & $346(36.6 \%)$ & $635(23.5 \%)$ & $145(42.0 \%)$ & $676(25.3 \%)$ & $104(27.5 \%)$ \\
\hline - Spring (March-June) & $558(26.5 \%)$ & $255(27.0 \%)$ & $697(25.8 \%)$ & $115(33.3 \%)$ & $714(26.7 \%)$ & $99(26.2 \%)$ \\
\hline - Summer (June-September) & $636(30.2 \%)$ & $162(17.1 \%)$ & $758(28.0 \%)$ & $40(11.6 \%)$ & $705(26.4 \%)$ & $93(24.6 \%)$ \\
\hline Autumn (September-December) & $476(22.6 \%)$ & $182(19.3 \%)$ & $613(22.7 \%)$ & $45(13.0 \%)$ & $576(21.6 \%)$ & $82(21.7 \%)$ \\
\hline
\end{tabular}

*Data are presented as mean and standard deviation or absolute value $(\mathrm{n})$ and percentage

${ }^{1}$ low education (no education, primary education, and lower vocational education), intermediate education (intermediate vocational education, higher secondary education, and vocational education) and high education (higher professional education, university)

URI upper respiratory tract infection, LRI lower respiratory tract infection, GI gastrointestinal tract infection 


\section{Supplemental Table 2 - Network parameters that were used as potential predictors separated for infection status}

\begin{tabular}{|c|c|c|c|c|c|c|}
\hline & $\begin{array}{r}\text { No URI } \\
(n=2103)\end{array}$ & $\begin{array}{r}\text { URI } \\
(n=945)\end{array}$ & $\begin{array}{r}\text { No LRI } \\
(\mathrm{n}=2703)\end{array}$ & $\begin{array}{r}\text { LRI } \\
(n=345)\end{array}$ & $\begin{array}{r}\text { No GI } \\
(n=2671)\end{array}$ & $\begin{array}{r}G \mid \\
(n=378)\end{array}$ \\
\hline Network size & $9.7(5.1)$ & $10.2(5.3)$ & $9.8(5.1)$ & $10.2(5.5)$ & $9.8(5.2)$ & $10.4(5.2)$ \\
\hline \multicolumn{7}{|l|}{ Contact frequency } \\
\hline Total contacts per half year & $229(144)$ & 227 (139) & $229(143)$ & $223(134)$ & $227(142)$ & $236(137)$ \\
\hline Total friend contacts per half year & $19(1-82)$ & $20(3-72)$ & $19(2-74)$ & $20(3-90)$ & $18(2-71)$ & $45(5-98)$ \\
\hline Total family contacts per half year ${ }^{\ddagger}$ & $73(18-144)$ & $66(14-144)$ & $72(18-144)$ & $61(13-120)$ & $70(18-144)$ & $74(14-144)$ \\
\hline Total household contacts per half year & $48(48-48)$ & $48(48-48)$ & $48(48-48)$ & $48(48-48)$ & $48(48-48)$ & $48(48-48)$ \\
\hline Total neighbour contacts per half year ${ }^{\ddagger}$ & $0(0-2)$ & $0(0-2)$ & $0(0-2)$ & $0(0-2)$ & $0(0-2)$ & $0(0-4)$ \\
\hline Total acquaintance contacts per half year ${ }^{\ddagger}$ & $0(0-1)$ & $0(0-1)$ & $0(0-1)$ & $0(0-1)$ & $0(0-1)$ & $0(0-2)$ \\
\hline Total work relation contacts per half year ${ }^{\ddagger}$ & $0(0-0)$ & $0(0-1)$ & $0(0-0)$ & $0(0-2)$ & $0(0-0)$ & $0(0-0)$ \\
\hline Total child contacts per half year ${ }^{\ddagger}$ & $0(0-0)$ & $0(0-0)$ & $0(0-0)$ & $0(0-0)$ & $0(0-0)$ & $0(0-0)$ \\
\hline \multicolumn{7}{|l|}{ Proximity } \\
\hline $\begin{array}{l}\text { Percentage of network members who are household } \\
\text { members }^{\ddagger}\end{array}$ & $13(7-21)$ & $13(6-20)$ & $13(7-20)$ & $13(6-22)$ & $13(7-21)$ & $11(6-19)$ \\
\hline $\begin{array}{l}\text { Percentage of network members living within } \\
\text { walking distance }{ }^{\ddagger}\end{array}$ & $26(11-44)$ & $25(11-43)$ & $26(11-43)$ & $25(10-46)$ & $26(11-44)$ & $25(13-43)$ \\
\hline $\begin{array}{l}\text { Percentage of network members living less than } 1 / 2 \mathrm{~h} \\
\text { away by car }{ }^{\ddagger}\end{array}$ & $38(20-55)$ & $36(20-56)$ & $38(20-55)$ & $36(18-57)$ & $36(20-55)$ & $38(21-56)$ \\
\hline $\begin{array}{l}\text { Percentage of network members living more than } \\
1 / 2 \text { h away by car }{ }^{\ddagger}\end{array}$ & $6(0-21)$ & $8(0-25)$ & $7(0-22)$ & $8(0-25)$ & $6(0-22)$ & $10(0-25)$ \\
\hline Percentage of network members living further away ${ }^{\ddagger}$ & $0(0-0)$ & $0(0-0)$ & $0(0-0)$ & $0(0-0)$ & $0(0-0)$ & $0(0-0)$ \\
\hline \multicolumn{7}{|l|}{ Mixing } \\
\hline $\begin{array}{l}\text { Percentage of same-age network members }( \pm 5 \\
\text { years) } \\
\text { Heterogeneity }\end{array}$ & $44.7(21.5)$ & $43.23(20.4)$ & $44.6(21.3)$ & $41.4(20.0)$ & $44.4(21.2)$ & $43.0(20.9)$ \\
\hline \multicolumn{6}{|l|}{ Type of relationship } & $0.85(0.21)$ \\
\hline Percentage of family members ${ }^{\ddagger}$ & $59(42-78)$ & $57(40-75)$ & $59(42-75)$ & $54(38-73)$ & $59(42-75)$ & $55(37-74)$ \\
\hline Percentage of friends ${ }^{\ddagger}$ & $25(9-43)$ & $25(13-42)$ & $25(10-42)$ & $27(13-46)$ & $25(10-42)$ & $30(13-50)$ \\
\hline Percentage of acquaintances (colleague, neighbour, & $9(0-22)$ & $11(0-25)$ & $10(0-22)$ & $11(0-25)$ & $10(0-22)$ & $10(0-22)$ \\
\hline
\end{tabular}

club mate, other) $)^{\ddagger}$

Proxy for superficial contacts

Club membership (yes)

$1385(65.9 \%) \quad 621(65.9 \%) \quad 1786(66.1 \%) 219(63.8 \%) \quad 1757(65.9 \%) \quad 249(66.0 \%)$

Network density

Density friends (friends know each other)

- Totally agree (1)

- Agree (2)

- Neutral (3)

- Disagree (4)

- Totally disagree (5) $1385(65.9 \%)$

Density friends and family (friends know family)

- Totally agree (1)

- Agree (2)

- Neutral (3)

- Disagree (4)

- Totally disagree (5)

$642(30.6 \%) \quad 290(30.7 \%) \quad 822(30.5 \%) \quad 111(32.2 \%) \quad 823(30.9 \%) \quad 110(29.1 \%)$

$914(43.5 \%) \quad 425(45.0 \%) \quad 1197(44.4 \%) \quad 141(40.9 \%) \quad 1175(44.1 \%) \quad 165(43.7 \%)$

$239(15.7 \%) \quad 139(14.7 \%) \quad 412(15.3 \%) \quad 56(16.2 \%) \quad 414(15.5 \%) \quad 53(14.0 \%)$

$192(9.1 \%) \quad 81(8.6 \%) \quad 239(8.9 \%) \quad 34(9.9 \%) \quad 227(8.5 \%) \quad 46(12.2 \%)$

$22(1.0 \%) \quad 9(1.0 \%) \quad 28(1.0 \%) \quad 3(0.9 \%) \quad 27(1.0 \%) \quad 4(1.1 \%)$

Functional characteristics of the social network

Emotional support (discomfort)

Emotional support (important decisions)

Practical support

Informational support

$807(38.5 \%) \quad 397(42.1 \%) \quad 1067(39.6 \%) \quad 138(40.0 \%) \quad 1055(39.6 \%) \quad 150(39.7 \%)$ $909(43.3 \%) \quad 398(42.2 \%) \quad 1161(43.1 \%) \quad 145(42 . \%) \quad 1145(43.0 \%) \quad 162(42.9 \%)$ $262(12.5 \%) \quad 95(10.1 \%) \quad 322(11.9 \%) \quad 35(10.1 \%) \quad 320(12.0 \%) \quad 37(9.8 \%)$

$98(4.7 \%) \quad 47(5.0 \%) \quad 119(4.4 \%) \quad 26(7.5 \%) \quad 118(4.4 \%) \quad 27(7.1 \%)$ $21(1.0 \%) \quad 7(0.7 \%) \quad 27(1.0 \%) \quad 1(0.3 \%) \quad 26(1.0 \%) \quad 2(0.5 \%)$

\begin{tabular}{llllll}
$2.65(1.60)$ & $2.72(1.61)$ & $2.68(1.61)$ & $2.69(1.57)$ & $2.66(1.60)$ & $2.78(1.64)$ \\
$2.98(1.60)$ & $3.13(1.58)$ & $3.03(1.59)$ & $3.02(1.63)$ & $3.01(1.59)$ & $3.16(1.60)$ \\
$2.77(1.53)$ & $2.78(1.52)$ & $2.77(1.53)$ & $2.82(1.47)$ & $2.78(1.53)$ & $2.75(1.52)$ \\
$3.18(1.66)$ & $3.27(1.68)$ & $3.22(1.67)$ & $3.13(1.68)$ & $3.20(1.66)$ & $3.25(1.70)$ \\
\hline
\end{tabular}

* Data are presented as mean and standard deviation or absolute value $(n)$ and percentage, unless stated otherwise

‡ Due to skewed distribution, data are presented as median and IQR.

URI upper respiratory tract infection, LRI lower respiratory tract infection, GI gastrointestinal tract infection 



\section{Part II}

Social networks in relation to type 2 diabetes 


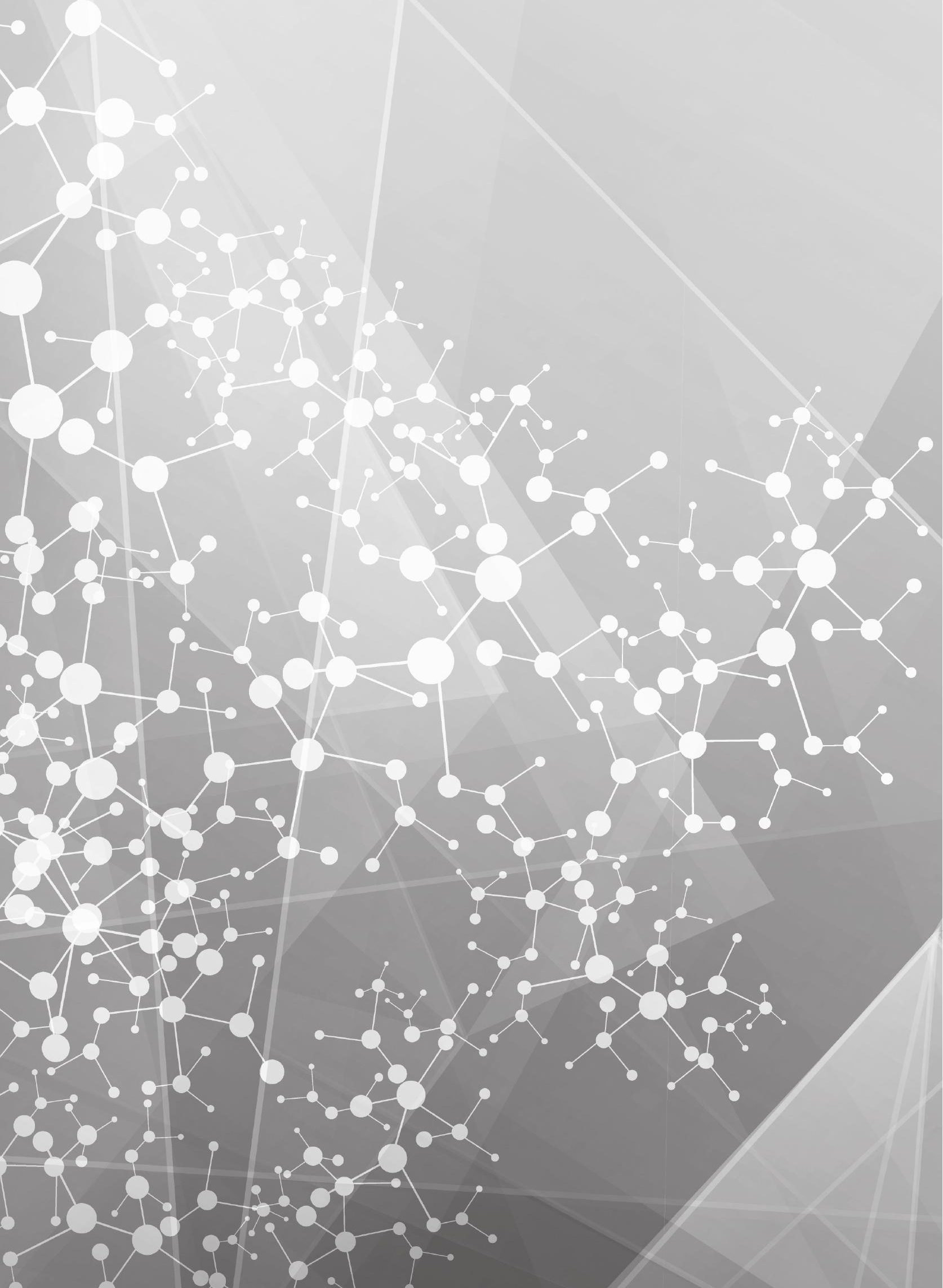




\section{Chapter 4}

Socially isolated individuals are more prone to have newly diagnosed and prevalent type 2 diabetes mellitus - The Maastricht Study -

Stephanie Brinkhues, Nicole H.T.M. Dukers-Muijrers, Christian J.P.A. Hoebe, Carla J.H. van der Kallen, Pieter C. Dagnelie, Annemarie Koster, Ronald M.A. Henry, Simone J.S. Sep, Nicolaas C. Schaper, Coen D. A. Stehouwer, Hans

Bosma, Paul H.M. Savelkoul, Miranda T. Schram 


\section{Abstract}

Background: Social isolation is associated with type 2 diabetes (T2DM), but it is unclear which elements play a crucial role in this association. Therefore, we assessed the associations of a broad range of structural and functional social network characteristics with normal glucose metabolism, pre-diabetes, newly diagnosed T2DM and previously diagnosed T2DM.

Methods: Participants originated from The Maastricht Study, a population-based cohort study ( $\mathrm{n}=2861$, mean age $60.0 \pm 8.2$ years, 49\% female, 28.8\% T2DM (oversampled)). Social network characteristics were assessed through a name generator questionnaire. Diabetes status was determined by an oral glucose tolerance test. We used multinomial regression analyses to investigate the associations between social network characteristics and diabetes status, stratified by sex.

Results: More socially isolated individuals (smaller social network size) more frequently had newly diagnosed and previously diagnosed T2DM, while this association was not observed with pre-diabetes. In women, proximity and the type of relationship was associated with newly diagnosed and previously diagnosed T2DM. A lack of social participation was associated with pre-diabetes as well as with previously diagnosed T2DM in women, and with previously diagnosed T2DM in men. Living alone was associated with higher odds of previously diagnosed T2DM in men, but not in women. Less emotional support related to important decisions, less practical support related to jobs, and less practical support for sickness were associated with newly diagnosed and previously diagnosed T2DM in men and women, but not in pre-diabetes.

Conclusion: This study shows that several aspects of structural and functional characteristics of the social network were associated with newly and previously diagnosed T2DM, partially different for men and women. These results may provide useful targets for T2DM prevention efforts. 


\section{Background}

The growing number of people with chronic conditions, such as type 2 diabetes mellitus (T2DM), is a rising problem in health care. An estimated 171 million individuals worldwide had T2DM in 2000, and this number is expected to increase to 366 million individuals in 2030 , with a higher prevalence in men [1]. Because T2DM leads to severe complications and significantly reduces life expectancy [2], and multiborbidity is common [3], these figures underline the need for interventions that can prevent the development of T2DM. Several environmental and lifestyle factors, as well as psychosocial factors such as depression and stress, have been identified as relevant for the development of T2DM [4-7]. Recently, there is raising interest for the role of social network characteristics in the development of T2DM [7-14]. Prevention strategies that promote social integration and participation may prove promising [15-18]. Among individuals with T2DM, beneficial effects of social support have been reported on diabetes care [19], activation for self-management [20], and health/health-related behaviors [21].

Given the results of previous research, a more detailed and conjoint investigation of a broad range of social network characteristics is essential. Previous studies on social network characteristics have typically focused on either structural or functional characteristics, while both have been found to associate with T2DM risk [7-14]. For example, the single indicator low emotional support is associated with a doubled risk of T2DM in women [7], while prevalent T2DM is also related to lower emotional support [8]. Negative friend support increases the odds of T2DM by $30 \%$ in both men and women [14]. In addition, poor structural support has been shown to increase the risk of T2DM in men by 50\%, particularly evident among those with a low education level [9]. Furthermore, several studies have found that living alone was an independent predictor of T2DM in men, but not in women [7, 11, 12]. In contrast, one study reported that high social integration increased the odds of T2DM in men [12]. However, the associations of social network characteristics with pre-diabetes or newly diagnosed T2DM were less clear, studies accounting for pre-diabetes and newly diagnosed T2DM are rare [12, 13].

In light of these considerations, the aim of the present study was to assess the associations of a broad range of social network characteristics with diabetes status. Specifically, we assessed whether structural characteristics such as social network size, contact frequency, type of relationship, living alone and social participation are associated with pre-diabetes and newly diagnosed and previously diagnosed T2DM. Next, we addressed the question of whether functional characteristics of the social network (social support) are associated with pre-diabetes, newly diagnosed T2DM and previously diagnosed T2DM. To investigate the differences between men and women, all analyses were stratified by sex. 


\section{Methods}

\section{Study population}

We used data from The Maastricht Study, an observational prospective population-based cohort study. The rationale and methodology have been described previously [22]. In brief, the study focuses on the etiology, pathophysiology, complications and comorbidities of type 2 diabetes mellitus (T2DM) and is characterized by an extensive phenotyping approach. The study uses state-of-the-art imaging techniques and extensive biobanking to determine both determinants and clinical outcomes of health status.

Eligible for participation were all individuals aged between 40 and 75 years and living in the southern part of the Netherlands. Participants with and without diabetes were recruited through mass media campaigns and from the municipal registries and the regional Diabetes Patient Registry via mailings. Recruitment was stratified according to known T2DM status, with an oversampling of individuals with T2DM, for reasons of efficiency. Enrollment started in November 2010 and is still ongoing, aiming to include 10.000 participants. The present report includes cross-sectional data from the first 3451 participants, who completed the baseline survey between November 2010 and September 2013. The examinations of each participant were performed within a time window of three months. Further information on The Maastricht study can be found elsewhere [22].

After excluding participants who did not provide data on their social network ( $n=447(12.9 \%)$, the main reason for missing data was incomplete questionnaires), participants with type 1 diabetes ( $n=33$ ), and other types of diabetes $(n=4)$, and participants with missing information on covariates $(n=106)$, a total of 2861 participants were included in the present analyses. The participants without social network data did not differ from those with these data with respect to diabetes status, sex, educational level, or body mass index (BMI). However, the participants who did not provide social network data were slightly younger than those who did (mean age 59 versus 60 years, $(p<0.001)$ ).

\section{Measurements}

\section{Glucose metabolism status}

To determine glucose metabolism status, all participants (except those who used insulin) underwent a standardized $75 \mathrm{~g}$ oral glucose tolerance test (OGTT) after an overnight fast [22]. Glucose metabolism was defined according to the World Health Organization 2006 criteria as normal glucose metabolism (NGM), impaired fasting glucose (IFG), impaired glucose tolerance (IGT), or T2DM [23]. Individuals on diabetes medication were classified as having T2DM. We defined pre-diabetes as having either IFG or IGT and newly diagnosed (unaware) T2DM as negative self-reported T2DM with a positive OGTT. 


\section{Social network questionnaire}

Data on individual social networks were collected through a questionnaire using a name generator method [24, 25]. A detailed description of this questionnaire can be found in the supplemental file (see Supplemental file 1). The name generator first requires a respondent to identify actual persons, and then several additional questions about these individuals are asked (sex, age, type of relationship, geographic distance, and the number of members who provided informational, practical or emotional support).

\section{Structural characteristics of the social network}

The structural network characteristics were computed from the questionnaire. In brief, network size was defined as the total number of unique network members (alters) mentioned in the questionnaire. Total contacts per half year was defined as the sum of all contacts per half year. In addition, the percentage of network members that the participant (ego) had daily/weekly contact with, that were household members, that lived within walking distance, and the percentage of network members that were family members or friends was computed. Those social network constructs of percentages within the network were defined in steps of $10 \%$. Based on an average network size of 10 network members, a change in one network member corresponds to $10 \%$.

Living alone was defined as a person who lived alone in his household. Social participation was defined as membership in, for instance, a sports club, religious group, volunteer organization, discussion group, self-support group, internet club, or other organization. Additional information on structural social network characteristics used in the present study can be found in table 1.

\section{Functional characteristics of the social network (social support)}

Participants were asked to indicate the number of members who provided informational support, emotional support related to discomfort, emotional support related to important decisions, practical support related to jobs, and practical support related to sickness. For every type of support, participants could name a maximum of 5 network members. This results in a possible range of 0 to 5 for the functional characteristics of the social network. Additional information on functional social network characteristics used in the present study can be found in table 1 .

\section{General measurements}

Self-administered questionnaires were used to assess educational level, employment status, smoking status, alcohol consumption, history of cardiovascular disease (CVD), diabetes medication use and diabetes duration. Body mass index (BMI) and hypertension were measured the study centre [22] General health was assessed with the SF-36 Health Survey and transformed scale scores were calculated according to Ware et al. (1994) [26]. 


\section{Statistical analysis}

Descriptive analyses were performed to examine the characteristics of the study population, and the results were presented as the mean and standard deviation (SD) or percentages and numbers. To assess the differences between participants with NGM, pre-diabetes, newly diagnosed T2DM and previously diagnosed T2DM, we performed chi-square, analysis of variance (ANOVA) and Kruskal-Wallis tests, as appropriate. We conducted multinomial logistic regression analyses to examine the association of the social network variables with diabetes status, Using NGM as reference. For every network variable, odds ratios (ORs) and $95 \%$ confidence intervals $(95 \% \mathrm{Cls})$ were reported. For descriptive purposes, social network variables were reversed, i.e., multiplied by -1 (lower values on social network variables indicated risk factor). Every network variable was assessed separately, risk estimates were adjusted for age, BMl, educational level, employment status, alcohol consumption, smoking status, hypertension, prior CVD and general health status (SF36). As previous research has shown different associations between social network and diabetes status between men and women $[7,9,11,12]$, we tested for statistical interactions (effect modification) of the network variables with sex. Because the majority of the social network variables showed an interaction with sex $(p<0.1)$, all analyses were stratified by sex. All analyses were conducted using IBM SPSS software version 21.0 (IBM Corp. Armonk, NY, USA). Associations with $p \leq 0.05$ were considered statistically significant.

\section{Results}

The overall study population consisted of 2861 participants with a mean age of $60.0 \pm 8.2$ years, of whom slightly less than half were women (49\%). Table 2 presents descriptive characteristics according to diabetes status. A total of $1623(56.7 \%)$ participants had a normal glucose metabolism status (NGM), 430 (15.0\%) had pre-diabetes, 111 (3.9\%) were newly diagnosed as T2DM at study entry, and 697 (24.4\%) had previously diagnosed T2DM. Participants with T2DM were older, more often men, had a higher BMI, were lower educated, were more often retired, were more often current smokers, were less often high alcohol consumers, and had prior CVD and hypertension more often than participants with NGM or prediabetes. In participants with previously diagnosed T2DM, the median self-reported diabetes duration was 7 years (IQR 3.0-12.0). Participants with newly diagnosed T2DM were more often higher educated, less often obese, less often current smokers, more often high alcohol consumers and had prior CVD and hypertension less often than participants with previously diagnosed T2DM.

\section{Description of structural characteristics of the social network}

Figure 1 shows a simplified representation of the social network size, contact frequency, geographic distance, and proportions of family members and friends according to diabetes status for both men and women. In summary, the network size was 12, 11, 9, and 8 in women with NGM, pre-diabetes, newly 
Table 1-Variable descriptions of the structural and functional social network characteristics

$\begin{array}{llr}\text { Variable name } & \text { Definition } & \begin{array}{c}\text { Unit of } \\ \text { measurement } \\ \text { (possible } \\ \text { range) }\end{array} \\ \text { Structural characteristics of the social network } & \mathrm{N} \\ \text { Network size } & \begin{array}{r}\text { The total number of unique network members mentioned in the } \\ \text { questionnaire. Participants with a smaller social network size were } \\ \text { considered as more socially isolated. }\end{array} & (0-40)\end{array}$

\section{Contact frequency}

Total contacts per half A contact was defined as an interaction between persons. Total contacts year (interactions between persons) per half year were computed as follows.

We used the highest contact frequency (e.g., daily contact) for every network member as an indicator of the actual contact frequency. Second, we recoded the answer categories of the questionnaire to an estimated number of contacts per half year. For example, "half-yearly" was assumed to comprise one contact, "quarterly" two contacts, "monthly" 6 contacts and "daily or weekly" 48 contacts. Third, we computed the sum of all contacts per half year as the total contact frequency.

Percentage of We calculated the percentage of network members that the participant had

daily-weekly contact daily or weekly contact with as the number of daily/weekly contacts divided by network size.

\begin{tabular}{|c|c|c|}
\hline \multicolumn{3}{|l|}{ Proximity } \\
\hline $\begin{array}{l}\text { Percentage of network } \\
\text { members living within } \\
\text { walking distance }\end{array}$ & $\begin{array}{l}\text { We considered geographic proximity as the percentage of all network } \\
\text { members who lived within walking distance, calculated as the number of } \\
\text { network members living within walking distance divided by network size. }\end{array}$ & $\begin{array}{r}\% \\
(0-100)\end{array}$ \\
\hline \multicolumn{3}{|l|}{ Type of relationship } \\
\hline $\begin{array}{l}\text { Percentage household } \\
\text { members }\end{array}$ & $\begin{array}{l}\text { We calculated the percentage of household members as the number of } \\
\text { network members living in the same household divided by network size. }\end{array}$ & $\begin{array}{r}\% \\
(0-100) \\
\end{array}$ \\
\hline $\begin{array}{l}\text { Percentage family } \\
\text { members }\end{array}$ & $\begin{array}{l}\text { We calculated the percentage of family members within the network as the } \\
\text { number of family members divided by the network size. }\end{array}$ & $\begin{array}{r}\% \\
(0-100) \\
\end{array}$ \\
\hline Percentage friends & $\begin{array}{l}\text { We calculated the percentage of friends within the network as the number } \\
\text { of friends divided by the network size. }\end{array}$ & $\begin{array}{r}\% \\
(0-100)\end{array}$ \\
\hline Living alone & Living alone was defined as a person who lived alone in his/ her household. & (yes/no) \\
\hline Social participation & $\begin{array}{l}\text { Social participation was defined as membership in, for instance, a sports } \\
\text { club, religious group, volunteer organization, discussion group, self-support } \\
\text { group, internet club, or other organization. }\end{array}$ & (yes/no) \\
\hline \multicolumn{3}{|c|}{ Functional characteristics of the social network } \\
\hline Informational support & $\begin{array}{l}\text { Informational support was defined as the number of network members that } \\
\text { give advice on problems }\end{array}$ & $\begin{array}{r}N \\
(0-5)\end{array}$ \\
\hline $\begin{array}{l}\text { Emotional support } \\
\text { (discomfort) }\end{array}$ & $\begin{array}{l}\text { Emotional support related to discomfort was defined as the number of } \\
\text { network members that provide emotional support when participants were } \\
\text { feeling unwell }\end{array}$ & $\begin{array}{r}N \\
(0-5)\end{array}$ \\
\hline $\begin{array}{l}\text { Emotional support } \\
\text { (important decisions) }\end{array}$ & $\begin{array}{l}\text { Emotional support related to important decisions was defined as the } \\
\text { number of network members that provide the opportunity to discuss } \\
\text { important matters }\end{array}$ & $\begin{array}{r}N \\
(0-5)\end{array}$ \\
\hline Practical support (jobs) & $\begin{array}{l}\text { Practical support related to jobs was defined as the number of network } \\
\text { members that help with small and larger jobs around the house }\end{array}$ & $\begin{array}{r}N \\
(0-5) \\
\end{array}$ \\
\hline $\begin{array}{l}\text { Practical support } \\
\text { (sickness) }\end{array}$ & $\begin{array}{l}\text { Practical support related to sickness was defined as the number of network } \\
\text { members that provide practical help when participants were sick }\end{array}$ & $\begin{array}{r}N \\
(0-5)\end{array}$ \\
\hline
\end{tabular}


diagnosed T2DM and previously diagnosed T2DM, respectively. In men, the network size was 10 in NGM and pre-diabetes and 7 in newly diagnosed and previously diagnosed T2DM. The total number of contacts per half year was $268,252,224,212$ in women with NGM, pre-diabetes, newly diagnosed T2DM and previously diagnosed T2DM, respectively, and 224, 216, 175, 189 for men, respectively. The percentage of daily/weekly contacts was $46.3 \%$ in NGM and $54.2 \%$ in previously diagnosed T2DM. The percentage of family members was $55.9 \%$ in the NGM group and $64.7 \%$ in the previously diagnosed T2DM group. The percentage of friends was $30.0 \%$ in NGM and $21.4 \%$ in previously diagnosed T2DM (table 2).

The prevalence of living alone was $14.7 \%, 17.4 \%, 17.1 \%$ and $20.2 \%$ and the prevalence of social participation was $71.6 \%, 64.2 \%, 61.1 \%$, and $56.4 \%$ in NGM, pre-diabetes, newly diagnosed T2DM and previously diagnosed T2DM, respectively (table 2).

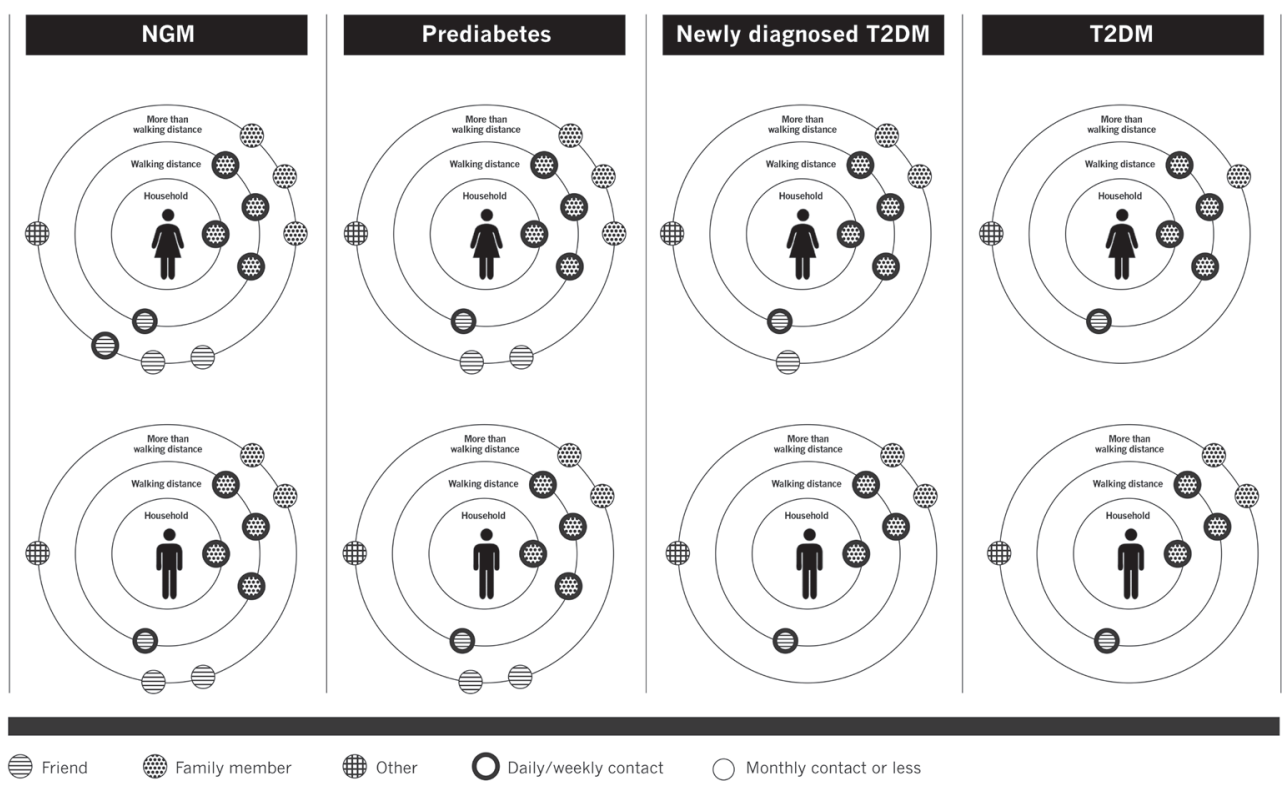

Figure 1 - Structural network characteristics stratified by diabetes status among women and men

\section{Description of functional characteristics of the social network}

Participants with newly diagnosed and previously diagnosed T2DM reported lower levels of informational support related to advice on problems, emotional support related to discomfort and related to important decisions and practical support related to jobs around the house and related to sickness than participants with NGM or pre-diabetes (table 2). 
Table 2 - General and social network characteristics of the study population

\begin{tabular}{|c|c|c|c|c|c|}
\hline & NGM (n=1623) & $\begin{array}{l}\text { Pre-diabetes } \\
\qquad(\mathrm{n}=\mathbf{4 3 0})\end{array}$ & $\begin{array}{r}\text { Newly } \\
\text { diagnosed T2DM } \\
\text { (n=111) }\end{array}$ & $\begin{array}{r}\text { Previously } \\
\text { diagnosed T2DM } \\
(n=697)\end{array}$ & P-value ${ }^{1}$ \\
\hline \multicolumn{6}{|l|}{ General measurements } \\
\hline Age & $58.1 \pm 8.1$ & $61.6 \pm 7.5$ & $62.9 \pm 7.5$ & $62.7 \pm 7.7$ & $<0.001$ \\
\hline Male sex (\%) & 42.2 & 53.3 & 63.1 & 69.4 & $<0.001$ \\
\hline Body mass index $\left(\mathrm{kg} / \mathrm{m}^{2}\right)$ & $25.5 \pm 3.6$ & $27.7 \pm 4.3$ & $28.8 \pm 4.8$ & $29.9 \pm 5.0$ & \\
\hline \multicolumn{6}{|l|}{ Educational level (\%) } \\
\hline - $\operatorname{low}^{2}$ & 26.1 & 34.7 & 34.2 & 47.1 & $<0.001$ \\
\hline - intermediate ${ }^{3}$ & 27.5 & 28.1 & 30.6 & 27.7 & \\
\hline - high $^{4}$ & 45.7 & 36.3 & 34.2 & 24.5 & \\
\hline \multicolumn{6}{|l|}{ Employment status (\%) } \\
\hline - employed & 46.8 & 35.3 & 28.8 & 27.8 & $<0.001$ \\
\hline - retired & 26.6 & 36.0 & 45.0 & 37.0 & \\
\hline - no paid job & 19.6 & 19.8 & 19.8 & 20.1 & \\
\hline - not known & 7.1 & 8.8 & 6.3 & 15.1 & \\
\hline \multicolumn{6}{|l|}{ Smoking status (\%) } \\
\hline - never & 39.6 & 29.8 & 33.3 & 27.7 & $<0.001$ \\
\hline - former & 48.4 & 57.0 & 57.7 & 55.8 & \\
\hline - current & 11.9 & 13.3 & 8.1 & 16.1 & \\
\hline Alcohol consumption, glasses per week & $7.3 \pm 7.1$ & $9.1 \pm 10.6$ & $9.3 \pm 10.6$ & $6.1 \pm 8.5$ & $<0.001$ \\
\hline Prior CVD (\%) & 11.6 & 12.1 & 20.7 & 27.5 & $<0.001$ \\
\hline Hypertension (\%) & 41.2 & 63.6 & 75.7 & 83.9 & $<0.001$ \\
\hline Diabetes medication use (\%) & $\mathrm{n} / \mathrm{a}$ & $\mathrm{n} / \mathrm{a}$ & $\mathrm{n} / \mathrm{a}$ & 90.9 & $n / a$ \\
\hline $\begin{array}{l}\text { Diabetes duration (years; median, Q1-Q3; } \\
\mathrm{n}=567 \text { ) }\end{array}$ & $\mathrm{n} / \mathrm{a}$ & $\mathrm{n} / \mathrm{a}$ & $\mathrm{n} / \mathrm{a}$ & $7.0(3.0-12.0)$ & $\mathrm{n} / \mathrm{a}$ \\
\hline \multicolumn{6}{|c|}{ Structural characteristics of the social network } \\
\hline Network size & $11.00 \pm 5.15$ & $10.02 \pm 5.08$ & $7.68 \pm 4.59$ & $7.61 \pm 4.38$ & $<0.001$ \\
\hline \multicolumn{6}{|l|}{ Contact frequency } \\
\hline Total contacts per half year & $249.33 \pm 144.09$ & $233.13 \pm 145.26$ & $193.14 \pm 123.39$ & $196.55 \pm 125.58$ & $<0.001$ \\
\hline Percentage of daily-weekly contact & $46.29 \pm 24.41$ & $47.15 \pm 25.09$ & $53.67 \pm 28.04$ & $54.16 \pm 28.01$ & $<0.001$ \\
\hline \multicolumn{6}{|l|}{ Proximity } \\
\hline $\begin{array}{l}\text { Percentage of network members living } \\
\text { within walking distance }\end{array}$ & $28.96 \pm 21.28$ & $30.79 \pm 23.60$ & $27.51 \pm 24.07$ & $27.67 \pm 24.20$ & 0.158 \\
\hline \multicolumn{6}{|l|}{ Type of relationship } \\
\hline Percentage household members & $14.00 \pm 12.48$ & $14.42 \pm 13.84$ & $21.19 \pm 20.71$ & $17.53 \pm 17.41$ & $<0.001$ \\
\hline Percentage family members & $55.94 \pm 22.34$ & $58.30 \pm 23.68$ & $61.78 \pm 27.22$ & $64.68 \pm 26.00$ & $<0.001$ \\
\hline Percentage friends & $30.05 \pm 20.30$ & $27.23 \pm 20.95$ & $22.76 \pm 21.06$ & $21.43 \pm 21.96$ & $<0.001$ \\
\hline Living alone (\%) & 14.7 & 17.4 & 17.1 & 20.2 & $<0.05$ \\
\hline Social participation $(\%)$ & 71.6 & 64.2 & 61.1 & 56.4 & $<0.001$ \\
\hline \multicolumn{6}{|c|}{ Functional characteristics of the social network } \\
\hline Informational supporta & $3.5 \pm 1.6$ & $3.2 \pm 1.7$ & $2.7 \pm 1.7$ & $2.7 \pm 1.7$ & $<0.001$ \\
\hline Emotional support (discomfort) a & $3.0 \pm 1.6$ & $2.6 \pm 1.6$ & $2.1 \pm 1.5$ & $2.2 \pm 1.5$ & $<0.001$ \\
\hline Emotional support (important decisions) ${ }^{\mathrm{a}}$ & $3.4 \pm 1.5$ & $2.9 \pm 1.6$ & $2.5 \pm 1.7$ & $2.4 \pm 1.5$ & $<0.001$ \\
\hline Practical support (jobs) ${ }^{\mathrm{a}}$ & $3.0 \pm 1.5$ & $2.7 \pm 1.5$ & $2.3 \pm 1.4$ & $2.4 \pm 1.4$ & $<0.001$ \\
\hline Practical support (sickness) a & $2.5 \pm 1.4$ & $2.2 \pm 1.4$ & $1.8 \pm 1.3$ & $1.9 \pm 1.3$ & $<0.001$ \\
\hline
\end{tabular}

Total study population n=2861, NGM normal glucose metabolism, T2DM type 2 diabetes mellitus (newly or previously diagnosed).

${ }^{1} p$-values were obtained from ANOVA ( $p$ for trend)/ Kruskal-Wallis/ Chi-Square tests.

${ }^{2}$ low education (no education, primary education, and lower vocational education) ${ }^{3}$ intermediate education (intermediate vocational education, higher secondary education, and vocational education) ${ }^{4}$ high education (higher professional education, university)

${ }^{a}$ Social support variables have a range from 0 to 5 . Values are means (SD), unless stated otherwise. 


\section{Association of structural characteristics of the social network with diabetes status}

Table 3 shows that each fewer network member reported (smaller network size) was associated with $12 \%$ higher odds of newly diagnosed T2DM and a $8 \%$ higher odds of previously diagnosed T2DM in women and an 10\% and 5\% higher odds of newly diagnosed T2DM and previously diagnosed T2DM in men, respectively, compared to NGM. Each 10\% drop in network members living within walking distance was associated with an 21\% higher odds of newly diagnosed T2DM and with an 9\% higher odds of previously diagnosed T2DM in women. Every additional 10\% of the network that was a household member was associated with a 25\% higher odds of newly diagnosed T2DM and an 15\% higher odds of previously diagnosed T2DM in women and a 29\% higher odds of newly diagnosed T2DM in men. Each $10 \%$ drop in network members who were friends was associated with a $14 \%$ higher odds of previously diagnosed T2DM in women. In women, no significant associations between living alone and diabetes were observed. In men, living alone was associated with a $59 \%$ higher odds of pre-diabetes (borderline significant), a $84 \%$ higher odds of newly diagnosed T2DM (borderline significant), and a $94 \%$ higher odds of previously diagnosed T2DM compared to NGM (table 3). A lack of social participation was associated with a $60 \%$ higher odds of pre-diabetes and a $112 \%$ higher odds of previously diagnosed T2DM in women, compared to NGM (table 3). In men, lack of social participation was associated with a $42 \%$ higher odds of having previously diagnosed T2DM. In figure 2, ORs for social participation and living alone were depicted.

\section{Association of functional characteristics of the social network with diabetes status}

One unit less emotional support on important decisions was associated with a $34 \%$ higher odds of newly diagnosed T2DM in women. One unit less practical support with small jobs was associated with a 16\% higher odds of previously diagnosed T2DM in women. One unit less practical support with sickness was associated with a $45 \%$ higher odds of newly diagnosed T2DM and a $21 \%$ higher odds of previously diagnosed T2DM in women, compared to NGM. In men, one unit less emotional support on important decisions was associated with a 19\% higher odds of newly diagnosed T2DM and a 11\% higher odds of previously diagnosed T2DM. One unit less practical support with small jobs was associated with a $21 \%$ higher odds of newly diagnosed T2DM in men. One unit less practical support with sickness was associated with a $25 \%$ higher odds of newly diagnosed T2DM and a $13 \%$ higher odds of previously diagnosed T2DM in men, compared to NGM. 


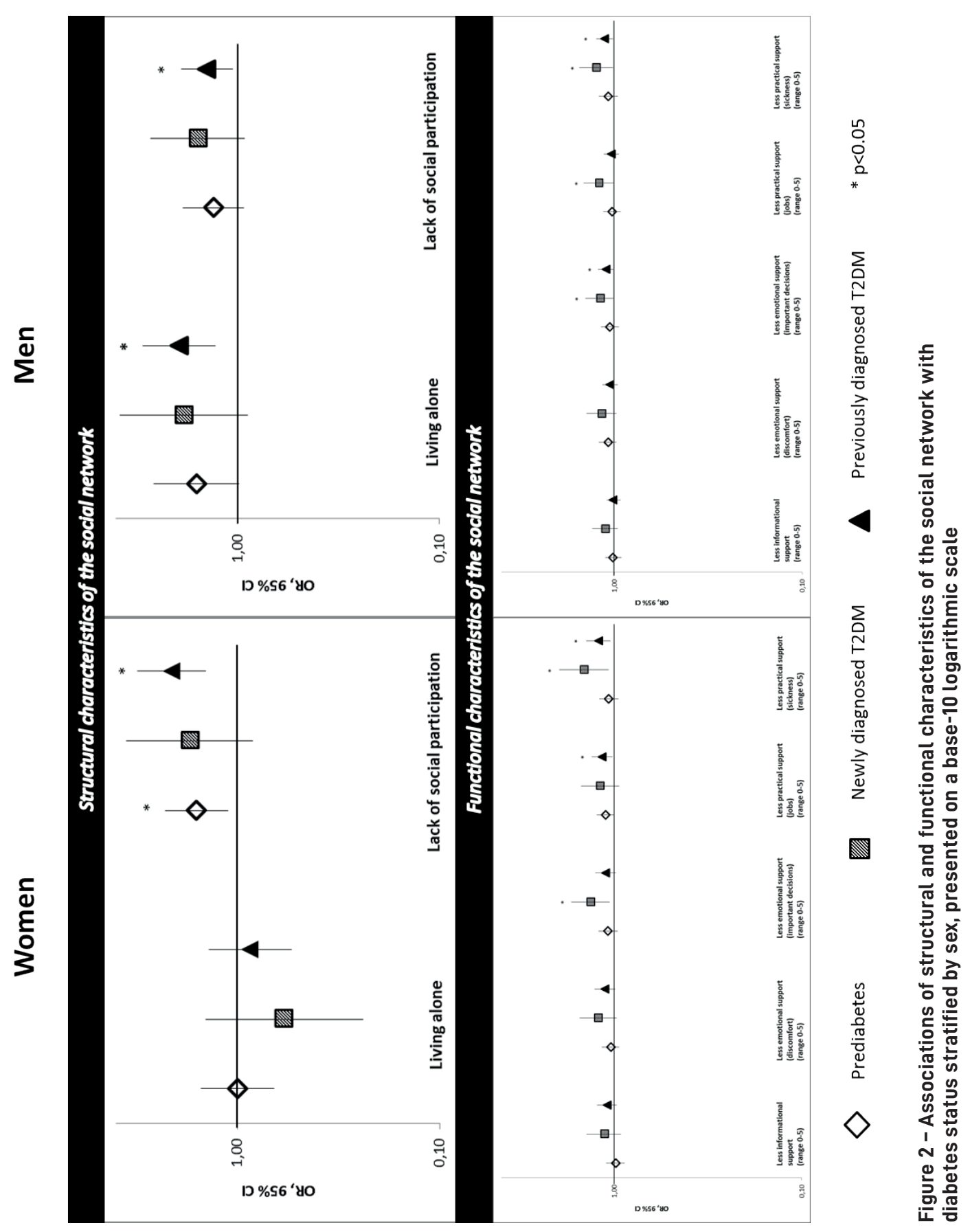


Table 3 - Associations of social network characteristics with diabetes status stratified by sex

\begin{tabular}{|c|c|c|c|c|c|c|}
\hline & & & utcome variabl & es stratified by & $\operatorname{sex}$ & \\
\hline & & Women & & & Men & \\
\hline & Pre- & Newly & Previously & Pre-diabetes & Newly & Previously \\
\hline & diabetes & diagnosed & diagnosed & $(n=229)$ & diagnosed & diagnosed \\
\hline Reference category; NGM & $(n=201)$ & T2DM (n=41) & T2DM (n=213) & & T2DM $(n=70)$ & T2DM $(n=484)$ \\
\hline & OR $(95 \% \mathrm{Cl})$ & OR $(95 \% \mathrm{Cl})$ & OR $(95 \% \mathrm{Cl})$ & OR $(95 \% \mathrm{Cl})$ & OR (95\%Cl) & OR $(95 \% \mathrm{Cl})$ \\
\hline
\end{tabular}

\section{Explanatory variables}

\begin{tabular}{|c|c|c|c|c|c|c|}
\hline \multicolumn{7}{|c|}{ Structural characteristics of the social network } \\
\hline Smaller network size (for every & 1.02 & $1.12^{* *}$ & $1.08^{* * *}$ & 0.99 & $1.10^{* *}$ & $1.05^{* *}$ \\
\hline fewer network member) & $(0.99-1.06)$ & $(1.03-1.22)$ & $(1.04-1.13)$ & $(0.95-1.02)$ & $(1.03-1.18)$ & $(1.02-1.09)$ \\
\hline \multicolumn{7}{|l|}{ Contact frequency } \\
\hline Total contacts per half year (for & 1.00 & 0.98 & $0.98^{*}$ & 1.00 & $0.98 \#$ & 0.99 \\
\hline every 10 additional contacts) & $(0.99-1.01)$ & $(0.96-1.01)$ & $(0.97-1.00)$ & $(0.99-1.01)$ & $(0.96-1.00)$ & $(0.98-1.02)$ \\
\hline Percentage of daily-weekly contact & 0.99 & 1.10 & $1.07 \#$ & 0.99 & $1.08 \#$ & 1.04 \\
\hline (for every additional $10 \%$ ) & $(0.92-1.05)$ & $(0.97-1.26)$ & $(0.99-1.15)$ & $(0.93-1.05)$ & $(0.98-1.19)$ & $(0.98-1.09)$ \\
\hline \multicolumn{7}{|l|}{ Proximity } \\
\hline \multicolumn{7}{|l|}{ Percentage of network members } \\
\hline living within walking distance (for & 1.03 & $1.21^{*}$ & $1.09^{*}$ & 0.98 & 1.02 & $1.05 \#$ \\
\hline every fewer 10\%) & $(0.95-1.11)$ & $(1.02-1.42)$ & $(1.01-1.19)$ & $(0.91-1.05)$ & $(0.91-1.13)$ & $(0.99-1.12)$ \\
\hline \multicolumn{7}{|l|}{ Type of relationship } \\
\hline Percentage household members & 1.06 & $1.25^{* *}$ & $1.15^{*}$ & 0.96 & $1.29^{* * *}$ & 0.99 \\
\hline (for every additional $10 \%$ ) & $(0.93-1.20)$ & $(1.05-1.50)$ & $(1.03-1.29)$ & $(0.85-1.08)$ & $(1.12-1.49)$ & $(0.90-1.09)$ \\
\hline Percentage family members (for & 1.02 & 1.06 & $1.08 \#$ & 0.98 & 1.04 & 1.03 \\
\hline every additional $10 \%)$ & $(0.94-1.10)$ & $(0.92-1.22)$ & $(0.99-1.17)$ & $(0.92-1.04)$ & $(0.94-1.16)$ & $(0.97-1.09)$ \\
\hline Percentage friends (for every $10 \%$ & 1.05 & 1.14 & $1.14^{* *}$ & 1.00 & 1.08 & 1.04 \\
\hline \multirow[t]{2}{*}{ less) } & $(0.96-1.14)$ & $(0.96-1.35)$ & $(1.04-1.26)$ & $(0.93-1.08)$ & $(0.95-1.22)$ & $(0.98-1.11)$ \\
\hline & 1.00 & 0.59 & 0.87 & $1.59 \#$ & $1.84 \#$ & $1.94^{* *}$ \\
\hline \multirow[t]{2}{*}{ Living alone } & $(0.66-1.52)$ & $(0.24-1.44)$ & $(0.54-1.39)$ & $(0.98-2.60)$ & $(0.89-3.81)$ & $(1.29-2.93)$ \\
\hline & $1.60^{* *}$ & 1.72 & $2.12^{* * *}$ & 1.31 & $1.57 \#$ & $1.42^{*}$ \\
\hline Lack of social participation & $(1.12-2.27)$ & $(0.84-3.55)$ & $(1.44-3.13)$ & $(0.93-1.85)$ & $(0.92-2.68)$ & $(1.06-1.90)$ \\
\hline \multicolumn{7}{|c|}{ Functional characteristics of the social network } \\
\hline & 0.98 & 1.13 & 1.09 & 1.02 & 1.12 & 1.02 \\
\hline Less informational supporta & $(0.88-1.10)$ & $(0.92-1.40)$ & $(0.97-1.23)$ & $(0.92-1.12)$ & $(0.96-1.31)$ & $(0.93-1.10)$ \\
\hline Less emotional support & 1.04 & $1.22 \#$ & $1.12 \#$ & 1.08 & $1.17 \#$ & 1.06 \\
\hline (discomfort) a & $(0.94-1.16)$ & $(0.97-1.53)$ & $(0.99-1.27)$ & $(0.98-1.21)$ & $(0.98-1.41)$ & $(0.96-1.16)$ \\
\hline Less emotional support (important & 1.08 & $1.34^{*}$ & $1.11 \#$ & 1.06 & $1.19^{*}$ & $1.11^{*}$ \\
\hline \multirow[t]{2}{*}{ decisions) $^{a}$} & $(0.96-1.21)$ & $(1.06-1.69)$ & $(0.98-1.26)$ & $(0.95-1.18)$ & $(1.00-1.43)$ & $(1.01-1.22)$ \\
\hline & 1.11\# & 1.19 & $1.16^{*}$ & 1.03 & $1.21^{*}$ & 1.04 \\
\hline \multirow[t]{2}{*}{ Less practical support (jobs)a } & $(1.00-1.24)$ & $(0.94-1.50)$ & $(1.02-1.32)$ & $(0.93-1.15)$ & $(1.01-1.46)$ & $(0.95-1.14)$ \\
\hline & 1.07 & $1.45^{*}$ & $1.21^{*}$ & 1.08 & $1.25^{*}$ & $1.13^{*}$ \\
\hline Less practical support (sickness) a & $(0.95-1.20)$ & $(1.07-1.96)$ & $(1.05-1.41)$ & $(0.96-1.21)$ & $(1.02-1.54)$ & $(1.02-1.25)$ \\
\hline
\end{tabular}

All analyses were adjusted for age, body mass index, educational level, employment status, alcohol consumption, smoking status, Hypertension, prior CVD and general health (SF36). NGM, normal glucose metabolism; T2DM, type 2 diabetes mellitus. ${ }^{a}$ Social support variables have a range from 0 to 5 . OR; Odds ratio, $95 \% \mathrm{Cl} ; 95 \%$ Confidence interval. $\# p \leq 0.1^{*} p \leq 0.05^{* *} p \leq 0.01^{* * *} p \leq 0.001$ 


\section{Discussion}

This study is the first to assess the associations between T2DM and a broad range of functional and structural network characteristics in adults. The study shows that more socially isolated individuals (smaller social network size) more frequently had newly diagnosed and previously diagnosed T2DM, while this association was not observed with pre-diabetes. In women, proximity and the type of relationship was associated with newly diagnosed and previously diagnosed T2DM. A lack of social participation was associated with pre-diabetes as well as with previously diagnosed T2DM in women, and with previously diagnosed T2DM in men. Living alone was associated with higher odds of previously diagnosed T2DM in men, but not in women. Less emotional support related to important decisions was associated with newly diagnosed T2DM in women, and both newly and previously diagnosed T2DM in men. Less practical support related to jobs was associated with previously diagnosed T2DM in women and newly diagnosed T2DM in men. Less practical support for sickness was associated with newly diagnosed and previously diagnosed T2DM in men and women. These associations were not observed in pre-diabetes.

All associations between social network characteristics and diabetes status were independent of $B M I$, educational level, employment status, alcohol consumption, smoking status, general health status and chronic conditions as prior CVD and hypertension.

\section{Structural social network characteristics}

The present study showed that social isolation, indicated by a smaller social network size, was associated with higher odds of newly diagnosed and previously diagnosed T2DM in men and women. This finding is in line with longitudinal analyses conducted by Altevers et al. (2015), and Lukaschek et al. (2017) who found that poor structural support (measured by Social Network index [SNI], including a measure of social network size) increased the risk of T2DM [9, 27]. In addition, our data show that a smaller social network size was only associated with T2DM, not with pre-diabetes. This is also consistent with longitudinal data, which did not find significant associations of social integration, including structural characteristics, with pre-diabetes [12]. Furthermore, we as well as Gallo et al. (2015) observed associations between structural network characteristics and T2DM among both sexes [13], while Altevers et al. (2015) found this association among men, but not among women [9]. A possible explanation for this discrepancy is that Altevers et al. (2015) limited the variability in their sample by dichotomizing the Social Network Index (SNI), while we and Gallo et al. (2015) used a continuous scale. Therefore, their non-significant findings in women may be attributable to low power [9].

In women, higher percentages of network members living within walking distance and higher percentages household members were associated with newly and previously diagnosed T2DM. Similarly, a network composed of fewer friends was associated with higher odds of previously diagnosed T2DM 
in women, suggesting that the smaller network size in T2DM is largely attributable to having less friends than those with NGM. The associations of proximity and the type of relationship with T2DM in women indicate that a network that is centralized to those with the closest relationships, with less network members at a social and geographical distance, is associated with T2DM. In men, we observed that higher percentages of household members were associated with newly diagnosed T2DM. Furthermore, these associations were again not observed in pre-diabetes.

As we are the first to address the composition of the social network in terms of proximity and type of relationship in relation to T2DM, and as significant associations have mostly been observed for women, further research is needed to corroborate our findings.

Living alone was associated with higher odds of newly diagnosed and previously diagnosed T2DM in men, but not in women. This finding is consistent with previous longitudinal studies that identified living alone as a risk factor for T2DM [11, 27], while having a partner decreases the risk for T2DM [12] in men but not in women. Moreover, similar to Hilding et al. (2015), we only found borderline significant associations between living alone and pre-diabetes [12]. However, these non-significant risk estimates may be attributable to a low power, as we had a relatively small sample to address this association (less than 40 men with pre-diabetes were living alone).

The lack of social participation was associated with pre-diabetes in women and with previously diagnosed T2DM in both men and women. In longitudinal research, participation in social activities has been shown to decrease the risk of pre-diabetes and T2DM in women and the risk of pre-diabetes in men [12]. However, in this cross-sectional study, we cannot exclude the possibility that early changes in glucose metabolism may cause non-specific complaints such as tiredness and feeling unwell, which may explain why individuals chose to limit their social participation. In either scenario, social participation may serve as a target for intervention or an indicator suitable for diabetes prevention strategies.

\section{Functional social network characteristics}

In the present study, we observed that less emotional support with important decisions was associated with newly diagnosed T2DM in women, and both newly and previously diagnosed T2DM in men. Less practical support with small jobs was associated with previously diagnosed T2DM in women and newly diagnosed T2DM in men. Less practical support for sickness was associated with newly diagnosed and previously diagnosed T2DM in men and women. Both Norberg et al. (2007) and Jones et al. (2015) showed that low emotional support was associated with T2DM in women [7] and older adults [8], although their methods used to assess functional support were less detailed. The longitudinal results from Norberg et al. (2007) suggest that low functional support increases the risk of T2DM [7].

To our knowledge, this study is the first to assess the association of a broad range of functional support measures with pre-diabetes, newly diagnosed T2DM and previously diagnosed T2DM. Our re- 
sults indicate that emotional support in important decisions, and practical support with small jobs and in sickness were important characteristics that should be addressed in T2DM prevention strategies. However, in this cross-sectional study, we cannot assess whether participants received an absolutely lower level of functional support, or whether they perceive it as less adequate to their needs (that means relatively lower), and therefore, their satisfaction with functional support is lower. Recently, it has been shown that low social network satisfaction is associated with increased risk of T2DM [27].

\section{Strengths \& Limitations}

A major strength of the current study was the measurement of structural and functional characteristics with the use of a name generator, one of the best known, most detailed and most widely used instruments to examine ego-centered network data [28]. This resulted in a much broader range of structural and functional social network characteristics than assessed in previous studies. Next, we were able to examine the associations of structural and functional network characteristics in individuals with pre-diabetes, newly diagnosed and previously diagnosed T2DM compared to those with NGM. The associations of pre-diabetes and newly diagnosed T2DM have rarely been studied before. Moreover, we adjusted the analyses for several different variables, i.e. age, body mass index, educational level, employment status, smoking status, alcohol consumption, general health and chronic medical conditions, showing robust results, which makes residual confounding unlikely. Finally, the population-based design of The Maastricht Study and its size were key assets [22].

A few limitations should also be mentioned. The study is cross-sectional in nature, and therefore, the possibility of reverse causality cannot be excluded. Furthermore, as we performed multiple statistical tests, our analyses may include false positive results. However, the majority of significant associations had a $p$-value $\leq 0.01$ or even $\leq 0.001$, limiting the chance of false positive findings. Additionally, the present study population consisted of relatively healthy participants, as is common in population-based cohort studies, and it is possible that we did not include those in the population who were the most socially isolated. Therefore, we may have underestimated the effect sizes.

\section{Implications}

Targeting social network characteristics may prove a promising prevention strategy for T2DM. More socially isolated individuals (smaller network size) more often had T2DM. Broadening their network should be encouraged, as we have shown that a smaller social network size was associated with T2DM in both men and women. Moreover, social participation was associated with pre-diabetes and previously diagnosed T2DM, stimulating participants to became members of a club may also be considered in future intervention development. In addition, social participation may be used as an indicator in dia- 
betes prevention strategies. Moreover, interventions aiming to generate behavioral change (e.g., physical activity) may also tailor to the social network of the participant, as it has been shown that network targeting can be used to increase the adoption of specific public health interventions [17]. In addition, as men living alone seem to be at a higher risk for the development of T2DM, they should be indicated as high-risk group.

Moreover, targeting social network characteristics may also have benefits for other chronic conditions, as it has been shown that most of those with a long-term disorder are multimorbid [29], and social network characteristics have been found to associate with cardiovascular, endocrine, and immune function [30]. In addition, social isolation and living alone have been found to increase the likelihood of mortality [31].

\section{Conclusions}

To conclude, this study was the first to assess a broad range of structural and functional social network characteristics and their associations with normal glucose metabolism, pre-diabetes, newly diagnosed T2DM and previously diagnosed T2DM in a large sample of 40- to 75-year-old adults. These results were independent of BMI, educational level, employment status, alcohol consumption, smoking status, general health status and chronic conditions as prior CVD and hypertension. Men and women who were more socially isolated, and who received less emotional and practical support, more frequently had newly and previously diagnosed T2DM, while this was not observed in individuals with pre-diabetes. In women, proximity and the type of relationship was associated with newly and previously diagnosed T2DM. A lack of social participation was associated with pre-diabetes in women, as well as with previously diagnosed T2DM in both sexes. Living alone was associated with higher odds of previously diagnosed T2DM in men, but not in women. This study shows that several aspects of structural and functional characteristics of the social network were associated with newly and previously diagnosed T2DM, partially different for men and women. These results may provide useful targets for T2DM prevention efforts. 


\section{References}

1. Wild S, Roglic G, Green A, Sicree R, King H: Global prevalence of diabetes estimates for the year 2000 and projections for 2030. Diabetes care 2004, 27(5):1047-1053.

2. Seshasai $S R$, Kaptoge $S$, Thompson A, Di Angelantonio E, Gao P, Sarwar N, Whincup PH, Mukamal KJ, Gillum RF, Holme I et al: Diabetes mellitus, fasting glucose, and risk of cause-specific death. The New England journal of medicine 2011, 364(9):829-841.

3. Barnett K, Mercer SW, Norbury M, Watt G, Wyke S, Guthrie B: Epidemiology of multimorbidity and implications for health care, research, and medical education: a cross-sectional study. The Lancet 2012, 380(9836):37-43.

4. Kahn SE, Hull RL, Utzschneider KM: Mechanisms linking obesity to insulin resistance and type 2 diabetes. Nature 2006, 444(7121):840-846.

5. Sigal RJ, Kenny GP, Wasserman DH, Castaneda-Sceppa C, White RD: Physical activity/exercise and Type 2 diabetes $A$ consensus statement from the American Diabetes Association. Diabetes care 2006, 29(6):1433-1438.

6. Knol M, Twisk J, Beekman A, Heine R, Snoek F, Pouwer F: Depression as a risk factor for the onset of type 2 diabetes mellitus. A meta-analysis. Diabetologia 2006, 49(5):837-845.

7. Norberg $M$, Stenlund $H$, Lindahl $B$, Andersson C, Eriksson JW, Weinehall L: Work stress and low emotional support is associated with increased risk of future type 2 diabetes in women. Diabetes Research and Clinical Practice 2007, 76(3):368-377.

8. Jones SM, Amtmann D, Gell NM: A psychometric examination of multimorbidity and mental health in older adults. Aging \& mental health 2015:1-9.

9. Altevers J, Lukaschek K, Baumert J, Kruse J, Meisinger C, Emeny R, Ladwig K: Poor structural social support is associated with an increased risk of Type 2 diabetes mellitus: findings from the MONICA/KORA Augsburg cohort study. Diabetic Medicine 2015.
10. Lidfeldt J, Nerbrand C, Samsioe G, Agardh C-D: Women living alone have an increased risk to develop diabetes, which is explained mainly by lifestyle factors. Diabetes Care 2005, 28(10):2531-2536.

11. Meisinger $\mathrm{C}$, Kandler $\mathrm{U}$, Ladwig K-H: Living alone is associated with an increased risk of type 2 diabetes mellitus in men but not women from the general population: the MONICA/ KORA Augsburg Cohort Study. Psychosomatic medicine 2009, 71(7):784-788.

12. Hilding A, Shen $C$, Östenson C-G: Social network and development of prediabetes and type 2 diabetes in middle-aged Swedish women and men. Diabetes Research and Clinical Practice 2015, 107(1):166-177.

13. Gallo LC, Fortmann AL, McCurley JL, Isasi CR, Penedo FJ, Daviglus ML, Roesch SC, Talavera GA, Gouskova N, Gonzalez F, 2nd et al: Associations of structural and functional social support with diabetes prevalence in U.S. Hispanics/Latinos: results from the HCHS/SOL Sociocultural Ancillary Study. Journal of behavioral medicine 2015, 38(1):160-170.

14. Hill PL, Weston SJ, Jackson JJ: Connecting social environment variables to the onset of major specific health outcomes. Psychology \& Health 2014, 29(7):753-767.

15. Heaney CA, Israel BA: Social networks and social support. Health behavior and health education: Theory, research, and practice 2008, 4:189-210.

16. Valente TW: Social networks and health: Models, methods, and applications. New York: Oxford 2010.

17. Kim DA, Hwong AR, Stafford D, Hughes DA, O'Malley AJ, Fowler JH, Christakis NA: Social network targeting to maximise population behaviour change: a cluster randomised controlled trial. The Lancet 2015, 386(9989):145-153.

18. Shaya FT, Chirikov VV, Howard D, Foster C, Costas J, Snitker S, Frimpter J, Kucharski K: Effect of social networks intervention in type 
2 diabetes: a partial randomised study. Journal of epidemiology and community health 2014 , 68(4):326-332.

19. van Dam HA, van der Horst FG, Knoops L, Ryckman RM, Crebolder HF, van den Borne BH: Social support in diabetes: a systematic review of controlled intervention studies. Patient education and counseling 2005, 59(1):1-12.

20. Bos-Touwen I, Schuurmans $M$, Monninkhof EM, Korpershoek Y, Spruit-Bentvelzen L, Ertugrul-van der Graaf I, de Wit N, Trappenburg J: Patient and Disease Characteristics Associated with Activation for Self-Management in Patients with Diabetes, Chronic Obstructive Pulmonary Disease, Chronic Heart Failure and Chronic Renal Disease: A Cross-Sectional Survey Study. Plos One 2015, 10(5).

21. Koetsenruijter J, van Lieshout J, Lionis C, Portillo MC, Vassilev I, Todorova E, Foss C, Gil MS, Knutsen IR, Angelaki A: Social support and health in diabetes patients: an observational study in six European countries in an era of austerity. PloS one 2015, 10(8):e0135079.

22. Schram MT, Sep SJ, van der Kallen CJ, Dagnelie PC, Koster A, Schaper N, Henry RM, Stehouwer CD: The Maastricht Study: an extensive phenotyping study on determinants of type 2 diabetes, its complications and its comorbidities. European journal of epidemiology 2014, 29(6):439-451.

23. World Health Organization: Definition and diagnosis of diabetes mellitus and intermediate hyperglycaemia. In. Geneva, Switserland; 2006.

24. McCallister L FC: A procedure for surveying personal networks. Sociological Methods and Research 1978:131-148.

25. van der Gaag M: Measurement of individual social capital. In. Groningen: ICS dissertation; 2005.

26. Ware JE, Koskinski M, Keller SD: SF-36 physical and mental health summary scales: A user's manual 2nd ed. Boston MA: The Health Institute; 1994.
27. Lukaschek K, Baumert J, Kruse J, Meisinger C, Ladwig KH: Sex differences in the association of social network satisfaction and the risk for type 2 diabetes. BMC Public Health 2017, 17(1):379.

28. Marin A: Are respondents more likely to list alters with certain characteristics?: Implications for name generator data. Social Networks 2004, 26(4):289-307.

29. Barnett K, Mercer SW, Norbury M, Watt G, Wyke $S$, Guthrie B: Epidemiology of multimorbidity and implications for health care, research, and medical education: a cross-sectional study. The Lancet, 380(9836):37-43.

30. Uchino BN, Cacioppo JT, Kiecolt-Glaser JK: The Relationship Between Social Support and Physiological Processes: A Review With Emphasis on Underlying Mechanisms and Implications for Health. Psychological Bulletin 1996, 119(3):488-531.

31. Holt-Lunstad J, Smith TB, Baker M, Harris T, Stephenson D: Loneliness and social isolation as risk factors for mortality: a meta-analytic review. Perspectives on psychological science : a journal of the Association for Psychological Science 2015, 10(2):227-237 
Supplemental material to chapter 4 


\section{Supplemental file 1. A detailed description of the social network questionnaire.}

\section{Social network questionnaire}

The participants received a questionnaire with seven questions on different types of contacts and were asked to name a maximum of five persons (network members). The questions concerned 1) persons who advised them on problems, 2) persons who could offer them practical help if they were sick, 3) persons who provided emotional support when they were feeling unwell, 4) persons who helped them with small and larger jobs around the house, 5) persons they visited for social purposes or with whom they could sometimes get together, and 6) persons with whom they could discuss important matters, and finally, 7) the participants were asked to name a maximum number of ten additional persons who were also important to them. In total, participants could name a maximum number of 40 network members. After every question and for each network member named, they were asked to indicate their frequency of contact with this person over the last six months (daily or weekly, monthly, quarterly, and half-yearly). This was asked for all seven types of contacts. Moreover, the participants were asked to identify their relationship to this person (e.g., partner, sister, friend, neighbor, etc. (28 options)), how far away this person lived (walking distance, less than half an hour away by car, more than half an hour away by car, more distant) and to indicate this person's sex and actual or estimated age.

The participants were also asked whether they were a member of a club (yes/no) and, if so, to identify the club(s) (sports club, religious group, volunteer organization, discussion group, self-support group, Internet club, or another organization) and how often they frequented it (daily/weekly, monthly, occasionally). 


\section{Supplemental Table 1-Associations of social network characteristics with diabetes status stratified} by sex, additionally adjusted for hypertension, prior CVD and general health status (SF36)

\begin{tabular}{|c|c|c|c|c|c|c|}
\hline \multirow{3}{*}{ Reference category; NGM } & \multicolumn{3}{|c|}{ Women ( $n=1366)$} & \multicolumn{3}{|c|}{ Men ( $n=1433)$} \\
\hline & $\begin{array}{c}\text { Pre- } \\
\text { diabetes } \\
(n=195)\end{array}$ & $\begin{array}{c}\text { Newly } \\
\text { diagnosed } \\
\text { T2DM ( } n=41)\end{array}$ & $\begin{array}{c}\text { T2DM } \\
(n=207)\end{array}$ & $\begin{array}{c}\text { Pre- } \\
\text { diabetes } \\
(\mathrm{n}=223)\end{array}$ & $\begin{array}{c}\text { Newly } \\
\text { diagnosed } \\
\text { T2DM }(n=69)\end{array}$ & $\begin{array}{c}\text { T2DM } \\
(n=471)\end{array}$ \\
\hline & OR $(95 \% \mathrm{CI})$ & OR $(95 \% \mathrm{Cl})$ & OR $(95 \% \mathrm{Cl})$ & OR $(95 \% \mathrm{Cl})$ & OR $(95 \% \mathrm{CI})$ & OR $(95 \% \mathrm{CI})$ \\
\hline \multicolumn{7}{|c|}{ Structural characteristics of the social network } \\
\hline $\begin{array}{l}\text { Smaller network size (for every } \\
\text { fewer network member) }\end{array}$ & $\begin{array}{r}1.02 \\
(0.99-1.06)\end{array}$ & $\begin{array}{r}1.11^{* *} \\
(1.03-1.21)\end{array}$ & $\begin{array}{r}1.10^{* * *} \\
(1.05-1.15)\end{array}$ & $\begin{array}{r}0.99 \\
(0.96-1.02)\end{array}$ & $\begin{array}{r}1.11^{* *} \\
(1.03-1.18)\end{array}$ & $\begin{array}{r}1.06^{* * *} \\
(1.02-1.09)\end{array}$ \\
\hline \multicolumn{7}{|l|}{ Contact frequency } \\
\hline $\begin{array}{l}\text { Total contacts per half year (for } \\
\text { every } 10 \text { additional contacts) }\end{array}$ & $\begin{array}{r}1.00 \\
(0.99-1.01)\end{array}$ & $\begin{array}{r}0.99 \\
(0.96-1.01)\end{array}$ & $\begin{array}{r}0.98^{* *} \\
(0.97-0.99)\end{array}$ & $\begin{array}{r}1.00 \\
(0.99-1.01)\end{array}$ & $\begin{array}{r}0.98^{*} \\
(0.96-1.00)\end{array}$ & $\begin{array}{r}0.99 \\
(0.98-1.00)\end{array}$ \\
\hline $\begin{array}{l}\text { Percentage of daily-weekly } \\
\text { contact (for every additional } \\
10 \% \text { ) }\end{array}$ & $\begin{array}{r}0.99 \\
(0.93-1.06)\end{array}$ & $\begin{array}{r}1.09 \\
(0.96-1.25)\end{array}$ & $\begin{array}{r}1.07 \\
(1.00-1.15)\end{array}$ & $\begin{array}{r}1.00 \\
(0.94-1.06)\end{array}$ & $\begin{array}{r}1.08 \\
(0.99-1.19)\end{array}$ & $\begin{array}{r}1.04 \\
(0.99-1.10)\end{array}$ \\
\hline \multicolumn{7}{|l|}{ Proximity } \\
\hline $\begin{array}{l}\text { Percentage of network members } \\
\text { living within walking distance } \\
\text { (for every fewer } 10 \% \text { ) }\end{array}$ & $\begin{array}{r}1.04 \\
(0.96-1.12)\end{array}$ & $\begin{array}{r}1.21^{*} \\
(1.02-1.42)\end{array}$ & $\begin{array}{r}1.08^{*} \\
(1.00-1.17)\end{array}$ & $\begin{array}{r}0.97 \\
(0.91-1.04)\end{array}$ & $\begin{array}{r}1.02 \\
(0.92-1.14)\end{array}$ & $\begin{array}{r}1.05 \\
(0.99-1.11)\end{array}$ \\
\hline \multicolumn{7}{|l|}{ Type of relationship } \\
\hline $\begin{array}{l}\text { Percentage household members } \\
\text { (for every additional } 10 \% \text { ) }\end{array}$ & $\begin{array}{r}1.06 \\
(0.93-1.20)\end{array}$ & $\begin{array}{r}1.25^{* *} \\
(1.05-1.49)\end{array}$ & $\begin{array}{r}1.16^{* *} \\
(1.04-1.31)\end{array}$ & $\begin{array}{r}0.95 \\
(0.84-1.07)\end{array}$ & $\begin{array}{r}1.26^{* * *} \\
(1.09-1.45)\end{array}$ & $\begin{array}{r}0.99 \\
(0.98-1.09)\end{array}$ \\
\hline $\begin{array}{l}\text { Percentage family members (for } \\
\text { every additional } 10 \% \text { ) }\end{array}$ & $\begin{array}{r}1.02 \\
(0.94-1.10)\end{array}$ & $\begin{array}{r}1.07 \\
(0.93-1.23)\end{array}$ & $\begin{array}{r}1.07 \\
(0.99-1.16)\end{array}$ & $\begin{array}{r}0.97 \\
(0.91-1.04)\end{array}$ & $\begin{array}{r}1.03 \\
(0.93-1.14)\end{array}$ & $\begin{array}{r}1.03 \\
(0.98-1.09)\end{array}$ \\
\hline $\begin{array}{l}\text { Percentage friends (for every } \\
10 \% \text { less) }\end{array}$ & $\begin{array}{r}1.04 \\
(0.96-1.13)\end{array}$ & $\begin{array}{r}1.13 \\
(0.96-1.34)\end{array}$ & $\begin{array}{r}1.14^{* *} \\
(1.04-1.25)\end{array}$ & $\begin{array}{r}1.00 \\
(0.93-1.07)\end{array}$ & $\begin{array}{r}1.07 \\
(0.95-1.21)\end{array}$ & $\begin{array}{r}1.05 \\
(0.99-1.12)\end{array}$ \\
\hline Living alone (\%) & $\begin{array}{r}1.05 \\
(0.69-1.58)\end{array}$ & $\begin{array}{r}0.59 \\
(0.24-1.44)\end{array}$ & $\begin{array}{r}0.99 \\
(0.63-1.56)\end{array}$ & $\begin{array}{r}1.59 \\
(0.98-2.58)\end{array}$ & $\begin{array}{r}1.98 \\
(0.98-4.02)\end{array}$ & $\begin{array}{r}2.03^{* * *} \\
(1.34-3.05)\end{array}$ \\
\hline No club membership (\%) & $\begin{array}{r}1.64^{* *} \\
(1.15-2.32)\end{array}$ & $\begin{array}{r}1.66 \\
(0.81-3.41)\end{array}$ & $\begin{array}{r}2.42^{* * *} \\
(1.66-3.54)\end{array}$ & $\begin{array}{r}1.28 \\
(0.91-1.80)\end{array}$ & $\begin{array}{r}1.54 \\
(0.90-2.63)\end{array}$ & $\begin{array}{r}1.44^{* *} \\
(1.08-1.93)\end{array}$ \\
\hline \multicolumn{7}{|c|}{ Functional characteristics of the social network } \\
\hline Less informational support ${ }^{\mathrm{a}}$ & $\begin{array}{r}0.98 \\
(0.88-1.09)\end{array}$ & $\begin{array}{r}1.11 \\
(0.90-1.36)\end{array}$ & $\begin{array}{r}1.12^{*} \\
(1.00-1.25)\end{array}$ & $\begin{array}{r}1.01 \\
(0.92-1.11)\end{array}$ & $\begin{array}{r}1.12 \\
(0.96-1.31)\end{array}$ & $\begin{array}{r}1.02 \\
(0.94-1.11)\end{array}$ \\
\hline $\begin{array}{l}\text { Less emotional support } \\
\text { (discomfort) }^{a}\end{array}$ & $\begin{array}{r}1.03 \\
(0.92-1.14)\end{array}$ & $\begin{array}{r}1.19 \\
(0.95-1.49)\end{array}$ & $\begin{array}{r}1.14^{*} \\
(1.01-1.29)\end{array}$ & $\begin{array}{r}1.08 \\
(0.97-1.20)\end{array}$ & $\begin{array}{r}1.19 \\
(1.00-1.44)\end{array}$ & $\begin{array}{r}1.05 \\
(0.96-1.16)\end{array}$ \\
\hline $\begin{array}{l}\text { Less emotional support } \\
\text { (important decisions) }^{\mathrm{a}}\end{array}$ & $\begin{array}{r}1.07 \\
(0.96-1.20)\end{array}$ & $\begin{array}{r}1.29^{*} \\
(1.03-1.63)\end{array}$ & $\begin{array}{r}1.15^{*} \\
(1.02-1.31)\end{array}$ & $\begin{array}{r}1.05 \\
(0.95-1.17)\end{array}$ & $\begin{array}{r}1.20^{*} \\
(1.00-1.43)\end{array}$ & $\begin{array}{r}1.13^{* *} \\
(1.03-1.23)\end{array}$ \\
\hline Less practical support (jobs)a & $\begin{array}{r}1.10 \\
(0.98-1.23)\end{array}$ & $\begin{array}{r}1.17 \\
(0.93-1.48)\end{array}$ & $\begin{array}{r}1.18^{* *} \\
(1.04-1.34)\end{array}$ & $\begin{array}{r}1.03 \\
(0.92-1.14)\end{array}$ & $\begin{array}{r}1.21^{*} \\
(1.01-1.46)\end{array}$ & $\begin{array}{r}1.04 \\
(0.95-1.14)\end{array}$ \\
\hline $\begin{array}{l}\text { Less practical support (sickness) } \\
\text { a }\end{array}$ & $\begin{array}{r}1.04 \\
(0.93-1.18) \\
\end{array}$ & $\begin{array}{r}1.41^{*} \\
(1.05-1.89) \\
\end{array}$ & $\begin{array}{r}1.24^{* *} \\
(1.07-1.43) \\
\end{array}$ & $\begin{array}{r}1.07 \\
(0.96-1.21) \\
\end{array}$ & $\begin{array}{r}1.28^{*} \\
(1.04-1.57) \\
\end{array}$ & $\begin{array}{r}1.15^{* *} \\
(1.03-1.27) \\
\end{array}$ \\
\hline
\end{tabular}

All analyses were adjusted for age, body mass index, educational level, employment status, hypertension, prior CVD, and general health.

NGM, normal glucose metabolism; T2DM, type 2 diabetes mellitus. ${ }^{a}$ Social support variables have a range from 1 to 5 . OR; Odds ratio, $95 \% \mathrm{Cl} ; 95 \%$ Confidence interval. ${ }^{*} p \leq 0.05^{* *} p \leq 0.01{ }^{* * *} p \leq 0.001$. Data on hypertension, prior CVD and general health were missing in 168 participants. 


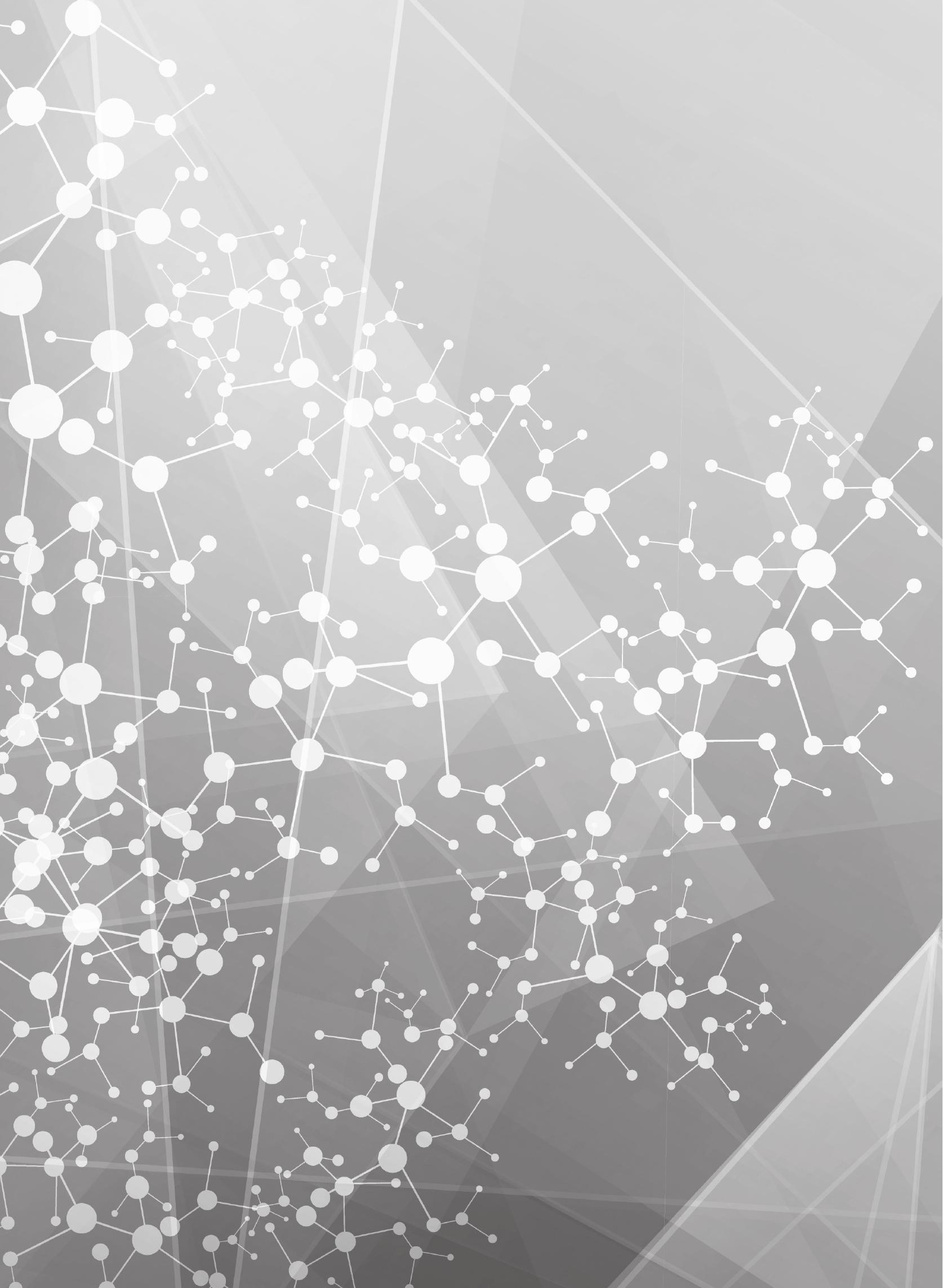




\section{Chapter 5}

Social network characteristics are associated with type 2 diabetes complications - The Maastricht Study -

Stephanie Brinkhues, Nicole H.T.M. Dukers-Muijrers, Christian J.P.A. Hoebe, Carla J.H. van der Kallen, Annemarie Koster, Ronald M.A. Henry, Coen D.A. Stehouwer, Paul H.M. Savelkoul, Nicolaas C. Schaper, Miranda T. Schram 


\section{Abstract}

Objective: The relation between clinical complications and social network characteristics in type 2 diabetes mellitus (T2DM) has hardly been studied. Therefore, we examined the associations of social network characteristics with macro- and microvascular complications in T2DM and investigated whether these associations were independent of glycemic control, quality of life, and well-known cardiovascular risk factors.

Research design and methods: Participants with T2DM originated from the Maastricht Study, a population-based cohort study ( $n=797$, mean age 62.767 .6 years, 31\% female). Social network characteristics were assessed through a name generator questionnaire. Diabetes status was determined by an oral glucose tolerance test. Macro- and microvascular complications were defined as a history of cardiovascular disease and the presence of impaired vibratory sense and/or retinopathy and/or albuminuria, respectively. We assessed cross-sectional associations of social network characteristics with macro- and microvascular complications by use of logistic regression adjusted for age, HbA1c, quality of life, and cardiovascular risk factors, stratified for sex.

Results: A smaller network size, higher percentages of family members, and lower percentages of friends were independently associated with macrovascular complications

in both men and women. A smaller network size and less informational support were independently associated with microvascular complications in women, but not in men.

Conclusions: This study shows that social network characteristics were associated with macro and microvascular complications. Health care professionals should be aware of the association of the social network with T2DM outcomes. In the development of strategies to reduce the burden of disease, social network characteristics should be taken into account. 


\section{Introduction}

Macro- and microvascular complications of type 2 diabetes mellitus (T2DM) are associated with increased disability, reduced quality of life (QoL), reduced life expectancy, and substantial economic impact for society [1]. Multiple studies have shown the beneficial effects of improved blood glucose levels, blood pressure, cholesterol levels, smoking cessation, and other lifestyle behaviors on the risk of complications [1-3]. Recent data suggest that there may be an important influence of the social network on diabetes self management and complications [4-12]. Available studies in T2DM have either focused on functional network characteristics [4,5], which include measures on social support, such as emotional support, practical support, or informational support [13], or on structural network characteristics, which refer to network size, contact frequency, or the type of relationship within the social network [14,15]. For instance, higher levels of social support, a functional network characteristic, have been associated with lower blood pressure, lower LDL cholesterol, better glycemic control, and improved lifestyle behaviors [4-6]. In addition, low levels of social support have been associated with the prevalence of T2DM [16], as well as with lower QoL and higher mortality in T2DM [10,11]. Data from the general population have convincingly shown that a lack of social support is associated with an increased cardiovascular disease (CVD) risk [17].

Structural characteristics, such as a smaller network size, have also been associated with the prevalence of T2DM [16]. In the general population, a smaller network has been associated with the incidence of stroke [18] and mortality [19], whereas in patients with a chronic condition, a wider variety of social interactions was found to support physical health and emotional well-being [7]. Furthermore, in patients with T2DM with complications, a smaller network size has been associated with the incidence of chronic kidney disease and mortality [12]. Previous studies highlight the potential of social network interventions to lower the risk of diabetes complications via improved glycemic control [20]. However, evidence on the direct association of functional and structural network characteristics with T2DM complications is scarce.

In view of the above, we assessed the associations of functional and structural social network characteristics with macro- and microvascular complications in T2DM and investigated whether these associations were independent of glycemic control, QoL, and cardiovascular risk factors.

\section{Research design and methods}

\section{Study population}

We used data from The Maastricht Study, an observational prospective population-based cohort study. The rationale and methodology have been described previously [21]. In brief, the study focuses on the etiology, pathophysiology, complications and comorbidities of type 2 diabetes mellitus (T2DM) and is characterized by an extensive phenotyping approach. Eligible for participation were all indi- 
viduals aged between 40 and 75 years and living in the southern part of the Netherlands. Participants were recruited through mass media campaigns and from the municipal registries and the regional Diabetes Patient Registry via mailings. Recruitment was stratified according to known T2DM status, with an oversampling of individuals with T2DM, for reasons of efficiency. The present report includes cross-sectional data from the first 3451 participants, who completed the baseline survey between November 2010 and September 2013. The examinations of each participant were performed within a time window of three months. The study has been approved by the institutional medical ethical committee (NL31329.068.10) and the Minister of Health, Welfare and Sports of the Netherlands (Permit 131088-105234-PG). All participants gave written informed consent. In the present report, all participants with type 2 diabetes ( $n=975$ ) were included. Complete data on social network, potential confounders and macro- or microvascular complications were available in 797 participants. The reasons for missing data were incomplete questionnaires ( $n=97)$, and missing data on covariates and macro- or microvascular complications ( $n=81$ ) (see supplementary Figure $\mathrm{S} 1$ ).

\section{Measurements}

\section{Diabetes status}

To determine T2DM, all participants (except those who used insulin) underwent a standardized $75 \mathrm{~g}$ oral glucose tolerance test (OGTT) after an overnight fast [21]. T2DM was defined according to the World Health Organization 2006 criteria [22]. Individuals on diabetes medication, but without type 1 diabetes mellitus, were considered to have T2DM [21].

\section{Macrovascular complications}

Macrovascular complications were defined as a self-reported history of myocardial infarction, and/or cerebrovascular infarction or hemorrhage, and/or percutaneous artery angioplasty of the coronary arteries, abdominal arteries, peripheral arteries or carotid artery, and/or vascular surgery on the coronary, abdominal, peripheral or carotid arteries.

\section{Microvascular complications}

Microvascular complications were defined as the presence of diabetic retinopathy and/or impaired vibratory sense and/or albuminuria. To determine the presence of diabetic retinopathy, fundus photography of both eyes was performed. All fundus photographs were made with a non-mydriatic auto fundus camera (Model AFC-230, Nidek, Gamagori, Japan), and evaluated by a trained and experienced grader in a masked fashion and in case of any doubt or an abnormal finding, the fundus photograph was discussed with a medical retina specialist. Based on these fundus photographs, the presence of diabetic retinopathy was graded according to the Diabetic Retinopathy Disease Severity Scale and the International Clinical Diabetic Retinopathy Disease Severity Scale [23]. Fundus photography was im- 
plemented some months after the start of The Maastricht Study. In 107 participants with type 2 diabetes without fundus photographs, data could be supplemented by data from the general practitioner. The highest grade of the left or right eye was counted to dichotomize the presence of retinopathy [21].

Vibration perception thresholds (VPTs) were tested with a Horwell Neurothesiometer (Scientific Laboratory Supplies, Nottingham, U.K.) in order to assess the presence of impaired vibratory sense. VPTs were tested three times at the distal phalanx of the hallux of the right and left foot [21]. The mean of the three measurements for the least sensitive foot was used in further analyses (impaired vibratory sense was defined as VPT $>25$ V) [24].

To assess urinary albumin excretion (UAE), participants were requested to collect two 24-hour urine samples. Urinary albumin concentration was measured with a standard immunoturbidimetric assay by an automatic analyzer (due to a change of supplier, by the Beckman Synchron LX20 and the Roche Cobas 6000) and multiplied by collection volume to obtain 24-hour UAE. A urinary albumin concentration below the detection limit of the assay $(2 \mathrm{mg} / \mathrm{L}$ for the Beckman Synchron $\mathrm{LX} 20$ and $3 \mathrm{mg} / \mathrm{L}$ for the Roche Cobas 6000) was set at $1.5 \mathrm{mg} / \mathrm{L}$ before multiplying by collection volume. Only urine collections with a collection time between 20 and 28 hours were considered valid. If needed, UAE was extrapolated to 24-hour excretion. For this study, UAE was preferably based on the average of 224-hour urine collections (available in $>90 \%$ of the participants) [21,25]. Albuminuria was defined as an albumin excretion $\geq 30 \mathrm{mg} / 24 \mathrm{~h}$ [25].

\section{General measurements}

Self-administered questionnaires were used to assess educational level, employment status, smoking status, alcohol consumption, and diabetes duration. Body mass index (BMI) and hypertension were measured at the study center [21]. Glycosylated hemoglobin A1c (HbAlc) and total/HDL cholesterol were determined as described elsewhere [21]. Health related quality of life (QoL) was assessed with the SF-36 Health Survey and transformed scale scores were calculated according to Ware et al. (1994) [26].

\section{Social network data collection}

Data on individual social networks were collected through a questionnaire using a name generator method, one of the most widely used instruments for examining egocentric network data [27, 28]. An egocentric network refers to a network centered on a specific individual (i.e. the participant), called the ego. Each person who has a relationship with the participant (ego) was defined as a network member (called alter) [27, 28]. The name generator/interpreter is used to map the participants' social network and to collect information about the network members [27, 28]. The name generator included seven questions on different types of contacts, participants were asked to name a maximum of five network members per question. Questions concerned (1) persons who advised them on problems, (2) persons who could offer them practical help if they were sick, (3) persons who provided emotional support when they were feeling unwell, (4) persons who helped them with small and larger jobs around the 
house, (5) persons they visited for social purposes or that they could go out with sometimes, and (6) persons with whom they could discuss important matters and, finally, (7) participants were asked to name a maximum number of 10 additional persons who were also important for them because of mutual activities. In total, participants could name a maximum number of 40 network members. After every question and for each network member named, they were asked to indicate their frequency of contact with this person over the last 6 months (daily or weekly, monthly, quarterly, and half-yearly). Moreover, the participants were asked to identify their relationship to this person (e.g. partner, sister, friend, neighbour, etc. (28 options)), how far away this person lived, and to indicate this person's sex and age.

\section{Functional characteristics of the social network (social support)}

Participants were asked to indicate the names of contacts who provided informational support related to advice on any problems, emotional support related to discomfort, emotional support related to important decisions, practical support related to jobs, and practical support related to sickness. For every type of support, participants could name a maximum of 5 network members. This results in a possible range of 0 to 5 for the functional network characteristics.

\section{Structural characteristics of the social network}

The structural network characteristics were computed from the name generator data. We calculated the social network size, contact frequency, proximity, type of relationship, single household size and participation in social activities. In brief, network size was defined as the total number of unique network members (alters) mentioned in the questionnaire. Total contacts per half year was defined as the sum of all contacts per half year. In addition, the percentage of network members that the participant (ego) had daily/weekly contact with, that were household members, that lived within walking distance, and the percentage of network members that were family members or friends was computed. Those social network constructs of percentages within the network were defined in steps of $10 \%$ (based on an average network size of 10 network members, a change in one network member corresponds to $10 \%$ ).

Single household size (living alone) was defined as a person who lived alone in his household. Participation in social activities was defined as membership in, for instance, a religious group, volunteer organization, discussion group, self-support group, internet club, or other organization. A summary of all functional and structural network characteristics can also be found in supplemental table S1.

\section{Statistical analysis}

Descriptive analyses were performed to examine the characteristics of the study population. To assess the differences between participants with and without complications, we performed chi-square, independent-sample t-tests and Kruskal-Wallis tests, as appropriate. 
We conducted binary logistic regression analyses to examine the association of the social network variables with macrovascular/ microvascular complications. In all analyses, associations were assessed for macrovascular vs. no complications and microvascular vs. no complications. For every network variable, odds ratios (ORs) and $95 \%$ confidence intervals ( $95 \% \mathrm{Cls}$ ) were reported. For descriptive purposes, network variables were reversed, i.e., multiplied by -1 (lower values on social network variables indicated as risk factor). Associations between network variables and complications were presented in four different models, adjusted for several confounders. In earlier studies were glycemic control, QoL, and cardiovascular risk factors often associated with diabetes complications [1-3], and -in other studies- also with social networks $[4,7-9,11]$. Therefore, we considered these variables as potential confounders in our analyses. Model 1 was adjusted for age and sex as important covariates in the relation between social networks and health outcomes, model 2 additionally adjusted for Hba1c to assess the hypothesis whether the association is explained by the level of glycemic control, model 3 additionally adjusted for QoL to assess whether the association is explained by differences in QoL, and model 4 additionally adjusted for cardiovascular risk factors as possible confounders; BMI, hypertension, Total/HDL cholesterol ratio, smoking status, educational level and employment status. As previous studies have shown sex differences in the associations between social network and T2DM [29-31], we tested for statistical interactions (effect modification) between the network variables and sex. The associations between social network variables and macrovascular complications showed no interaction with sex. The majority of the associations between social network variables and microvascular complications showed an interaction with $\operatorname{sex}(p<0.1)$, therefore we stratified these analyses by sex. All analyses were conducted using IBM SPSS software version 21.0 (IBM Corp. Armonk, NY, USA). A p-value $<0.05$ was considered statistically significant.

\section{Results}

The study population consisted of 797 T2DM participants with a mean age of $62.7 \pm 7.7$ years, of whom about one third was women (31.4\%). Table 1 presents the general characteristics for the population, stratified by macro- and microvascular complication status. In total 411 participants (51.6\%) had no complications, 217 participants (27.2\%) had macrovascular complications, 254 participants (31.9\%) had microvascular complications, of whom 85 (10.7\%) participants had both macro- and microvascular complications. Participants with macro- or microvascular complications were somewhat older, more often men, had a longer T2DM duration, a higher Hbalc, had an adverse CVD risk profile, a lower educational level, and were less often employed compared to participants without complications. 
Table 1 - General and social network characteristics of the study population ( $n=797$ ) stratified for the presence of macro- and microvascular complications

\begin{tabular}{|c|c|c|c|c|c|}
\hline & $\begin{array}{c}\text { No } \\
\text { Complications } \\
(n=411)\end{array}$ & $\begin{array}{l}\text { Macrovascular } \\
\text { complications } \\
(\mathrm{n}=217)\end{array}$ & p-value ${ }^{b}$ & $\begin{array}{l}\text { Microvascular } \\
\text { complications } \\
(n=254)\end{array}$ & p-value ${ }^{c}$ \\
\hline \multicolumn{6}{|l|}{ Demographic characteristics } \\
\hline Age (years) & $61.5 \pm 7.8$ & $64.1 \pm 7.1$ & $<0.001$ & $64.2 \pm 7.2$ & $<0.001$ \\
\hline Male sex (\%) & 60.8 & 75.6 & $<0.001$ & 80.7 & $<0.001$ \\
\hline $\begin{array}{l}\text { Educational level }{ }^{4} \text {, low/ } \\
\text { intermediate/high (\%) }\end{array}$ & 43.1/29.2/27.7 & $51.2 / 27.6 / 21.2$ & 0.104 & 47.67/27.2/25.2 & 0.512 \\
\hline $\begin{array}{l}\text { Employment status, } \\
\text { Employed/retired/no paid job/ } \\
\text { unknown (\%) }\end{array}$ & $33.1 / 35.5 / 21.4 / 10.0$ & 22.1/42.9/19.8/15.2 & 0.010 & 23.6/42.5/16.9/16.9 & 0.002 \\
\hline $\begin{array}{l}\text { Smoking status, never/ } \\
\text { former/current }(\%)\end{array}$ & $32.6 / 54.7 / 12.7$ & 21.2/61.3/17.5 & 0.007 & 24.8/56.7/18.5 & 0.031 \\
\hline $\begin{array}{l}\text { Alcohol consumption }{ }^{5} \text {, none/ } \\
\text { low/high (\%) }\end{array}$ & 28.0/54.6/17.3 & $36.1 / 46.3 / 17.6$ & 0.087 & 29.1/48.8/22.0 & 0.233 \\
\hline $\begin{array}{l}\text { Quality of life, physical } \\
\text { component }\end{array}$ & $49.3 \pm 8.1$ & $47.7 \pm 10.3$ & $<0.001$ & $45.1 \pm 10.4$ & $<0.001$ \\
\hline $\begin{array}{l}\text { Quality of life, mental } \\
\text { component }\end{array}$ & $53.46 \pm 8.40$ & $51.39 \pm 9.97$ & 0.010 & $52.37 \pm 9.55$ & 0.135 \\
\hline \multicolumn{6}{|l|}{ Clinical characteristics } \\
\hline Body mass index $\left(\mathrm{kg} / \mathrm{m}^{2}\right)$ & $29.09 \pm 5.00$ & $30.61 \pm 4.72$ & $<0.001$ & $30.31 \pm 5.03$ & 0.002 \\
\hline $\begin{array}{l}\text { Diabetes duration (years; } \\
\text { median, IQR) }\end{array}$ & $5.0\left(3-10^{\prime}\right)$ & $7\left(3-12^{2}\right)$ & 0.007 & $9\left(4-17^{3}\right)$ & $<0.001$ \\
\hline $\mathrm{Hbalc}(\mathrm{mmol} / \mathrm{mol})$ & $49.8 \pm 8.9$ & $53.8 \pm 12.3$ & $<0.001$ & $55.1 \pm 14.3$ & $<0.001$ \\
\hline Hba1c (\%) & $6.7 \pm 0.8$ & $7.1 \pm 1.1$ & $<0.001$ & $7.2 \pm 1.3$ & $<0.001$ \\
\hline $\begin{array}{l}\text { Systolic Blood Pressure } \\
(\mathrm{mmHg})\end{array}$ & $140.0 \pm 15.8$ & $143.0 \pm 18.9$ & 0.045 & $145.7 \pm 19.0$ & $<0.001$ \\
\hline $\begin{array}{l}\text { Diastolic Blood Pressure } \\
(\mathrm{mmHg})\end{array}$ & $77.8 \pm 9.4$ & $75.5 \pm 10.0$ & 0.003 & $77.3 \pm 9.5$ & 0.505 \\
\hline Hypertension ${ }^{6}(\%)$ & 75.2 & 93.1 & $<0.001$ & 90.2 & $<0.001$ \\
\hline $\begin{array}{l}\text { Total/ HDL cholesterol } \\
(\mathrm{mmol} / \mathrm{l})\end{array}$ & $3.7 \pm 1.2$ & $3.7 \pm 1.1$ & 0.974 & $3.7 \pm 1.1$ & 0.980 \\
\hline \multicolumn{6}{|c|}{ Functional characteristics of the social network } \\
\hline Informational support ${ }^{\&}$ & $2.93 \pm 1.70$ & $2.51 \pm 1.61$ & 0.003 & $2.59 \pm 1.70$ & 0.013 \\
\hline $\begin{array}{l}\text { Emotional support } \\
\text { (discomfort) \& }\end{array}$ & $2.32 \pm 1.52$ & $1.99 \pm 1.42$ & 0.008 & $2.04 \pm 1.42$ & 0.019 \\
\hline $\begin{array}{l}\text { Emotional support (important } \\
\text { decisions) \& }\end{array}$ & $2.61 \pm 1.58$ & $2.19 \pm 1.47$ & 0.001 & $2.33 \pm 1.44$ & 0.018 \\
\hline Practical support (jobs) ${ }^{8}$ & $2.55 \pm 1.43$ & $2.18 \pm 1.38$ & 0.002 & $2.22 \pm 1.37$ & 0.004 \\
\hline Practical support (sickness) \& & $1.99 \pm 1.35$ & $1.71 \pm 1.21$ & 0.014 & $1.87 \pm 1.25$ & 0.283 \\
\hline \multicolumn{6}{|c|}{ Structural characteristics of the social network } \\
\hline Network size & $8.19 \pm 4.58$ & $6.59 \pm 3.67$ & $<0.001$ & $7.12 \pm 4.16$ & 0.003 \\
\hline \multicolumn{6}{|l|}{ Contact frequency } \\
\hline Total contacts per half year & $203.0 \pm 123.7$ & $186.0 \pm 125.4$ & 0.108 & $182.4 \pm 125.1$ & 0.040 \\
\hline $\begin{array}{l}\text { Percentage of daily-weekly } \\
\text { contact }\end{array}$ & $51.87 \pm 27.09$ & $56.71 \pm 29.40$ & 0.040 & $51.89 \pm 30.28$ & 0.994 \\
\hline
\end{tabular}




\section{Proximity}

Percentage of network members living within walking distance

\section{Type of relationship}

Percentage household members

$16.82 \pm 16.36$

$61.97 \pm 25.48$

$23.86 \pm 21.90$

Percentage friends

Single household size (living alone) (\%)

Participation in social activities (\%)
19.2

43.1

$\begin{array}{rr}18.22 \pm 19.41 & 0.365 \\ 67.77 \pm 28.70 & 0.013 \\ 16.77 \pm 20.22 & <0.001\end{array}$

26.7

0.141

$42.9 \quad 0.946$

$\begin{array}{rr}17.97 \pm 19.03 & 0.426 \\ 63.09 \pm 27.54 & 0.595 \\ 20.47 \pm 22.52 & 0.056\end{array}$

$24.0 \quad 0.141$

a No complications was defined as absence of both macrovascular- and microvascular complications. ${ }^{\mathrm{b}}$ no complications vs. macrovascular complications, ${ }^{\mathrm{c}}$ no complications vs. microvascular complica-

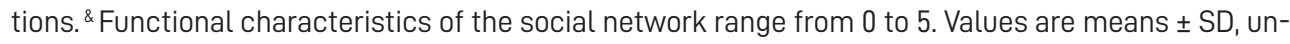
less stated otherwise. Data on diabetes duration was available in ${ }^{1} n=286,{ }^{2} n=167,{ }^{3} n=197$ participants. ${ }^{4}$ Educational level (low educational level; no education, primary education, and lower vocational education, intermediate educational level; intermediate vocational education, higher secondary education, and vocational education and high educational level; higher professional education, university). ${ }^{5}$ Alcohol consumption (non-consumers, low consumers; $\leq 7$ glasses per week for women, $\leq 14$ glasses per week for men, and high consumers; $>7$ glasses per week for women, >14 glasses per week for men). ${ }^{6}$ Hypertension was defined as an office systolic blood pressure $\geq 140 \mathrm{mmHg}$, an office diastolic blood pressure $\geq 90 \mathrm{mmHg}$ and (or) the use of antihypertensive medication.

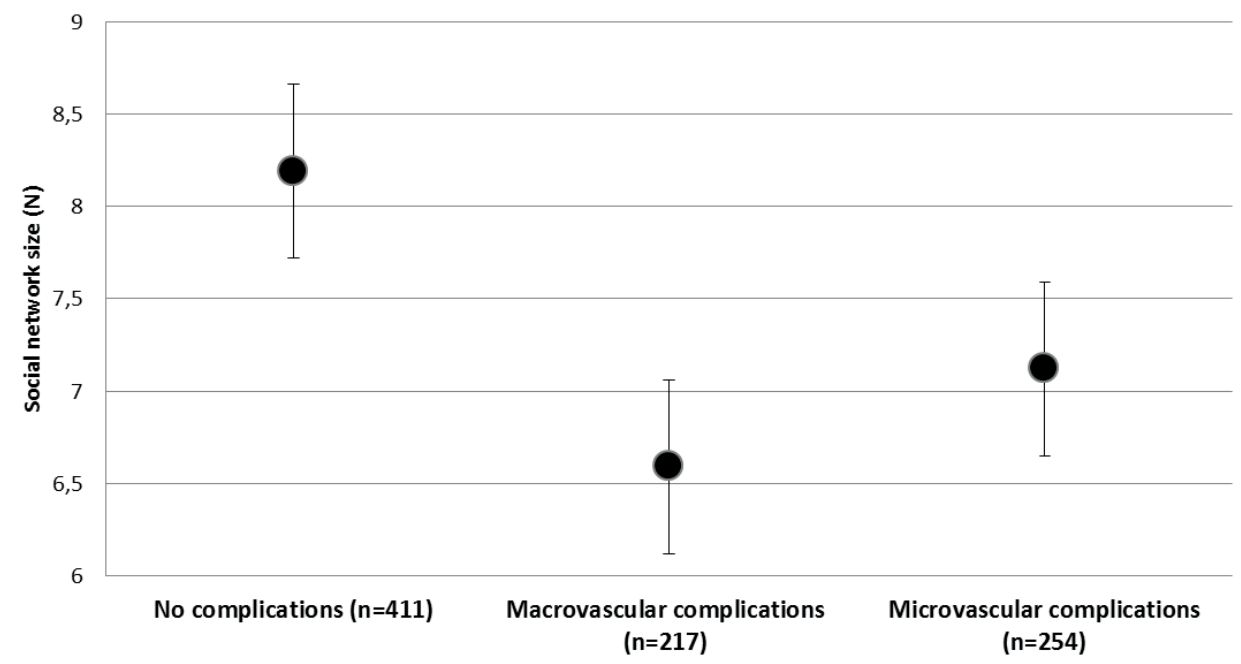

Figure 1 - The average social network size according to complication status. 


\section{Functional network characteristics and macrovascular complications}

Table 2 shows that less informational support was associated with a $11 \%$ higher odds of macrovascular complications, adjusted for age, sex and Hbalc (model 2). Additional adjustment for QoL and cardiovascular risk factors attenuated this association (OR 1.07 [0.95-1.20]). Less emotional support on important decisions was associated with a $13 \%$ higher odds of macrovascular complications (model 2). Additional adjustment for QoL and cardiovascular risk factors attenuated this association (OR 1.04 [0.911.21]). Less practical support with jobs around the house was associated with a $14 \%$ higher odds of macrovascular complications (model 2). Additional adjustment slightly attenuated this association (OR 1.12 [0.98-1.29]).

\section{Structural network characteristics and macrovascular complications}

A smaller network size was associated with a $6 \%$ higher odds of macrovascular complications, compared to those without complications, in the fully adjusted model (Table 2, model 4). The average social network size according to complication status is presented in figure 1.

Every additional $10 \%$ of the network that was contacted daily or weekly was associated with a $6 \%$ higher odds of macrovascular complications (model 2). These associations were slightly attenuated after further adjustment for QoL and cardiovascular risk factors (OR 1.06 [0.99-1.13]). Every additional $10 \%$ of the network that was a family member was associated with a $8 \%$ higher odds of macrovascular complications, and each $10 \%$ drop in the number of friends was associated with a $12 \%$ higher odds of macrovascular complications, in fully adjusted models. Living alone was associated with a $53 \%$ higher odds of macrovascular complications (model 2). Additional adjustment for QoL and cardiovascular risk factors attenuated this association (OR 1.28 [0.82-2.01]). 
Table 2 - Associations of social network characteristics with macrovascular complications

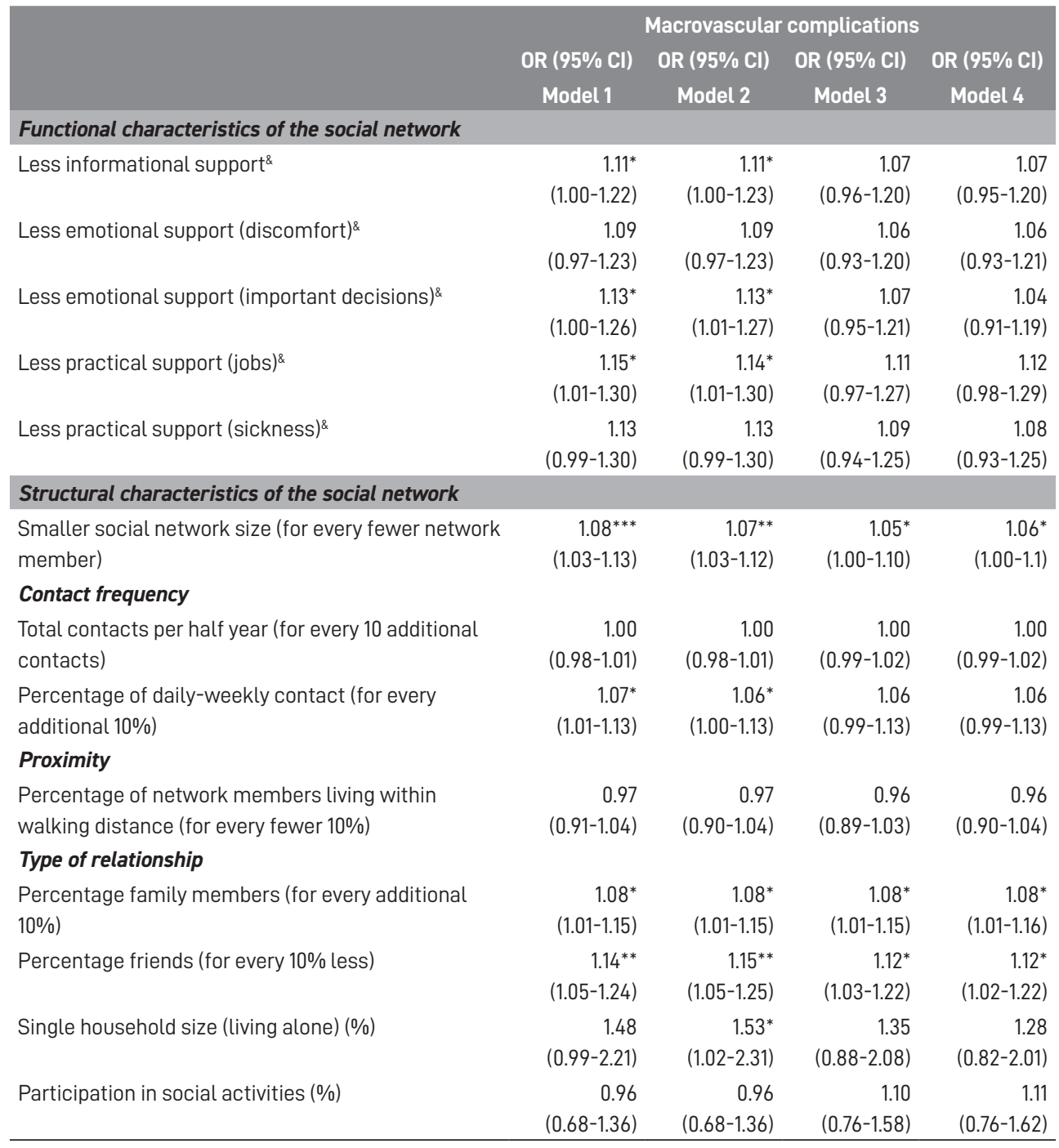

Macrovascular complications $(n=217)$, reference category; No complications $(n=411)$. \& Functional characteristics of the social network have a range from 0 to $5 .{ }^{*} p \leq 0.05^{* *} p \leq 0.01{ }^{* * *} p \leq 0.001$.

Model 1: adjusted for sex and age

Model 2: adjusted for sex, age, and Hba1c

Model 3: adjusted for sex, age, Hbalc and Quality of life (QoL)

Model 4: adjusted for sex, age, Hba1c, QoL, hypertension, body mass index, Total/HDL cholesterol, smoking status, educational level and employment status 


\section{Functional network characteristics and microvascular complications}

Table 3 shows that in women, less informational support was associated with a $33 \%$ higher odds of microvascular complications, after full adjustment (model 4). Less emotional support when feeling unwell was associated with a $33 \%$ higher odds of microvascular complications (model 3). Additional adjustment for cardiovascular risk factors slightly attenuated this association (OR 1.27 [0.95-1.71]). Less emotional support with important decisions was associated with a $27 \%$ higher odds of microvascular complications (model 2). Additional adjustment for QoL and cardiovascular risk factors attenuated this association (OR 1.14 [0.84-1.53]). In women, less practical support with jobs around the house was associated with a $41 \%$ higher odds of microvascular complications, after adjustment for age (model 1). However, additional adjustment for glycemic control, QoL and cardiovascular risk factors attenuated this association (OR 1.29 [0.94-1.77]).

No significant associations between functional characteristics of the social network with microvascular complications were observed in men (Table 3 ).

\section{Structural network characteristics and microvascular complications}

In women, each fewer network member reported (smaller network size) was associated with a 15\% higher odds of microvascular complications, compared to those without complications, in the fully adjusted model (Table 3, model 4). Other structural social network characteristics were not associated with microvascular complications in women. In men, living alone was associated with a $72 \%$ higher odds of microvascular complications, (Table 3, model 2), this association attenuated to borderline significance after adjustment for cardiovascular risk factors (OR 1.56 [0.93-2.64] $p=0.093$ ). Further, no significant associations between other structural characteristics of the social network were observed in men. 
Table 3 - Associations of social network characteristics with microvascular complications

\begin{tabular}{|c|c|c|c|c|}
\hline \multirow{3}{*}{ In women } & \multicolumn{4}{|c|}{ Microvascular complications } \\
\hline & OR $(95 \% \mathrm{Cl})$ & OR $(95 \% \mathrm{Cl})$ & OR $(95 \% \mathrm{Cl})$ & OR $(95 \% \mathrm{CI})$ \\
\hline & Model 1 & Model 2 & Model 3 & Model 4 \\
\hline \multicolumn{5}{|l|}{ Functional characteristics of the social network } \\
\hline Less informational support ${ }^{\&}$ & $\begin{array}{r}1.36^{* *} \\
(1.10-1.68)\end{array}$ & $\begin{array}{r}1.31^{*} \\
(1.05-1.63)\end{array}$ & $\begin{array}{r}1.31^{*} \\
(1.04-1.65)\end{array}$ & $\begin{array}{r}1.33^{*} \\
(1.03-1.71)\end{array}$ \\
\hline Less emotional support (discomfort) ${ }^{2}$ & $\begin{array}{r}1.45^{* *} \\
(1.13-1.86)\end{array}$ & $\begin{array}{r}1.37^{*} \\
(1.06-1.77)\end{array}$ & $\begin{array}{r}1.33^{*} \\
(1.02-1.73)\end{array}$ & $\begin{array}{r}1.27 \\
(0.95-1.71)\end{array}$ \\
\hline Less emotional support (important decisions) ${ }^{\mathbb{R}}$ & $\begin{array}{r}1.27^{*} \\
(1.01-1.59)\end{array}$ & $\begin{array}{r}1.27^{*} \\
(1.00-1.62)\end{array}$ & $\begin{array}{r}1.21 \\
(0.93-1.56)\end{array}$ & $\begin{array}{r}1.14 \\
(0.84-1.53)\end{array}$ \\
\hline Less practical support (jobs)\& & $\begin{array}{r}1.41^{*} \\
(1.08-1.85)\end{array}$ & $\begin{array}{r}1.31 \\
(0.99-1.74)\end{array}$ & $\begin{array}{r}1.26 \\
(0.95-1.68)\end{array}$ & $\begin{array}{r}1.29 \\
(0.94-1.77)\end{array}$ \\
\hline Less practical support (sickness) ${ }^{\mathbb{R}}$ & $\begin{array}{r}1.32 \\
(0.96-1.81)\end{array}$ & $\begin{array}{r}1.36 \\
(0.96-1.91)\end{array}$ & $\begin{array}{r}1.29 \\
(0.92-1.83)\end{array}$ & $\begin{array}{r}1.26 \\
(0.87-1.83)\end{array}$ \\
\hline \multicolumn{5}{|l|}{ Structural characteristics of the social network } \\
\hline $\begin{array}{l}\text { Smaller network size (for every fewer network } \\
\text { member) }\end{array}$ & $\begin{array}{r}1.15^{* *} \\
(1.05-1.27)\end{array}$ & $\begin{array}{r}1.13^{*} \\
(1.02-1.24)\end{array}$ & $\begin{array}{r}1.10 \\
(0.99-1.22)\end{array}$ & $\begin{array}{r}1.15^{*} \\
(1.02-1.29)\end{array}$ \\
\hline \multicolumn{5}{|l|}{ Contact frequency } \\
\hline $\begin{array}{l}\text { Total contacts per half year (for every } 10 \text { additional } \\
\text { contacts) }\end{array}$ & $\begin{array}{r}0.97 \\
(0.94-1.00)\end{array}$ & $\begin{array}{r}0.97 \\
(0.94-1.01)\end{array}$ & $\begin{array}{r}0.97 \\
(0.94-1.01)\end{array}$ & $\begin{array}{r}0.97 \\
(0.93-1.00)\end{array}$ \\
\hline $\begin{array}{l}\text { Percentage of daily-weekly contact (for every } \\
\text { additional } 10 \% \text { ) }\end{array}$ & $\begin{array}{r}1.09 \\
(0.97-1.23)\end{array}$ & $\begin{array}{r}1.06 \\
(0.93-1.21)\end{array}$ & $\begin{array}{r}1.01 \\
(0.88-1.16)\end{array}$ & $\begin{array}{r}1.04 \\
(0.89-1.21)\end{array}$ \\
\hline \multicolumn{5}{|l|}{ Proximity } \\
\hline $\begin{array}{l}\text { Percentage of network members living within } \\
\text { walking distance (for every fewer } 10 \% \text { ) }\end{array}$ & $\begin{array}{r}0.98 \\
(0.86-1.13)\end{array}$ & $\begin{array}{r}0.99 \\
(0.85-1.14)\end{array}$ & $\begin{array}{r}0.97 \\
(0.83-1.13)\end{array}$ & $\begin{array}{r}1.01 \\
(0.84-1.20)\end{array}$ \\
\hline \multicolumn{5}{|l|}{ Type of relationship } \\
\hline $\begin{array}{l}\text { Percentage family members (for every additional } \\
10 \%)\end{array}$ & $\begin{array}{r}1.06 \\
(0.92-1.21)\end{array}$ & $\begin{array}{r}1.02 \\
(0.89-1.18)\end{array}$ & $\begin{array}{r}0.97 \\
(0.83-1.12)\end{array}$ & $\begin{array}{r}1.05 \\
(0.89-1.25)\end{array}$ \\
\hline Percentage friends (for every $10 \%$ less) & $\begin{array}{r}1.14 \\
(0.97-1.35)\end{array}$ & $\begin{array}{r}1.10 \\
(0.93-1.31)\end{array}$ & $\begin{array}{r}1.02 \\
(0.85-1.22\end{array}$ & $\begin{array}{r}1.05 \\
(0.87-1.28)\end{array}$ \\
\hline Single household size (living alone) (\%) & $\begin{array}{r}0.83 \\
(0.38-1.82)\end{array}$ & $\begin{array}{r}0.88 \\
(0.39-1.90)\end{array}$ & $\begin{array}{r}0.86 \\
(0.35-2.11)\end{array}$ & $\begin{array}{r}0.73 \\
(0.27-2.00)\end{array}$ \\
\hline Participation in social activities (\%) & $\begin{array}{r}0.88 \\
(0.61-1.30)\end{array}$ & $\begin{array}{r}0.90 \\
(0.61-1.32)\end{array}$ & $\begin{array}{r}0.95 \\
(0.63-1.41)\end{array}$ & $\begin{array}{r}0.94 \\
(0.62-1.41)\end{array}$ \\
\hline
\end{tabular}




\begin{tabular}{|c|c|c|c|c|}
\hline In men & $\begin{array}{l}\text { OR }(95 \% \mathrm{Cl}) \\
\quad \text { Model } 1\end{array}$ & $\begin{array}{l}\text { OR }(95 \% \mathrm{CI}) \\
\quad \text { Model } 2\end{array}$ & $\begin{array}{l}\text { OR }(95 \% \mathrm{CI}) \\
\text { Model } 3\end{array}$ & $\begin{array}{l}\text { OR }(95 \% \mathrm{Cl}) \\
\text { Model } 4\end{array}$ \\
\hline \multicolumn{5}{|l|}{ Functional characteristics of the social network } \\
\hline Less informational support ${ }^{\&}$ & $\begin{array}{r}1.01 \\
(0.90-1.12)\end{array}$ & $\begin{array}{r}1.00 \\
(0.90-1.12)\end{array}$ & $\begin{array}{r}0.96 \\
(0.86-1.08)\end{array}$ & $\begin{array}{r}0.96 \\
(0.85-1.09)\end{array}$ \\
\hline Less emotional support (discomfort) $)^{2}$ & $\begin{array}{r}0.95 \\
(0.83-1.09)\end{array}$ & $\begin{array}{r}0.94 \\
(0.82-1.08)\end{array}$ & $\begin{array}{r}0.93 \\
(0.81-1.06)\end{array}$ & $\begin{array}{r}0.93 \\
(0.81-1.07)\end{array}$ \\
\hline Less emotional support (important decisions) ${ }^{\&}$ & $\begin{array}{r}0.98 \\
(0.86-1.12)\end{array}$ & $\begin{array}{r}0.98 \\
(0.86-1.12)\end{array}$ & $\begin{array}{r}0.94 \\
(0.83-1.08)\end{array}$ & $\begin{array}{r}0.93 \\
(0.80-1.07)\end{array}$ \\
\hline Less practical support (jobs) ${ }^{\mathrm{R}}$ & $\begin{array}{r}1.07 \\
(0.93-1.22)\end{array}$ & $\begin{array}{r}1.06 \\
(0.93-1.22)\end{array}$ & $\begin{array}{r}1.04 \\
(0.90-1.19)\end{array}$ & $\begin{array}{r}1.05 \\
(0.91-1.21)\end{array}$ \\
\hline Less practical support (sickness) $)^{8}$ & $\begin{array}{r}0.98 \\
(0.85-1.13)\end{array}$ & $\begin{array}{r}0.97 \\
(0.84-1.13)\end{array}$ & $\begin{array}{r}0.92 \\
(0.79-1.07)\end{array}$ & $\begin{array}{r}0.92 \\
(0.79-1.08)\end{array}$ \\
\hline \multicolumn{5}{|l|}{ Structural characteristics of the social network } \\
\hline $\begin{array}{l}\text { Smaller network size (for every fewer network } \\
\text { member) }\end{array}$ & $\begin{array}{r}1.01 \\
(0.97-1.06)\end{array}$ & $\begin{array}{r}1.01 \\
(0.96-1.05)\end{array}$ & $\begin{array}{r}0.99 \\
(0.95-1.04)\end{array}$ & $\begin{array}{r}0.99 \\
(0.94-1.05)\end{array}$ \\
\hline \multicolumn{5}{|l|}{ Contact frequency } \\
\hline $\begin{array}{l}\text { Total contacts per half year (for every } 10 \text { additional } \\
\text { contacts) }\end{array}$ & $\begin{array}{r}1.00 \\
(0.98-1.01)\end{array}$ & $\begin{array}{r}1.00 \\
(0.98-1.01)\end{array}$ & $\begin{array}{r}1.00 \\
(0.99-1.02)\end{array}$ & $\begin{array}{r}1.00 \\
(0.99-1.02)\end{array}$ \\
\hline $\begin{array}{l}\text { Percentage of daily-weekly contact (for every } \\
\text { additional } 10 \% \text { ) }\end{array}$ & $\begin{array}{r}0.98 \\
(0.92-1.05)\end{array}$ & $\begin{array}{r}0.97 \\
(0.91-1.04)\end{array}$ & $\begin{array}{r}0.97 \\
(0.91-1.04)\end{array}$ & $\begin{array}{r}0.97 \\
(0.91-1.04)\end{array}$ \\
\hline \multicolumn{5}{|l|}{ Proximity } \\
\hline $\begin{array}{l}\text { Percentage of network members living within } \\
\text { walking distance (for every fewer 10\%) }\end{array}$ & $\begin{array}{r}1.00 \\
(0.93-1.09)\end{array}$ & $\begin{array}{r}0.98 \\
(0.90-1.06)\end{array}$ & $\begin{array}{r}0.97 \\
(0.90-1.06)\end{array}$ & $\begin{array}{r}0.97 \\
(0.89-1.05)\end{array}$ \\
\hline \multicolumn{5}{|l|}{ Type of relationship } \\
\hline $\begin{array}{l}\text { Percentage family members (for every additional } \\
10 \%)\end{array}$ & $\begin{array}{r}0.99 \\
(0.93-1.07)\end{array}$ & $\begin{array}{r}0.99 \\
(0.92-1.06)\end{array}$ & $\begin{array}{r}1.00 \\
(0.93-1.08)\end{array}$ & $\begin{array}{r}1.01 \\
(0.93-1.09)\end{array}$ \\
\hline Percentage friends (for every $10 \%$ less) & $\begin{array}{r}1.02 \\
(0.93-1.10)\end{array}$ & $\begin{array}{r}1.01 \\
(0.93-1.10)\end{array}$ & $\begin{array}{r}1.01 \\
(0.92-1.10)\end{array}$ & $\begin{array}{r}1.01 \\
(0.92-1.11)\end{array}$ \\
\hline Single household size (living alone) (\%) & $\begin{array}{r}1.64^{*} \\
(1.02-2.62)\end{array}$ & $\begin{array}{r}1.72^{*} \\
(1.06-2.78)\end{array}$ & $\begin{array}{r}1.49 \\
(0.91-2.45)\end{array}$ & $\begin{array}{r}1.56 \\
(0.93-2.64)\end{array}$ \\
\hline Participation in social activities (\%) & $\begin{array}{r}0.90 \\
(0.46-1.75) \\
\end{array}$ & $\begin{array}{r}0.98 \\
(0.49-1.97) \\
\end{array}$ & $\begin{array}{r}1.04 \\
(0.50-2.18) \\
\end{array}$ & $\begin{array}{r}1.41 \\
(0.60-3.32) \\
\end{array}$ \\
\hline
\end{tabular}

In women; microvascular complications ( $n=49$ ), reference category no complications ( $n=161)$. In men; microvascular complications ( $n=205)$, reference category no complications $(n=250)$. ${ }^{\text {F Functional char- }}$ acteristics of the social network have a range from 0 to $5 .{ }^{*} p \leq 0.05^{* *} p \leq 0.01$.

Model 1: adjusted for age

Model 2: adjusted for sex, age, and Hbalc

Model 3: adjusted for sex, age, Hbalc and Quality of life (QoL)

Model 4: adjusted for sex, age, Hbalc, QoL, hypertension, body mass index, Total/HDL cholesterol, smoking status, educational level and employment status 


\section{Conclusions}

To the best of our knowledge, this study is the first to specifically assess the association of functional and structural characteristics of the social network with clinical complications of T2DM. A smaller social network size was associated with macrovascular complications in both men and women with T2DM. Moreover, the type of relationship in terms of family members and friends was associated with macrovascular complications, participants with higher percentages of family members or lower percentages of friends had a significantly higher odds ratio of macrovascular complications. These associations appeared to be independent of glycemic control, QoL, and other cardiovascular risk factors. Further, a smaller social network size and less informational support was associated with microvascular complications only in women with T2DM. In men, living alone was associated with microvascular complications, however, this association was explained by QoL and CVD risk factors.

\section{Macrovascular complications}

Functional characteristics of the social network, lower levels of informational, emotional and practical support, were significantly associated with macrovascular complications in the models adjusted for sex, age and Hba1c. These observations are similar to previous findings by Orth-Gomer et al. (1993), demonstrating that a lack of social support is a risk factor for coronary heart disease [17]. Moreover, our findings complement existing literature on the beneficial effects of social support on cardio metabolic control [4, 5], health-related QoL [10], and mortality [11] in patients with type 2 diabetes.

A smaller social network size was independently associated with macrovascular complications in both men and women. Our results mirror previous findings in the general population, where a smaller social network has been associated with an increased risk for CVD [18]. In addition, another study has shown an association of a smaller social network with poor diabetes self-management skills [9].

Further, we observed that in terms of network composition, participants with higher percentages of family members or lower percentages of friends had a significantly higher odds ratio of macrovascular complications. The results may indicate that participants with a smaller social network that is centralized to family members were at higher risk to develop macrovascular complications. However, as our study was of cross-sectional nature, the order of events could also occur vice versa. Patients with macrovascular complications could lose friends and may be in need of informal care of their family members, which leads to a smaller network that is mainly composed of family members. This is similar to results from Conway et al. (2013), which demonstrated that compositional changes in social networks across the lifespan due to illness was greatest among non-family members, while addition of network members was more likely among family members [32]. Further (longitudinal) studies are needed to confirm our findings and address the order of events. 


\section{Microvascular complications}

In our analyses, informational, emotional and practical support were associated with microvascular complications in women when adjusted for age. After adjustment for glycemic control, QoL, and other cardiovascular risk factors, this association was no longer significant for emotional and practical support but the odds remained increased in the fully adjusted models. Therefore, the attenuation due to adjustment may be attributable to a lack of power, as we had a relatively small sample of women with microvascular complications ( $n=49$ ). In addition, the odds presented are conservative estimates, as we adjusted the associations for a broad range of potential confounders, which may be overcorrection. Our findings on the association of social support with microvascular complications complement existing evidence on the beneficial effects of social support on glycemic control and BP in T2DM [4,5], both risk factors for microvascular complications $[2,3]$.

A smaller social network size was independently associated with higher odds of microvascular complications in women. Our results mirror Dunkler et al.'s study (2015), which demonstrated that a smaller social network size was an independent risk factor for chronic kidney disease in T2DM patients with end-organ damage [12]. However, this study did not report on any sex differences. Our results extend their findings as we used a population-based sample of individuals with T2DM. Moreover, we used a more detailed investigation of the social network size with a name generator, one of the most widely used instruments for examining egocentric network data [27, 28]. In men, living alone was associated with microvascular complications, however, this association attenuated to a borderline significant association in the fully adjusted model. Nonetheless, we did not find any other significant associations of structural or functional social network characteristics with microvascular complications in men.

Discrepant findings between men and women have previously been found in several studies that examined the association of social network characteristics and the development of T2DM [29-31], or metabolic control in patients with T2DM $[5,33]$. A possible explanation is that these discrepancies may be attributable to different coping strategies among men and women, as men more frequently use problem-solving coping strategies and seek less social support, while women integrate social and emotional aspects more frequently into their coping strategies [34-36]. This suggests that preventive strategies based on social network characteristics aiming to reduce microvascular complications should primarily be tailored to women. Yet, further research is needed to corroborate our findings in T2DM women. In addition, the underlying mechanisms for sex-specific differences in microvascular complications should be investigated. 


\section{Strengths \& Limitations}

The strength of this study include its population-based design, and the comprehensive assessment of functional and structural network characteristics, and macro- and microvascular T2DM complications. In addition, we used a name generator, one of the best known, most detailed and most widely used instruments to examine egocentric network data [27, 28]. Furthermore, study participants were well-characterized, allowing adjustment for an extensive series of potential confounders, which makes residual confounding unlikely, and therefore conservative estimates of the actual associations are presented.

Some limitations should also be mentioned. The study is cross-sectional in nature, and therefore, causality cannot be examined. In addition, non-significant findings in women with microvascular complications may be attributable to low power, as we had a relatively low number of women with microvascular complications in our study population.

\section{Conclusions and recommendations}

To conclude, the present study shows that social network characteristics were associated with macro- and microvascular T2DM complications, in part independent of glycemic control, QoL and cardiovascular risk factors.

The current study highlights the importance of social support and social network members for patients with T2DM. Health care professionals should be aware of the relation of the social network with T2DM outcomes. Knowledge of a patient's network and social support may render treatment strategies and lifestyle interventions more effective when tailored to the specific needs and network characteristics of a patient with diabetic complications. Further studies are needed to determine the potential role of network characteristics in the development of diabetic complications and their interaction with treatment. Social network characteristics may be an independent target in non-pharmaceutical and non-medical interventions that aim to prevent the development of clinical complications in T2DM. Our findings support the efforts to develop effective interventions that tailor social network characteristics $[13,37,38]$, however, it is important to assess whether these interventions meet the needs of T2DM patients with complications. Based on the results of our study, we would suggest that social network size, the type of relationships and social support should be addressed in future interventions aiming to reduce the burden of disease in T2DM. For example, broadening the social network should be encouraged, as reinforcement of social networking has been shown to improve Hbalc and blood glucose [37]. Moreover, interventions aiming to generate behavioural change (e.g., physical activity) may also tailor to the social network of the participant, as it has been shown that network targeting can be used to increase the adoption of specific public health interventions [38]. Finally, when designing such interventions, potential differences in social network characteristics between males and females should be taken into account. 


\section{References}

1. Federation ID. IDF Diabetes Atlas, 7th edn. Brussels, Belgium: 2015.

2. Holman RR, Paul SK, Bethel MA, Matthews DR, Neil HA. 10-year follow-up of intensive glucose control in type 2 diabetes. The New England journal of medicine. 2008;359(15):1577-89.

3. Holman RR, Paul SK, Bethel MA, Neil HA, Matthews DR. Long-term follow-up after tight control of blood pressure in type 2 diabetes. The New England journal of medicine. 2008;359(15):1565-76.

4. Strom JL, Egede LE. The impact of social support on outcomes in adult patients with type 2 diabetes: a systematic review. Current diabetes reports. 2012;12(6):769-81.

5. Stopford R, Winkley K, Ismail K. Social support and glycemic control in type 2 diabetes: A systematic review of observational studies. $\mathrm{Pa}$ tient education and counseling. 2013;93(3):54958.

6. Rees CA, Karter AJ, Young BA. Race/ethnicity, social support, and associations with diabetes self-care and clinical outcomes in NHANES. The Diabetes educator. 2010;36(3):435-45.

7. Reeves D, Blickem C, Vassilev I, Brooks $H_{1}$ Kennedy A, Richardson $G$, et al. The contribution of social networks to the health and self-management of patients with long-term conditions: a longitudinal study. PLoS One. 2014;9(6):e98340

8. Koetsenruijter J, van Lieshout J, Lionis C, Portillo MC, Vassilev I, Todorova E, et al. Social support and health in diabetes patients: an observational study in six European countries in an era of austerity. PloS one. 2015;10(8):e0135079.

9. Vassilev I, Rogers A, Kennedy A, Wensing $M_{\text {, }}$ Koetsenruijter J, Orlando R, et al. Social Network Type and Long-Term Condition Management Support: A Cross-Sectional Study in Six European Countries. PLoS One. 2016;11(8):e0161027.

10. Bourdel-Marchasson I, Druet $C$, Helmer $C$, Eschwege $E_{1}$ Lecomte $P$, Le-Goff $M$, et al. Correlates of health-related quality of life in French people with type 2 diabetes. Diabetes
Res Clin Pract. 2013;101(2):226-35.

11. Zhang X, Norris SL, Gregg EW, Beckles G. Social support and mortality among older persons with diabetes. The Diabetes educator. 2007;33(2):273-81.

12. Dunkler $D$, Kohl $M$, Heinze $G$, Teo KK, Rosengren A, Pogue J, et al. Modifiable lifestyle and social factors affect chronic kidney disease in highrisk individuals with type 2 diabetes mellitus. Kidney international. 2015;87(4):784-91.

13. Heaney CA, Israel BA. Social networks and social support. Health behavior and health education: Theory, research, and practice. 2008:4:189-210.

14. Antonucci TC, Lansford JE, Schaberg L, Smith

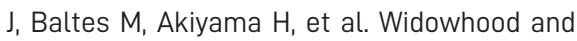
illness: A comparison of social network characteristics in France, Germany, Japan, and the United States. Psychology and aging. 2001;16(4):655.

15. Ashida S, Heaney CA. Differential associations of social support and social connectedness with structural features of social networks and the health status of older adults. Journal of Aging and Health. 2008;20(7):872-93.

16. Brinkhues $S$, Dukers-Muijrers $\mathrm{NH}$, Hoebe CJ, van der Kallen CJ, Dagnelie PC, Koster A, et al. Socially isolated individuals are more prone to have newly diagnosed and prevalent type 2 diabetes mellitus-the Maastricht study-. BMC public health. 2017;17(1):955.

17. Orth-Gomer K, Rosengreen A, Wilhelmsen L. Lack of Social Support and Incidence of Coronary Heart Disease in Middle-Aged Swedish Men. Psychosomatic Medicine. 1993;55:37-43.

18. Nagayoshi $M$, Everson-Rose $S A$, Iso $H$, Mosley $T H$, Rose KM, Lutsey PL. Social network, social support, and risk of incident stroke: Atherosclerosis Risk in Communities study. Stroke. 2014;45(10):2868-73.

19. Ellwardt $L$, van Tilburg $T$, Aartsen $M$, Wittek $R$, Steverink N. Personal networks and mortality risk in older adults: a twenty-year longitudinal study. PloS one. 2015;10(3):e0116731. 
20. Qi L, Liu Q, Qi X, Wu N, Tang W, Xiong H. Effectiveness of peer support for improving glycaemic control in patients with type 2 diabetes: a meta-analysis of randomized controlled trials. BMC Public Health. 2015;15(1):471.

21. Schram MT, Sep SJ, van der Kallen CJ, Dagnelie PC, Koster A, Schaper N, et al. The Maastricht Study: an extensive phenotyping study on determinants of type 2 diabetes, its complications and its comorbidities. European journal of epidemiology. 2014;29(6):439-51.

22. World Health Organization. Definition and diagnosis of diabetes mellitus and intermediate hyperglycaemia. Geneva, Switserland: 2006.

23. American Academy of Ophtalmology Retina/ Vitreous Panel: Preferred practice pattern ${ }^{\circledR}$ guidelines. Diabetic retinopathy, San Francisco, CA, American Academy of Opthalmology, 2014.

24. Boulton AJ, Malik RA, Arezzo JC, Sosenko JM. Diabetic somatic neuropathies. Diabetes care. 2004;27(6):1458-86.

25. Martens RJ, Kooman JP, Stehouwer CD, Dagnelie PC, van der Kallen CJ, Koster A, et al. Estimated GFR, Albuminuria, and Cognitive Performance: The Maastricht Study. American journal of kidney diseases: the official journal of the National Kidney Foundation. 2016.

26. Ware JE, Koskinski M, Keller SD. SF-36 physical and mental health summary scales: A user's manual 2nd ed. Boston MA: The Health Institute; 1994.

27. Marsden PV. Network data and measurement. Annual review of sociology. 1990;16(1):435-63.

28. McCallister L FC. A procedure for surveying personal networks. Sociological Methods and Research. 1978:131-48.

29. Altevers J, Lukaschek K, Baumert J, Kruse J, Meisinger C, Emeny R, et al. Poor structural social support is associated with an increased risk of Type 2 diabetes mellitus: findings from the MONICA/KORA Augsburg cohort study. Diabetic Medicine. 2015.

30. Meisinger $\mathrm{C}$, Kandler $\mathrm{U}$, Ladwig $\mathrm{K}-\mathrm{H}$. Living alone is associated with an increased risk of type 2 diabetes mellitus in men but not women from the general population: the MONICA/ KORA Augsburg Cohort Study. Psychosomatic medicine. 2009; 71(7):784-8.
31. Hilding A, Shen C, Östenson C-G. Social network and development of prediabetes and type 2 diabetes in middle-aged Swedish women and men. Diabetes Research and Clinical Practice. 2015;107(1):166-77. doi: http://dx.doi.org/10.1016/j. diabres.2014.09.057.

32. Conway F, Magai C, Jones S, Fiori K, Gillespie M. A six-year follow-up study of social network changes among African-American, Caribbean, and US-born Caucasian urban older adults. The International Journal of Aging and Human Development. 2013;76(1):1-27.

33. Kaplan RM, Hartwell SL. Differential effects of social support and social network on physiological and social outcomes in men and women with Type II diabetes mellitus. Health Psychology. 1987;6(5):387.

34. Kvam SH, Lyons JS. Assessment of coping strategies, social support, and general health status in individuals with diabetes mellitus. Psychological reports. 1991;68(2):623-32.

35. Diehl M, Coyle N, Labouvie-Vief G. Age and sex differences in strategies of coping and defense across the life span. Psychology and aging. 1996;11(1):127-39.

36. Enzlin P, Mathieu C, Demyttenaere K. Gender differences in the psychological adjustment to type 1 diabetes mellitus: an explorative study. Patient Educ Couns. 2002;48(2):139-45.

37. Shaya FT, Chirikov VV, Howard D, Foster C, Costas J, Snitker S, et al. Effect of social networks intervention in type 2 diabetes: a partial randomised study. Journal of epidemiology and community health. 2014;68(4):326-32.

38. Kim DA, Hwong AR, Stafford D, Hughes DA, O'Malley AJ, Fowler JH, et al. Social network targeting to maximise population behaviour change: a cluster randomised controlled trial. The Lancet. 2015;386(9989):145-53. 

Supplemental material to chapter 5 


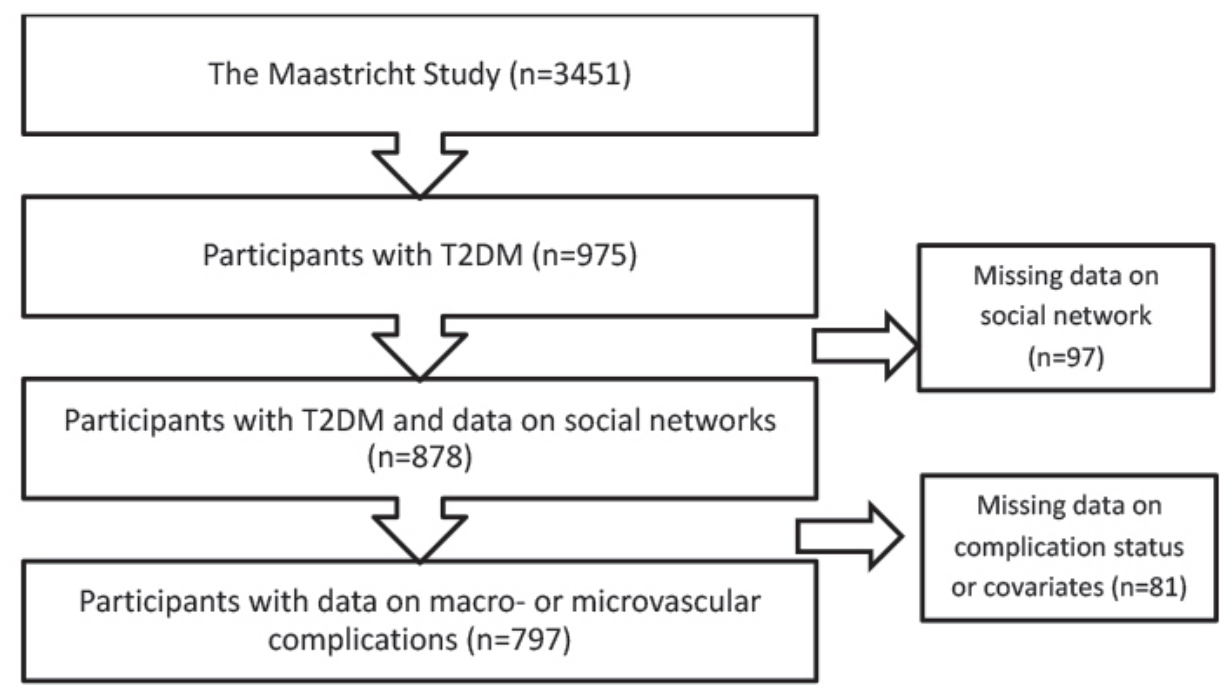

Supplemental Figure 1 - Flow chart on the study population 


\section{Supplemental Table 1-Variable descriptions of the functional and structural social network characteristics}

\begin{tabular}{|c|c|c|}
\hline Variable name & Definition & $\begin{array}{l}\text { Unit of } \\
\text { measurement } \\
\text { (possible } \\
\text { range) }\end{array}$ \\
\hline \multicolumn{3}{|c|}{ Functional characteristics of the social network } \\
\hline Informational support & $\begin{array}{l}\text { Informational support was defined as the number of network members that } \\
\text { give advice on problems }\end{array}$ & $\begin{array}{r}N \\
(0-5)\end{array}$ \\
\hline $\begin{array}{l}\text { Emotional support } \\
\text { (discomfort) }\end{array}$ & $\begin{array}{l}\text { Emotional support related to discomfort was defined as the number of } \\
\text { network members that provide emotional support when participants were } \\
\text { feeling unwell }\end{array}$ & $\begin{array}{r}N \\
(0-5)\end{array}$ \\
\hline $\begin{array}{l}\text { Emotional support } \\
\text { (important decisions) }\end{array}$ & $\begin{array}{l}\text { Emotional support related to important decisions was defined as the } \\
\text { number of network members that provide the opportunity to discuss } \\
\text { important matters }\end{array}$ & $\begin{array}{r}N \\
(0-5)\end{array}$ \\
\hline Practical support (jobs) & $\begin{array}{l}\text { Practical support related to jobs was defined as the number of network } \\
\text { members that help with small and larger jobs around the house }\end{array}$ & $\begin{array}{r}N \\
(0-5)\end{array}$ \\
\hline $\begin{array}{l}\text { Practical support } \\
\text { (sickness) }\end{array}$ & $\begin{array}{l}\text { Practical support related to sickness was defined as the number of network } \\
\text { members that provide practical help when participants were sick }\end{array}$ & $\begin{array}{r}N \\
(0-5)\end{array}$ \\
\hline
\end{tabular}

\begin{tabular}{|c|c|c|}
\hline \multicolumn{3}{|c|}{ Structural characteristics of the social network } \\
\hline Network size & $\begin{array}{l}\text { The total number of unique network members mentioned in the } \\
\text { questionnaire. }\end{array}$ & $\begin{array}{r}N \\
(0-40)\end{array}$ \\
\hline
\end{tabular}

Total contacts per half A contact was defined as an interaction between persons. Total contacts year (interactions between persons) per half year were computed as follows.

We used the highest contact frequency (e.g., daily contact) for every network member as an indicator of the actual contact frequency. Second, we recoded the answer categories of the questionnaire to an estimated number of contacts per half year. For example, "half-yearly" was assumed to comprise one contact, "quarterly" two contacts, "monthly" 6 contacts and "daily or weekly" 48 contacts. Third, we computed the sum of all contacts per half year as the total contact frequency.

Percentage of We calculated the percentage of network members that the participant had

daily-weekly contact daily or weekly contact with as the number of daily/weekly contacts divided by network size.

\begin{tabular}{|c|c|c|}
\hline \multicolumn{3}{|l|}{ Proximity } \\
\hline $\begin{array}{l}\text { Percentage of network } \\
\text { members living within } \\
\text { walking distance }\end{array}$ & $\begin{array}{l}\text { We considered geographic proximity as the percentage of all network } \\
\text { members who lived within walking distance, calculated as the number of } \\
\text { network members living within walking distance divided by network size. }\end{array}$ & $\begin{array}{r}\% \\
(0-100)\end{array}$ \\
\hline \multicolumn{3}{|l|}{ Type of relationship } \\
\hline $\begin{array}{l}\text { Percentage household } \\
\text { members }\end{array}$ & $\begin{array}{l}\text { We calculated the percentage of household members as the number of } \\
\text { network members living in the same household divided by network size. }\end{array}$ & $\begin{array}{r}\% \\
(0-100) \\
\end{array}$ \\
\hline $\begin{array}{l}\text { Percentage family } \\
\text { members }\end{array}$ & $\begin{array}{l}\text { We calculated the percentage of family members within the network as the } \\
\text { number of family members divided by the network size. }\end{array}$ & $\begin{array}{r}\% \\
(0-100) \\
\end{array}$ \\
\hline Percentage friends & $\begin{array}{l}\text { We calculated the percentage of friends within the network as the number } \\
\text { of friends divided by the network size. }\end{array}$ & $\begin{array}{r}\% \\
(0-100) \\
\end{array}$ \\
\hline $\begin{array}{l}\text { Single household size } \\
\text { (living alone) }\end{array}$ & $\begin{array}{l}\text { Single household size was defined as a person who lived alone in his/ her } \\
\text { household. }\end{array}$ & (yes/no) \\
\hline $\begin{array}{l}\text { Participation in social } \\
\text { activities }\end{array}$ & $\begin{array}{l}\text { Participation in social activities was defined as membership in, for instance, } \\
\text { a sports club, religious group, volunteer organization, discussion group, } \\
\text { self-support group, internet club, or other organization. }\end{array}$ & (yes/no) \\
\hline
\end{tabular}




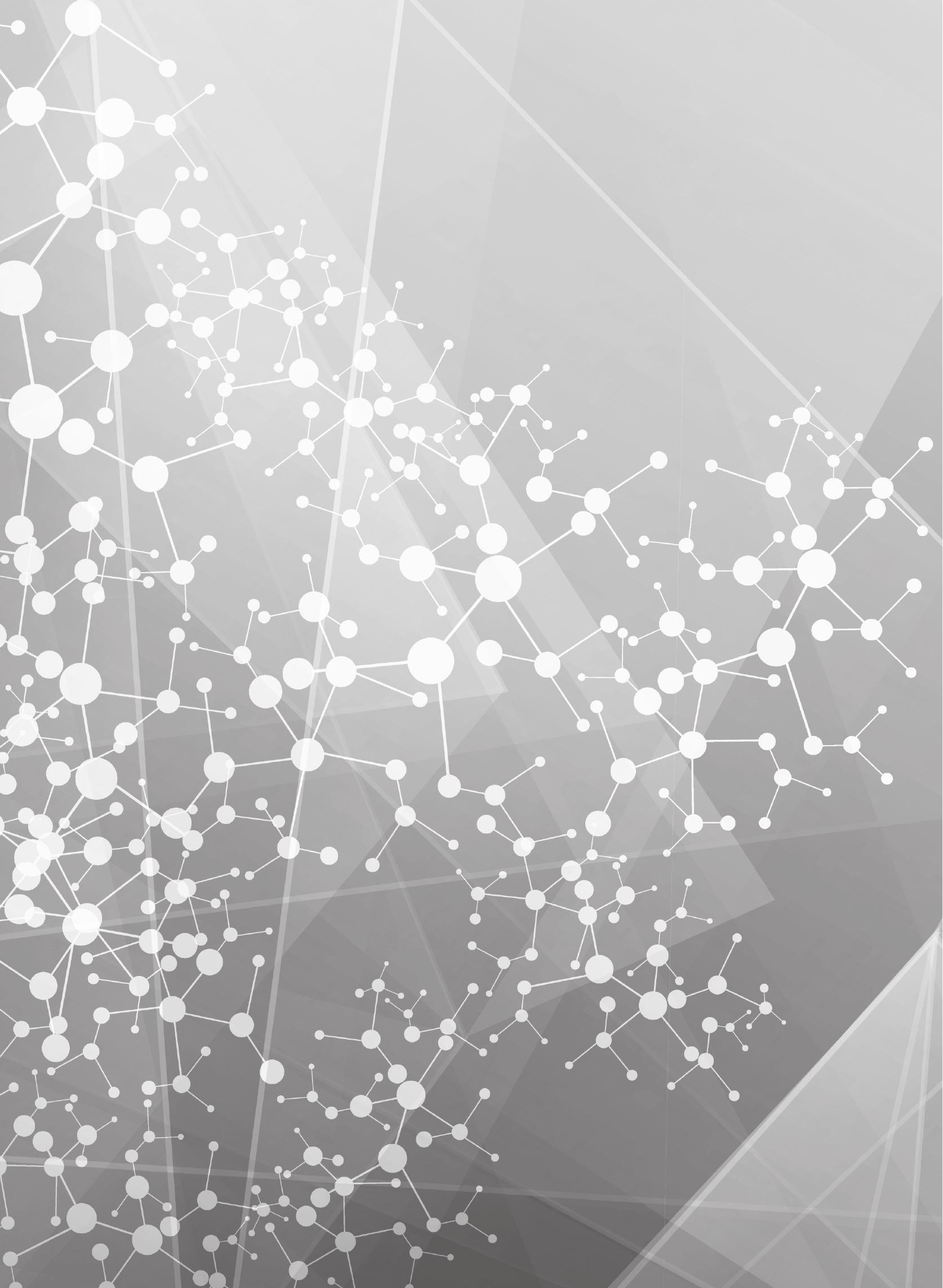




\section{Chapter 6}

General discussion 
Due to the growing group of older people, infectious disease and type 2 diabetes mellitus (T2DM) impose an enormous burden on healthcare systems and society. The need to unravel new possibilities for effective prevention strategies is therefore of utmost importance, both from a scientific perspective and from a societal perspective.

Over the last decades, the association between social networks and health has become widely recognized [1, 2], the WHO now lists 'social support networks' as determinant of health [3]. A detailed and conjoint investigation of the association between social network characteristics and infectious diseases, T2DM and its complications could offer new insights for future prevention strategies.

Therefore, the overall aim of this thesis was to examine the associations of a broad range of structural and functional social network characteristics with infectious disease and type 2 diabetes, using a novel approach of combined epidemiological and social network research.

In this chapter, we discuss the main findings of the studies on infectious diseases, T2DM and its complications. Next, an overview of the methodological considerations and challenges is presented. Finally, the potential of social networks for prevention strategies is discussed and future directions are suggested.

\section{Main findings}

\section{Social network and infectious diseases}

Infectious diseases are a major cause of mortality in older persons [4]. We currently face a gap in the management of infectious disease in older persons: a growing population [5], living longer [6], and being more susceptible to infections $[4,7]$. If we would be able to slightly lower the level of infectious disease prevalence, we might have more health impact at population level ('the population strategy') compared to individual treatment of patients (a much smaller group) [8].

In chapter 2, we identified both detrimental and beneficial associations of social network characteristics with with upper respiratory tract infections (URI), lower respiratory tract infections (LRI) and gastrointestinal tract infections (GI). A larger social network size, and a higher percentage of network members who were friends or acquaintances were associated with higher odds of URI, LRI and/or GI (detrimental). A higher total number of contacts, higher percentages of network members of the same age, and higher percentages of family members/ acquaintances were associated with lower odds of URI, LRI and/or G (beneficial). Results highlight the importance of network composition in terms of types of network members (friends, family, age) for the prevalence of infectious diseases. Previous research on infection patterns using mathematical models shows the usefulness of transmission parameters estimated directly from real data [9]. This study provides such new empirical data on the social network at the participant level, and may therefore be used to complement mathematical models of infection spread. Moreover, our findings were a first step towards the development of non-pharmaceutical infection prevention strategies, as discussed in the next chapter. 
In chapter 3, we focussed on the possible contributions of social networks for infection prevention strategies by use of statistical prediction models. The ability to predict upper respiratory infections (URI), lower respiratory infections (LRI), and gastrointestinal tract infections (GI) in independently living older persons would greatly benefit population and individual health. Social network parameters have so far not been included in prediction models. Previous attempts to develop a prediction model based on demographic, environmental, and lifestyle characteristics alone explained only a relatively small proportion of the occurrence of respiratory infections or GI [10]. Therefore, in chapter 3, we describe the development and internal validation of prediction models for URI, LRI, and GI based on a range of variables including social network parameters. The use of social network parameters in prediction models for URI, LRI, and GI seems highly promising, as all models showed adequate discriminative performance (AUC: $65-71 \%$ ) and good calibration. The main finding was that the social network parameters are strong independent predictors for infections in middle-aged and older persons. Moreover, most social network parameters that were predictive for URI, LRI and GI in our models showed a beneficial association with the three infections.

\section{Social network and type 2 diabetes}

To date, T2DM is one of the most prevalent diseases worldwide, and a growing public health burden in middle-aged and older persons [11]. T2DM can be prevented or even reversed with appropriate lifestyle changes such as healthy dietary behavior and sufficient physical activity [12]. However, the social context of patients is often neglected in regular care. Patients at risk and those who already have T2DM usually receive lifestyle advice on dietary habits and physical activity, and when needed, medication. A clear picture on the association between social network characteristics and T2DM could offer new insights for the prevention and treatment of T2DM. In chapter 4, we examined the associations of structural and functional network characteristics in individuals with pre-diabetes, newly diagnosed and previously diagnosed T2DM compared to those with normal glucose metabolism (NGM). The associations between social network characteristics and pre-diabetes and newly diagnosed T2DM have rarely been studied previously, as such data are scarce $[13,14]$. Chapter 4 demonstrates an association of structural and functional social network characteristics with newly and previously diagnosed T2DM, partially different for men and women. More socially isolated individuals (smaller social network size) more frequently had newly diagnosed and previously diagnosed T2DM. In women, proximity and the type of relationship was associated with newly diagnosed and previously diagnosed T2DM. A lack of social participation was associated with pre-diabetes as well as with previously diagnosed T2DM in women, and with previously diagnosed T2DM in men. Living alone was associated with higher odds of previously diagnosed T2DM in men, but not in women. Less emotional support related to important decisions, less practical support related to jobs, and less practical support for sickness were associated with newly diagnosed and previously diagnosed T2DM in men and women, but not in pre-diabetes. These results may provide useful targets for T2DM prevention efforts, as discussed in the after next section of this chapter. 
Having T2DM is associated with an increased risk for the development of macro- (e.g. myocardial infarction, stroke, peripheral arterial disease) and micro vascular complications (e.g. neuropathy, retinopathy, and nephropathy) $[15,16]$. As chapter 4 showed an association of several aspects of the social network with T2DM, we hypothesized an association of the social network with clinical complications as well. However, the relation between clinical complications and social network characteristics in type 2 diabetes (T2DM) has hardly been studied due to a lack of data [17]. Within The Maastricht Study we were able to examine the associations of social network characteristics with macro- and microvascular complications in T2DM, and investigated whether these associations were independent of glycemic control, quality of life, and well-known cardiovascular risk factors. Results were presented in

chapter 5. We showed an association of social network characteristics such as the network size, the type of relationship, and social support with macro- and/or microvascular complications, again partially different for men and women. A smaller social network size was associated with macrovascular complications in both men and women with T2DM. Moreover, participants with higher percentages of family members or lower percentages of friends had a significantly higher odds ratio of macrovascular complications. Further, a smaller social network size and less informational support was associated with microvascular complications only in women with T2DM.

\section{How do social networks affect health?}

Notably, mechanisms which could explain how social networks affect immune response, T2DM and its complications are not yet fully elucidated. Several mechanisms through which social networks may affect health have been proposed, including person- to- person contacts, the provision of social support, social influence, social engagement, and access to resources [18-21]. The transmission of infectious diseases by person- to- person contacts is broadly studied. Large social networks were associated with close proximity interactions with a broad range of people and hence an increased risk of exposure to a broad range of infectious agents $[9,22,23]$. Infectious diseases spread from person-toperson by direct contact (e.g. shaking hands or hugging), indirect contact (e.g. via contaminated objects), or by airborne transmission [24]. However, the mechanisms through which social network characteristics may increase immune function or affect T2DM and related complications were less elucidated $[20,25]$. Larger social networks and higher levels of social support may potentially have a buffering effect on the pathophysiologic processes in the body [26]. Prior studies have provided evidence for the buffering hypothesis stating social relations protect individuals from potentially adverse effects of stressful events [27]. Moreover, social networks may have important impact on an individuals lifestyle and self-management through social influence and access to resources [28]. A larger social network may help people to improve or maintain a healthy lifestyle, for example the awareness on a healthy diet containing fresh fruit and vegetables, and being physically active is important, could be higher within a large and diverse network. In addition, a more diverse network may also consist of more people who already have a more healthy lifestyle, and could therefore act as a role model for other network members [29]. 


\section{Methodological considerations and challenges}

The results of the studies in this thesis need to be interpreted with consideration of methodological limitations and challenges. The study design, selection of the study population, and social network assessment used in this thesis will be discussed in the following paragraphs.

\section{Study design}

Within the studies presented in this thesis, we used cross-sectional data from The Maastricht Study, a large scale population-based cohort study [30]. One of the advantages of The Maastricht Study is its population-based design. Moreover, the comprehensive assessment of functional and structural network characteristics provides new empirical data on the social network at the participant level. Furthermore, study participants were well-characterized, allowing adjustment for an extensive series of potential confounders, which makes residual confounding unlikely [31]. However, all analyses within this thesis were of observational nature, in a cross-sectional setting. Therefore, causality could not be determined. As both the independent and the outcome variables were measured at the same point in time, reverse causality cannot be excluded [32].

\section{Selection of the study population}

Procedures used to include participants or factors that influence participation in a study may result in selection bias [31]. "The common element of such biases is that the relation between exposure and disease is different for those who participate and for all of them who should have been theoretically eligible for study, including those who do not participate" [31]. When selection bias occurs, associations in a study may differ from those in the source population, which may lead to overestimation or underestimation of the effect size of the association [31]. The extensive phenotyping of The Maastricht Study forces participants to cover 4 half-day visits at the research center, which may be difficult for relatively unhealthy individuals (e.g. individuals with mobility problems), or those who work and travel a lot and have many contacts, or on the contrary, those in the population who were the most socially isolated. Therefore, selection bias may have occurred in the studies presented in this thesis.

Second, the age-range of the study population of 40-75 years may be a limitation for the associations assessed in part I of this thesis. As inclusion starts from the age of 40 , and the mean age of the study population was 60 years, this may lead to an underrepresentation of young children in the participants network, while it has been shown that children and teenagers may have an important role in the spread of close-contact infections [33]. However, this is only applicable for participants in the younger age-range, as with increasing age, the probability of grandchildren rises. 


\section{Social network assessment}

Social networks are, by definition, hard to measure [22]. Our assessment of egocentric social networks also has strengths and limitations. Social networks can be measured by different methods, such as observations, contact diaries and surveys [23]. One of the survey methods is the name generator/interpreter method used in this thesis.

Name generators are characterized by self-reported data, and self-report may be subject to bias, such as recall bias. In the studies presented in this thesis, we used a specific type of Name Generator, called the "exchange relationship name generator", originally developed by McCallister and Fischer (1978) [34]. This method uses questions featuring various support exchanges between people, to which respondents reply with names of people with whom they have exchanged or possibly could perform future exchanges [34]. The list of network members recalled via Name Generators may be biased towards network members who are closer to the respondent, who have shared a longer history with the respondent, and who know more of the respondents other network members [35]. Nonetheless, networks generated with the exchange type Name Generator have been shown to be larger than those with other types of name generators [36]. For the purpose of this thesis, the exchange relationship name generator seems to be the most useful instrument: it elicits the largest and most diverse networks, thereby having the highest potential to minimize recall bias.

Further, the assumptions made to calculate the total number of contacts may under- or overestimate the actual total number of contacts. For every network members named, the highest contact frequency (e.g. monthly contact) was used as an indicator of actual contact frequency, and as participants report to meet one network member every month on several questions, this network member is assumed to be met on a monthly basis. It is possible however that the participant met this network member once a month for one activity, but also once a month for another activity. Moreover, the "daily or weekly" answer category was assumed to refer to two contacts per week. This assumption, too, may result in an under- or overestimation of the actual contact frequency.

Another point to be discussed for part I of this thesis is that close contacts are a better proxy for several infection transmissions than total contacts [22,37]. Our assessment consisted of seven name generator items on different types of interactions, some of these types require direct close interactions (such as visits for social purposes or offering practical help), and other types of interactions may also have occurred by telephone/internet conversations (such as provision of emotional support or advise on problems). Therefore, estimations of the total network size and total contact frequency may over represent the actual number of close proximity interactions. To assess the proportion of close proximity interactions vs. the proportion of interactions which may potentially have occurred by telephone/internet, we additionally computed the network size and total contact frequency from those type of interactions with network members which are by definition in close proximity and/or household contacts. The social network size restricted to close proximity interactions was 8,5 network members in a total number of network members of 10 , therefore, the large majority $(86 \%)$ of the interactions for each study participant are in close proximity. The total contact frequency of close proximity interac- 
tions of these four types was 202 out of 231 per half year. Therefore, the large majority ( $87 \%$ ) of the total contact frequency was in close proximity. The remaining contacts may have occurred by telephone/ internet but are probably also (in part) direct close proximity interactions as they concern advice on problems, emotional support, and discussion of important matters. For the assessment of the relationship between social networks and infectious diseases, we were both interested in the direct transmission of an infection from one individual to another, and the underlying mechanisms on immune function and susceptibility. Therefore, we feel that inclusion of potentially indirect contact is relevant to examine both the detrimental and beneficial associations of the social network.

Another limitation of the name generator may be missing information on the duration of contacts between the participant and the network members, which has often been used in infectious disease modelling $[33,38,39]$. These models assume a linear function between the average dose of infectious material ingested by an individual and the duration and intensity of the contact with an infectious individual [40]. However, it is not yet elucidated whether a longer duration and higher intensity of contacts have beneficial effects as well.

\section{Potential of social networks for prevention strategies}

\section{Infectious diseases}

Chapter $\mathbf{2}$ and $\mathbf{3}$ showed detrimental as well as beneficial associations with URI, LRI and GI. Based on the results of our studies and previous investigations, we feel that the potential of the social network parameters for infectious disease prevention strategies is twofold. First, the beneficial social network parameters may be used as potential determinants which can be reinforced by preventive interventions. Current EU policy expects older persons to take care of themselves as much as possible with help of their social network [41]. New prevention strategies should fit this policy. For example, in future prevention strategies, the relation to close proximity and same-age network members could be reinforced. Moreover, future prevention strategies may aim to enhance practical and informational support from network members. Previously, higher levels of social support have already been shown to associate with enhanced immune function $[42,43]$. Second, the prediction rules could be used to compute an individual's probability of an infection given a defined set of parameters. For example, the prediction models may be used in a practical tool which could be offered to middle-aged and older people in order to calculate their risk of infection, followed by an tailored advice on infection prevention (e.g. hand and environmental hygiene). The use of social network based prediction models in the prevention of infections in middle-aged and older persons may result in high benefits on a population level, contributing to "healthy ageing" of the population.

Reinforcement of the beneficial characteristics of the social network or the use of social network based prediction rules would be a novel approach within infectious disease control in the Netherlands, which is mainly focused on surveillance, outbreak management and vaccination strategies [44]. We 
feel that such a novel approach is highly promising and further investigation, especially in longitudinal data, would be valuable.

\section{Type 2 diabetes and its complications}

Chapter $\mathbf{4}$ and $\mathbf{5}$ highlight the associations of social support and social network members with both T2DM and diabetes complications. We feel that health care professionals should be aware of the relation between the social network and T2DM and related complications. Recently, Holdt-Lunstadt et al. (2016) concluded that attention to social connections needs to be incorporated into existing treatment and prevention strategies [45]. Knowledge of a patients network and social support may render treatment strategies and lifestyle interventions more effective when tailored to the specific needs and network characteristics of the individual. The social context can be of crucial importance to adopt and succeed in lifestyle change, and therefore, prevention strategies aiming to generate behavioral change (e.g., dietary advice, physical activity) may also tailor the social network of the participant, as network targeting has been shown to increase the adoption of specific prevention strategies [46]. Moreover, social network characteristics itself may prove an independent target in non-pharmaceutical and nonmedical prevention strategies which aim to prevent the development of T2DM as well as in T2DM patients to prevent clinical complications. Our findings support the efforts to develop effective prevention strategies which tailor social network characteristics [46-49], however, it is important to assess whether these prevention strategies meet the specific needs of the participant.

Based on the results of our studies and previous investigations, we would suggest to consider structural as well as functional characteristics of the social network in future prevention strategies. For example, socially isolated individuals, with a smaller social network size, more often had T2DM and macro- and microvascular complications. Broadening the social network may be encouraged, as reinforcement of social networking has been shown to improve Hbalc and blood glucose [48]. Moreover, lack of social participation was associated with pre-diabetes and previously diagnosed T2DM, therefore, stimulating participants to become member of a club may also be considered in future prevention strategies. Further, we would suggest to address the type of relationships and social support in future prevention strategies aiming to reduce the burden of disease in T2DM. Our results mirror previous findings, indicating that men living alone have a higher risk for the development of T2DM [50]. Therefore, we feel that men living alone should be indicated as high-risk group.

Notably, when including social network characteristics in future prevention strategies, differences in social network characteristics between men and women should be taken into account, there is no "one size fits all" approach. 


\section{Future directions}

In this thesis, we consistently showed associations of structural and functional social network characteristics with infectious diseases, T2DM and diabetes complications. Based on the findings discussed in this thesis, I recommend that future research should preferably...

\section{...include longitudinal data}

The evidence provided in this thesis comes from a series of cross-sectional analyses. Some of our findings were confirmed in longitudinal studies, however, as we conducted a more detailed and conjoint investigation of the association between structural and functional social network characteristics and infectious diseases, T2DM and its complications, new insights provided in this thesis need confirmation in longitudinal data.

...include exploration on the underlying pathways

The influence of social networks on health is complex and multifactorial [45]. Pathways and mechanisms through which social networks could affect immune response, T2DM and its complications are not yet fully understood. Therefore, more evidence on the possible pathways and mechanisms is essential.

...take potential differences between men and women into account

Within the studies presented in this thesis, we found partially different associations between social network characteristics and T2DM and microvascular complications for men and women. However, the associations of social network characteristics with infectious diseases and macrovascular complications did not differ for men and women. Future studies on the associations between social networks and health-related outcomes should examine potential sex differences.

...incorporate social network characteristics in future prevention strategies

This thesis provided important insight in the associations between social networks and health. Based on evidence provided in this thesis and by previous investigations, I suggest to incorporate social networks in future prevention strategies.

...investigate a practical application

The use of social network based prediction models in the prevention of infections in middle-aged and older persons may result in high benefits on a population level. Based on the findings in chapter 3,1 suggest to translate the prediction models into practical infection-prevention strategies, for example into a practical web-tool. 


\section{References}

1. Heaney, C.A. and B.A. Israel, Social networks and social support, in Health Behavior and Health Education, K. Glanz, B.K. Rimer, and K. Viswanath, Editors. 2008, Jossey Bass: San Francisco. p. 189-210.

2. Berkmann, L.F., et al., From social integration to health: Durkheim in the new millennium. Social Science \& Medicine, 2000. 51: p. 843-857.

3. World Health Organization. The determinants of health. 1-6-2018]; Available from: http:// www.who.int/hia/evidence/doh/en/.

4. Yoshikawa, T.T., Epidemiology and unique aspects of aging and infectious diseases. Clinical Infectious Diseases, 2000. 30(6): p. 931-3.

5. World Health Organization, Active Ageing: A Policy Framework. 2002, World Health Organization: Geneva.

6. Rechel, B., et al., Ageing in the European Union. The Lancet, 2013. 381(9874): p. 1312-1322.

7. Strausbaugh, L.J., Emerging health care-associated infections in the geriatric population. Emerging Infectious Diseases, 2001. 7(2): $p$. 268-71.

8. Rose, G., Sick individuals and sick populations. International journal of epidemiology, 2001. 30(3): p. 427-432.

9. Wallinga, J., P. Teunis, and M. Kretzschmar, Using data on social contacts to estimate age-specific transmission parameters for respiratory-spread infectious agents. American Journal of Epidemiology, 2006. 164(10): p. 936944.

10. Hovi, T., et al., Development of a prognostic model based on demographic, environmental and lifestyle information for predicting incidences of symptomatic respiratory or gastrointestinal infection in adult office workers. Trials, 2016. 17(1): p. 545.

11. Wild, S., et al., Global prevalence of diabetes estimates for the year 2000 and projections for 2030. Diabetes care, 2004. 27(5): p. 1047-1053.

12. Steyn, N.P., et al., Diet, nutrition and the prevention of type 2 diabetes. Public Health Nutr, 2004. 7(1a): p. 147-65.
13. Hilding, A., C. Shen, and C.-G. Östenson, Social network and development of prediabetes and type 2 diabetes in middle-aged Swedish women and men. Diabetes Research and Clinical Practice, 2015. 107(1): p. 166-177.

14. Gallo, L.C., et al., Associations of structural and functional social support with diabetes prevalence in U.S. Hispanics/Latinos: results from the HCHS/SOL Sociocultural Ancillary Study. J Behav Med, 2015. 38(1): p. 160-70.

15. Williams, R., L. Van Gaal, and C. Lucioni, Assessing the impact of complications on the costs of Type II diabetes. Diabetologia, 2002. 45(7): p. S13-S17.

16. Beulens, J.W., D.E. Grobbee, and B. Nealb, The global burden of diabetes and its complications: an emerging pandemic. European Journal of Cardiovascular Prevention \& Rehabilitation, 2010. 17(1 suppl): p. s3-s8.

17. Dunkler, D., et al., Modifiable lifestyle and social factors affect chronic kidney disease in highrisk individuals with type 2 diabetes mellitus. Kidney international, 2015. 87(4): p. 784-791.

18. Berkman, L.F. and T. Glass, Social integration, social networks, social support, and health. Social epidemiology, 2000. 1: p. 137-173.

19. 19. Umberson, D. and J.K. Montez, Social Relationships and Health: A Flashpoint for Health Policy. J Health Soc Behav, 2010. 51(Suppl): p. S54-66.

20. 20. Uchino, B.N., et al., Psychological Pathways Linking Social Support to Health Outcomes: A Visit with the "Ghosts" of Research Past, Present, and Future. Social science \& medicine (1982), 2012. 74(7): p. 949-957.

21. Martire, L.M. and M.M. Franks, The role of social networks in adult health: introduction to the special issue. Health Psychology, 2014. 33(6): p. 501.

22. Salathé, M., et al., A high-resolution human contact network for infectious disease transmission. Proceedings of the National Academy of Sciences, 2010. 107(51): p. 22020-22025.

23. Read, J.M., et al., Close encounters of the infectious kind: methods to measure social mix- 
ing behaviour. Epidemiology \& Infection, 2012. 140(12): p. 2117-2130.

24. Stein, M.L., et al., Comparison of Contact Patterns Relevant for Transmission of Respiratory Pathogens in Thailand and the Netherlands Using Respondent-Driven Sampling. PloS one, 2014. 9(11): p. e113711.

25. Cohen, S., et al., Social Ties and susceptibility to the Common Cold. JAMA, 1997. 277(24): p. 19401944.

26. Uchino, B.N., J.T. Cacioppo, and J.K. Kiecolt-Glaser, The Relationship Between Social Support and Physiological Processes: A Review With Emphasis on Underlying Mechanisms and Implications for Health. Psychological Bulletin, 1996. 119(3): p. 488-531.

27. Cohen, S. and T.A. Wills, Stress, social support, and the buffering hypothesis. Psychological bulletin, 1985. 98(2): p. 310.

28. Newton-John, T.R., et al., 'Are you sure you're going to have another one of those?': A qualitative analysis of the social control and social support models in type 2 diabetes. Journal of Health Psychology, 2017. 22(14): p. 1819-1829.

29. Heijmans, N., J. van Lieshout, and M. Wensing, Social network composition of vascular patients and its associations with health behavior and clinical risk factors. PloS one, 2017. 12(9): p. e0185341.

30. Schram M, et al., The Maastricht Study: An Extensive Phenotyping Study on Determinants of Type 2 Diabetes, its Complications and its Comorbidities. European Journal of Epidemiology, 2014.

31. Rothman, K.J., S. Greenland, and T.L. Lash, Modern epidemiology. 2008.

32. Stommel, M. and C. Wills, Clinical research: Concepts and principles for advanced practice nurses. 2004: Lippincott Williams \& Wilkins.

33. Mossong, J.L., et al., Social contacts and mixing patterns relevant to the spread of infectious diseases. PLoS medicine, 2008. 5(3): p. e74.

34. McCallister, L. and C. Fischer, A procedure for surveying personal networks. Sociological Methods and Research 1978. 7: p. 131-148.

35. Marin, A., Are respondents more likely to list al- ters with certain characteristics?: Implications for name generator data. Social Networks, 2004. 26(4): p. 289-307.

36. Van Sonderen, E., et al., Personal network delineation: A comparison of the exchange, affective and role-relation approach. 1990.

37. Kucharski, A.J., et al., The contribution of social behaviour to the transmission of influenza $A$ in a human population. PLoS pathogens, 2014. 10(6): p. e1004206.

38. tehle, J., et al., Simulation of an SEIR infectious disease model on the dynamic contact network of conference attendees. BMC Med, 2011. 9: p. 87.

39. Machens, A., et al., An infectious disease model on empirical networks of human contact: bridging the gap between dynamic network data and contact matrices. BMC Infect Dis, 2013. 13: p. 185.

40. Smieszek, T., A mechanistic model of infection: why duration and intensity of contacts should be included in models of disease spread. Theoretical Biology and Medical Modelling, 2009. 6(1): p. 25.

41. REPORT FROM THE COMMISSION TO THE EUROPEAN PARLIAMENT, THE COUNCIL, THE EUROPEAN ECONOMIC AND SOCIAL COMMITTEE AND THE COMMITTEE OF THE REGIONS on the implementation, results and overall assessment of the 2012 European Year for Active Ageing and Solidarity between Generations. 2014, Council of the European Union: Brussels.

42. Miyazaki, T., et al., Association between perceived social support and Th1 dominance. Biological psychology, 2005. 70(1): p. 30-37.

43. Lutgendorf, S.K., et al., Social support, psychological distress, and natural killer cell activity in ovarian cancer. Journal of Clinical Oncology, 2005. 23(28): p. 7105-7113.

44. Riesmeijer, R.M. and J.T. van Dissel, RIVM-Centrum Infectieziektebestrijding Strategie 20162021. 2017.

45. Holt-Lunstad, J. and T.B. Smith, Loneliness and social isolation as risk factors for CVD: implications for evidence-based patient care and scientific inquiry. Heart, 2016. 102(13): p. 987989. 
46. Kim, D.A., et al., Social network targeting to maximise population behaviour change: a cluster randomised controlled trial. The Lancet, 2015. 386(9989): p. 145-153.

47. Heaney, C.A. and B.A. Israel, Social networks and social support. Health behavior and health education: Theory, research, and practice, 2008. 4: p. $189-210$

48. Shaya, F.T., et al., Effect of social networks intervention in type 2 diabetes: a partial randomised study. Journal of epidemiology and community health, 2014. 68(4): p. 326-332.

49. Spencer-Bonilla, G., et al., A systematic review and meta-analysis of trials of social network interventions in type 2 diabetes. BMJ Open, 2017. 7(8).

50. Meisinger, C., U. Kandler, and K.-H. Ladwig, Living alone is associated with an increased risk of type 2 diabetes mellitus in men but not women from the general population: the MONICA/KORA Augsburg Cohort Study. Psychosomatic medicine, 2009. 71(7): p. 784-788. 



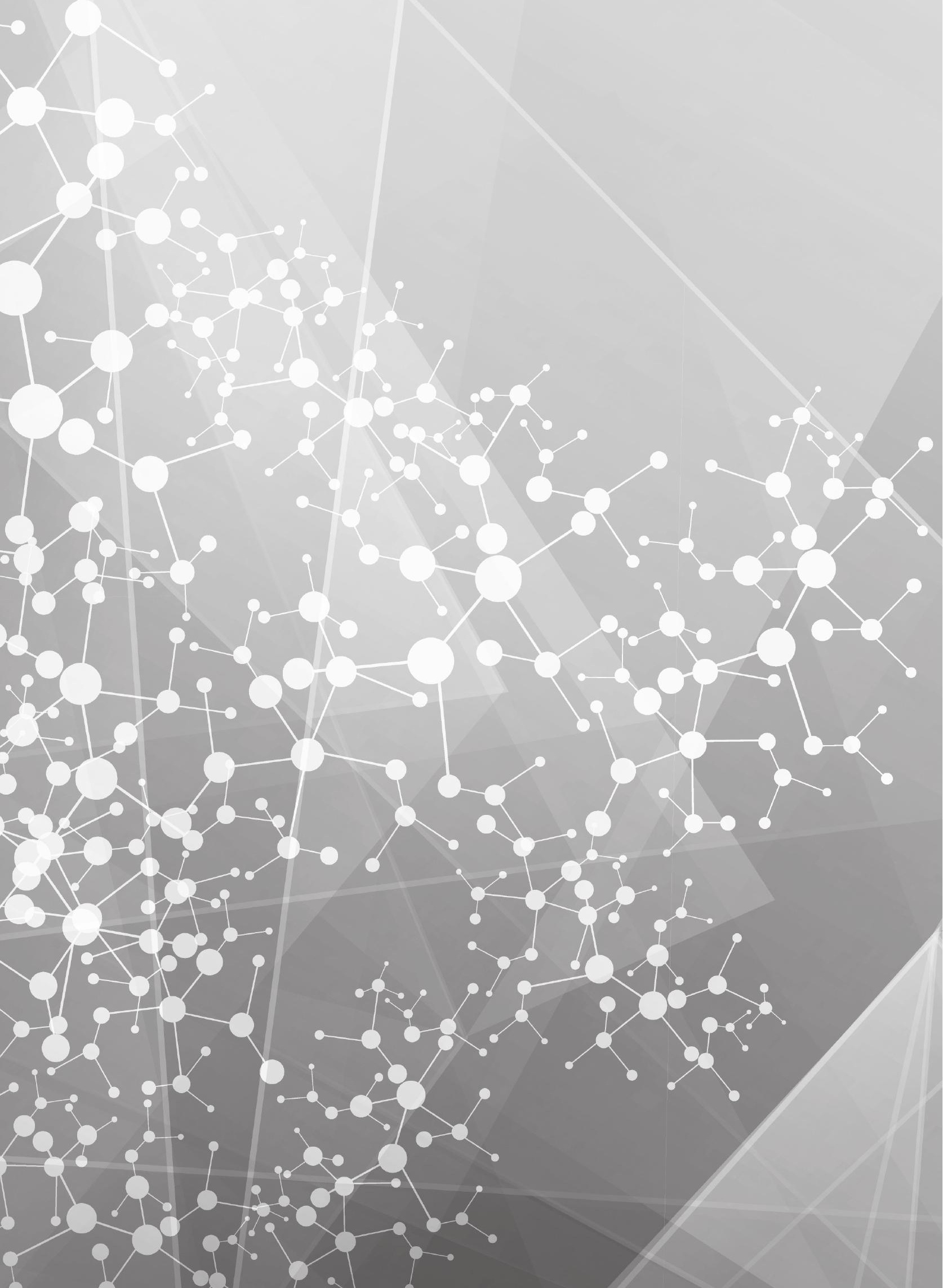




\section{Chapter 7}

\section{Summary}

Samenvatting

Valorisation of the thesis

Dankwoord

Curriculum Vitae

Portfolio

List of Publications 

Summary 
Population ageing has become a global issue. Due to the growing group of older people, infectious disease and type 2 diabetes mellitus (T2DM) impose an enormous burden on healthcare systems and society. Therefore, there is a need to increase knowledge about how to promote good health among older persons and how to prevent costly and negative impacts on the population as a whole. Over the last decades, there is increasing recognition for the powerful influence of social relationships on morbidity and mortality. In this thesis, we focussed on the associations between social networks and health, illustrated by studies on infectious diseases and type 2 diabetes mellitus (T2DM).

Most infections are spread through social networks (detrimental effect). However, social networks may also lower infection acquisition (beneficial effect). In chapter 2 we assessed the detrimental and beneficial associations of social network characteristics with upper respiratory tract infections (URI), lower respiratory tract infections (LRI), gastrointestinal tract infections (GI), and urinary tract infections (UTI). A larger network size was associated with a higher prevalence of URI and GI, while a high total number of contacts was associated with less URI and LRI. In addition, participants with networks mainly composed of friends presented a higher prevalence of LRI and GI, as opposed to those with a higher family percentage, who presented lower LRI and GI prevalences. Finally, a higher percentage of network members of the same age was associated with lower URI, LRI and GI prevalences. We found no clear associations with UTI. This study provides new empirical data on the social network at the participant level, and may therefore be used to complement mathematical models of infection spread. Moreover, our findings were a first step towards the development of non-pharmaceutical infection prevention strategies, as discussed in the next chapter.

The ability to predict infectious diseases in independently living older persons would greatly benefit population and individual health. Social network parameters have so far not been included in prediction models. In chapter 3 , we developed and internally validated three prediction models for URI, LRI and $\mathrm{Gl}$ in a period of two months. The models were able to discriminate between those who experienced an infection and those who did not, and had good calibration. The main finding was that the social network parameters are strong independent predictors for infections in middle-aged and older persons. Moreover, most social network parameters had a beneficial association with the three infections. As such, social network parameters are likely to be highly promising concepts in future infection prevention strategies in older persons living at home. This study shows that the preventive potential of the social network parameters is twofold. Social network parameters may be used as potential determinants that can be addressed in a practical intervention in older persons, or in a predictive tool to compute an individual's probability of an infection.

Although T2DM is preventable, the prevalence is still raising. A clear picture on the association between social network characteristics and T2DM could contribute to effective prevention strategies for T2DM. In chapter $\mathbf{4}$ we assessed the associations of a broad range of structural and functional social 
network characteristics with normal glucose metabolism, pre-diabetes, newly diagnosed T2DM and previously diagnosed T2DM. More socially isolated individuals (smaller social network size) more frequently had newly diagnosed and previously diagnosed T2DM, while this association was not observed with pre-diabetes. In women, proximity and the type of relationship was associated with newly diagnosed and previously diagnosed T2DM. A lack of social participation was associated with pre-diabetes as well as with previously diagnosed T2DM in women, and with previously diagnosed T2DM in men. Living alone was associated with higher odds of previously diagnosed T2DM in men, but not in women. Less emotional support related to important decisions, less practical support related to jobs, and less practical support for sickness were associated with newly diagnosed and previously diagnosed T2DM in men and women, but not in pre-diabetes. This study shows an association of several aspects of structural and functional characteristics of the social network with newly and previously diagnosed T2DM, partially different for men and women. These results may provide useful targets for T2DM prevention strategies.

Patients with T2DM have an increased risk for the development of micro- (e.g. neuropathy, retinopathy, and nephropathy) and macrovascular complications (e.g. myocardial infarction, stroke, peripheral arterial disease). In chapter 5 we examined the associations of social network characteristics with macro- and microvascular complications in T2DM, and investigated whether these associations were independent of glycemic control, quality of life, and well-known cardiovascular risk factors. A smaller social network size was associated with macrovascular complications in both men and women with T2DM. Moreover, the type of relationship in terms of family members and friends was associated with macrovascular complications, participants with higher percentages of family members or lower percentages of friends had a significantly higher odds ratio of macrovascular complications. These associations appeared to be independent of glycemic control, QoL, and other cardiovascular risk factors. Further, a smaller social network size and less informational support was associated with microvascular complications only in women with T2DM. In men, living alone was associated with microvascular complications, however, this association was explained by QoL and CVD risk factors. Health care professionals should be aware of the association of the social network with T2DM outcomes. In the development of prevention strategies, social network characteristics should be taken into account.

In chapter 6, we discuss the main findings of the studies on infectious diseases, T2DM and its complications. Next, an overview of the methodological considerations and challenges is presented. Finally, the potential of social networks for prevention strategies is discussed and future directions are suggested. The studies presented in this thesis consistently showed associations of structural and functional social network characteristics with infectious disease, T2DM and diabetes complications. Our results indicate that social networks may be a promising target in infection prevention strategies, as well as in prevention strategies aiming to reduce the prevalence of T2DM and micro-/ macrovascular complications. 

Samenvatting 
Vergrijzing van de bevolking is een wereldwijd probleem. Vanwege de groeiende groep ouderen vormen vooral infectieziekten en diabetes mellitus type 2 (T2DM) een grote belasting voor de gezondheidszorg en de samenleving. Daarom is er behoefte aan meer kennis over het bevorderen van de gezondheid van ouderen en de preventie van de dure en negatieve gevolgen voor de hele bevolking. In de afgelopen decennia is er steeds meer erkenning gekomen voor de sterke invloed van sociale relaties op morbiditeit en mortaliteit. In dit proefschrift hebben we ons gericht op de associaties tussen sociale netwerken en gezondheid, aan de hand van studies over infectieziekten en type 2 diabetes mellitus (T2DM).

De meeste infecties worden verspreid via sociale netwerken (negatief effect). Echter, sociale netwerken kunnen de infectie-acquisitie ook verminderen (positief effect).

In hoofdstuk 2 hebben wij zowel negatieve als positieve associaties van sociale netwerkkenmerken met bovenste luchtweginfecties, onderste luchtweginfecties, maag-darminfecties en urineweginfecties onderzocht. Een groter sociaal netwerk was geassocieerd met een hogere prevalentie van bovenste luchtweginfecties en maag-darminfecties, terwijl een groter aantal contactmomenten geassocieerd was met een lagere prevalentie van bovenste en onderste luchtweginfecties. Bovendien vertoonden deelnemers met netwerken die voornamelijk bestonden uit vrienden een hogere prevalentie van onderste luchtweginfecties en maag-darminfecties. Daarentegen vertoonden mensen met netwerken die voornamelijk bestonden uit familieleden een lagere prevalentie van onderste luchtweginfecties en maag-darminfecties. Ten slotte was een hoger percentage netwerkleden van dezelfde leeftijd geassocieerd met lagere prevalentie van bovenste en onderste luchtweginfecties en maagdarminfecties. We hebben geen duidelijke associaties kunnen aantonen tussen het sociale netwerk en urineweginfecties. Deze studie biedt nieuwe, empirische gegevens over het sociale netwerk op persoonsniveau en kan daarom worden gebruikt als aanvulling op mathematische modellen voor de berekening van de verspreiding van infectieziekten. Bovendien waren onze bevindingen een eerste stap naar de ontwikkeling van niet-farmaceutische infectiepreventiestrategieën, zoals besproken in het volgende hoofdstuk.

De mogelijkheid om infectieziekten te voorspellen bij zelfstandig wonende ouderen zou de individuele gezondheid en de volksgezondheid enorm ten goede komen. Sociale netwerkkenmerken zijn tot nu toe nog niet gebruikt in predictiemodellen. In hoofdstuk $\mathbf{3}$ hebben we predictiemodellen ontwikkeld en intern gevalideerd voor bovenste luchtweginfecties, onderste luchtweginfecties, en maag-darminfecties in een periode van twee maanden. Deze drie modellen konden onderscheid maken tussen mensen die wel of geen infectie hebben gehad, en hadden een goede kalibratie. De belangrijkste bevinding was dat de sociale netwerkkenmerken sterke onafhankelijke voorspellers zijn voor infecties bij mensen van middelbare leeftijd en ouderen. Bovendien vertoonden de meeste sociale netwerkparameters een voordelige associatie met de drie infecties. Mede hierdoor zijn sociale netwerkkenmerken veelbelovende concepten voor infectiepreventiestrategieën. Het preventieve potentieel van de sociale netwerkkenmerken is tweeledig. Sociale netwerkkenmerken kunnen gebruikt worden in een praktische 
interventie voor ouderen als potentiële determinanten, of in een voorspellende "tool" om de persoonlijke kans op een infectie te berekenen.

Ondanks dat T2DM voorkomen kan worden, neemt de prevalentie nog steeds toe. Een duidelijk beeld van de relatie tussen sociale netwerkkenmerken en T2DM kan bijdragen aan effectieve preventiestrategieën voor T2DM. In hoofdstuk $\mathbf{4}$ hebben we associaties onderzocht van een breed spectrum aan structurele en functionele sociale netwerkkenmerken met een normaal glucosemetabolisme, prediabetes, nieuw gediagnosticeerd T2DM en eerder gediagnosticeerd T2DM. Meer sociaal-geïsoleerde individuen (kleiner sociaal netwerk) hadden vaker nieuwe en eerder gediagnosticeerde T2DM, terwijl deze associatie niet werd aangetoond bij pre-diabetes. Bij vrouwen was de geografische afstand en het type relatie geassocieerd met nieuwe en eerder gediagnosticeerde T2DM. Een gebrek aan sociale participatie was geassocieerd met pre-diabetes en met eerder gediagnosticeerde T2DM bij vrouwen, en alleen met eerder gediagnosticeerd T2DM bij mannen. Alleenwonend was geassocieerd met eerder gediagnosticeerde T2DM bij mannen, maar niet bij vrouwen. Minder emotionele steun bij belangrijke beslissingen, minder praktische ondersteuning bij klusjes en minder praktische ondersteuning bij ziekte waren geassocieerd met nieuw gediagnosticeerde en eerder gediagnosticeerde T2DM bij mannen en vrouwen, maar niet met pre-diabetes. Deze studie toont een associatie van verschillende aspecten van structurele en functionele kenmerken van het sociale netwerk met nieuw en eerder gediagnosticeerd T2DM, soms verschillend voor mannen en vrouwen. Deze resultaten kunnen aangrijpingspunten bieden voor T2DM-preventiestrategieën.

Patiënten met T2DM hebben een verhoogd risico op de ontwikkeling van macro- (bijvoorbeeld myocardiaal infarct, beroerte, perifere arteriële ziekte) en microvasculaire complicaties (bijvoorbeeld neuropathie, retinopathie en nefropathie). In hoofdstuk $\mathbf{5}$ hebben we de associaties van sociale netwerkkenmerken met macro- en microvasculaire complicaties in T2DM onderzocht en gekeken of deze associaties onafhankelijk waren van glycemische controle, kwaliteit van leven en andere bekende cardiovasculaire risicofactoren. Een kleiner sociaal netwerk was geassocieerd met macrovasculaire complicaties bij zowel mannen als vrouwen met T2DM. Bovendien was het type relatie, met name het percentage familieleden en vrienden, geassocieerd met macrovasculaire complicaties. Deelnemers met hogere percentages familieleden of lagere percentages vrienden hadden vaker macrovasculaire complicaties. Deze associaties waren onafhankelijk van glycemische controle, kwaliteit van leven en andere cardiovasculaire risicofactoren. Verder was bij vrouwen met T2DM een kleiner sociaal netwerk en minder informatieve ondersteuning geassocieerd met microvasculaire complicaties. Bij mannen was alleenwonend geassocieerd met microvasculaire complicaties, maar deze associatie werd verklaard door kwaliteit van leven en risicofactoren voor hart- en vaatziekten. Gezondheidsdeskundigen zouden zich bewust moeten worden van de associatie tussen het sociale netwerk en T2DM-uitkomsten. Bij de ontwikkeling van preventiestrategieën zou rekening moeten worden gehouden met iemands sociaal netwerk. 
In hoofdstuk 6 bespreken we de belangrijkste bevindingen van de onderzoeken naar infectieziekten, T2DM en diabetescomplicaties. Vervolgens wordt een overzicht van de methodologische overwegingen en uitdagingen gepresenteerd. Ten slotte wordt het potentieel van sociale netwerken voor preventiestrategieën en toekomstige richtingen besproken. De studies in dit proefschrift hebben consequent associaties aangetoond van structurele en functionele sociale netwerkkenmerken met infectieziekten, T2DM en diabetescomplicaties. Onze resultaten wijzen erop dat het sociaal netwerk een veelbelovend aangrijpingspunt kan zijn in infectiepreventiestrategieën, evenals in preventiestrategieën die gericht zijn op het verminderen van de prevalentie van T2DM en van micro-/macrovasculaire complicaties. 
Valorisation of the thesis 


\section{Valorisation addendum}

Over the last decade, population ageing has become a global issue and, according to the WHO, one of the greatest challenges in the $21^{\text {st }}$ century. The research presented in this thesis is of importance for both science and society, as it is driven by a societal problem and practical question, i.e. how can we increase health in the growing group of older persons?

\section{Infectious diseases}

\section{Social relevance}

Human aging is increasingly represented by frailty, with declining reserve function of many organ systems, including the immune system. The incidence and severity of infectious diseases among older individuals are often associated with several comorbidities, resulting in a large burden of morbidity and mortality. Part one of this thesis is based on a gap in the current management of infections in older persons: a growing population, living longer, and being more susceptible to infections. If we would be able to slightly lower the level of infectious disease prevalence, we might have more health impact at population level ('the population strategy') compared to individual treatment of patients (a much smaller group). Improved preventive strategies that are applicable to the growing group of older people living at home, are likely to render gains on the economic (i.e. reduced costs, such as treatments-costs), and individual level (improved quality of life, self-management).

\section{Target groups, activities and innovations resulting from this thesis}

An important purpose of scientific research is to ensure that the results will impact society by making it suitable for translation into products, services, processes or new activities. Part 1 of this thesis showed detrimental as well as beneficial associations with URI, LRI and GI. Based on the results of our studies and previous investigations, we feel that the potential of the social network parameters for infectious disease prevention strategies is twofold. First, the beneficial social network parameters may be used as potential determinants which can be reinforced by preventive interventions. Current EU policy expects older persons to take care of themselves as much as possible with help of their social network. New prevention strategies should fit this policy. For example, in future prevention strategies, the relation to close proximity and same-age network members could be reinforced. Moreover, future prevention strategies may aim to enhance practical and informational support from network members. Previously, higher levels of social support have already been shown to associate with enhanced immune function. Second, the prediction rules could be used to compute an individual's probability of an infection given a defined set of parameters. For example, the prediction models may be used in a practical tool which could be offered to middle-aged and older people in order to calculate their risk of infection, followed by an tailored advice on infection prevention (e.g. 
hand and environmental hygiene). At this time, I am translating the prediction models (chapter 3 ) into a practical web-based intervention, a simple web-tool for independently living older persons. With this web-tool, we aim to achieve reduced infectious burden among older people using a practical infection-prevention strategy. The prognostic tool may help older people to raise awareness for their social network or to trigger early preventive actions (e.g. personalized advice). The tool may also help formal caregivers (such as GPs) in their practical infection-management of older people. For example, older people who visit their GP many times during the winter season because of common cold/ influenza-like symptoms may be advised to make use of the web-tool by their GP. In older people themselves, the web-tool may help them to become aware of their social network and to improve the beneficial social network aspects. The combination of social network and prediction models in a non-pharmaceutical web-based intervention to improve infection prevention and the quality of the social network in older persons is highly innovative.

\section{Type 2 diabetes}

\section{Social relevance}

To date, type 2 diabetes mellitus (T2DM) is one of the most prevalent diseases worldwide, and a growing public health burden in middle-aged and older persons.

The impact of diabetes on patients' quality of life is high as treatment of T2DM involves intensive daily self-management of glucose monitoring, dietary behaviors, physical activity, and when needed, diabetes medication. Moreover, patients with T2DM have an increased risk for the development of macro- (e.g. myocardial infarction, stroke, peripheral arterial disease) and microvascular complications (e.g. neuropathy, retinopathy, and nephropathy). T2DM and its' complications impose a substantial burden on patients, their surroundings, and society. T2DM can be prevented or even reversed with appropriate lifestyle changes such as healthy dietary behavior and sufficient physical activity. However, the social context of patients is often neglected in regular care. Patients at risk and those who already have T2DM usually receive lifestyle advice on dietary habits and physical activity, and when needed, medication. This thesis provided new insights for the prevention and treatment of T2DM and diabetes complications. 


\section{Target groups, activities and innovations resulting from this thesis}

Findings in this thesis are of importance for all individuals at risk, and those having T2DM and related complications. Knowledge of a patients network and social support may render treatment strategies and lifestyle interventions more effective when tailored to the specific needs and network characteristics of the individual. The social context can be of crucial importance to adopt and succeed in lifestyle change, and therefore, prevention strategies aiming to generate behavioral change (e.g., dietary advice, physical activity) may also tailor the social network of the participant. Previous research has shown that network targeting increases the adoption of specific prevention strategies. Moreover, social network characteristics itself may prove an independent target in non-pharmaceutical and non-medical prevention strategies which aim to prevent the development of T2DM as well as in T2DM patients to prevent clinical complications. Our findings support the efforts to develop effective prevention strategies which tailor social network characteristics, however, it is important to assess whether these prevention strategies meet the specific needs of the participant.

Based on the results of our studies and previous investigations, we would suggest to consider structural as well as functional characteristics of the social network in future prevention strategies. For example, socially isolated individuals, with a smaller social network size, more often had T2DM and macro- and microvascular complications. Broadening the social network may be encouraged, as reinforcement of social networking has been shown to improve Hbalc and blood glucose. Moreover, lack of social participation was associated with pre-diabetes and previously diagnosed T2DM, therefore, stimulating participants to become member of a club may also be considered in future prevention strategies. Further, we would suggest to address the type of relationships and social support in future prevention strategies aiming to reduce the burden of disease in T2DM. Our results mirror previous findings, indicating that men living alone have a higher risk for the development of T2DM. Therefore, we feel that men living alone should be indicated as high-risk group.

Notably, when including social network characteristics in future prevention strategies, differences in social network characteristics between men and women should be taken into account, there is no "one size fits all" approach. 
Dankwoord 
Dit proefschrift was er niet geweest zonder de hulp van velen. Ik wil graag iedereen hartelijk bedanken die een bijdrage aan dit proefschrift heeft geleverd, op wat voor manier dan ook. Een aantal personen wil ik hiervoor in het bijzonder bedanken:

Als eerste wil ik mijn promotieteam, Prof. dr. Christian Hoebe, Prof. dr. Paul Savelkoul, Dr. Nicole Dukers-Muijrers en Dr. Miranda Schram bedanken. Door jullie vertrouwen in mij, heb ik vertrouwen in mezelf gekregen.

Beste Christian, ik wil je bedanken voor je begeleiding en betrokkenheid die je toonde tijdens mijn promotietraject. Van jouw ideeën en feedback heb ik veel geleerd. Ook wil ik je bedanken voor je hulp en support waar ik altijd op kon rekenen in de afgelopen 5 jaar.

Beste Paul, ik wil je bedanken voor je expertise en waardevolle feedback die je hebt ingebracht in mijn promotietraject. Veel dank dat je mijn tweede promotor was.

Beste Nicole, vanaf dag 1 heb je me gestimuleerd om mijn competenties te ontwikkelen en mijn weg te vinden in deze bijzondere combinatie van onderwerpen. Daarbij stond je altijd klaar voor mij, voor vragen en ideeën, maar ook voor support als er weer eens een obstakel te overwinnen was. Ook was je altijd heel enthousiast en positief, en van je expertise en ervaring heb ik heel veel geleerd. Heel veel dank dat je mijn co-promotor was.

Beste Miranda, wat heb ik een ongelofelijk geluk gehad dat jij mijn tweede co-promotor was. Ook bij jou kon ik altijd terecht. Van jouw passie en expertise in diabetes onderzoek, en je glasheldere uitleg heb ik veel geleerd. Je hebt enorm bijgedragen aan de totstandkoming van dit boekje, en daar ben ik je zeer dankbaar voor.

Leden van de beoordelingscommissie, Prof. dr. GeertJan Dinant, Prof. dr. Klasien Horstman, Dr. Femke Rutters, en Prof. dr. Koos van der Velden, hartelijk dank voor de tijd die jullie genomen hebben om mijn proefschrift te lezen en te beoordelen.

Een speciaal woord van dank aan Dr. Sander van Kuijk, Prof. dr. Mirjam Kretzschmar en Prof. dr. Nicolaas Schaper voor jullie bijdrage aan de hoofdstukken in dit proefschrift.

Alle overige coauteurs, Prof. dr. H. Bosma, Prof. dr. P. Dagnelie, Prof. dr. N. de Vries, Dr. R.M.A. Henry, Prof. dr. M.W.J. Jansen, Dr. A. Koster, J. Maes, Dr. S.J.S. Sep, Dr. C.J.H. van der Kallen, Prof. dr. F.R.J. Verhey, hartelijk dank voor jullie bijdrage tijdens het schrijven van de artikelen in dit proefschrift.

Mede-promovendi en collega's van de GGD, Afdeling Seksuele Gezondheid, Infectieziekten en Milieu. Jeanne, ik vond het ontzettend leuk dat wij de afgelopen vijf jaar samen door dit traject mochten gaan, met heel verschillende onderwerpen, maar toch vaak dezelfde problemen. Ik kon met alle vragen, maar ook met alle verhalen bij jou terecht, en ik ben ontzettend blij dat we nu ook nog de laatste stap samen gaan en je mijn paranimf bent. Veel succes met je promotie! 
Geneviève, vanaf dag 1 kon ik altijd aankloppen als ik vragen had, en ik heb veel van je geleerd. Veel dank voor alle adviezen, leuke momenten en je support in de afgelopen vijf jaar!

Kevin, Lisanne, Jeanine, Juliën, Ymke, Mitch en Patricia, ik heb altijd genoten van de leuke koffiepauzes, gesprekken, wandelingen, en uitjes met jullie samen. Dank jullie wel voor het interesse in mijn onderzoek, en jullie steun bij alle pieken en dalen. Anne-Marie, bedankt voor alle R tips, Sunbelt was gezellig!

Dames van het secretariaat, bedankt voor de ondersteuning. Ine en Helen, alles kon ik jullie vragen, en binnen secondes was het geregeld.

Team IZB, bedankt voor het meedenken en waardevolle discussies gedurende dit traject.

Mede-promovendi en collega's van de afdeling Medische Microbiologie van het MUMC+, bedankt voor de feedback en suggesties bij overleggen en presentatie-oefensessies, en de gezelligheid tijdens de onderzoeker-uitjes.

Mede-promovendi en collega's bij De Maastricht Studie, ik wil jullie allemaal danken voor de prettige samenwerking, de gezelligheid, uitjes, pauzes, gesprekken, feestjes en congressen, maar ook alle tips en adviezen rondom mijn promotietraject. Ik zal deze tijd nooit meer vergeten. Een speciaal woord aan het 'team' van de V2; Julianne, Jeroen V., Jeroen S., Niki, Tan Lai en Sytze, veel dank voor de leuke tijd die ik met jullie had.

Collega's van MEMIC, Ralph en Jacqueline, bedankt voor al jullie werk en hulp bij de dataverwerking.

Das Leben ist kein Ponyhof - oder doch?

Ein ganz besonderer Dank geht an all die Menschen, die mein Leben täglich zu einem „Ponyhof" machen.

Allen voran meine „Mädels" Bianca, Monique und Michelle. Danke für zahllose Stunden am Stall, unvergessliche Partys, wunderschöne Urlaube und einfach all die Zeit, die wir in den letzten zwei Jahrzehnten miteinander verbracht haben.

Luisa und Martina, danke für alle Gespräche, gemeinsamen Erlebnisse und Erinnerungen.

Astrid, Dir und Deiner Familie bin ich sehr dankbar für den täglichen Ausgleich, das Training, die Turniere und die vielen tollen Erfahrungen.

Liebe Stallgemeinschaft, es sind einfach zu viele Personen um jeden persönlich zu nennen, trotzdem möchte ich Euch allen danken für Eure moralische Unterstützung in dieser Zeit. 
Sven, mein Herz. Du hast mir in dieser Zeit immer zur Seite gestanden, mich immer unterstützt und mit mir in die selbe Richtung geblickt. Danke, dass Du immer für mich da warst!

Papa, ich konnte mich immer auf Dich verlassen, Du hast immer alles für mich gegeben und dafür bin ich Dir sehr dankbar.

Tobi, mein kleiner großer Bruder. Danke, dass ich immer auf Dich zählen konnte und Du mir heute als Paranimf zur Seite stehst.

Mama, Dir gebührt mein größter Dank. Danke für alles! Danke, dass Du immer für mich da warst, dass Du immer an mich geglaubt hast. Danke, dass Du mir immer wieder bestätigt hast, dass ich auf dem richtigen Weg bin, und danke, dass Du niemals an mir gezweifelt hast.

Tief verbunden und dankbar bin ich meinen Großeltern, die den heutigen Tag gerne noch miterlebt hätten. 
Curriculum Vitae 


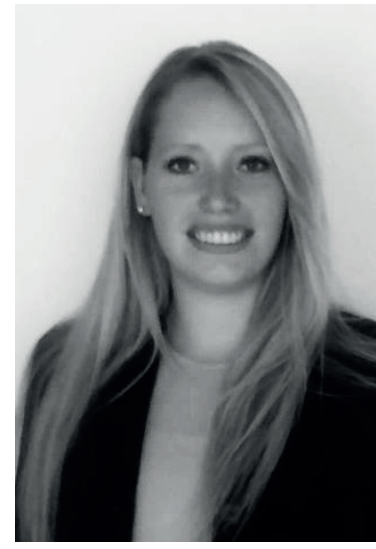

Stephanie Brinkhues was born on the $20^{\text {th }}$ of September 1989 in Aachen, Germany. In 2009, she graduated from secondary school at the Anne-Frank-Gymnasium in Aachen. Following this she studied Health Sciences at Maastricht University where she obtained the degrees Bachelor of Science (BSc) in 2012 and Master of Science (MSc) in 2013. In September 2013 Stephanie started her PhD research project at The Maastricht Study, embedded in the Care and Public Health Research Institute (CAPHRI) and the CARIM School for Cardiovascular Diseases at Maastricht University, in collaboration with the department of Medical Microbiology of the Maastricht University Medical Center (MUMC+) and the Public Health Service South Limburg. She conducted her PhD research under supervision of Prof. dr. C.J.P.A. Hoebe, Prof. dr. P.H.M. Savelkoul, Dr. N.H.T.M. Dukers-Muijrers and Dr. M.T. Schram.

Currently, Stephanie is working as postdoc researcher at Maastricht University within the Care and Public Health Research Institute CAPHRI, in collaboration with the Department of Medical Microbiology of the Maastricht University Medical Center (MUMC+) and the Department of Sexual Health, Infectious Diseases and Environmental Health at the Public Health Service South Limburg (GGD Zuid-Limburg). 
Portfolio 


\section{Grants}

2018

Personal travel grant for the European Scientific Conference on Applied Infectious Disease

Epidemiology (ESCAIDE), Malta.

2018

SaNAE Implementation project

Project coordinator: S. Brinkhues

Project members: Dr. N.H.T.M. Dukers-Muijrers, Prof. dr. C.J.P.A. Hoebe, Prof. dr. M. Zeegers,

Prof. dr. ir.M.W.J. Jansen, Prof. dr. N. de Vries, V.P.J. Claessen, Prof. dr. J.W.L. Cals, Dr. A.J.M.

Drenthen, N. Bouwmeester-Vincken, F. Hamers, Dr. S.M.J. van Kuijk, Mr. P. Vranken

Funded by ZonMW (5220020021)

2016

Personal travel grant for the Annual Meeting of the European Association for the Study of Diabetes (EASD), Munich.

2015

Improving infectious burden prediction using social network assessment in elderly - SaNAE study Project coordinator: Dr. N.H.T.M. Dukers-Muijrers

Project members: S. Brinkhues, Prof. dr. C.J.P.A. Hoebe, Prof. dr. ir.M.W.J. Jansen, Dr. S.M.J. van Kuijk, Jo Maes, Prof. dr. N. de Vries, Prof. dr. P. Savelkoul and Dr. M. Mooi, Prof. dr. Mirjam Kretzschmar, Dr. M. Schram

Funded by ZonMW (522002002)

\section{Courses and training}

2018

Using R and 'igraph' for Social Network Analysis by Michal Bojanowski.

Visualizing Social Networks by Jürgen Pfeiffer.

2016

Introduction to Social Network Analysis using UCINET and Netdraw, University of Manchester.

Training Presentation Skills, Maastricht University. 


\section{5}

Clinical Prediction Models, Theory \& Practice, Maastricht University.

\section{4}

PhD Research Writing II for Health sciences, Maastricht University.

\section{Presentations}

\section{International}

$38^{\text {th }}$ Annual meeting of the International Network for Social Network Analysis, Sunbelt Social network conference 2018, Utrecht, the Netherlands.

52nd Annual Meeting of the European Association for the Study of Diabetes (EASD) 2016, Munich, Germany.

8th European Congress of Epidemiology Healthy Living 2015, Maastricht, the Netherlands.

\section{National}

28ste Transmissiedag Infectieziekten 2018, Amersfoort.

Maastricht Study Participants Symposium 2018, Maastricht.

Annual Dutch Diabetes Research Meeting 2017, Oosterbeek.

Annual CAPHRI Research Conference 2017, Valkenburg.

Research day Medical Microbiology 2017, Maastricht.

Annual CAPHRI Research Conference 2016, Valkenburg.

Annual Dutch Diabetes Research Meeting 2015, Oosterbeek.

Annual CAPHRI Research Conference 2015, Maastricht.

\section{Societal impact}

Media coverage article 'Socially isolated individuals are more prone to have newly diagnosed and prevalent type 2 diabetes mellitus - The Maastricht Study- '

More than 600 media hits (https://biomedcentral.altmetric.com/details/30638368)

Altmetric Attention Score: 1086

In the top $5 \%$ of all research outputs scored by Altmetric 
Highlights:

The research attracted the attention of national and international media. In the UK, it was covered by outlets including Daily Mail and The Times. It was also covered by Press Association which led to wide syndication throughout the country. It was also reported by ABC in Spain and widely syndicated in India and the US. 
List of publications 
2018

Stephanie Brinkhues, Nicole H.T.M. Dukers-Muijrers, Christian J.P.A. Hoebe, Carla J.H. van der Kallen, Annemarie Koster, Ronald M.A. Henry, Hans Bosma, Coen D. A. Stehouwer, Paul H.M. Savelkoul, Nicolaas C. Schaper, Miranda T. Schram. Social network characteristics are associated with type 2 diabetes complications - The Maastricht Study - Diabetes Care 2018; 41:1-9

Stephanie Brinkhues, Miranda T. Schram, Christian J.P.A. Hoebe, Mirjam E.E. Kretzschmar, Annemarie Koster, Pieter C. Dagnelie, Simone J.S. Sep, Sander M.J. van Kuijk, Paul H.M. Savelkoul, Nicole H.T.M. Dukers-Muijrers. Social networks in relation to self-reported symptomatic infections in individuals aged 40-75 - The Maastricht Study - BMC Infectious Diseases, 2018, 18.1:300

S. Brinkhues, S.M.J. van Kuijk, C.J.P.A. Hoebe, P.H.M. Savelkoul, M.E.E. Kretzschmar, M.W.J. Jansen, N. de Vries, S.J.S. Sep, P.C. Dagnelie, N.C.Schaper, F.R.J. Verhey, H. Bosma, J. Maes, M.T. Schram, N.H.T.M. Dukers-Muijrers. Development of prediction models for upper- and lower respiratory and gastrointestinal tract infections using social network parameters in middle-aged and older persons - The Maastricht Study - Epidemiology \& Infection, 2018, 146.5: 533-543

2017

Stephanie Brinkhues, Nicole H.T.M. Dukers-Muijrers, Christian J.P.A. Hoebe, Carla J.H. van der Kallen, Pieter C. Dagnelie, Annemarie Koster, Ronald M.A. Henry, Simone J.S. Sep, Nicolaas C. Schaper, Coen D. A. Stehouwer, Hans Bosma, Paul H.M. Savelkoul, Miranda T. Schram. Socially isolated individuals are more prone to have newly diagnosed and prevalent type 2 diabetes mellitus - The Maastricht Study - BMC Public Health, 2017, 17.1: 955

Smit, E., Brinkhues, S., Hoving, C., de Vries, H. Subgroups among Smokers in Preparation: A Cluster Analysis using the I-Change Model. Substance Use and Misuse, 2017.

\section{Other publications}

Stephanie Brinkhues, 2017. With a little help from my friends - Getting people out of social isolation could help prevent type 2 diabetes. BMC Series Blog.

Stephanie Brinkhues, Nicole H.T.M. Dukers-Muijrers, Christian J.P.A. Hoebe, Carla J.H. van der Kallen, Pieter C. Dagnelie, Annemarie Koster, Ronald M.A. Henry, Simone J.S. Sep, Nicolaas C. Schaper, Coen D. A. Stehouwer, Hans Bosma, Paul H.M. Savelkoul, Miranda T. Schram. Newly diagnosed and prevalent type 2 diabetes patients are socially isolated: The Maastricht Study. Abstract reviews, EMJ Diabetes 4.1, October 2016 